Agricultures tropicales en poche

Directeur de la collection

Philippe Lhoste

\title{
Les cultures fourragères
}

H.D. Klein, G. Rippstein, J. Huguenin,

B. Toutain, H. Guerin, D. Louppe

Éditions Quæ, CTA, Presses agronomiques de Gembloux 


\section{À propos du CTA}

Le Centre technique de coopération agricole et rurale (CTA) est une institution internationale conjointe des États du Groupe ACP (Afrique, Caraïbes, Pacifique) et de l'Union européenne (UE). Il intervient dans les pays ACP pour améliorer la sécurité alimentaire et nutritionnelle, accroître la prospérité dans les zones rurales et garantir une bonne gestion des ressources naturelles. Il facilite l'accès à l'information et aux connaissances, favorise l'élaboration des politiques agricoles dans la concertation et renforce les capacités des institutions et communautés concernées.

Le CTA opère dans le cadre de l'Accord de Cotonou et est financé par l'UE.

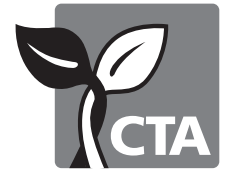

CTA, Postbus 380, 6700 AJ Wageningen, Pays-Bas www.cta.int

Éditions Quæ, RD 10, 78026 Versailles Cedex, France

www.quae.com

Presses agronomiques de Gembloux, Passage des Déportés, 2,

B-5030 Gembloux, Belgique

www.pressesagro.be

(C) Quæ, CTA, Presses agronomiques de Gembloux 2014

ISBN (Quæ) : 978-2-7592-2168-4

ISBN CTA : 978-92-9081-557-0

ISBN (PAG) : 978-2-87016-131-9

ISSN : $1778-6568$

(C) Le code de la propriété intellectuelle interdit la photocopie à usage collectif sans autorisation des ayants droit. Le non-respect de cette disposition met en danger l'édition, notamment scientifique, et est sanctionné pénalement. Toute reproduction même partielle du présent ouvrage est interdite sans autorisation du Centre français du droit de copie (CFC), 20 rue des Grands-Augustins, Paris $6^{\text {e }}$.

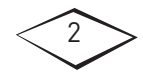




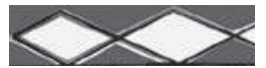

\section{Table des matières}

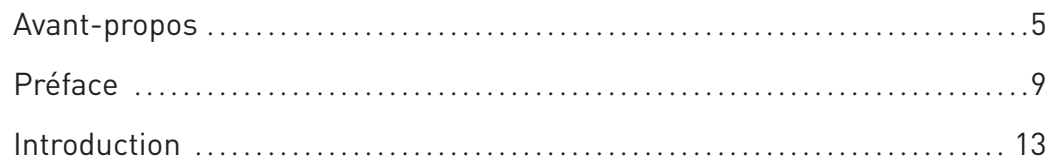

Partie 1

Quelles productions fourragères choisir?

1. La diversité des plantes fourragères ..................... 19

Les graminées ........................................... 20

Les légumineuses herbacées ............................... 33

Les arbres et arbustes .................................... 40

2. La diversité des milieux tropicaux ....................... 47

Les grands types de climats ................................. 47

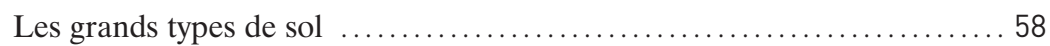

3. La diversité des usages et des fonctions ..................6 63

Lusage fourrager pour alimenter les animaux ........................ 64

Pour d'autres usages et fonctions ............................. 83

4. La diversité des systèmes de production .................. 97

Les systèmes fourragers dans les systèmes d'alimentation ............. 97

Comment ajuster l'offre fourragère et les besoins des animaux? ......... 98

Les systèmes fourragers dans l'exploitation .......................... 103

Places et usages des cultures fourragères dans les systèmes d'élevage .... 108

\section{Partie 2}

Comment cultiver, exploiter et entretenir les plantes fourragères?

5. La culture des plantes fourragères ...................... 117

La préparation de la surface cultivée ............................. 117

La préparation du sol ........................................ 125

Limplantation des semences ou des plants ....................... 126

Semis ou plantations? ....................................... 130

Les modes d'implantation et les types de couverts installés ............. 132

Les fertilisations de fond au semis .............................. 142

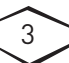


6. L'exploitation des plantes fourragères ..................... 143

Des productions de fourrages très variables ........................ 144

Lexploitation par pâturage direct ............................. 148

Utilisation des fourrages après la coupe et modes de conservation ...... 161

Les productions animales permises ............................ 169

Deux aliments particuliers .................................... 173

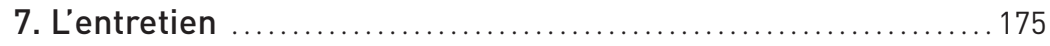

La conduite des prairies favorable à leur maintien .................. 176

Les fertilisations organique et minérale ........................... 178

Le contrôle des mauvaises herbes ............................... 184

La prévention et la lutte contre les maladies et parasites ............... 193

Régénérer, rénover et réhabiliter les pâturages ...................... 195

8. Les particularités des fourrages ligneux ................... 201

Linstallation des ligneux ................................... 201

La gestion et l'utilisation des ligneux fourragers .................... 211

Conclusion ............................................. 217

9. La production de semences fourragères ................... 219

Comment produire des semences fourragères ...................... 219

Comment récolter et conditionner les semences ................... 222

10. L'économie des cultures fourragères .................... 225

Les principaux éléments à prendre en compte ...................... 225

Lévaluation détaillée des coûts de production ..................... 226

Critères économiques d'aide à la décision pour l'implantation

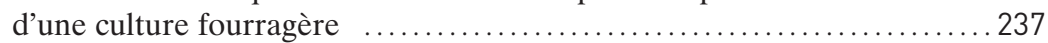

Conclusion .............................................. 238

Conclusion générale ......................................... 241

Valorisation de la grande diversité des cultures fourragères $\ldots . \ldots \ldots . .241$

Bien concevoir des systèmes de production cohérents,

intégrés et rentables ........................................ 242

Les perspectives ........................................ 244

Glossaire ................................................. 247

Bibliographie ............................................ 253

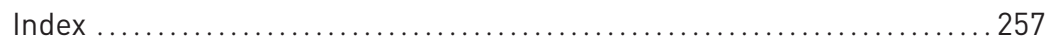

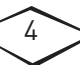




\section{$>$ Avant-propos}

La collection «Agricultures tropicales en poche»a été créée par un consortium comprenant le CTA de Wageningen (localisé aux Pays-Bas), les Presses agronomiques de Gembloux (Belgique) et les Éditions Quæ (France). Cette collection, comprend trois séries d'ouvrages pratiques consacrés aux productions animales, aux productions végétales et aux questions transversales.

Ces guides pratiques sont destinés avant tout aux producteurs, aux techniciens et aux conseillers agricoles. Ils se révèlent être également d'utiles sources de références pour les chercheurs, les cadres des services techniques, les étudiants de l'enseignement supérieur et les agents des programmes de développement rural.

Le présent ouvrage est consacré aux cultures fourragères tropicales. Ce sujet reste d'une importance capitale dans le développement durable des régions chaudes. La production fourragère est en effet le principal levier de l'amélioration de l'alimentation des herbivores et donc de la productivité des systèmes d'élevage concernés. Elle joue également un rôle essentiel dans la durabilité des systèmes mixtes qui allient productions végétales et animales. Nombre de systèmes agro-écologiques qui sont tout à fait d'actualité se fondent sur une bonne intégration des plantes fourragères dans ces systèmes de production : elles y jouent en effet un rôle central pour l'alimentation des animaux, la production de fumure organique et partant, l'entretien de la fertilité des parcelles cultivées. Enfin, des fonctions écologiques et économiques plus globales trouvent leur place dans des démarches pertinentes de développement : lutte antiérosive et protection des sols, séquestration du carbone, production de biocarburants, marquage du foncier et de l'espace grâce aux ligneux fourragers ou à usage multiples, etc.

L'ouvrage, organisé en deux parties, traite d'abord de la diversité des plantes fourragères et de leurs usages en fonction des milieux et des systèmes d'élevage dans lesquels elles s'insèrent; puis des techniques de production, depuis l'implantation des cultures jusqu'à leur exploitation. Sont également abordées les problématiques des ligneux fourragers, de la production des semences fourragères et de l'économie de la production fourragère dans le cadre des systèmes de production.

Ce projet d'ouvrage a été lancé en 2008. Guy Roberge, qui en était l'initiateur, est décédé en 2011, sans avoir pu le terminer. Ensuite, ce projet a été repris par une nouvelle équipe sous la coordination

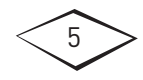


de Henri-Dominique Klein. Ce manuel est le fruit du travail collectif entrepris avec six chercheurs issus du Cirad, qui ont mis en commun leurs connaissances et leurs expériences des pâturages et des cultures fourragères acquises dans différentes régions du monde tropical. Ces auteurs, fortement impliqués, sont :

- Henri-Dominique Klein, rédacteur de la première heure, riche de ses connaissances sur les cultures fourragères en Afrique subtropicale, plus particulièrement celles à usages multiples en systèmes mixtes, et sur la gestion et l'amélioration des prairies dans le Pacifique Sud;

- Georges Rippstein, porteur d'une large expérience africaine et sudaméricaine sur la gestion de pâturages naturels et cultivés en zones de savanes;

- Johann Huguenin, ayant une grande expérience de l'Afrique tropicale humide, du Bassin amazonien, notamment sur l'établissement et l'entretien des prairies, ainsi que des régions arides de la Corne de l'Afrique, du Sahel et de l'Afrique du Nord;

- Bernard Toutain, spécialiste des plantes fourragères, y compris des ligneuses, et grand connaisseur de l'Afrique tropicale sèche et du Pacifique Sud;

- Hubert Guerin, spécialiste de l'alimentation animale et de la valeur alimentaire des fourrages, porteur aussi des développements de projets fourragers;

- Dominique Louppe, chercheur forestier, chargé des sujets relatifs aux arbres fourragers et aux ligneux.

D'autres collaborations ont été sollicitées ponctuellement : Véronique Alary, Alain Le Masson pour les aspects économiques; Paulo Salgado, Vincent Blanfort et Sylvia Fontaine pour leur expérience dans les pays de l'océan Indien, notamment à la Réunion; Patrice Grimaud pour son expérience en Ouganda et au Burkina Faso; Christian Baranger pour sa connaissance du Paraná au Brésil. Que tous ces contributeurs soient vivement remerciés.

D'autres personnes ont participé au succès de ce projet : Corinne Cohen (Cirad) au lancement de l'ouvrage, Didier Richard pour sa relecture, ainsi que Claire Parmentier (PAG), Claire Jourdan-Ruf (Éditions Quæ) et Philippe Radigon (Cirad, multimédia) pour l'édition et la mise en forme finale de la version papier et du cédérom.

Cet ouvrage, à la fois synthétique et complet, est enrichi d'un cédérom qui apporte des illustrations et des études de cas correspondant à des contextes agroclimatiques et à des systèmes d'élevage divers des régions tropicales, ainsi qu'une bibliographie augmentée pour chaque chapitre

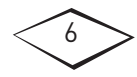


par des liens vers des textes de référence numérisés. Il constitue donc une synthèse actualisée sur le thème complexe des cultures fourragères tropicales; il sera d'une grande utilité pour les acteurs du développement engagés dans des projets de natures diverses intégrant des plantes fourragères.

Philippe Lhoste, directeur de la collection Agricultures tropicales en poche

\section{Encadré 1. Hommage à Guy Roberge}

Nous tenons à rendre hommage à Guy Roberge, disparu en 2011, et nous souhaitons honorer ici sa mémoire. En effet, il fut l'initiateur de ce projet qui lui tenait à cour, mais qu'il n'a pu réaliser pour des raisons de santé et de temps. Agronome des cultures fourragères au Centre international en recherche agronomique pour le développement (Cirad), où il a conduit la totalité de sa carrière, il avait acquis de très solides connaissances scientifiques et une grande expérience pratique, notamment en Afrique de l'Ouest et en Asie tropicale. Il avait valorisé ces expériences dans de nombreuses publications et dans un ouvrage «Les cultures fourragères tropicales» (Cirad, 1999, collection Repères), dont il avait assuré avec Bernard Toutain la coédition scientifique. Ces résultats sont également valorisés dans ce nouvel ouvrage.

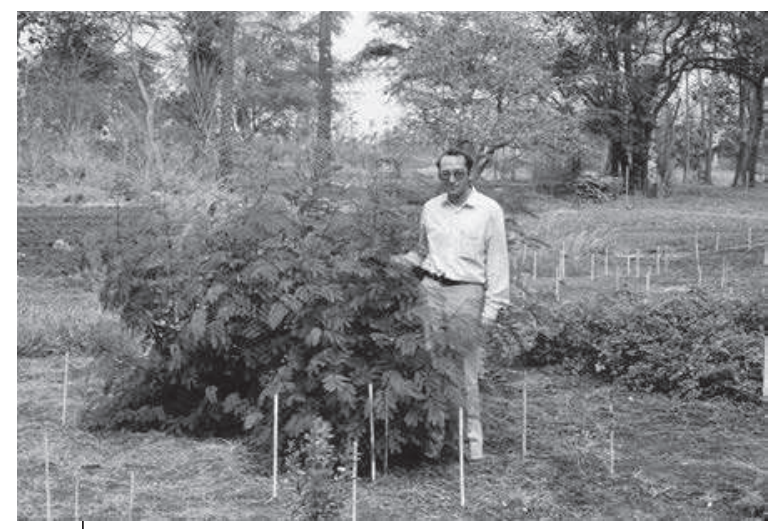

Photo 1.

Guy Roberge dans l'herbarium (placette de Leucaena) de la station de recherche de Sangalkam, Sénégal. (๑ D. Soltner)

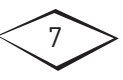





\section{$\triangle$ Préface}

L'une des raisons de l'importance particulière des plantes fourragères dans le monde est l'énorme étendue des terres consacrées à l'élevage. Trois à quatre milliards d'hectares, soit près de $80 \%$ de toutes les terres utilisées pour la production agricole, servent à nourrir le bétail. La production animale, pour sa part, prend une importance croissante dans les pays en développement : la demande en produits de l'élevage y a connu une croissance spectaculaire au cours des deux dernières décennies et devrait continuer à progresser - on parle de «révolution de l'élevage». Cette demande croissante ne peut être satisfaite que par une production animale accrue. Cependant, des considérations éthiques amènent à nourrir les ruminants avec des fourrages plutôt qu'avec des aliments à base de céréales concurrents de l'alimentation humaine. Dans ce contexte, il faut souligner les qualités bien connues des principaux fourrages tropicaux, car celles-ci sont la clé des systèmes de production en régions tropicales : à savoir le fort potentiel de production de la plupart des graminées tropicales en raison de leur type de photosynthèse en $\mathrm{C} 4$, et la qualité nutritionnelle généralement élevée des légumineuses grâce à la capacité de fixation de l'azote de la plupart des espèces et de la résistance à la sécheresse de beaucoup d'entre elles.

Il est largement admis que, pour parvenir aux augmentations de production nécessaires, il faut passer par l'amélioration de la plupart des nombreux systèmes fourragers qui existent sous les tropiques, par leur intensification et leur diversification, sans nouvelle extension des défrichements agricoles. Dans ce contexte, on pourrait tirer un avantage particulier de la très grande diversité des plantes fourragères tropicales et de leurs ressources génétiques, notamment en termes d'adaptation naturelle à des environnements marginaux, afin de produire des fourrages avec le minimum d'intrants sur des terres qui sont impropres à l'agriculture, sans de gros investissements.

Outre cet important enjeu de la production, les considérations environnementales prennent de plus en plus d'importance. Dans la communauté non scientifique, la production animale à partir des prairies et des fourrages tropicaux est souvent tenue pour responsable de la destruction d'écosystèmes riches en biodiversité, telles que les forêts primaires tropicales, et de l'apparition de paysages improductifs extrêmement dégradés. Une telle critique, cependant, ne tient pas compte du fait que le premier aspect est un problème d'extension des terres de culture (lequel dépend à son tour des politiques gouvernementales

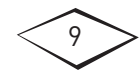


de développement), alors que le second, plutôt que d'être une caractéristique inévitable des pâturages tropicaux, est un problème de gestion des pâturages concernés. Cependant, il y a un problème environnemental considérable inhérent à l'élevage des ruminants : l'émission de méthane $\left(\mathrm{CH}_{4}\right)$, un important gaz à effet de serre (GES), provenant de la fermentation dans le rumen. Afin d'atténuer ces émissions naturelles, la stratégie la plus appropriée serait d'accroître la productivité des animaux, principalement en améliorant la qualité nutritive des fourrages; ce qui réduirait les émissions de méthane par unité de gros bétail produit.

Si on analyse l'impact des pâturages et des fourrages tropicaux sur l'environnement, on arrive à la conclusion du rôle potentiellement favorable des pâturages et des fourrages tropicaux.

Les pâturages et les plantes fourragères tropicales fournissent généralement une couverture permanente au sol, hormis bien sûr les espèces à cycle court. De cette façon, on évite l'érosion du sol et ses conséquences défavorables sur la fertilité du sol. Une conséquence particulièrement importante de l'érosion est la perte de matière organique du sol de l'horizon superficiel. En effet, la matière organique est considérée comme un très important puits de carbone, ainsi la couverture permanente du sol n'est pas seulement favorable à une gestion appropriée des ressources naturelles, mais elle contribue aussi à la réduction des émissions de gaz à effet de serre et donc à limiter le réchauffement climatique.

Les pâturages tropicaux, en particulier dans les systèmes sylvopastoraux associant arbres et élevage sur les mêmes terres, sont également de plus en plus reconnus comme ayant un potentiel élevé de séquestration de dioxyde de carbone $\left(\mathrm{CO}_{2}\right)$. La condition préalable à la prévention de la dégradation des pâturages est l'application d'une bonne gestion de l'occupation des sols. Dans ce contexte, il a été démontré que les espèces fourragères bien adaptées au climat et au sol, principalement les légumineuses herbacées, arbustives et arborées fixatrices d'azote, ont un fort potentiel de prévention de la dégradation des terres et même de récupération. En outre, les recherches récentes ont montré que les graminées tropicales, principalement des Brachiaria, ont la capacité d'inhiber la nitrification dans les sols, contribuant de cette façon à réduire les émissions d'un autre gaz à effet de serre important, l'oxyde nitreux $\left(\mathrm{N}_{2} \mathrm{O}\right)$.

Une autre propriété notable des plantes fourragères tropicales (principalement les légumineuses, mais aussi les graminées), utile à la fois

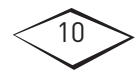


à la gestion des ressources naturelles et à l'amélioration de la production agricole, est leur potentiel d'amélioration chimique et physique des sols. Cette propriété est particulièrement appréciable en système agropastoral (associant agriculture et élevage), par exemple dans les rotations de fourrages avec des cultures.

Depuis les années 1960, les recherches dans les pays tropicaux ont apporté des progrès substantiels de production et de productivité des pâturages et des fourrages. L'IEMVT (Institut d'élevage et de médecine vétérinaire tropicale) et plus tard le Cirad y ont largement contribué, comme le montre ce livre, principalement dans les pays francophones, mais aussi en Amérique latine, par des projets de recherche en partenariat avec les acteurs locaux. Les aspects concernant l'impact potentiel des pâturages et des fourrages tropicaux sur l'amélioration de la production animale, sur les ressources naturelles et sur l'environnement, sont présentés dans cet ouvrage.

Sans aucun doute, un tel manuel axé sur les pratiques et le développement, qui inclut des guides concrets pour la production de fourrages et leur gestion adéquate, est un outil très précieux qui peut être lu ou consulté par les étudiants, les praticiens, les agents de développement et les chercheurs.

Rainer Schultze-Kraft, ancien professeur à l'Université de Hohenheim,

Stuttgart, Allemagne; scientifique émérite au Centre international d'Agriculture tropicale (Ciat), Cali, Colombie

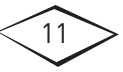





\section{$>$ Introduction}

La façon la moins onéreuse d'alimenter des herbivores domestiques consiste à les mener dans la végétation naturelle : les animaux se déplacent sur le «parcours» ou l'herbage à la recherche des plantes qu'ils apprécient, ingérant si possible le fourrage dont ils ont besoin pour l'entretien et la production, et disséminant leurs déjections. Mais l'éleveur a généralement une maîtrise partielle de la ration de ses animaux : selon les pâturages et les saisons, le fourrage naturel peut manquer ou être de médiocre qualité. Des répercussions sur le développement, la production recherchée (lait, viande, etc.) et la santé peuvent alors apparaître.

La maîtrise de l'affouragement et des pâtures suppose donc que la culture de fourrage soit une production délibérée de matières végétales pour nourrir le bétail. Celle-ci est pratiquée dans les régions où les fourrages naturels ne sont pas assez riches ou sont inaccessibles, mais aussi pour avoir des productions plus intensives. En plus des plantes et des pâturages naturels, on applique des techniques culturales adéquates (travail du sol, semis, entretien) pour produire des fourrages complémentaires. Ce sont les «cultures fourragères».

Les formes de cultures fourragères sont nombreuses; on peut semer : - de l'herbe pour créer une prairie améliorée qui sera ensuite pâturée ou fauchée pour faire des réserves;

- une plante annuelle qui sera intégralement récoltée pour faire de l'ensilage ou pour stocker ses graines;

- des espèces pérennes que l'on fauche de temps en temps pour obtenir du fourrage vert et qui repoussera, etc.

Le choix des cultures fourragères est multiple : on choisit d'abord le mode de culture (pure, en dérobé après une céréale, etc.), le mode d'exploitation (pâture, coupe), le mode de conservation (stockage en vert ou en sec) et l'espèce selon ses qualités (plante tendre, plante riche en protéines ou à haut rendement, plante produisant des grains pour une alimentation riche de complément, etc.). Il est possible de bénéficier de différentes améliorations génétiques notamment pour la valeur alimentaire, la productivité et la répartition de la production au cours de l'année, etc.

Sous toutes les latitudes, des éleveurs pratiquant un système d'élevage extensif s'ingénient à trouver des aliments complémentaires pour les animaux qui en ont le plus besoin, par exemple pour une femelle

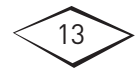


laitière, des animaux de trait, de jeunes animaux, des mâles que l'on engraisse pour une fête ou une vente, ou une bête de prestige. On leur réserve alors des compléments divers provenant de l'exploitation agricole, des résidus de culture (pailles de céréales et fanes de légumineuses), des déchets de cuisine (sons), des graines (maïs ou sorgho), des feuilles d'arbres et des fruits (gousses) et des fanes de légumineuses.

Lamélioration des productions animales dépend non seulement de l'amélioration génétique et de la maîtrise de la santé du bétail, mais aussi pour beaucoup de l'alimentation des animaux. Pour cela, l'éleveur doit s'efforcer d'atténuer les déficits saisonniers par un approvisionnement en aliments complémentaires de qualité et/ou des fourrages, en particulier en saison sèche en zone tropicale - comme en hiver en zone tempérée. Produire des cultures fourragères permet à l'éleveur de gérer les apports alimentaires de son bétail; l'introduction de cultures dans le système fourrager s'organise selon les objectifs d'élevage, d'amélioration des performances du troupeau et des conduites de toutes les cultures. L'ensemble des surfaces consacrées aux pâturages, aux parcours naturels, aux produits de postrécolte et à l'affouragement en stabulation, bases de l'alimentation des animaux herbivores, représente actuellement $26 \%$ des terres émergées, ce qui correspond à des biomasses annuelles de fourrage considérables.

À ce jour, les cultures fourragères, très employées dans nombre de pays tempérés, ont rencontré dans les zones tropicales un succès variable selon les continents. L'Australie a été en pointe pour la recherche et pour leur diffusion dès la seconde guerre mondiale. Les cultures fourragères se sont très vite diffusées en Amérique centrale et en Amérique du Sud, ainsi que dans les Caraïbes; mais elles le sont moins en Asie et encore moins en Afrique, où leur extension apparaît contrastée avec une diffusion plus large en Afrique de l'Est, en Afrique du Sud et au Nigeria, qu'en Afrique centrale et dans les autres pays d'Afrique de l'Ouest. Ces écarts dépendent beaucoup des conditions agroclimatiques et foncières, des capacités d'investissement permettant d'intensifier le système de production et des revenus obtenus, donc des prix de vente des produits d'élevage.

Ce manuel porte sur la production et l'utilisation des fourrages cultivés en pays tropicaux, c'est-à-dire d'espèces semées ou bouturées, avec ou sans labour, entretenues et soignées, éventuellement fertilisées comme une culture, et produisant une biomasse mise à la disposition des animaux selon les objectifs de production des éleveurs. Les plantes

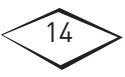


fourragères, très nombreuses, proviennent d'espèces identifiées dans les milieux naturels et sélectionnées sur différents caractères, certaines le sont dans des centres de recherche publics ou privés, nationaux ou internationaux et elles sont parfois multipliées dans des fermes semencières.

Les informations reprises dans cet ouvrage et le cédérom qui l'accompagne s'adressent principalement aux éleveurs, aux techniciens et ingénieurs désireux d'introduire des espèces fourragères pour nourrir les animaux, améliorer la fertilité du sol, lutter contre l'érosion ou encore produire des semences fourragères.

Linformation rassemblée trouve en partie sa source dans les expérimentations et les recherches entreprises depuis un demi-siècle par les chercheurs de l'IEMVT, devenu Cirad en 1985, avec leurs partenaires des pays tropicaux, et elle a été largement complétée par les acquis, issus d'autres instituts français, étrangers et internationaux, publiés et adoptés par les éleveurs des pays tropicaux.

Après la publication de «Cultures fourragères tropicales» (Roberge et Toutain, 1999), nous avons souhaité publier un manuel synthétique et pratique. Une première partie est destinée à guider le choix des plantes fourragères et une seconde partie est consacrée à la culture et à la gestion des plantes fourragères. Louvrage est complété par un cédérom, qui comprend, outre un grand nombre de documents et de fiches sur les cultures fourragères, des études de cas synthétiques sur l'utilisation des plantes fourragères dans divers systèmes d'élevage des régions tropicales, des exemples de pratiques de culture et d'utilisation des fourrages dans des situations réelles.

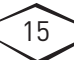





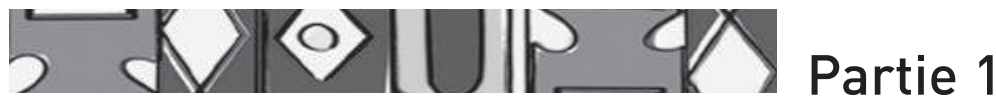

\section{Quelles productions fourragères choisir?}

Il n'existe pas de limites bien nettes entre la culture proprement dite des fourrages et les interventions sur la végétation naturelle pour en améliorer la qualité ou la production, ni entre la culture de plantes vivrières et leur utilisation comme fourrage (résidus de cultures et plantes à usages multiples).

Selon les types de productions animales et les niveaux d'intensification, le rôle des apports fourragers s'apprécie différemment selon qu'on les destine à la production laitière (système laitier), très sensible aux variations de disponibilité et de qualité, ou à la production de viande (système allaitant), moins exigeant quant à la régularité des apports alimentaires. De nombreuses plantes fourragères servent aussi à la couverture du sol et à l'amélioration de la fertilité du sol.

Cette première partie décrit la diversité des plantes et des milieux, montre l'éventail des objectifs de production de fourrages et présente des démarches pour aider les éleveurs dans le choix des cultures et des plantes fourragères.

Léleveur qui fait le projet d'établir une culture fourragère doit intégrer des éléments aussi différents que le type d'élevage recherché, le climat et le sol, les surfaces disponibles et leur éloignement, les caractéristiques biologiques et fourragères des plantes, le prix et la disponibilité des semences et des outils, et les opportunités dont il peut tirer parti. La diversité des plantes fourragères cultivées permet de répondre à la plupart des situations.

Le choix des plantes fourragères s'appuie sur les quatre facteurs suivants, que l'éleveur combine en fonction de ses objectifs jusqu'à l'élaboration de son projet fourrager :

- la diversité des plantes;

- la diversité des milieux tropicaux;

- la diversité des usages;

- la diversité des systèmes de production.

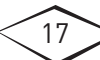





\section{La diversité des plantes fourragères}

Les espèces fourragères cultivées, très nombreuses, ont été repérées dans les milieux naturels parce qu'elles étaient bien consommées par le bétail, puis elles ont été sélectionnées génétiquement sur différents caractères. Elles appartiennent principalement à deux familles botaniques : les graminées ou Poaceae (herbacées) et les légumineuses (herbacées et ligneuses) (encadré 1.1).

Dans la nature, les graminées sont moins diversifiées que les légumineuses; on trouve environ 10000 espèces de graminées et 17000 espèces de légumineuses. Les graminées recouvrent des surfaces beaucoup plus importantes que les légumineuses, ont des productions de biomasse plus élevées et sont plus largement cultivées, notamment pour établir des prairies. Certains genres intéressants appartiennent à d'autres familles et conviennent à des milieux particuliers; c'est le cas du cactus (famille des Cactaceae) pour les régions sèches, des Atriplex (famille des Chenopodiaceae) pour les terres arides un peu salinisées, des Artemisia (famille des Asteraceae), arbrisseaux adaptés aux steppes arides, et de certains arbres et arbustes de diverses autres familles (Meliaceae, Rhamnaceae, Capparidaceae, etc.).

La sélection génétique a porté sur leur adaptation à différents milieux (température, alimentation en eau, sol), leur résistance aux maladies ou à des ravageurs, leur capacité de production assurant des biomasses élevées (herbe à éléphant), leur productivité et leur production de semences. Elle a également considéré la valeur alimentaire, notamment des graminées, et aussi, dans une moindre mesure, des légumineuses (luzernes). Les espèces ont été croisées naturellement ou artificiellement (hybrides), puis cultivées avec plus ou moins d'intrants (engrais, traitements phytosanitaires); actuellement, certaines espèces sont améliorées par de nouvelles techniques génétiques.

Les caractères physiologiques, comme la résistance à la sécheresse ou au gel, et les caractères morphologiques, comme le port des plantes herbacées (cespiteux, dressé, gazonnant), la proportion entre feuille et tige, sont aussi des critères de sélection et de choix. Par exemple, la nature et l'importance des tissus de soutien sont différentes selon la

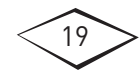


forme de la plante, ce qui se répercute sur sa valeur alimentaire. Cette diversité d'architecture végétale se retrouve également chez les arbres fourragers dont les rameaux, les feuilles, les fleurs et les fruits ont une accessibilité, une préhensibilité et une appétence variables selon les espèces animales.

La durée du cycle végétatif et la pérennité sont des critères majeurs pour classer les plantes fourragères. On tient compte aussi des modes de reproduction, par voies sexuée, végétative ou apomictique, car ces critères déterminent les conditions et les coûts d'installation, puis la stabilité génétique à long terme. Les espèces annuelles s'intègrent facilement dans des assolements agricoles classiques. En revanche, les espèces pérennes demandent d'autres modalités d'organisation. La longévité de ces cultures dépend aussi beaucoup de la bonne adaptation aux conditions de milieu et des modalités d'exploitation et d'entretien.

\section{Les graminées}

La famille des Gramineae (ou Poaceae) tient une place considérable dans l'alimentation des hommes - puisqu'elle compte presque toutes les céréales - et dans celle des animaux - les plantes herbacées les plus communes dans les pâturages étant des graminées. Les céréales, domestiquées dès le début de l'agriculture, ont permis l'essor des grandes civilisations. Elles sont devenues des sources importantes de matières premières pour l'alimentation des animaux domestiques dans les systèmes intensifiés.

Les graminées usuelles sont parvenues à un degré d'évolution avancé, qui se traduit par la miniaturisation des pièces florales et la spécialisation des espèces à des environnements très variés. Les 9700 espèces connues se répartissent dans presque tous les écosystèmes terrestres de la planète.

Les graminées peuvent être annuelles ou vivaces, selon la durée du cycle de développement :

- les annuelles ne se développent qu'au cours de la saison des pluies et ensuite la plante entière se dessèche et meurt; le maintien de l'espèce d'une année sur l'autre exige la formation de graines mûres, processus qui peut être entravé par l'exploitation intense du végétal;

- les vivaces (ou pérennes) persistent plusieurs années consécutives grâce à leurs racines et leurs bourgeons latéraux situés le plus souvent au ras du sol dans les zones tropicales.

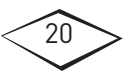




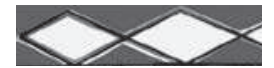

\section{Encadré 1.1. Rappel des caractéristiques des plantes}

\section{Les caractères biologiques}

- La morphologie de la plante : uniculmaire, cespiteux (pluriculmaire) et gazonnant (stolonifère, plus rarement rhizomateux).

- Le cycle de végétation : annuel (durée du cycle), pérenne (durée de la culture).

- Le type de plante, ce qui détermine la famille : principalement les graminées et les légumineuses.

- Le mode de reproduction : par semis, par resemis naturel, par voie végétative (boutures, stolons, éclats de souche).

- La régularité de la croissance végétale : saisonnée ou constante.

- Ladaptation au milieu.

- La rusticité et la résilience aux aléas climatiques : résistance à la sécheresse et tolérance à l'engorgement, à l'ombrage.

- Les besoins en eau, la tolérance à la sécheresse.

- Les besoins en température, éventuellement la tolérance aux températures fraîches, aux gelées.

- Les besoins d'ensoleillement.

- Les types de sols : la texture, le pH, la fertilité.

- La tolérance à des stress induits par les pratiques ou les incidents de gestion : surpâturage, feu, défaut de fertilisation ou d'irrigation.

\section{Les caractères agronomiques}

- La facilité de mise en place et d'entretien : semis ou plantations, besoins éventuels en rhizobium.

- La compétitivité par rapport aux adventices.

- Laptitude à l'association avec d'autres plantes.

- La résistance aux maladies et parasites.

- La tenue au pâturage, la capacité de repousse, les refus, la reprise après la coupe.

\section{Les qualités fourragères}

- L'aptitude à être consommée : l'appétibilité, l'ingestibilité.

- La valeur nutritive : teneurs en énergie, azote, minéraux.

- La plasticité aux modes d'exploitation.

Les graminées présentent en zones tropicales des types morphologiques différents (uniculmaire, cespiteux, gazonnant) dont la distinction permet de comprendre les dynamiques de croissance et les types d'utilisation :

- les graminées uniculmaires (figure 1.1) ne forment pas de touffes ou de rosettes. Elles ont un seul chaume qui peut se ramifier dans sa partie aérienne;

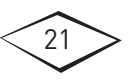




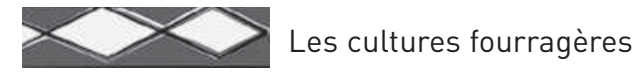

- les graminées cespiteuses (figure 1.2) sont caractérisées par une croissance des talles en touffes très nombreuses, en taches, en plages ou en grandes étendues. La plupart de ces espèces produisent des graines viables et sont multipliées par semis. Elles offrent l'avantage de résister particulièrement bien aux incendies et à la sécheresse grâce à la superposition de gaines foliaires qui protègent les bourgeons. La plupart des espèces cespiteuses sont particulièrement bien adaptées à la zone intertropicale. Les principales sont Panicum maximum (photo 1.1), Andropogon gayanus, Hyparrhenia rufa, Pennisetum purpureum (photo 1.4);

- les graminées gazonnantes sont caractérisées par une croissance de type prostré avec des stolons ou des rhizomes qui assurent la reproduction végétative, leur donnant un port étalé et leur permettant une colonisation horizontale par plaques (figure 1.3). Il se forme ainsi un gazon dense et feutré, mais relativement peu résistant aux incendies. La plupart des espèces, qui produisent peu ou pas de semences viables et se propagent essentiellement par voie végétative, constituent l'essentiel des pâturages de la zone humide. Les plus courantes sont Brachiaria humidicola (photo 1.3), Brachiaria mutica, Cynodon dactylon, Digitaria decumbens, Stenotaphrum secundatum. Certains genres produisent également des graines comme les Brachiaria et plus particulièrement B. ruziziensis (photo 1.2)

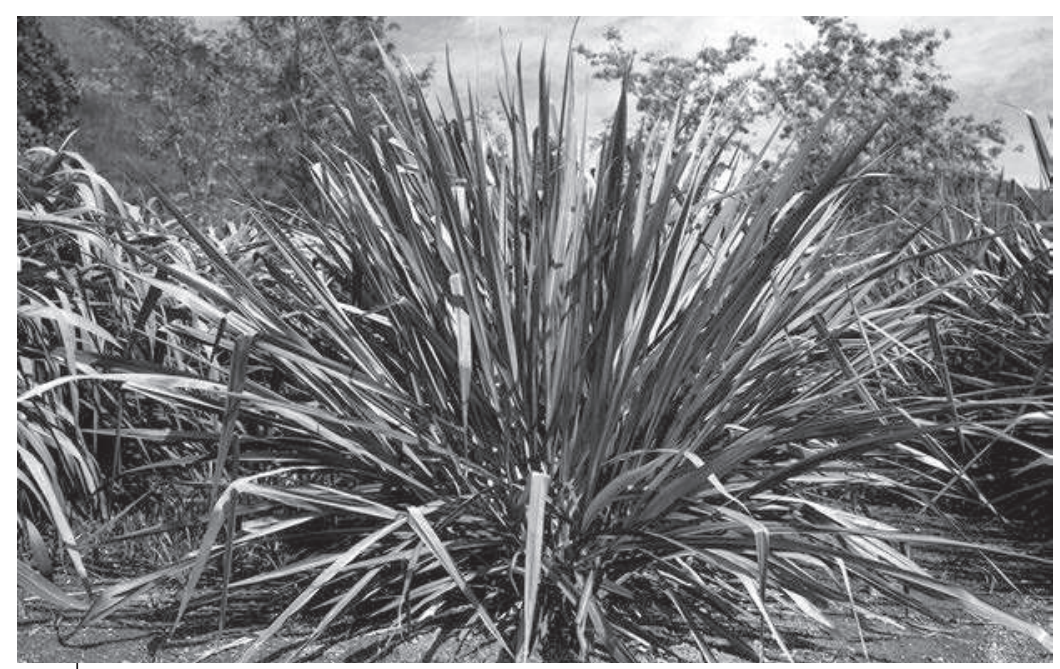

Photo 1.1.

Panicum maximum cultivar Hamil, graminée cespiteuse de haute taille, à touffes avec des feuilles larges, Burkina Faso. (๑ B. Toutain)

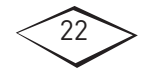



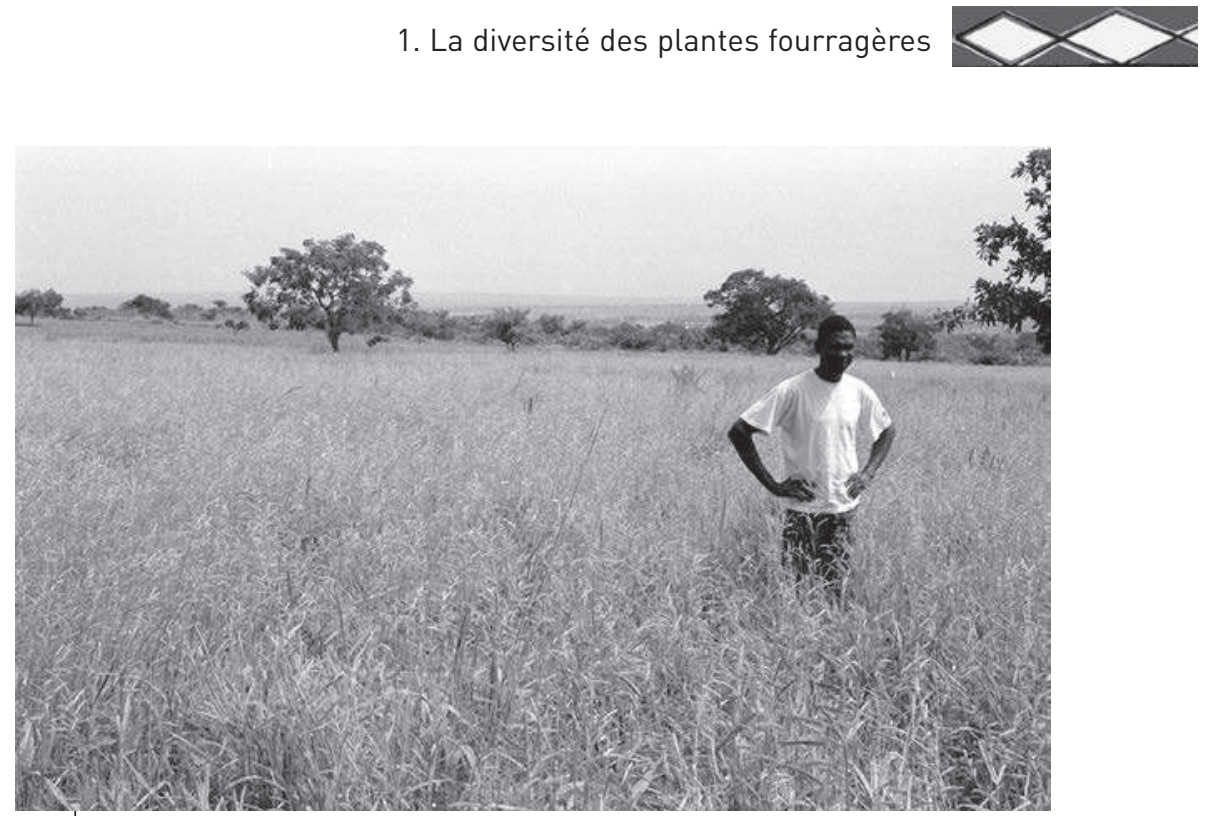

Photo 1.2.

Culture de Brachiaria ruziziensis à proximité de Bobo Dioulasso au Burkina Faso. (๑ B. Toutain)

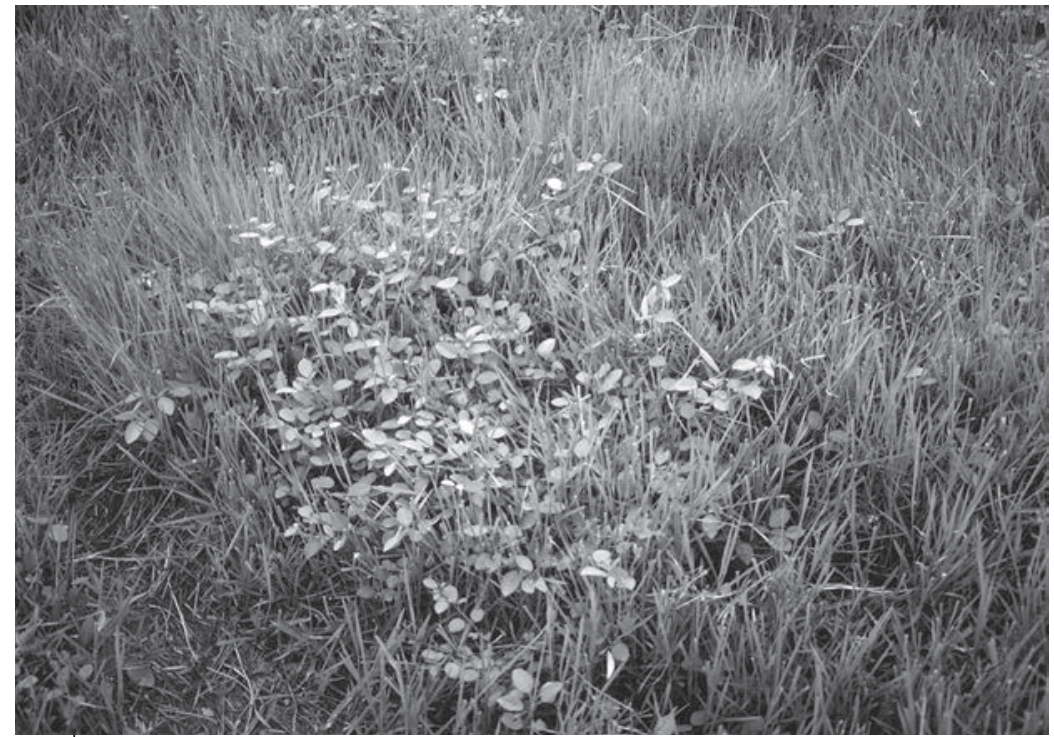

Photo 1.3.

Brachiaria humidicola (Koronivia grass), graminée gazonnante, stolonifère à port étalé, associée à Desmodium ovalifolium, Guyane française.

(๑ H. D. Klein)

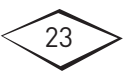



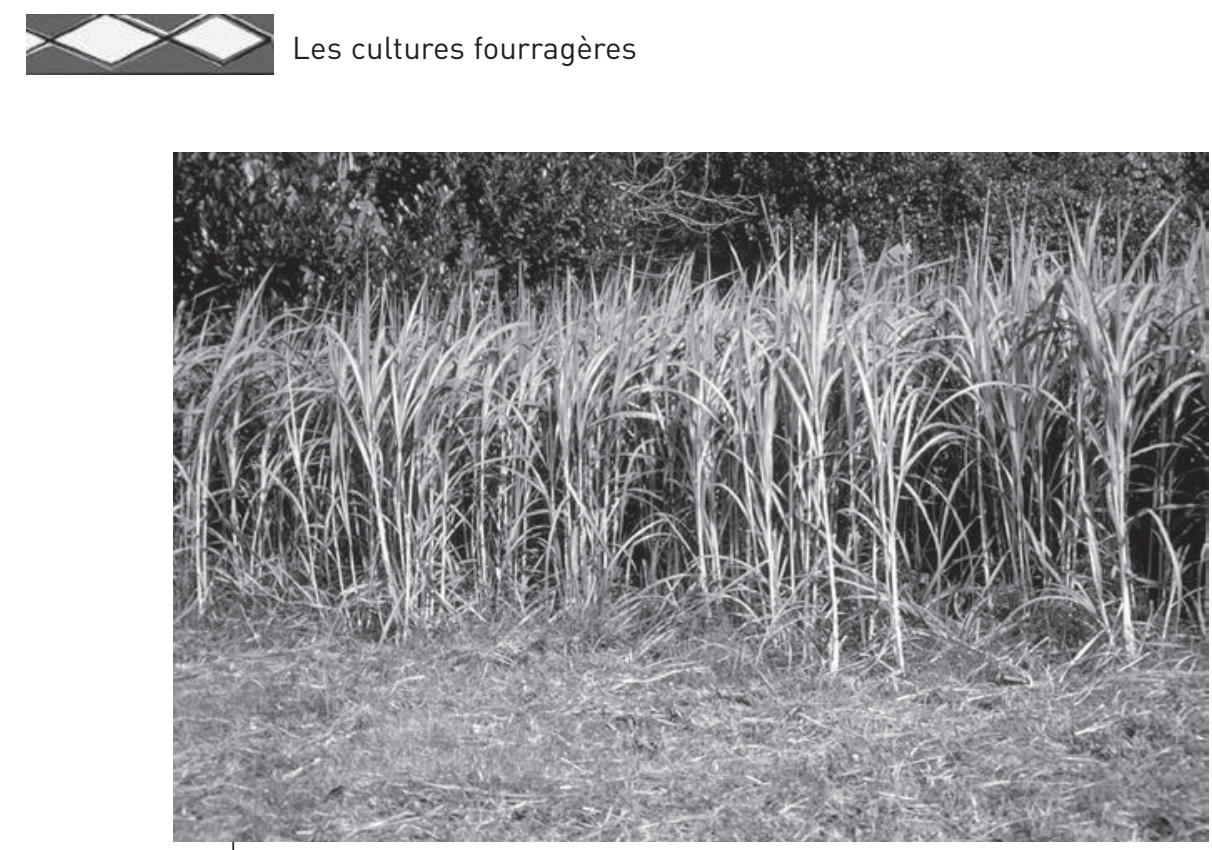

Photo 1.4.

Pennisetum purpureum, graminée cespiteuse à fort développement, coupée pour alimenter les vaches laitières maintenues en stabulation, Mayotte. (৫ H. D. Klein)

Les graminées fourragères sont pour la plupart héliophiles, c'est-à-dire qu'elles poussent en plein soleil, en terrain découvert ou peu ombragé. Leur grande production de semences, leurs capacités de régénération végétative et leur pouvoir couvrant en font de redoutables concurrentes pour d'autres plantes et leur confèrent une capacité importante de colonisation des terrains découverts.

Avec une croissance rapide, des capacités de production importantes et des rapports feuilles-tiges élevés, les graminées restent la base de l'alimentation des herbivores. Les feuilles des graminées ont une durée de vie génétiquement déterminée et meurent à l'issue de leur cycle. Ainsi on peut évaluer le nombre de degrés-jours nécessaires à l'émission d'une feuille, cette caractéristique étant variable selon les espèces.

Lappétence des graminées pour les herbivores s'explique par la texture relativement tendre de leurs tissus, leur goût discret et leur odeur non marquée par des substances désagréables ou répulsives, l'absence ou la faible teneur en substances toxiques ou en tanins, la richesse en glucides digestibles (celluloses, sucres solubles, etc.) et en matières azotées, la facilité à les pâturer et à les brouter, leur abondance.

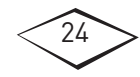



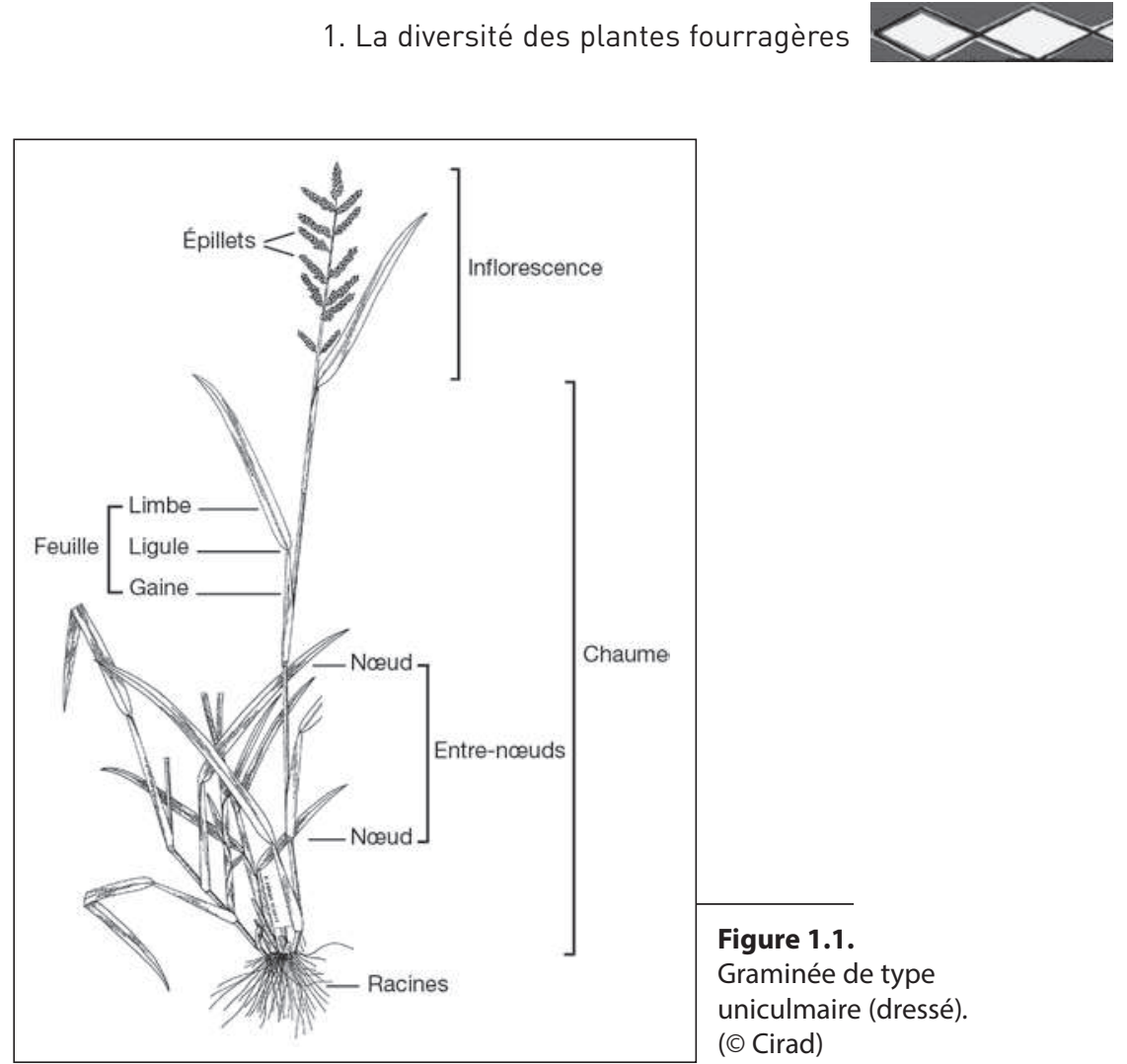

Figure 1.1.

Graminée de type uniculmaire (dressé). (๔) Cirad)

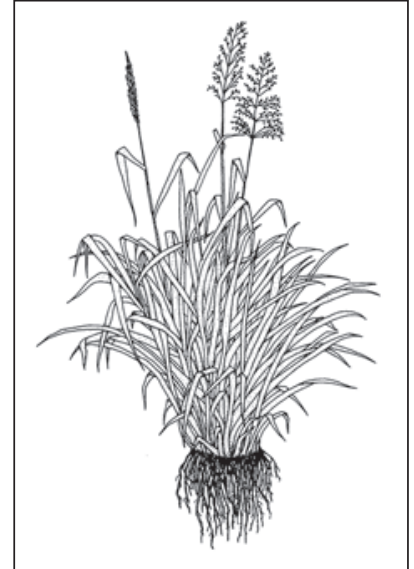

Figure 1.2.

Graminée de type cespiteux à port dressé. (๑ Cirad)

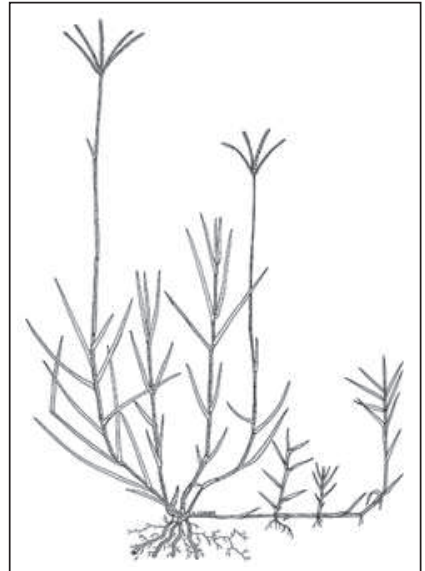

Figure 1.3.

Graminée de type

gazonnant, à port étalé. (๔ Cirad)

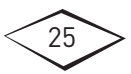




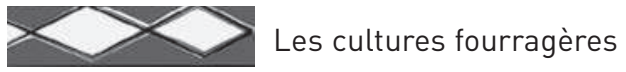

On peut noter cependant que :

- ces caractères sont très diversement répartis à l'intérieur de la famille. Dans un même lieu, certaines espèces sont délaissées par les animaux, alors que d'autres sont surpâturées. La sélection s'exerce aussi à l'intérieur d'une espèce en fonction du stade de développement; - les qualités nutritives sont globalement moins bonnes en pays chauds qu'en pays tempérés, car les plantes sont plus fibreuses, plus lignifiées et en conséquence moins digestibles. Elles sont bien ingérées à condition que l'éleveur admette un taux de refus important (de 10 à $30 \%$ ), beaucoup plus élevé qu'en milieu tempéré où le taux moyen de refus est de $5 \%$.

Le métabolisme énergétique de base de la photosynthèse explique l'écart entre les espèces de climat tempéré qui ont un cycle du carbone en $\mathrm{C} 3$ et les espèces de climat tropical qui ont un cycle en $\mathrm{C} 4{ }^{1}$. Ces cycles aboutissent à la production de glucides plus ou moins complexes, le principal étant la cellulose. Le cycle en $\mathrm{C} 4$ est beaucoup plus efficace en milieu tropical et fonctionne avec moins d'azote que celui en $\mathrm{C} 3$; les espèces en $\mathrm{C} 4$ ont un développement optimal à des températures plus élevées que les espèces en $\mathrm{C} 3$ (entre 30 et $40^{\circ} \mathrm{C}$ et 15 et $20^{\circ} \mathrm{C}$ respectivement) et leur croissance est rapide, exploitant au maximum une période de végétation courte.

Dans ces conditions optimales de lumière et de température, ces espèces produisent deux à trois fois plus de biomasse que les espèces en C3 par rapport à l'énergie interceptée par unité de surface. Par contre, elles produisent aussi davantage de constituants pariétaux (des membranes) peu digestibles (les tissus de soutien sont plus importants car ces plantes sont plus hautes) et leur teneur en matière azotée est plus faible, d'où une valeur alimentaire beaucoup moins bonne. Quelques espèces en $\mathrm{C} 4$, tels que le maïs et le sorgho, ont connu un fort développement sous des climats tempérés suite à des programmes de sélection qui ont proposé des variétés adaptées à des conditions climatiques plus froides.

La capacité de repousse après pâture ou fauche, voire après feu, est importante, mais diffère selon les types de graminées, les modes et les rythmes d'exploitation (pâture ou fauche) et la hauteur de la coupe :

- les graminées annuelles coupées en vert se régénèrent peu ou meurent;

1 Les plantes en $\mathrm{C} 3$ ne produisent des chaînes carbonées qu'en présence de lumière, alors que les plantes en $\mathrm{C} 4$ emmagasinent de l'énergie pour permettre à la plante de produire des chaînes carbonées la nuit, d'où leur croissance plus rapide.

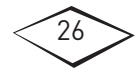


- les graminées cespiteuses pérennes, coupées ou brûlées vont repousser et produire de nouvelles talles, à condition que leurs bourgeons aient été préservés. Une touffe de graminée pérenne est comparable à un bouquet de tiges d'âges différents, chaque tige développant ses feuilles, son chaume et son inflorescence. Tant que le plateau de tallage est intact et n'est pas épuisé, il peut produire de nouvelles talles. Une coupe effectuée à la montaison (phase précédant l'apparition de l'inflorescence) retarde la phase de reproduction jusqu'à la floraison d'autres talles. La section de la tige loin de sa base permet souvent des repousses au niveau des nœuds en-dessous de la coupe;

- les espèces gazonnantes (à port étalé) pâturées ou fauchées produisent des tiges prostrées, ce qui accroît la tendance à l'étalement et au recouvrement du sol.

Linitiation florale, mécanisme biologique interne qui déclenche l'apparition des inflorescences, dépend principalement de facteurs externes. On distingue : les espèces photopériodiques, sensibles aux variations de la longueur du jour, donc de la saison; les espèces thermopériodiques, dont le cycle est lié aux valeurs de température accumulées au-dessus du zéro de végétation, la date de floraison dépend alors des températures de l'année et du lieu de végétation (encadré 1.2).

\section{Encadré 1.2. La phénologie des graminées}

Phase végétative. Cette phase commence à la levée de la graine et se termine à l'apparition des premiers nœuds, avec l'émergence des premiers ensembles gaines-feuilles et éventuellement de talles latérales.

Montaison. Cette étape couvre l'élongation de la tige et l'apparition des nœuds. Le bourgeon floral se trouve à l'extrémité de la tige, caché par la gaine foliaire supérieure.

Épiaison. Ce stade est celui de l'apparition du bourgeon floral hors de la dernière gaine et différenciation de l'inflorescence.

Floraison. Ce stade est celui de l'apparition des fleurs et des organes reproducteurs (pistil et étamines).

Fructification. Cette étape couvre la formation des graines jusqu'à leur maturité.

Dissémination des semences. Au cours de cette phase, les graines, avec ou sans leurs enveloppes selon les espèces, sont mûres et se détachent de la plante. La tige fertile meurt et se dessèche.

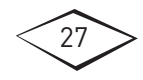


Les graminées fourragères peuvent être cultivées en association avec d'autres plantes moyennant des modes de gestion permettant de contrôler les effets de la concurrence entre plantes : par exemple les graminées dressées laissent de l'espace aux autres plantes herbacées. Lassociation d'une graminée et d'une légumineuse est bénéfique grâce à l'enrichissement du sol par les légumineuses, notamment en azote, et à la bonne absorption de l'azote du sol par les graminées.

Chez certaines graminées, des rhizobactéries présentes à proximité des racines leur permettent de récupérer un peu d'azote d'origine atmosphérique, mais cette modalité est bien moins efficace que la véritable symbiose des légumineuses.

Un œil non averti peut confondre les graminées et les plantes herbacées appartenant à la famille des Cyperaceae. Ces plantes herbacées ont une tige plutôt triangulaire, et les fleurs comme les fruits diffèrent notablement car ils sont construits sur la base de pièces florales par trois pour les Cyperaceae, au lieu de deux pour les graminées.

Les caractères habituels des graminées sont :

- des racines fasciculées à partir du collet de la plante;

- des tiges appelées chaumes, composées de nœuds et d'entrenœuds;

- des feuilles naissant aux nœuds et formant une gaine qui se prolonge en limbe allongé; entre gaine et limbe présence ou non d'une ligule;

- des fleurs très petites et nombreuses, enveloppées chacune par deux glumelles (une inférieure et une supérieure) faites de deux pièces opposées, sorte de coquilles protégeant l'ovule puis la graine;

- des épillets, unités élémentaires de l'inflorescence composées d'une ou plusieurs fleurs et entourées par deux glumes, une inférieure et une supérieure;

- des inflorescences au sommet de la tige composées d'épillets regroupés en épis, en panicules ou en racèmes paniculés, digités, subdigités ou géminés.

La caractérisation des inflorescences des graminées est à la base de toutes les clefs de détermination (figures 1.4 à 1.11).

Le tableau 1.1 présente les graminées tropicales les plus importantes qui peuvent être cultivées dans différents milieux et régions tropicales. Sont mentionnés les noms scientifiques et communs, les types morphologiques, l'adaptation au milieu, les utilisations et les précautions d'usage, ainsi que les rendements moyens (ordres de grandeur) étant entendu que ces rendements peuvent être très variables.

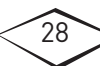




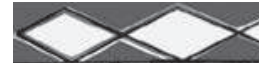

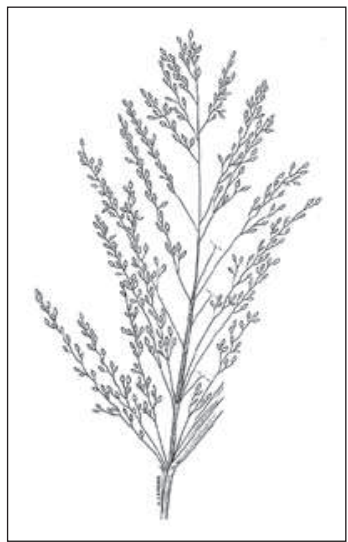

Figure 1.4.

Panicule vraie.

(๑ Cirad)

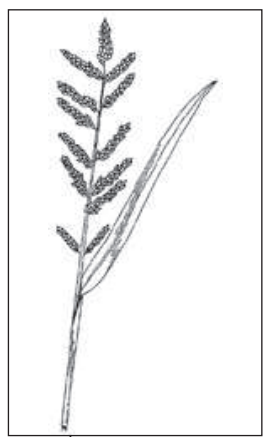

Figure 1.6.

Racème paniculé.

(๔ Cirad)

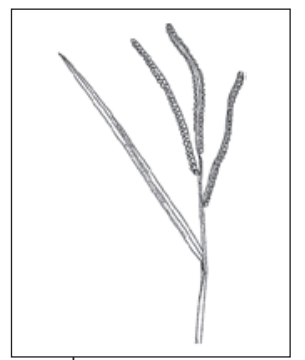

Figure 1.8.

Racème subdigité.

(৫ Cirad)

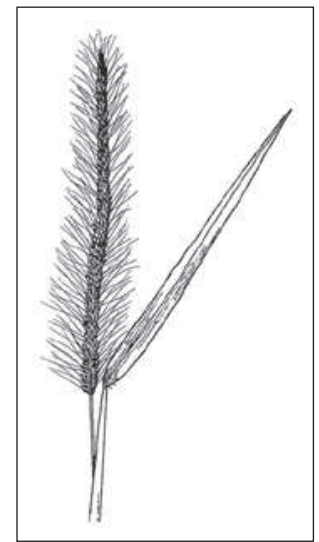

Figure 1.5.

Panicule spiciforme, épi.

(๔ Cirad)

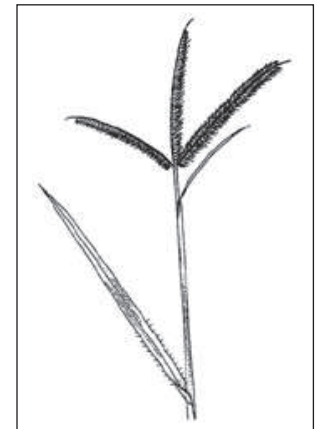

Figure 1.7.

Racème digité

(๑ Cirad)

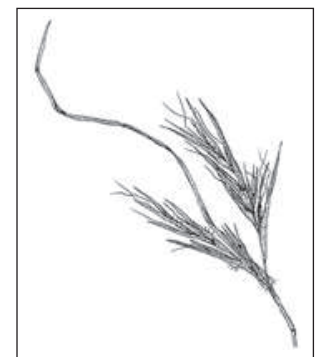

Figure 1.9.

Racème géminé. (๑ Cirad)

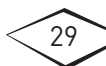




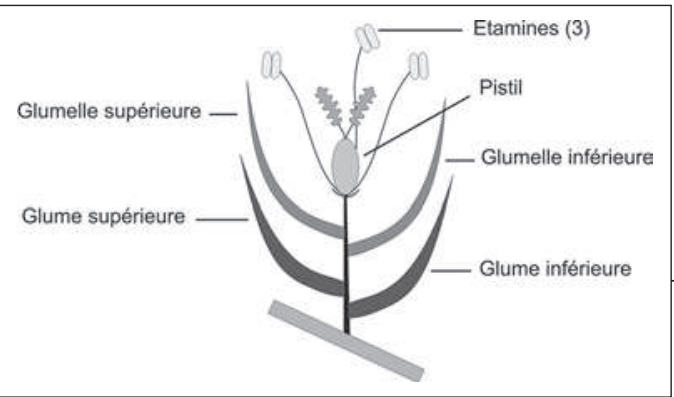

Figure 1.10.

Épillet uniflore

(๑) Cirad)

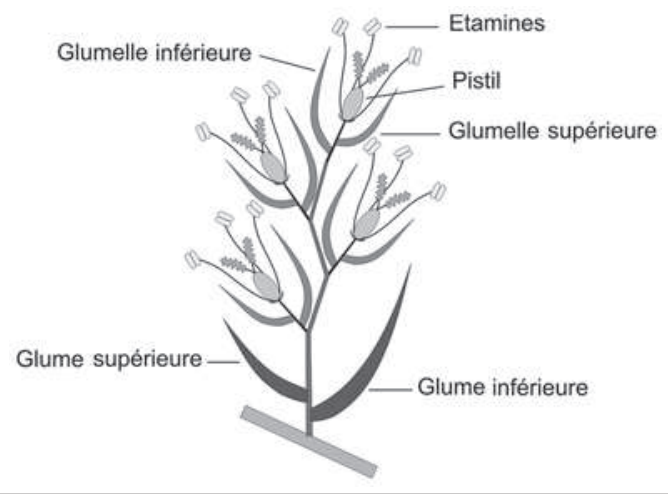

Figure 1.11

Épillet pluriflore. (๔) Cirad)

Tableau 1.1. Principales graminées fourragères herbacées tropicales cultivées.

\begin{tabular}{|c|c|c|c|c|}
\hline $\begin{array}{l}\text { Nom scientifique } \\
\text { commun } \\
\text { Cultivar courant } \\
\text { (pays } \\
\text { d'obtention) }\end{array}$ & Type de plante & $\begin{array}{l}\text { Pluviométrie } \\
\text { optimale } \\
\text { Adaptation au } \\
\text { milieu } \\
\text { Zones de culture } \\
\text { recommandées }\end{array}$ & $\begin{array}{l}\text { Utilisations et } \\
\text { précautions }\end{array}$ & $\begin{array}{l}\text { Rendement } \\
\text { (tonnes MS/ } \\
\text { ha/an) }\end{array}$ \\
\hline $\begin{array}{l}\text { Andropogon } \\
\text { gayanus } \\
\text { Gayanus } \\
\text { (Gambie) }\end{array}$ & $\begin{array}{l}\text { Pérenne } \\
\text { cespiteuse } \\
\text { Hautes touffes } \\
\text { dressées à } \\
\text { rhizomes courts }\end{array}$ & $\begin{array}{l}\text { De } 500 \text { à } \\
1500 \text { mm/an } \\
\text { Saison sèche } \\
\text { nette de } 9 \text { mois } \\
\text { Terres profondes } \\
\text { drainées }\end{array}$ & $\begin{array}{l}\text { Prairie permanente } \\
\text { en rotation } \\
\text { Jachères en } \\
\text { Afrique } \\
\text { Résistante au feu } \\
\text { et à la sécheresse }\end{array}$ & $\begin{array}{l}\text { Faible } \\
\text { productivité } \\
4 \text { à } 10 \\
\text { jusqu'à } 30\end{array}$ \\
\hline $\begin{array}{l}\text { Brachiaria } \\
\text { brizantha } \\
\text { Palisade grass : } \\
\text { cv. Marandu } \\
\text { (Amérique du } \\
\text { Sud) }\end{array}$ & $\begin{array}{l}\text { Pérenne } \\
\text { stolonifère } \\
\text { Touffes dressées } \\
\text { un peu étalées }\end{array}$ & $\begin{array}{l}\text { Plus de } \\
800 \mathrm{~mm} / \mathrm{an} \\
\text { Saison sèche } \\
\text { de } 3 \text { à } 6 \text { mois } \\
\text { Sols fertiles } \\
\text { divers }\end{array}$ & $\begin{array}{l}\text { Prairie permanente } \\
\text { ou en rotation } \\
\text { Répond bien à la } \\
\text { fertilisation } \\
\text { Coupe en vert et } \\
\text { bon foin }\end{array}$ & $\begin{array}{l}\text { Productivité } \\
\text { moyenne } \\
8 \text { à } 20\end{array}$ \\
\hline
\end{tabular}

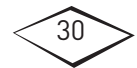




\begin{tabular}{|c|c|c|c|c|}
\hline $\begin{array}{l}\text { Nom scientifique } \\
\text { commun } \\
\text { Cultivar courant } \\
\text { (pays } \\
\text { d'obtention) }\end{array}$ & Type de plante & $\begin{array}{l}\text { Pluviométrie } \\
\text { optimale } \\
\text { Adaptation au } \\
\text { milieu } \\
\text { Zones de culture } \\
\text { recommandées }\end{array}$ & $\begin{array}{l}\text { Utilisations et } \\
\text { précautions }\end{array}$ & $\begin{array}{l}\text { Rendement } \\
\text { (tonnes MS/ } \\
\text { ha/an) }\end{array}$ \\
\hline $\begin{array}{l}\text { Brachiaria } \\
\text { decumbens } \\
\text { Signal grass : } \\
\text { cv. Basilisk } \\
\text { (Australie) }\end{array}$ & $\begin{array}{l}\text { Pérenne } \\
\text { stolonifère } \\
\text { rhizomateuse } \\
\text { Touffes un peu } \\
\text { étalées }\end{array}$ & $\begin{array}{l}\text { Plus de } \\
1000 \mathrm{~mm} / \mathrm{an} \\
\text { Saison sèche } \\
\text { courte } \\
\text { Sols très divers, } \\
\text { même lessivés }\end{array}$ & $\begin{array}{l}\text { Prairie permanente } \\
\text { ou en rotation } \\
\text { Valorise très bien } \\
\text { la fertilisation } \\
\text { Intoxications } \\
\text { possibles } \\
\text { (mycotoxines) }\end{array}$ & $\begin{array}{l}\text { Productivité } \\
\text { moyenne } \\
8 \text { à } 15 \\
\text { jusqu'à } 20\end{array}$ \\
\hline $\begin{array}{l}\text { Brachiaria } \\
\text { ruziziensis } \\
\text { Ruzi grass }\end{array}$ & $\begin{array}{l}\text { Pérenne dressée } \\
\text { à touffes étalées } \\
\text { Peu durable } \\
\text { Se resème } \\
\text { spontanément }\end{array}$ & $\begin{array}{l}\text { De } 1200 \text { à } \\
2000 \text { mm/an } \\
\text { Sols divers bien } \\
\text { drainés, pas } \\
\text { acides } \\
\text { Très sensible à la } \\
\text { cercosporiose }\end{array}$ & $\begin{array}{l}\text { Prairie permanente } \\
\text { ou en rotation } \\
\text { Valorise bien la } \\
\text { fertilisation } \\
\text { Rendements } \\
\text { inférieurs à } \\
\text { B. decumbens }\end{array}$ & $\begin{array}{l}\text { Productivité } \\
\text { moyenne } \\
6 \text { à } 15 \\
\text { jusqu'à } 25\end{array}$ \\
\hline $\begin{array}{l}\text { Cenchrus ciliaris } \\
\text { Buffel grass : } \\
\text { cv. Biloela, } \\
\text { cv. Molopo, } \\
\text { cv. American }\end{array}$ & $\begin{array}{l}\text { Pérenne dressée } \\
\text { Extrêmement } \\
\text { variable }\end{array}$ & $\begin{array}{l}300 \text { à } 750 \mathrm{~mm} / \mathrm{an} \\
\text { Sols divers } \\
\text { drainés, sableux } \\
\text { ou argileux, } \\
\text { riches }\end{array}$ & $\begin{array}{l}\text { Prairie permanente } \\
\text { ou en rotation } \\
\text { Teneur non } \\
\text { négligeable en } \\
\text { oxalate } \\
\text { Résistante à la } \\
\text { sécheresse }\end{array}$ & $\begin{array}{l}\text { Productivité } \\
\text { faible } \\
2 \text { à } 9 \\
\text { jusqu'à } 20\end{array}$ \\
\hline $\begin{array}{l}\text { Chloris gayana } \\
\text { Rhodes grass : } \\
\text { cv. Pioneer, } \\
\text { cv. Callide, } \\
\text { cv. Gayndah }\end{array}$ & $\begin{array}{l}\text { Pérenne } \\
\text { stolonifère } \\
\text { Touffes dressées } \\
\text { Se resème } \\
\text { spontanément }\end{array}$ & $\begin{array}{l}\text { De } 750 \text { à } \\
1500 \mathrm{~mm} / \mathrm{an} \\
\text { Tolérante à la } \\
\text { gelée et à la } \\
\text { salinité modérée } \\
\text { Sols divers bien } \\
\text { drainés }\end{array}$ & $\begin{array}{l}\text { Prairie permanente } \\
\text { de courte durée } \\
\text { Tolère une } \\
\text { mauvaise gestion } \\
\text { Fournit un bon } \\
\text { foin }\end{array}$ & $\begin{array}{l}\text { Productivité } \\
\text { moyenne } \\
15 \text { à } 25\end{array}$ \\
\hline $\begin{array}{l}\text { Cynodon dactylon } \\
\text { Couch grass, } \\
\text { Bermuda grass }\end{array}$ & $\begin{array}{l}\text { Pérenne } \\
\text { stolonifère } \\
\text { Rhizomateuse à } \\
\text { feuilles fines } \\
\text { Multiplication } \\
\text { par graines ou } \\
\text { végétative }\end{array}$ & $\begin{array}{l}\text { De } 625 \text { à } \\
1750 \text { mm/an } \\
\text { Climat tempéré } \\
\text { chaud et } \\
\text { subtropical } \\
\text { Sols drainés } \\
\text { profonds } \\
\text { Tolérante à } \\
\text { la salinité et } \\
\text { l'inondation }\end{array}$ & $\begin{array}{l}\text { Prairie } \\
\text { permanente, gazon } \\
\text { Résiste au } \\
\text { surpâturage } \\
\text { Plante de } \\
\text { couverture dans } \\
\text { les vergers }\end{array}$ & $\begin{array}{l}\text { Productivité } \\
\text { moyenne } \\
5 \text { à } 15\end{array}$ \\
\hline $\begin{array}{l}\text { Digitaria eriantha } \\
\text { Ex Digitaria } \\
\text { decumbens } \\
\text { Pangola grass }\end{array}$ & $\begin{array}{l}\text { Pérenne } \\
\text { stolonifère, } \\
\text { gazonnante } \\
\text { ou rhizomateuse } \\
\text { (variable) } \\
\text { Multiplication } \\
\text { végétative }\end{array}$ & $\begin{array}{l}\text { Plus de } 1000 \text { mm } \\
\text { Saison sèche } \\
\text { courte } \\
\text { Jusqu'à } 1000 \mathrm{~m} \\
\text { d'altitude } \\
\text { Sols divers } \\
\text { jusqu'à pH } 8, \\
\text { riches }\end{array}$ & $\begin{array}{l}\text { Prairie permanente } \\
\text { Tolère une } \\
\text { mauvaise gestion } \\
\text { À fertiliser }\end{array}$ & $\begin{array}{l}\text { Productivité } \\
\text { forte } \\
10 \text { à } 20 \\
\text { jusqu'à } 30\end{array}$ \\
\hline
\end{tabular}

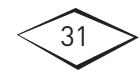


Tableau 1.1. Principales graminées fourragères herbacées tropicales cultivées. (suite)

\begin{tabular}{|c|c|c|c|c|}
\hline $\begin{array}{l}\text { Nom scientifique } \\
\text { commun } \\
\text { Cultivar courant } \\
\text { (pays } \\
\text { d'obtention) }\end{array}$ & Type de plante & $\begin{array}{l}\text { Pluviométrie } \\
\text { optimale } \\
\text { Adaptation au } \\
\text { milieu } \\
\text { Zones de culture } \\
\text { recommandées }\end{array}$ & $\begin{array}{l}\text { Utilisations et } \\
\text { précautions }\end{array}$ & $\begin{array}{l}\text { Rendement } \\
\text { (tonnes MS/ } \\
\text { ha/an) }\end{array}$ \\
\hline $\begin{array}{l}\text { Echinochloa } \\
\text { stagnina } \\
\text { Bourgou }\end{array}$ & $\begin{array}{l}\text { Pérenne } \\
\text { cespiteuse } \\
\text { Tiges flottantes, } \\
\text { aquatiques }\end{array}$ & $\begin{array}{l}\text { Lieux longtemps } \\
\text { inondés } \\
\text { Zones } \\
\text { équatoriale, } \\
\text { tropicale et } \\
\text { d'altitude }\end{array}$ & $\begin{array}{l}\text { Fourrage à } \\
\text { couper pendant } \\
\text { l'inondation } \\
\text { Prairie à pâturer } \\
\text { après l'inondation }\end{array}$ & $\begin{array}{l}\text { Productivité } \\
\text { moyenne } \\
10 \text { à } 20\end{array}$ \\
\hline $\begin{array}{l}\text { Hyparrhenia rufa } \\
\text { Jaragua }\end{array}$ & $\begin{array}{l}\text { Pérenne } \\
\text { cespiteuse, } \\
\text { touffes hautes }\end{array}$ & $\begin{array}{l}\text { Plus de } 800 \mathrm{~mm} \\
\text { Sols bien } \\
\text { alimentés en eau, } \\
\text { voire inondés }\end{array}$ & $\begin{array}{l}\text { Prairie } \\
\text { permanente, ou en } \\
\text { rotation } \\
\text { Résiste au feu, } \\
\text { tolérante à } \\
\text { sécheresse }\end{array}$ & $\begin{array}{l}\text { Productivité } \\
\text { faible } \\
6 \text { à } 15\end{array}$ \\
\hline $\begin{array}{l}\text { Lolium } \\
\text { multiflorum } \\
\text { Ray-grass d'Italie }\end{array}$ & $\begin{array}{l}\text { Pérenne } \\
\text { cespiteuse } \\
\text { Petites touffes } \\
\text { denses dressées }\end{array}$ & $\begin{array}{l}\text { Plante tempérée } \\
\text { convenant aux } \\
\text { régions chaudes } \\
\text { À fertiliser et } \\
\text { irriguer }\end{array}$ & $\begin{array}{l}\text { Prairie temporaire } \\
\text { intensive } \\
\text { Fourrage de bonne } \\
\text { qualité } \\
\text { Rares intoxications } \\
\text { (mycotoxines) }\end{array}$ & $\begin{array}{l}\text { Productivité } \\
\text { faible } \\
5 \text { à } 10, \\
\text { jusqu'à } 15\end{array}$ \\
\hline $\begin{array}{l}\text { Panicum } \\
\text { maximum } \\
\text { Guinea grass } \\
\text { cv. Hamil, } \\
\text { Makueni, } \\
\text { Coloniao cv. } \\
\text { C1, T58, } \\
\text { Vencedor }\end{array}$ & $\begin{array}{l}\text { Pérenne } \\
\text { cespiteuse } \\
\text { (touffes denses) } \\
\text { Multiplication } \\
\text { par graines } \\
\text { ou plantation } \\
\text { d'éclats de } \\
\text { souche } \\
\text { Intolérante à } \\
\text { la salinité et à } \\
\text { l'engorgement }\end{array}$ & $\begin{array}{l}\text { Plus de } \\
1000 \mathrm{~mm} / \mathrm{an} \\
\text { Saison sèche } \\
\text { courte et nette } \\
\text { Sols divers non } \\
\text { inondés, même } \\
\text { moyennement } \\
\text { fertiles }\end{array}$ & $\begin{array}{l}\text { Prairie permanente } \\
\text { en rotation } \\
\text { Très durable } \\
\text { Pâture directe et } \\
\text { foin en alternance } \\
\text { Mérite d'être } \\
\text { fertilisée }\end{array}$ & $\begin{array}{l}\text { Forte capacité } \\
\text { de production } \\
15 \text { à } 30, \\
\text { jusqu'à } 50\end{array}$ \\
\hline $\begin{array}{l}\text { Pennisetum } \\
\text { clandestinum } \\
\text { Kikuyu : } \\
\text { cv. Whittet } \\
\text { (Australie) }\end{array}$ & $\begin{array}{l}\text { Pérenne } \\
\text { stolonifère } \\
\text { rampante } \\
\text { Très couvrante, } \\
\text { bonne } \\
\text { colonisatrice } \\
\text { Multiplication } \\
\text { végétative ou par } \\
\text { graines }\end{array}$ & $\begin{array}{l}\text { De } 1000 \text { à } \\
1600 \text { mm/an de } \\
\text { pluie, jusqu'à } \\
3000 \text { m d'altitude } \\
\text { Sols drainants, } \\
\text { riches, humides } \\
\text { en profondeur }\end{array}$ & $\begin{array}{l}\text { Prairie permanente } \\
\text { Pâturage en } \\
\text { rotation }\end{array}$ & $\begin{array}{l}\text { Productivité } \\
\text { forte } \\
10 \text { à } 20, \\
\text { jusqu'à } 30\end{array}$ \\
\hline $\begin{array}{l}\text { Pennisetum } \\
\text { purpureum } \\
\text { Herbe à } \\
\text { éléphant, Napier } \\
\text { Nombreux } \\
\text { cultivars }\end{array}$ & $\begin{array}{l}\text { Pérenne, touffes } \\
\text { dressées } \\
\text { Fortes tiges } \\
\text { dressées } \\
\text { de } 2 \text { à } 3 \mathrm{~m} \\
\text { Multiplication } \\
\text { végétative }\end{array}$ & $\begin{array}{l}1000 \mathrm{~mm} / \mathrm{an} \text { ou } \\
\text { plus } \\
\text { Sols toujours } \\
\text { humides et riches } \\
\text { Mérite d'être } \\
\text { fertilisée, peut } \\
\text { être irriguée }\end{array}$ & $\begin{array}{l}\text { Coupe en vert } \\
\text { plutôt que pâture } \\
\text { directe } \\
\text { Très appétente } \\
\text { Très durable } \\
\text { Production } \\
\text { d'agrocarburant, }\end{array}$ & $\begin{array}{l}\text { Forte capacité } \\
\text { de production } \\
15 \text { à } 30\end{array}$ \\
\hline
\end{tabular}

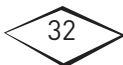




\begin{tabular}{|c|c|c|c|c|}
\hline $\begin{array}{l}\text { Nom scientifique } \\
\text { commun } \\
\text { Cultivar courant } \\
\text { (pays } \\
\text { d'obtention) }\end{array}$ & Type de plante & $\begin{array}{l}\text { Pluviométrie } \\
\text { optimale } \\
\text { Adaptation au } \\
\text { milieu } \\
\text { Zones de culture } \\
\text { recommandées }\end{array}$ & $\begin{array}{l}\text { Utilisations et } \\
\text { précautions }\end{array}$ & $\begin{array}{l}\text { Rendement } \\
\text { (tonnes MS/ } \\
\text { ha/an) }\end{array}$ \\
\hline $\begin{array}{l}\text { Setaria sphacelata } \\
\text { cv Narok, } \\
\text { Kazungula, } \\
\text { Nandi, } \\
\text { cv. Solander } \\
\text { (Australie) }\end{array}$ & $\begin{array}{l}\text { Pérenne } \\
\text { cespiteuse } \\
\text { Tiges dressées } \\
\text { Rhizomes courts }\end{array}$ & $\begin{array}{l}\text { Plus de } 750 \mathrm{~mm} / \\
\text { an, courte saison } \\
\text { sèche } \\
\text { Sols divers, } \\
\text { même argileux et } \\
\text { inondables } \\
\text { Faciles à semer }\end{array}$ & $\begin{array}{l}\text { Prairie permanente } \\
\text { en rotation } \\
\text { Ensilage et foin } \\
\text { Teneur assez } \\
\text { élevée en oxalates }\end{array}$ & $\begin{array}{l}\text { Bonne } \\
\text { productivité } \\
10 \text { à } 15 \\
\text { jusqu'à } 25\end{array}$ \\
\hline $\begin{array}{l}\text { Sorghum bicolor } \\
\text { Sorgho grain }\end{array}$ & $\begin{array}{l}\text { Céréale haute, } \\
\text { annuelle } \\
\text { Agrocarburant }\end{array}$ & $\begin{array}{l}\text { Pays à été chaud, } \\
\text { plus de } \\
350 \mathrm{~mm} / \mathrm{an} \\
\text { Sols pourvus } \\
\text { en eau, même } \\
\text { argileux } \\
\text { Peut être irrigué } \\
\text { et fertilisé }\end{array}$ & $\begin{array}{l}\text { Culture à couper } \\
\text { en vert ou à ensiler } \\
\text { Fanage possible } \\
\text { Risque de toxicité } \\
\text { cyanhydrique }\end{array}$ & $\begin{array}{l}\text { Productivité } \\
\text { moyenne } \\
4 \text { à } 10 \\
\text { jusqu'à } 20\end{array}$ \\
\hline $\begin{array}{l}\text { Stenotaphrum } \\
\text { secundatum } \\
\text { Buffalo grass } \\
\text { (Australie) }\end{array}$ & $\begin{array}{l}\text { Pérenne } \\
\text { rampante } \\
\text { stolonifère } \\
\text { Gazonnante si } \\
\text { régulièrement } \\
\text { coupée } \\
\text { Riche en sodium }\end{array}$ & $\begin{array}{l}\text { Climats chauds } \\
\text { Régions proches } \\
\text { de la mer } \\
\text { Sol drainant, bien } \\
\text { pourvu en eau } \\
\text { Peu tolérante à la } \\
\text { sécheresse }\end{array}$ & $\begin{array}{l}\text { Prairie permanente } \\
\text { pâturée en continu } \\
\text { Plante de } \\
\text { couverture, gazon } \\
\text { Tolérante à } \\
\text { l'ombre des } \\
\text { cocotiers }\end{array}$ & $\begin{array}{l}\text { Productivité } \\
\text { moyenne } \\
\text { de } 4 \text { à } 8\end{array}$ \\
\hline $\begin{array}{l}\text { Tripsacum laxum } \\
\text { Guatemala grass }\end{array}$ & $\begin{array}{l}\text { Pérenne } \\
\text { cespiteuse } \\
\text { Fortes tiges } \\
\text { dressées } \\
\text { de } 2 \text { à } 3 \mathrm{~m} \\
\text { Multiplication } \\
\text { végétative }\end{array}$ & $\begin{array}{l}\text { Climat tropical } \\
\text { humide } \\
\text { Sols bien pourvus } \\
\text { en eau et riches } \\
\text { Peu tolérante à } \\
\text { la sécheresse }\end{array}$ & $\begin{array}{l}\text { À couper en vert } \\
\text { Production } \\
\text { d'agrocarburants }\end{array}$ & $\begin{array}{l}\text { Très productive } \\
\text { dans bonnes } \\
\text { conditions } \\
15 \text { à } 25\end{array}$ \\
\hline
\end{tabular}

\section{Les légumineuses herbacées}

Les légumineuses sont, avec les graminées, les familles botaniques les plus utiles à l'alimentation dans le monde. Les légumineuses regroupent trois familles (ou sous-familles) : les Fabaceae (ou Papilionaceae), les Mimosaceae et les Caesalpiniaceae. Parmi les 17000 espèces connues, seules 3700 environ ont été repérées pour leurs qualités fourragères. La majorité des Fabaceae sont des plantes herbacées ou des arbustes et arbrisseaux, adaptés aux régions tropicales ou tempérées, tandis que la plupart des Mimosaceae et des Caesalpiniaceae sont des arbres et des arbustes des régions tropicales et méditerranéennes (figure 1.12, tableau 1.2, photo 1.5). 
Les traits majeurs des plantes appartenant à ces familles en rapport avec un usage fourrager sont les suivants :

- la richesse remarquable des feuilles, fruits et graines en matières azotées par rapport aux autres plantes, ce qui leur confère une valeur nutritive élevée;

- la capacité physiologique de symbiose avec des bactéries fixatrices d'azote atmosphérique (généralement au niveau des racines), permettant d'alimenter la plante en azote. Cette capacité, qui n'existe pas toujours chez les Caesalpiniaceae (plus primitives sur le plan de l'évolution), est fréquente chez les Mimosaceae, et commune chez les Fabaceae. Certaines légumineuses forment facilement des mycorhizes en s'associant avec des champignons, lesquels facilitent la mobilisation du phosphore au profit de la plante;

- la présence fréquente dans les organes annuels de substances chimiques répulsives ou toxiques (tanins) qui protègent la plante des prédateurs et limitent donc l'ingestion par les herbivores. Il faut donc prendre certaines précautions lorsqu'on utilise des légumineuses comme fourrage ou comme aliment pour l'animal ou l'homme.

Les légumineuses, du fait d'une photosynthèse en $\mathrm{C} 3$, sont approximativement deux à trois fois moins productives que les graminées tropicales en $\mathrm{C} 4$, mais elles présentent beaucoup d'autres avantages : - leur production au cours de l'année est plus régulière et dure plus longtemps;

- leur richesse en matières azotées permet de compenser la faible teneur en azote des fourrages à base de graminées, particulièrement pour les animaux qui ont des besoins élevés en azote, comme les animaux laitiers, les jeunes en croissance et les adultes en engraissement; - elles enrichissent également les sols en azote;

- leurs racines, souvent pivotantes, permettent de valoriser l'eau en profondeur (parfois à plusieurs mètres) et aussi des éléments nutritifs.

Les légumineuses fourragères, qui peuvent être cultivées en association avec des graminées, sont soit pâturées directement, soit récoltées pour être distribuées aussitôt (fourrage vert, feuillage), ou séchées et conservées comme réserves transportables, stockables et même commercialisables (fanes, foin, graines). Les tourteaux de graines déshuilées (arachide, soja) sont utilisés comme aliments concentrés pour le bétail (tableau 1.2). Sur le plan des contraintes, de nombreuses espèces de légumineuses sont vulnérables au pâturage.

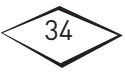



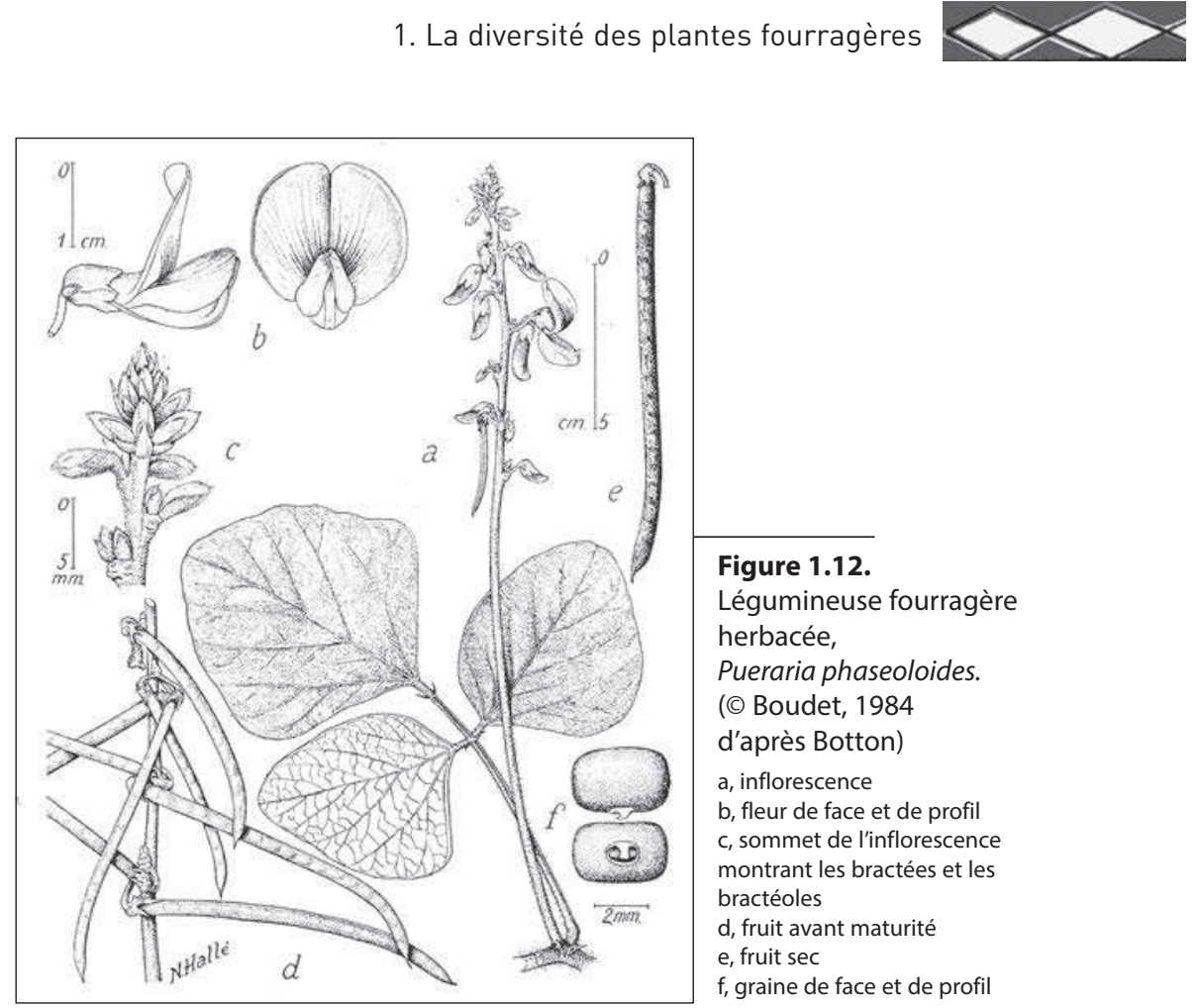

Figure 1.12.

Légumineuse fourragère herbacée,

Pueraria phaseoloides.

(๑) Boudet, 1984

d'après Botton)

$a$, inflorescence

$b$, fleur de face et de profil

c, sommet de l'inflorescence

montrant les bractées et les bractéoles

d, fruit avant maturité

e, fruit sec

$f$, graine de face et de profil

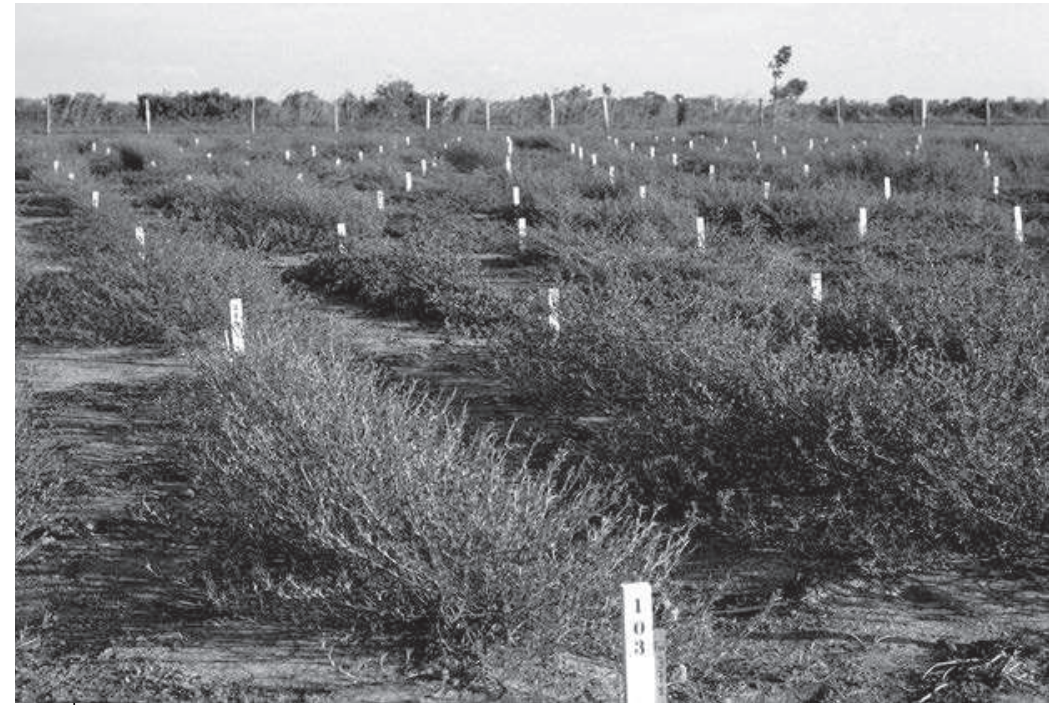

Photo 1.5.

Stylosanthes spp., luzerne tropicale : légumineuse fourragère,

collection de divers cultivars au Ciat, Cali, Colombie. (৫ B. Toutain)

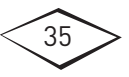


Le tableau 1.2 présente les principales légumineuses herbacées fourragères tropicales et subtropicales herbacées cultivées. Sont mentionnés les noms scientifiques et communs, le type de plantes, l'adaptation aux milieux, les utilisations et les précautions d'usage, ainsi que les rendements moyens.

Tableau 1.2. Principales légumineuses herbacées fourragères tropicales et subtropicales cultivées.

\begin{tabular}{|c|c|c|c|c|}
\hline $\begin{array}{l}\text { Nom } \\
\text { scientifique, } \\
\text { nom commun, } \\
\text { cultivars } \\
\text { courants }\end{array}$ & Type de plante & $\begin{array}{l}\text { Pluviométrie } \\
\text { optimale } \\
\text { Adaptation } \\
\text { au milieu } \\
\text { Zones de culture }\end{array}$ & $\begin{array}{l}\text { Utilisations et } \\
\text { précautions }\end{array}$ & $\begin{array}{l}\text { Production } \\
\text { (t MS/ha/an) }\end{array}$ \\
\hline $\begin{array}{l}\text { Aeschynomene } \\
\text { histrix } \\
\text { Joint-vetch } \\
\text { porc épic }\end{array}$ & $\begin{array}{l}\text { Subligneuse } \\
\text { pérenne } \\
\text { de } 30 \text { à } 80 \mathrm{~cm} \\
\text { Produit } \\
\text { beaucoup de } \\
\text { semences } \\
\text { Sensibilité à } \\
\text { l'anthracnose }\end{array}$ & $\begin{array}{l}\text { Entre } 1000 \text { à } \\
1500 \text { mm/an } \\
\text { Sols pauvres ou } \\
\text { modérément } \\
\text { fertiles } \\
\text { Sols plutôt } \\
\text { acides }\end{array}$ & $\begin{array}{l}\text { Enrichissement } \\
\text { de pâturages } \\
\text { permanents } \\
\text { Résiste à un } \\
\text { pâturage intensif } \\
\text { Sensibilité } \\
\text { aux coupes } \\
\text { fréquentes }\end{array}$ & 2 à 8 \\
\hline $\begin{array}{l}\text { Arachis pintoi } \\
\text { Arachide } \\
\text { fourragère }\end{array}$ & $\begin{array}{l}\text { Herbacée } \\
\text { pérenne, } \\
\text { rampante } \\
\text { Stolonifère, } \\
\text { fortes racines } \\
\text { pivotantes }\end{array}$ & $\begin{array}{l}\text { Entre } 1500 \text { et } \\
2000 \mathrm{~mm} / \mathrm{an} \\
\text { Sols divers } \\
\text { non engorgés }\end{array}$ & $\begin{array}{l}\text { Enrichissement } \\
\text { de prairies } \\
\text { permanentes } \\
\text { Supporte un fort } \\
\text { pâturage, même } \\
\text { continu } \\
\text { Plante de } \\
\text { couverture, } \\
\text { engrais vert }\end{array}$ & $\begin{array}{l}3 \text { à } 6, \\
\text { jusqu'à } 10, \\
\text { voire plus }\end{array}$ \\
\hline $\begin{array}{l}\text { Calopogonium } \\
\text { mucunoides } \\
\text { Mucunoides } \\
\text { calopogonium } \\
\text { Calopo }\end{array}$ & $\begin{array}{l}\text { Liane herbacée } \\
\text { pérenne } \\
\text { Se resème } \\
\text { spontanément } \\
\text { Comportement } \\
\text { de type annuel } \\
\text { en zones sèches }\end{array}$ & $\begin{array}{l}\text { Plus de } \\
1000 \mathrm{~mm} / \mathrm{an}, \\
\text { courte saison } \\
\text { sèche } \\
\text { Sols divers } \\
\text { drainants } \\
\text { Jusqu'à } 1800 \mathrm{~m} \\
\text { d'altitude }\end{array}$ & $\begin{array}{l}\text { Plante de } \\
\text { couverture, } \\
\text { engrais vert } \\
\text { Enrichissement } \\
\text { de pâturages à } \\
\text { graminées } \\
\text { Appétibilité } \\
\text { moyenne, plutôt } \\
\text { à l'état sec }\end{array}$ & $\begin{array}{l}3 \text { à } 6 \\
\text { Accessoirement } \\
\text { fourrager }\end{array}$ \\
\hline $\begin{array}{l}\text { Centrosema } \\
\text { pubescens } \\
\text { Centro }\end{array}$ & $\begin{array}{l}\text { Liane herbacée } \\
\text { pérenne } \\
\text { Fortes racines } \\
\text { pivotantes }\end{array}$ & $\begin{array}{l}\text { Plus de } 1500 \text {, } \\
\text { voire } \\
2000 \mathrm{~mm} / \mathrm{an} \\
\text { Sols divers, } \\
\text { même acides, } \\
\text { bien drainés }\end{array}$ & $\begin{array}{l}\text { Culture } \\
\text { fourragère } \\
\text { pâturée } \\
\text { Résiste à la } \\
\text { sécheresse }\end{array}$ & $\begin{array}{l}\text { Productive } \\
5 \text { à } 8\end{array}$ \\
\hline
\end{tabular}

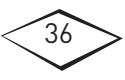




\begin{tabular}{|c|c|c|c|c|}
\hline $\begin{array}{l}\text { Nom } \\
\text { scientifique, } \\
\text { nom commun, } \\
\text { cultivars } \\
\text { courants }\end{array}$ & Type de plante & $\begin{array}{l}\text { Pluviométrie } \\
\text { optimale } \\
\text { Adaptation } \\
\text { au milieu } \\
\text { Zones de culture }\end{array}$ & $\begin{array}{l}\text { Utilisations et } \\
\text { précautions }\end{array}$ & $\begin{array}{l}\text { Production } \\
\text { (t MS/ha/an) }\end{array}$ \\
\hline $\begin{array}{l}\text { Chamaecrista } \\
\text { rotundifolia } \\
\text { synonyme: } \\
\text { Cassia } \\
\text { rotundifolia } \\
\text { cv. Winn } \\
\text { (Australie) }\end{array}$ & $\begin{array}{l}\text { Herbacée ou } \\
\text { subligneuse } \\
\text { prostrée } \\
\text { Annuelle ou } \\
\text { semi-pérenne } \\
\text { Se régénère } \\
\text { spontanément }\end{array}$ & $\begin{array}{l}\text { De } 500 \mathrm{~mm} \text { à } \\
1500 \mathrm{~mm} / \mathrm{an} \\
\text { Sols légers } \\
\text { filtrants, } \\
\text { même acides } \\
\text { Rendements } \\
\text { élevés en } \\
\text { semences }\end{array}$ & $\begin{array}{l}\text { Amélioration de } \\
\text { pâturages sur } \\
\text { sols acides } \\
\text { Appétibilité } \\
\text { moyenne }\end{array}$ & 3 à 6 \\
\hline $\begin{array}{l}\text { Clitoria ternatea } \\
\text { pois de } \\
\text { Cordofan }\end{array}$ & $\begin{array}{l}\text { Liane herbacée } \\
\text { pérenne } \\
\text { Rampante ou } \\
\text { grimpante }\end{array}$ & $\begin{array}{l}\text { de } 700 \text { à } \\
1500 \mathrm{~mm} / \mathrm{an} \\
\text { Sols divers } \\
\text { plutôt argileux } \\
\text { et fertiles }\end{array}$ & $\begin{array}{l}\text { Multiples } \\
\text { usages (banque, } \\
\text { fertilité, } \\
\text { revégétalisation) } \\
\text { Pâturage } \\
\text { difficile, plutôt } \\
\text { coupes }\end{array}$ & 3 à 6 \\
\hline $\begin{array}{l}\text { Desmanthus } \\
\text { virgatus } \\
\text { cv. Jaribu } \\
\text { (Australie) }\end{array}$ & $\begin{array}{l}\text { Sous-ligneux } \\
\text { érigé pérenne } \\
\text { Forte production } \\
\text { de semences }\end{array}$ & $\begin{array}{l}\text { Bien adaptée de } \\
600 \text { à } \\
1000 \mathrm{~mm} / \mathrm{an} \\
\text { Sols argileux, } \\
\text { riches }\end{array}$ & $\begin{array}{l}\text { Amélioration } \\
\text { de prairies sur } \\
\text { argiles noires } \\
\text { Haies, } \\
\text { agriculture en } \\
\text { couloirs }\end{array}$ & $\begin{array}{l}2 \text { à } 4 \\
\text { jusqu'à } 7\end{array}$ \\
\hline $\begin{array}{l}\text { Desmodium } \\
\text { intortum } \\
\text { Greenleaf } \\
\text { Desmodium }\end{array}$ & $\begin{array}{l}\text { Liane herbacée } \\
\text { pérenne } \\
\text { Rhizobium } \\
\text { spécifique }\end{array}$ & $\begin{array}{l}\text { Mêmes milieux } \\
\text { pour les } 2 \\
\text { Desmodium } \\
\text { Plus de } \\
1000 \mathrm{~mm} / \mathrm{an}\end{array}$ & $\begin{array}{l}\text { Appétibilité } \\
\text { moyenne } \\
\text { Amélioration } \\
\text { de pâturages à } \\
\text { graminées en } \\
\text { touffe }\end{array}$ & $\begin{array}{l}6 \text { à } 12 \\
\text { jusqu'à } 15\end{array}$ \\
\hline $\begin{array}{l}\text { Desmodium } \\
\text { uncinatum } \\
\text { Silverleaf } \\
\text { Desmodium }\end{array}$ & $\begin{array}{l}\text { Liane herbacée } \\
\text { pérenne } \\
\text { Rhizobium } \\
\text { spécifique } \\
\text { D. uncinatum } \\
\text { moins rustique } \\
\text { que D. intortum }\end{array}$ & $\begin{array}{l}\text { Peu tolérante à } \\
\text { la sécheresse } \\
\text { (<6 mois) } \\
\text { Sols divers } \\
\text { drainants }\end{array}$ & $\begin{array}{l}\text { Tolère des } \\
\text { températures } \\
\text { fraîches, mais } \\
\text { pas les gelées }\end{array}$ & $\begin{array}{l}6 \text { à } 12 \\
\text { jusqu'à } 15\end{array}$ \\
\hline $\begin{array}{l}\text { Lablab } \\
\text { purpureus } \\
\text { Dolichos lablab } \\
\text { Dolique }\end{array}$ & $\begin{array}{l}\text { Herbe annuelle } \\
\text { à semi-pérenne } \\
\text { Longues tiges } \\
\text { semi-dressées }\end{array}$ & $\begin{array}{l}\text { de } 500 \text { à } \\
1200 \text { mm/an } \\
\text { Sols divers, } \\
\text { non salés } \\
\text { Supporte la } \\
\text { sécheresse }\end{array}$ & $\begin{array}{l}\text { Fourrage vert } \\
\text { ou foin } \\
\text { Plante de } \\
\text { couverture } \\
\text { Engrais vert } \\
\text { et graines pour } \\
\text { les porcs }\end{array}$ & $\begin{array}{l}4 \text { de feuilles } \\
\text { et tiges } \\
2 \text { de graines }\end{array}$ \\
\hline
\end{tabular}

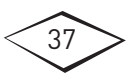


Tableau 1.2. Principales légumineuses herbacées fourragères tropicales et subtropicales herbacées cultivées. (suite)

\begin{tabular}{|c|c|c|c|c|}
\hline $\begin{array}{l}\text { Nom } \\
\text { scientifique, } \\
\text { nom commun, } \\
\text { cultivars } \\
\text { courants }\end{array}$ & Type de plante & $\begin{array}{l}\text { Pluviométrie } \\
\text { optimale } \\
\text { Adaptation } \\
\text { au milieu } \\
\text { Zones de culture }\end{array}$ & $\begin{array}{l}\text { Utilisations et } \\
\text { précautions }\end{array}$ & $\begin{array}{l}\text { Production } \\
\text { (t MS/ha/an) }\end{array}$ \\
\hline $\begin{array}{l}\text { Macroptilium } \\
\text { atropurpureum } \\
\text { Siratro }\end{array}$ & $\begin{array}{l}\text { Lianes } \\
\text { herbacées } \\
\text { pérennes } \\
\text { Résistantes à la } \\
\text { sécheresse } \\
\text { Sensibles } \\
\text { aux maladies } \\
\text { foliaires }\end{array}$ & $\begin{array}{l}\text { De } 650 \text { à } \\
1500 \mathrm{~mm} / \mathrm{an} \\
\text { Sols divers } \\
\text { drainants, plutôt } \\
\text { acides } \\
\text { Bonne fixation } \\
\text { d'azote }\end{array}$ & $\begin{array}{l}\text { Amélioration } \\
\text { pâturages sur } \\
\text { sols acides } \\
\text { Amélioration } \\
\text { pâturages à } \\
\text { graminées } \\
\text { dressées }\end{array}$ & 4 à 8 \\
\hline $\begin{array}{l}\text { Macroptilium } \\
\text { lathyroides } \\
\text { Phasey bean }\end{array}$ & $\begin{array}{l}\text { Herbacée } \\
\text { annuelle dressée } \\
\text { Se resème } \\
\text { partiellement } \\
\text { spontanément }\end{array}$ & $\begin{array}{l}\text { De } 750 \text { à } \\
2000 \text { mm/an } \\
\text { Sols divers, } \\
\text { même pauvres } \\
\text { et mal drainés }\end{array}$ & $\begin{array}{l}\text { Culture dérobée } \\
\text { Amélioration } \\
\text { de prairie en } \\
\text { première année }\end{array}$ & 4 à 8 \\
\hline $\begin{array}{l}\text { Medicago sativa } \\
\text { Luzerne } \\
\text { Nombreux } \\
\text { cultivars }\end{array}$ & $\begin{array}{l}\text { Herbacée } \\
\text { pérenne dressée } \\
\text { Sensible aux } \\
\text { champignons et } \\
\text { aux insectes } \\
\text { Rhizobium } \\
\text { spécifique } \\
\text { nécessaire }\end{array}$ & $\begin{array}{l}\text { Croissance de } \\
\text { saison froide } \\
\text { Sols fertiles } \\
\text { drainants, } \\
\text { légèrement } \\
\text { alcalins } \\
\text { Très bonne } \\
\text { valeur } \\
\text { fourragère }\end{array}$ & $\begin{array}{l}\text { Pâturée ou } \\
\text { fauchée } \\
\text { Consommée } \\
\text { vert, ensilée } \\
\text { ou fanée } \\
\text { Très souvent } \\
\text { cultivée sous } \\
\text { irrigation }\end{array}$ & $\begin{array}{l}\text { Forte capacité } \\
\text { de production } \\
8 \text { à } 15 \\
\text { jusqu'à } 25\end{array}$ \\
\hline $\begin{array}{l}\text { Mucuna pruriens } \\
\text { Pois Mascate }\end{array}$ & $\begin{array}{l}\text { Annuelle } \\
\text { grimpante ou } \\
\text { rampante } \\
\text { Vigoureuse, } \\
\text { croissance } \\
\text { rapide, jusqu'à } \\
15 \text { mètres de } \\
\text { long }\end{array}$ & $\begin{array}{l}\text { de } 1000 \text { à } \\
2500 \text { mm/an } \\
\text { Sols divers, y } \\
\text { compris sableux } \\
\text { Tolère de } \\
\text { faibles taux de } \\
\text { phosphates }\end{array}$ & $\begin{array}{l}\text { Culture } \\
\text { fourragère à } \\
\text { couper et à } \\
\text { faner } \\
\text { Engrais vert } \\
\text { et plante de } \\
\text { couverture } \\
\text { Envahissante, } \\
\text { pas facile à } \\
\text { associer }\end{array}$ & $\begin{array}{l}\text { Très productive } \\
5 \text { à } 15\end{array}$ \\
\hline $\begin{array}{l}\text { Neonotonia } \\
\text { wightii } \\
\text { Glycine javanica }\end{array}$ & $\begin{array}{l}\text { Liane pérenne } \\
\text { rampante ou } \\
\text { grimpante }\end{array}$ & $\begin{array}{l}750 \text { à } \\
1500 \text { mm/an, } \\
\text { saison sèche } \\
\text { courte } \\
\text { Sols fertiles, } \\
\text { plutôt argileux }\end{array}$ & $\begin{array}{l}\text { Prairie } \\
\text { permanente, } \\
\text { associée à une } \\
\text { graminée } \\
\text { Pâture directe } \\
\text { délicate, } \\
\text { pratiquer une } \\
\text { rotation }\end{array}$ & $\begin{array}{l}\text { Productive } \\
3 \text { à } 8, \\
\text { jusqu'à } 12\end{array}$ \\
\hline
\end{tabular}

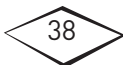




\begin{tabular}{|c|c|c|c|c|}
\hline $\begin{array}{l}\text { Nom } \\
\text { scientifique, } \\
\text { nom commun, } \\
\text { cultivars } \\
\text { courants }\end{array}$ & Type de plante & $\begin{array}{l}\text { Pluviométrie } \\
\text { optimale } \\
\text { Adaptation } \\
\text { au milieu } \\
\text { Zones de culture }\end{array}$ & $\begin{array}{l}\text { Utilisations et } \\
\text { précautions }\end{array}$ & $\begin{array}{l}\text { Production } \\
\text { (t MS/ha/an) }\end{array}$ \\
\hline $\begin{array}{l}\text { Phaseoloides } \\
\text { Pueraria } \\
\text { Kudzu tropical }\end{array}$ & $\begin{array}{l}\text { Liane pérenne } \\
\text { grimpante ou } \\
\text { rampante } \\
\text { Vigoureuse, } \\
\text { croissance lente }\end{array}$ & $\begin{array}{l}\text { Plus de } 1500 \\
\text { mm/an, saison } \\
\text { sèche courte } \\
\text { Sols divers, } \\
\text { plutôt fertiles } \\
\text { et acides }\end{array}$ & $\begin{array}{l}\text { Plante de } \\
\text { couverture } \\
\text { Pâture directe } \\
\text { ou mieux coupe } \\
\text { en vert }\end{array}$ & 5 à 10 \\
\hline $\begin{array}{l}\text { Pueraria } \\
\text { thunbergiana } \\
\text { Kudzu }\end{array}$ & $\begin{array}{l}\text { Liane pérenne } \\
\text { grimpante ou } \\
\text { rampante }\end{array}$ & $\begin{array}{l}\text { Climats } \\
\text { tempérés chauds } \\
\text { et tropicaux } \\
\text { Tolère le froid et } \\
\text { la gelée } \\
\text { Sols divers, } \\
\text { plutôt fertiles } \\
\text { et acides }\end{array}$ & $\begin{array}{l}\text { Plante de } \\
\text { couverture } \\
\text { Pâture directe } \\
\text { en rotation ou } \\
\text { coupe en vert } \\
\text { Moindre } \\
\text { appétibilité que } \\
\text { P. phaseoloides }\end{array}$ & 5 à 10 \\
\hline $\begin{array}{l}\text { Stylosanthes } \\
\text { guianensis } \\
\text { Luzerne du } \\
\text { Brésil, } \\
\text { Stylo cv. Cook } \\
\text { et cv. } 184 \text { (Ciat) }\end{array}$ & $\begin{array}{l}\text { Plante herbacée } \\
\text { ou subligneuse } \\
\text { Pérenne dressée } \\
\text { ou étalée } \\
\text { Certains } \\
\text { cultivars } \\
\text { sensibles à } \\
\text { l'anthracnose }\end{array}$ & $\begin{array}{l}\text { De } 1500 \text { à } 2500 \\
\text { mm/an } \\
\text { Sols divers, } \\
\text { même peu } \\
\text { fertiles et acides } \\
\text { Sols bien drainés }\end{array}$ & $\begin{array}{l}\text { Association } \\
\text { facile avec } \\
\text { graminées : } \\
\text { enrichissement } \\
\text { de prairies } \\
\text { permanentes, } \\
\text { amélioration } \\
\text { jachères en } \\
\text { association avec } \\
\text { céréales }\end{array}$ & $\begin{array}{l}5 \text { à } 10 \\
\text { jusqu'à } 20\end{array}$ \\
\hline $\begin{array}{l}\text { Stylosanthes } \\
\text { hamata } \\
\text { Caribbean Stylo } \\
\text { cv. Verano } \\
\text { (Australie) }\end{array}$ & $\begin{array}{l}\text { Herbacée } \\
\text { dressée annuelle } \\
\text { à bisannuelle } \\
\text { Se resème } \\
\text { spontanément } \\
\text { Tolérante à } \\
\text { l'anthracnose }\end{array}$ & $\begin{array}{l}\text { De } 500 \text { à } 1000 \\
\text { mm/an } \\
\text { Sols divers, } \\
\text { même peu } \\
\text { fertiles et acides } \\
\text { Sols bien drainés }\end{array}$ & $\begin{array}{l}\text { Pâturages } \\
\text { permanents, } \\
\text { cultures pures } \\
\text { ou associées } \\
\text { Amélioration } \\
\text { des jachères en } \\
\text { association } \\
\text { avec céréales } \\
\text { Sensible au gel }\end{array}$ & $\begin{array}{l}3 \text { à } 6 \\
\text { jusqu'à } 15\end{array}$ \\
\hline $\begin{array}{l}\text { Vigna } \\
\text { unguiculata } \\
\text { Niébé, Cowpea } \\
\text { Nombreux } \\
\text { cultivars } \\
\text { y compris } \\
\text { fourragers }\end{array}$ & $\begin{array}{l}\text { Herbacée } \\
\text { annuelle } \\
\text { semi-dressée } \\
\text { à dressée } \\
\text { Résistante } \\
\text { à la sécheresse } \\
\text { Très haute } \\
\text { valeur nutritive }\end{array}$ & $\begin{array}{l}\text { De } 450 \text { à } 1100 \\
\text { mm/an } \\
\text { Sols sableux, } \\
\text { de préférence } \\
\text { drainants } \\
\text { Sensible aux } \\
\text { parasites }\end{array}$ & $\begin{array}{l}\text { Culture pure ou } \\
\text { associée } \\
\text { aux céréales } \\
\text { à } 1 \text { ou } 2 \text { fins, } \\
\text { alimentaire } \\
\text { et/ou fourragère } \\
\text { Fanes coupées et } \\
\text { séchées pour la } \\
\text { saison sèche }\end{array}$ & $\begin{array}{l}3 \text { à } 6 \\
\text { jusqu'à } 10\end{array}$ \\
\hline
\end{tabular}

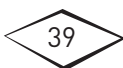




\section{Les arbres et arbustes}

De nombreuses espèces ligneuses des régions chaudes ont un intérêt fourrager. Les herbivores s'alimentent non seulement en broutant leurs feuilles mais aussi leurs fruits et parfois leurs fleurs. Cependant, seules quelques espèces d'arbres et d'arbustes montrent des qualités fourragères suffisamment intéressantes pour qu'elles soient cultivées (tableau 1.3).

Dans les zones arides ou semi-arides, les arbres se couvrent de feuilles nouvelles ou fructifient abondamment en fin de saison sèche. Les ligneux fourragers apportent alors aux herbivores un complément alimentaire important en fin de saison sèche, au moment où le fourrage herbacé se fait rare et a une faible valeur nutritive. Le fourrage ligneux, grâce aux matières azotées qu'il fournit, permet alors une meilleure digestion microbienne des matières cellulosiques des pailles dans le rumen. En outre, il est riche en éléments minéraux et en certaines vitamines, par exemple la vitamine A dont les carences rendent les animaux «aveugles» ou incapables de voir la nuit en zone sahélienne. Ce fourrage ligneux atténue ainsi les risques de carence liés aux fourrages herbacés secs qui sont pauvres en phosphore, cuivre, zinc, sodium et carotènes. Ce fourrage arboré permet donc aux animaux d'attendre, sans trop perdre de poids, l'arrivée des pluies et des herbes nouvelles. Dans les zones arides et semi-arides, même avec des reliquats de pailles sèches sur les parcours, les fourrages ligneux peuvent représenter jusqu'à $30 \%$ du régime alimentaire quotidien des bovins, $50 \%$ de celui des ovins et $80 \%$ de celui des caprins.

En régions plus humides, dans les savanes arborées à graminées pérennes qui produisent des repousses pendant une grande partie de la saison sèche, les ligneux jouent aussi un rôle fourrager important. Par exemple, d'après une étude menée dans le Nord de la Côte d'Ivoire, les ligneux et subligneux (petits arbustes de moins de 4 à $6 \mathrm{~m}$ de haut) représenteraient $10 \%$ du régime alimentaire des bovins, $20 \%$ pour les ovins et $80 \%$ pour les caprins.

En général, les ligneux servent de fourrage d'appoint aux bovins au moment où le fourrage herbacé vient à manquer, alors que les caprins les broutent toute l'année. La relation entre l'éleveur et l'arbre est donc différente selon les espèces animales qu'il élève et les modes d'élevage qu'il conduit, sur parcours naturels, en ranching ou en stabulation. Dans les pâturages, le bétail se nourrit directement, soit sur

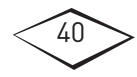


les branches à sa portée, soit sur du fourrage tombé au sol ou mis à sa disposition par l'émondage. Pour les animaux en stabulation, les feuillages sont récoltés soit en brousse, soit sur des haies fourragères ou dans des plantations et apportés au bétail - «cut and carry» des éleveurs anglo-saxons.

Pour créer des plantations fourragères, l'éleveur a le choix entre des espèces indigènes et exotiques. Les espèces indigènes présentent l'avantage d'avoir des exigences écologiques et des qualités connues et leurs semences et/ou boutures sont disponibles sur place. Lintroduction de ligneux exotiques est toujours plus risquée, dans la mesure où ces espèces peuvent ne pas supporter les conditions locales et disparaître après quelques années. En revanche, en l'absence de leurs prédateurs naturels, certaines espèces à fructification abondante peuvent devenir envahissantes; c'est le cas du Prosopis juliflora (prosopis ou mesquites) en Amérique du Nord et en Afrique (Djibouti, Kenya,...) ou du Leucaena leucocephala (figure 1.13, tableau 1.3 et photo 1.6) en Côte d'Ivoire et dans certaines îles du Pacifique.

La production de fourrage par les ligneux est extrêmement variable. Elle dépend du nombre de pieds à l'hectare (densité), de l'âge, de la taille, de la branchaison et du développement du houppier.

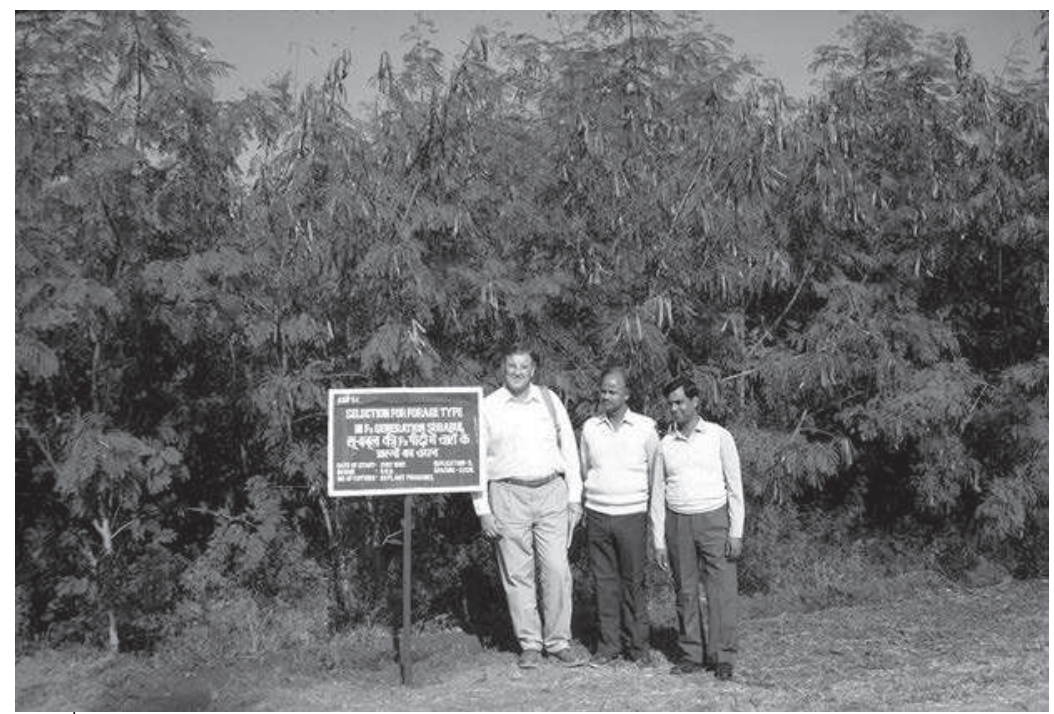

Photo 1.6.

Collection de Leucaena leucocephala, légumineuse ligneuse,

station de recherche de Jhansi, Uttar Pradesh, Inde. (৫ B. Toutain)

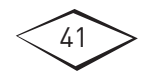




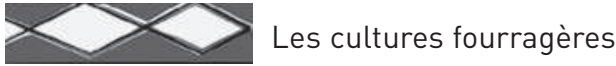

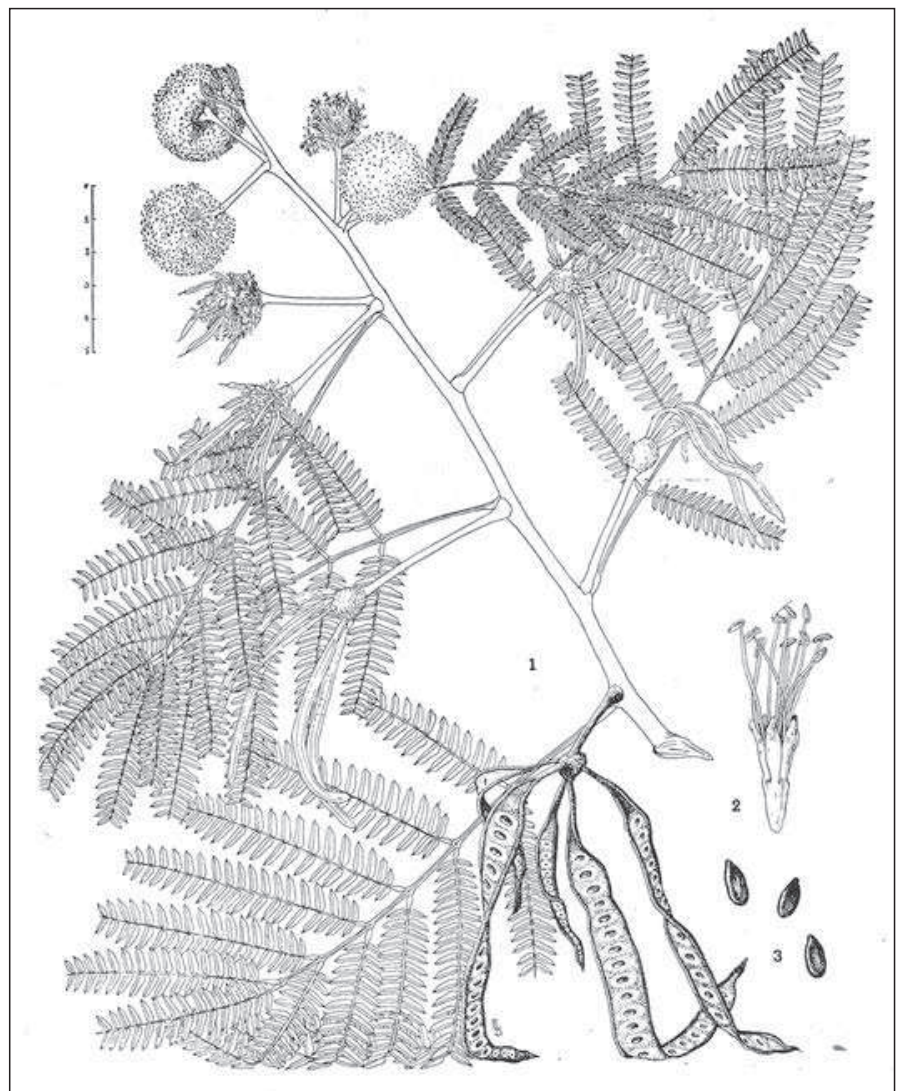

Figure 1.13.

Ligneux fourrager de la famille des légumineuses, Leucaena leucocephala.

(๔ Boudet, 1984, d'après M. A. Devillers [lcônes Plantarum Africanarum, fasc. $1 \mathrm{n}^{\circ}$ 8, IFAN, Dakar, 1983])

1 , rameau portant les inflorescences et les fruits; 2 , fleur; 3 , graine.

Les quantités de fourrage utilisables varient en fonction du mode d'exploitation (émondage ou broutage), de la saison d'utilisation, de la fertilité du sol et du climat.

Certaines espèces ont une croissance annuelle rapide, comme Samanea saman dans les régions tropicales et subtropicales bien alimentées en eau. Cette espèce plantée en fortes densités et exploitée quatre fois par an pourrait en conditions optimales produire jusqu'à 20 tonnes de matière sèche de fourrage par an. Mais, généralement, la plupart des

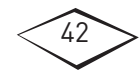


arbres ont une croissance beaucoup plus lente. Ainsi, les productions annuelles varient de moins de $100 \mathrm{~kg}$ de matière sèche par hectare au Sahel à plusieurs tonnes dans les zones humides.

La valeur nutritive des fourrages ligneux dépend en grande partie de leur teneur en lignine et en tanins. Ces constituants réduisent la digestibilité des fibres (celluloses, hémicelluloses) et des matières azotées dont les teneurs sont pourtant souvent élevées (supérieures à $10 \%$ et jusqu'à 20 ou $25 \%$ de la matière sèche). Certaines espèces contiennent des toxines et leur utilisation exige quelques précautions. Par exemple, chez Leucaena leucocephala, la mimosine du feuillage n'est neutralisée que par certaines bactéries du rumen des ruminants; ce fourrage est donc à déconseiller pour les monogastriques.

Les plantes fourragères ligneuses offrent donc des productions très diverses et ont de multiples fonctions, qui ne se limitent pas aux apports nutritifs; elles procurent également de l'ombre, servent à clôturer les parcelles et fournissent du bois dont une partie sert pour les enclos et les bâtiments d'élevage. Par la diversité des rôles qu'ils jouent et des produits qu'ils fournissent, les arbres, arbustes et buissons sont des éléments incontournables des paysages et des exploitations agricoles et d'élevage.

Les modes d'installation et de gestion des ligneux sont présentés en partie 2 .

Tableau 1.3. Exemples d'espèces ligneuses fourragères tropicales.

\begin{tabular}{|c|c|c|c|c|}
\hline $\begin{array}{l}\text { Nom scientifique, } \\
\text { nom commun, } \\
\text { cultivars courants }\end{array}$ & Type de plante & $\begin{array}{l}\text { Adaptation au } \\
\text { milieu } \\
\text { Zone de culture }\end{array}$ & $\begin{array}{l}\text { Utilisations et } \\
\text { précautions }\end{array}$ & Production \\
\hline $\begin{array}{l}\text { Acacia nilotica } \\
\text { var. indica babool }\end{array}$ & $\begin{array}{l}\text { Mimosaceae } \\
\text { Arbuste vivace } \\
\text { de } 2 \text { à } 10 \mathrm{~m} \\
\text { Facilement } \\
\text { établi par } \\
\text { graines }\end{array}$ & $\begin{array}{l}\text { Inde, régions } \\
\text { sèches } \\
\text { Large gamme } \\
\text { de sols plutôt } \\
\text { argileux } \\
\text { Tolérant à la } \\
\text { sécheresse }\end{array}$ & $\begin{array}{l}\text { Agroforesterie } \\
\text { Feuillage coupé } \\
\text { pour chèvres } \\
\text { Feuilles fanées } \\
\text { et conservées, } \\
\text { riches en tanins } \\
\text { Graines } \\
\text { alimentaires et } \\
\text { oléagineuses }\end{array}$ & $\begin{array}{l}10 \mathrm{~kg} \text { de } \\
\text { fourrage sec } \\
\text { par arbre }\end{array}$ \\
\hline $\begin{array}{l}\text { Acacia senegal } \\
\text { gommier }\end{array}$ & Mimosaceae & $\begin{array}{l}\text { Afrique } \\
\text { tropicale } \\
\text { semi-aride }\end{array}$ & $\begin{array}{l}\text { Feuillage brouté, } \\
\text { production de } \\
\text { gomme arabique }\end{array}$ & \\
\hline $\begin{array}{l}\text { Acacia tortilis } \\
\text { ssp. raddiana }\end{array}$ & Mimosaceae & $\begin{array}{l}\text { Afrique } \\
\text { tropicale semi- } \\
\text { aride et aride }\end{array}$ & $\begin{array}{l}\text { Feuillage } \\
\text { et gousses } \\
\text { fourragers }\end{array}$ & \\
\hline
\end{tabular}

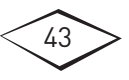


Tableau 1.3. Exemples d'espèces ligneuses fourragères tropicales. (suite)

\begin{tabular}{|c|c|c|c|c|}
\hline $\begin{array}{l}\text { Nom scientifique, } \\
\text { nom commun, } \\
\text { cultivars courants }\end{array}$ & Type de plante & $\begin{array}{l}\text { Adaptation au } \\
\text { milieu } \\
\text { Zone de culture }\end{array}$ & $\begin{array}{l}\text { Utilisations et } \\
\text { précautions }\end{array}$ & Production \\
\hline $\begin{array}{l}\text { Adansonia digitata } \\
\text { Baobab }\end{array}$ & Bombacaceae & $\begin{array}{l}\text { Afrique } \\
\text { tropicale, } \\
\text { Australie }\end{array}$ & $\begin{array}{l}\text { Feuillage coupé } \\
\text { pour les hommes } \\
\text { et le bétail } \\
\text { ombrage, etc. }\end{array}$ & \\
\hline $\begin{array}{l}\text { Cajanus cajan } \\
\text { Pois d'angole } \\
\text { Ambrevade }\end{array}$ & $\begin{array}{l}\text { Fabaceae } \\
\text { Arbustes de } 2 \\
\text { à } 4 \text { m } \\
\text { Annuelles ou } \\
\text { bisannuelles }\end{array}$ & $\begin{array}{l}\text { De } 600 \text { à } \\
1000 \mathrm{~mm} / \mathrm{an} \\
\text { Haies dans } \\
\text { champs et } \\
\text { jardins } \\
\text { Sols divers, } \\
\text { même peu } \\
\text { fertiles }\end{array}$ & $\begin{array}{l}\text { Graines } \\
\text { alimentaires } \\
\text { pour l'homme } \\
\text { Feuillage } \\
\text { coupé pour les } \\
\text { animaux } \\
\text { Engrais vert } \\
\text { riche en azote }\end{array}$ & $\begin{array}{l}2 \mathrm{t} \text { MS/ha/an } \\
\text { de fourrage } \\
\text { sec } \\
\text { jusqu'à } 15 \mathrm{t}\end{array}$ \\
\hline $\begin{array}{l}\text { Calliandra } \\
\text { calothyrsus } \\
\text { Pelo de Angel }\end{array}$ & $\begin{array}{l}\text { Mimosaceae } \\
\text { Arbuste de } 2 \\
\text { à } 6 \mathrm{~m}\end{array}$ & $\begin{array}{l}\text { De } 2000 \text { à } \\
4000 \mathrm{~mm} / \mathrm{an} \\
\text { Sols divers mais } \\
\text { drainants } \\
\text { En altitude de } \\
250 \text { à } 1300 \mathrm{~m}\end{array}$ & $\begin{array}{l}\text { Banque } \\
\text { fourragère } \\
\text { Feuillage } \\
\text { coupé pour les } \\
\text { animaux } \\
\text { Engrais vert, } \\
\text { ombre }\end{array}$ & $\begin{array}{l}\text { Très productif } \\
3 \text { à } \\
14 \mathrm{t} \mathrm{MS} / \mathrm{ha} / \mathrm{an}\end{array}$ \\
\hline $\begin{array}{l}\text { Faidherbia albida } \\
\text { Acacia albida }\end{array}$ & $\begin{array}{l}\text { Mimosaceae } \\
\text { Arbres de } \\
\text { grandes tailles } \\
\text { Protégées dans } \\
\text { les savanes } \\
\text { et les parcs }\end{array}$ & $\begin{array}{l}\text { Afrique } \\
\text { semi-aride et } \\
\text { subhumide } \\
\text { Sols plutôt } \\
\text { fertiles } \\
\text { Effet fertilisant } \\
\text { sur sols de } \\
\text { culture }\end{array}$ & $\begin{array}{l}\text { Gousses } \\
\text { collectées pour } \\
\text { le bétail } \\
\text { Feuilles à terre } \\
\text { broutées } \\
\text { Ombrage, bois } \\
\text { d'œuvre }\end{array}$ & \\
\hline $\begin{array}{l}\text { Gliricidia sepium } \\
\text { Madre de cacao }\end{array}$ & $\begin{array}{l}\text { Fabaceae } \\
\text { Arbuste vivace } \\
\text { de } 2 \text { à } 10 \mathrm{~m} \\
\text { Bonnes valeurs } \\
\text { nutritives }\end{array}$ & $\begin{array}{l}\text { De } 650 \text { à } \\
3500 \mathrm{~mm} / \mathrm{an} \\
\text { Large gamme de } \\
\text { sols bien drainés } \\
\text { Peu adapté } \\
\text { à la sécheresse } \\
\text { et au gel }\end{array}$ & $\begin{array}{l}\text { Haies } \\
\text { fourragères } \\
\text { Feuillage coupé } \\
\text { et transporté } \\
\text { Engrais vert, } \\
\text { ombre }\end{array}$ & $\begin{array}{l}2 \text { à } \\
20 \text { t MS/ha/an }\end{array}$ \\
\hline $\begin{array}{l}\text { Hibiscus tiliaceus, } \\
\text { Bourao }\end{array}$ & Malvaceae & $\begin{array}{l}\text { Tropiques } \\
\text { humides, îles du } \\
\text { Pacifique }\end{array}$ & $\begin{array}{l}\text { Haies, haies } \\
\text { fourragères } \\
\text { Feuillage coupé } \\
\text { Bois d'œuvre }\end{array}$ & \\
\hline $\begin{array}{l}\text { Khaya } \\
\text { senegalensis, } \\
\text { Caïlcédrat }\end{array}$ & $\begin{array}{l}\text { Meliaceae } \\
\text { Arbres de } \\
\text { grandes tailles }\end{array}$ & $\begin{array}{l}\text { Afrique } \\
\text { tropicale sèche }\end{array}$ & $\begin{array}{l}\text { Feuillage } \\
\text { émondé } \\
\text { Ombrage }\end{array}$ & \\
\hline
\end{tabular}

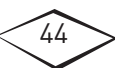




\begin{tabular}{|c|c|c|c|c|}
\hline $\begin{array}{l}\text { Nom scientifique, } \\
\text { nom commun, } \\
\text { cultivars courants }\end{array}$ & Type de plante & $\begin{array}{l}\text { Adaptation au } \\
\text { milieu } \\
\text { Zone de culture }\end{array}$ & $\begin{array}{l}\text { Utilisations et } \\
\text { précautions }\end{array}$ & Production \\
\hline $\begin{array}{l}\text { Leucaena } \\
\text { leucocephala } \\
\text { Leucène } \\
\text { Très nombreux } \\
\text { cultivars }\end{array}$ & $\begin{array}{l}\text { Mimosaceae } \\
\text { Arbustes à } \\
\text { arbres de } 2 \text { à } \\
20 \mathrm{~m}\end{array}$ & $\begin{array}{l}\text { De } 650 \text { à } 3000 \\
\text { mm/an } \\
\text { Sols divers } \\
\text { drainants et non } \\
\text { acides, proches } \\
\text { de la neutralité } \\
\text { Tolérant à } \\
\text { la sécheresse } \\
\text { et à la salinité }\end{array}$ & $\begin{array}{l}\text { Haies vives : } \\
\text { feuillages coupés } \\
\text { Amélioration } \\
\text { de pâturages } \\
\text { à graminées : } \\
\text { feuillages } \\
\text { pâturés } \\
\text { Très haute } \\
\text { valeur nutritive } \\
\text { Toxique pour } \\
\text { monogastriques }\end{array}$ & \\
\hline Moringa oleifera & Moringaceae & $\begin{array}{l}\text { Tropiques } \\
\text { subhumides }\end{array}$ & $\begin{array}{l}\text { Bords de jardins, } \\
\text { multi-usages } \\
\text { Feuillage } \\
\text { coupé pour les } \\
\text { animaux } \\
\text { Graines } \\
\text { pour floculer } \\
\text { les impuretés } \\
\text { de l'eau }\end{array}$ & \\
\hline $\begin{array}{l}\text { Pithecellobium } \\
\text { dulce }\end{array}$ & Mimosaceae & $\begin{array}{l}\text { Tropiques } \\
\text { humides et } \\
\text { subhumides }\end{array}$ & $\begin{array}{l}\text { Gousses } \\
\text { tombées } \\
\text { mangées (pulpe) } \\
\text { Ombrage }\end{array}$ & \\
\hline Prosopis juliflora & Mimosaceae & $\begin{array}{l}\text { Régions chaudes } \\
\text { semi-arides } \\
\text { Tend à être très } \\
\text { envahissant }\end{array}$ & $\begin{array}{l}\text { Reboisements } \\
\text { pour bois et } \\
\text { environnement } \\
\text { Haies } \\
\text { Feuillage } \\
\text { un peu brouté }\end{array}$ & \\
\hline $\begin{array}{l}\text { Pterocarpus } \\
\text { erinaceus }\end{array}$ & Fabaceae & $\begin{array}{l}\text { Afrique } \\
\text { de l'Ouest } \\
\text { subhumide }\end{array}$ & $\begin{array}{l}\text { Feuillage coupé } \\
\text { et transporté }\end{array}$ & \\
\hline Samanea saman & Mimosaceae & $\begin{array}{l}\text { Tropiques } \\
\text { humides }\end{array}$ & $\begin{array}{l}\text { Pulpe des } \\
\text { gousses tombées } \\
\text { mangées } \\
\text { Ombrage }\end{array}$ & \\
\hline $\begin{array}{l}\text { Ziziphus } \\
\text { mauritiana }\end{array}$ & Rhamnaceae & $\begin{array}{l}\text { Afrique } \\
\text { tropicale sèche } \\
\text { Le bois est un } \\
\text { bon combustible } \\
\text { Fruits } \\
\text { consommés par } \\
\text { les hommes }\end{array}$ & $\begin{array}{l}\text { Haies épineuses } \\
\text { servant de } \\
\text { clôtures } \\
\text { Feuillage } \\
\text { brouté par } \\
\text { les chèvres } \\
\text { Feuilles sèches } \\
\text { ramassées et } \\
\text { conservées }\end{array}$ & \\
\hline
\end{tabular}





\section{La diversité}

\section{des milieux tropicaux}

La ceinture tropicale recouvre une très grande variété de situations climatiques et édaphiques. Certaines conviennent bien à l'élevage pour des raisons sanitaires, comme les régions arides et subhumides, et d'autres aux cultures fourragères pour des raisons agronomiques, comme les régions humides 71 et subhumides. Les zones tropicales où les conditions sont très favorables à la fois aux animaux et aux végétaux sont situées essentiellement en zones d'altitude et dans le bassin amazonien.

Ce chapitre a pour objectif de fournir des éléments pour raisonner le choix des espèces fourragères en fonction des caractéristiques du milieu et d'indiquer les limites à la réussite de ces cultures. On envisagera essentiellement les facteurs climatiques et les sols. L'eau, élément indispensable aux plantes est un facteur commun de caractérisation tant du climat par les précipitations que du sol par la réserve hydrique.

Tous les facteurs environnementaux qui sont à l'origine de la diversité de milieux tropicaux sont intégrés dans deux domaines, le climat et le sol : le lieu géographique exprimé en latitude et longitude, avec les conséquences sur la durée du jour et la saison, l'altitude avec ses conséquences sur la température, la géologie avec ce qu'elle implique pour la nature et la composition des sols, la géomorphologie avec les notions de pente et de séquence de paysages. Lensemble de ces caractéristiques se traduisent par des variantes dans la nature des sols et les disponibilités en eau et déterminent la fertilité d'un sol.

\section{Les grands types de climats}

Lexpression «climat tropical» désigne un ensemble de climats très différents selon les régions, mais qui recouvrent quelques caractères communs : ils existent essentiellement entre les tropiques du Cancer et du Capricorne et l'on y inclut souvent les climats équatoriaux. Les points communs sont les températures moyennes élevées, l'absence de gelées sauf en altitude, des précipitations saisonnières avec un maximum presque toujours pendant les mois de jours longs (période estivale). 
Les différences entre les climats tropicaux et les climats tempérés chauds et méditerranéens sont telles que la plupart des plantes adaptées à l'une des zones climatiques ne peut s'acclimater durablement dans les autres zones; seules certaines plantes cultivées annuelles sont cultivables sous certaines conditions dans les différents climats car leur cycle est court.

Les principaux facteurs du climat en jeu pour la végétation des plantes fourragères sont communs à toute production végétale :

- la température moyenne, qui dépend de la latitude, du degré de continentalité (ou au contraire des influences océaniques), de l'altitude et bien sûr de la saison. Beaucoup de plantes tropicales ne résistent pas aux gelées;

- les précipitations, très variables selon les régions, tant en quantités qu'en répartitions au cours de l'année, qui servent de base aux classifications des climats tropicaux;

- l'évaporation, ou plus précisément l'évapotranspiration potentielle (ETP), indice qui traduit la quantité d'eau que des plantes pourraient transpirer si leur alimentation hydrique était non limitée. Lécart entre l'évapotranspiration et les précipitations est un indicateur de l'aridité. Des données comme le vent, l'évaporation de l'eau libre, l'ensoleillement, sont mesurées pour calculer l'évapotranspiration potentielle;

- la durée de la saison des pluies, la durée et la rigueur de la saison sèche sont des éléments très influents sur la croissance, le développement, la pérennité des plantes;

- la longueur du jour. Cette valeur n'est pas prise en considération car elle est relativement peu variable en zone intertropicale, sauf pour les plantes photopériodiques, ce qui conditionne l'apparition des fleurs; - l'ensoleillement, car la nébulosité peut varier suivant les saisons. Ainsi en période humide, lorsque la nébulosité est forte, la croissance des plantes est moindre qu'en saison humide ensoleillée, par exemple en Amazonie.

Sous climat tropical, la période avec les jours les plus longs correspond à la saison des pluies, appelée «hivernage» en zone soudanienne, qui coïncide avec l'activité végétative la plus forte. La période avec les jours les plus courts correspond à la saison sèche et froide. La période d'augmentation des températures, très chaude et très sèche dans les régions subhumides sèches est la «saison sèche chaude» ou «saison chaude». En Afrique de l'Ouest, sous climat tropical humide (baouléen) et en Afrique de l'Est, la saison sèche est interrompue par une «petite saison des pluies». 
Le caractère strict (pas de pluies) ou partiel (moins de $30 \mathrm{~mm}$ dans le mois) de la saison sèche contribue à la perception de la rigueur du climat et intervient dans l'adaptation des plantes non autochtones. Par exemple dans les régions sahéliennes, la saison des pluies dure de trois à quatre mois, le reste de l'année étant pratiquement sans précipitations, et dans les régions soudaniennes, la saison pluvieuse dure de quatre à sept mois. En région équatoriale humide, la période la moins humide (avec moins de $50 \mathrm{~mm}$ par mois) dure de trois à quatre mois.

La période de végétation active peut être déterminée à partir des données météorologiques moyennes (figure 2.1). Cette information est surtout utile dans les régions subhumides et les zones d'altitude comprenant une saison sèche nette pour décider des meilleures périodes de travaux culturaux et pour comparer avec les besoins climatiques des espèces utilisées. Pour cela, on doit disposer des moyennes mensuelles des précipitations et de l'évapotranspiration potentielle (ETP). On calcule alors la valeur «ETP/2». On estime que la période de végétation active commence lorsque la pluviométrie dépasse la valeur «ETP/2» et s'achève lorsque la pluviométrie devient inférieure à l'ETP. Il faut disposer d'un premier cumul de pluies de $50 \mathrm{~mm}$ pour pouvoir semer, et de 500 litres d'eau pour produire un kilo de matière sèche de fourrage.

Les plantes ont développé des caractères d'adaptation aux conditions climatiques tropicales. Les cuticules sont épaisses pour protéger les organes de l'évaporation, la pilosité des feuilles permet de lutter contre l'aridité, la longueur du cycle de végétation est en phase avec les variations climatiques saisonnières, les semences sont protégées par des enveloppes épaisses ou des mécanismes biochimiques de dormance pour pallier les départs incertains et irréguliers des précipitations en début de la saison des pluies.

Les températures optimales de végétation pour les plantes tropicales se situent souvent entre 25 et $35^{\circ} \mathrm{C}$. Des températures trop élevées peuvent provoquer le phénomène d'échaudage (accident physiologique provoquant une malformation des grains, qui restent de petite taille), suivi de la mortalité partielle ou totale de la plante. Le zéro de végétation au-dessous duquel la plante cesse de pousser apparaît souvent autour de $15^{\circ} \mathrm{C}\left(\right.$ de 0 à $5^{\circ} \mathrm{C}$ pour les plantes de climat tempéré). Le gel est souvent mortel pour ces plantes. Quand la température est modérée par l'altitude, la saison ou une influence océanique, certaines plantes de climat tempéré peuvent avoir des productions intéressantes aussi longtemps que la température reste modérée.

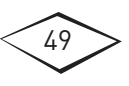




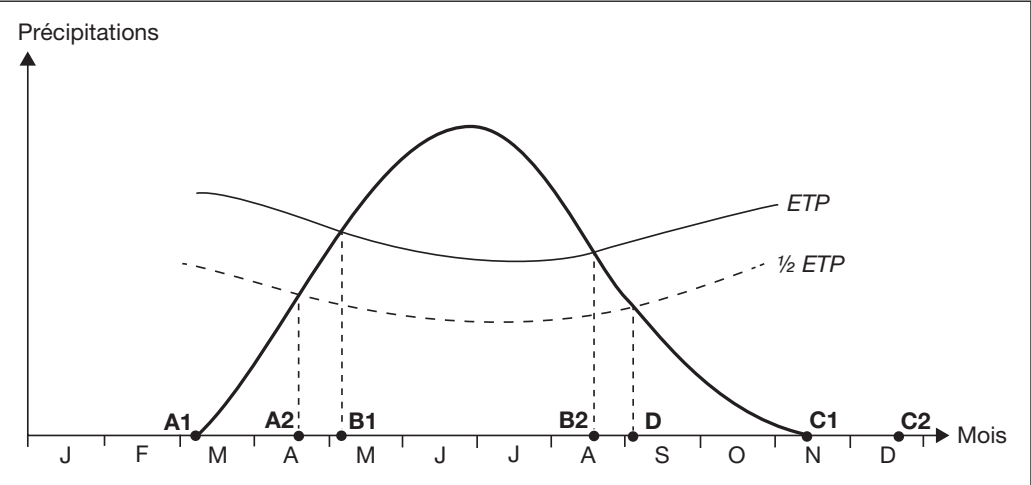

Figure 2.1. Diagrammes des pluies mensuelles et de l'évapotranspiration potentielle permettant de déterminer la période de végétation active. (๔ Mémento de l'agronome, 2002)

La projection sur l'axe des points d'intersection détermine des intervalles :

A1 C1 = saison pluvieuse. Elle ne rend compte que des apports, c'est-à-dire des précipitations de la première à la dernière pluie.

A2 C2 = saison humide. C'est la période qui va de l'instant où le déficit maximal du sol va en diminuant jusqu'au moment où ce déficit est de nouveau atteint dans la tranche d'exploitation racinaire

A2 B1 = période pré-humide, favorable aux semis

$\mathrm{B} 1 \mathrm{~B} 2$ = période humide, végétation active

B2 C2 = période post-humide, fructification et maturation, puis desséchement

On convient que la longueur de végétation active correspond à la période A2 D

Pour lutter contre l'effet desséchant des fortes températures, il est utile de réduire l'effet des vents et du soleil par des haies et des ombrages, aussi bien pour les végétaux que pour les animaux. Lombrage offre pour les plantes l'avantage de protéger les processus de mise en disponibilité de l'azote dans les premiers centimètres du sol. En revanche, la réduction de la lumière peut diminuer l'activité chlorophyllienne et donc la production végétative, florale et même semencière. La compétition pour l'eau entre les ligneux et les herbacées peut aussi réduire la production.

Ces caractéristiques du climat vont déterminer le choix des espèces fourragères qui seront adaptées à une zone donnée dans laquelle s'inscrit le projet de production.

\section{ID Principaux climats des régions chaudes}

Les principaux climats des régions chaudes du globe ont des répartitions très inégales selon les continents (figure 2.2). Pour chaque climat nous donnons succinctement les caractéristiques climatiques,

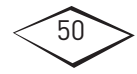


les zones concernées, la place de l'élevage et les principales espèces fourragères cultivées.

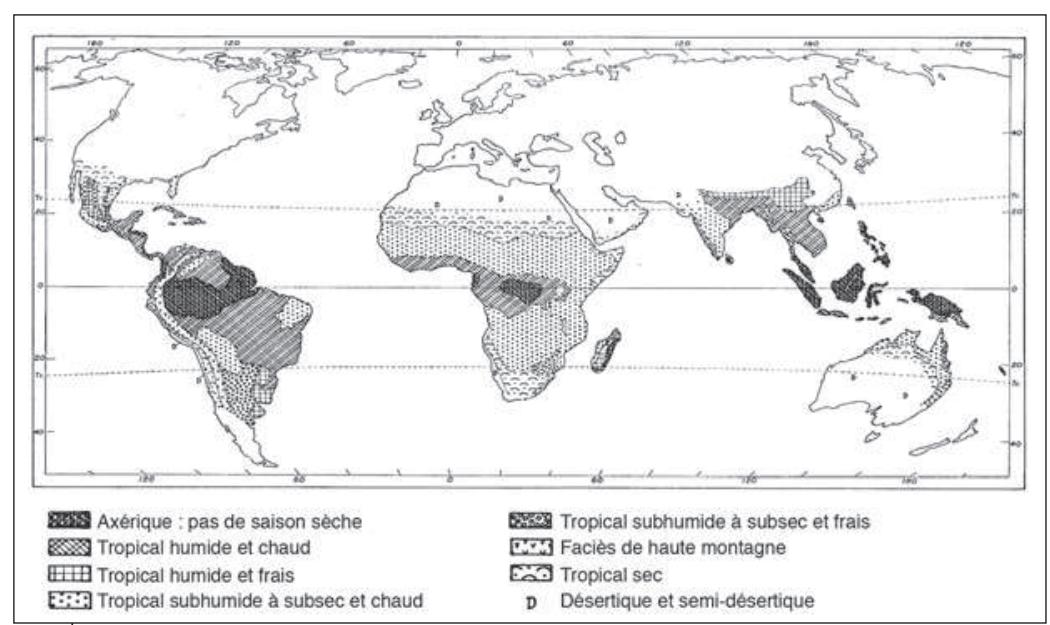

Figure 2.2. Principaux types climatiques en zones tropicales. (d'après Koechlin et al., 1981. Écosystèmes pâturés tropicaux. Recherches sur les ressources naturelles. XVI-Unesco, Pnud, FAO)

\section{ID Climat équatorial ou axérique (pas de saison sèche) et tropical humide}

Sur la figure 2.2, cela correspond aux zones «axérique», «tropical humide chaud» et «tropical humide frais».

Les températures moyennes sont constantes et assez élevées toute l'année $\left(24\right.$ à $\left.26^{\circ} \mathrm{C}\right)$ et l'amplitude thermique est faible (autour de $5^{\circ} \mathrm{C}$ ), ce qui permet des productions élevées. En climat équatorial, les précipitations sont abondantes (supérieures à $1500 \mathrm{~mm} / \mathrm{an}$ ) et la saison sèche est quasi inexistante, l'humidité relative de l'air est toujours très élevée. En climat tropical humide, la saison sèche est courte, moins de quatre mois à moins de $30 \mathrm{~mm}$. C'est le domaine de la forêt tropicale humide, la végétation y est dense.

Il concerne l'Afrique forestière, une grande partie de l'Amazonie (photo 2.1), la côte est de Madagascar, les archipels de l'Asie du Sud-Est, la Papouasie-Nouvelle-Guinée, l'Est du Queensland (Australie) et une partie des archipels du Pacifique Sud, dont la Polynésie française et le Vanuatu (photo 2.2).

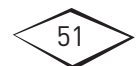




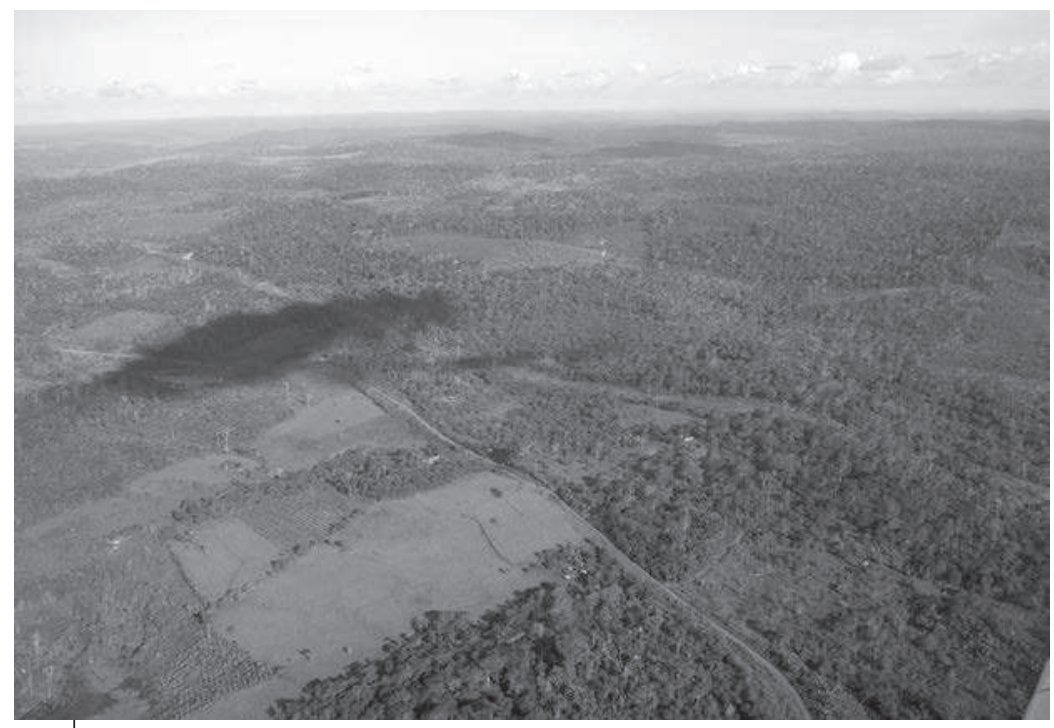

\section{Photo 2.1}

Pâturages permanents mis en place après déforestation de la forêt tropicale le long de la transamazonienne au Brésil. (@ J. Huguenin)

Les fourrages sont introduits le plus souvent dans des systèmes herbagers, notamment en ranching, mais ils peuvent être distribués en vert à l'auge dans de petites exploitations familiales. Les éleveurs utilisent des espèces à port dressé, à croissance rapide et donc plus productives.

Les cultures fourragères sont installées après déforestation, sur des prairies permanentes semées ou plantées, le fourrage est également coupé et distribué aux animaux. Aujourd'hui cette pratique est mise en cause, mais les anciens pâturages implantés sur défriche doivent être restaurés ou améliorés pour éviter de nouveaux déboisements pour l'élevage industriel.

Certaines plantes fourragères sont implantées en couvre-sol dans des plantations pérennes telles que des palmiers à huile, cocotiers (photo 2.2), hévéas, arbres pour bois d'œuvre, etc.

Les principales espèces cultivées sous ce climat sont :

- les graminées, Panicum maximum, Brachiaria brizantha, Brachiaria decumbens, Brachiaria humidicola, Brachiaria ruziziensis, Hyparrhenia rufa, Setaria anceps ou Digitaria swazilandensis pour les prairies permanentes, Tripsacum laxum et Pennisetum purpureum comme fourrages à couper;

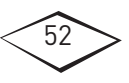


- les légumineuses herbacées, Arachis pintoi, Desmodium intortum, Desmodium heterocarpon, Desmodium uncinatum, Calopogonium mucunoides, Centrosema pubescens et Pueraria phaseoloïdes;

- les légumineuses ligneuses, Leucaena leucocephala, Gliricidia sepium et Flemingia macrophylla.

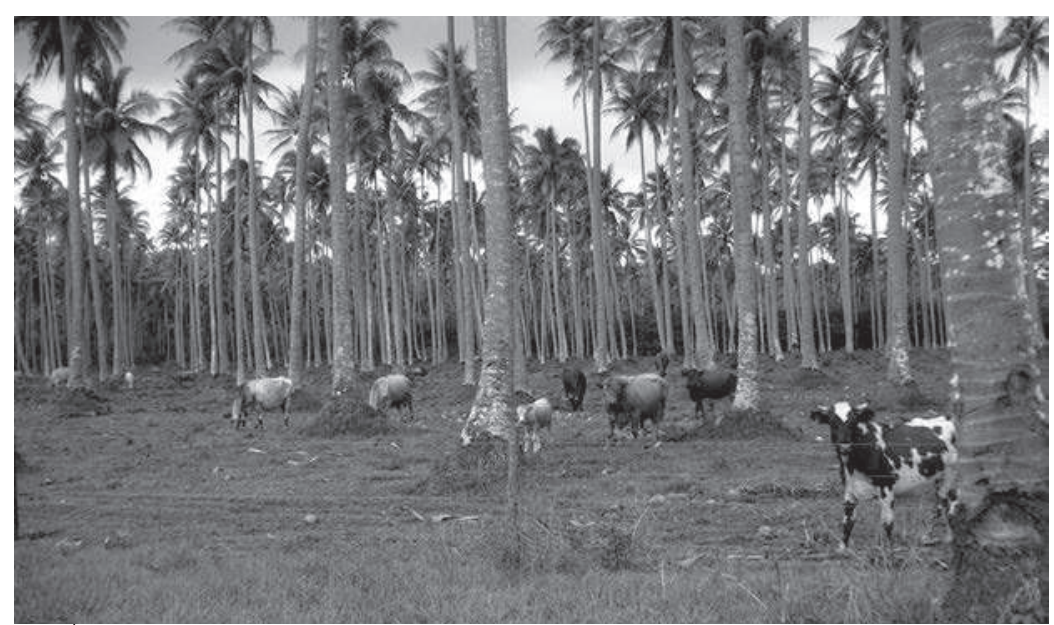

Photo 2.2.

Pâturage à Axonopus compressus et Paspalum conjugatum dans une plantation de cocotiers au Vanuatu. (๑ B. Toutain)

\section{ID Climat tropical subhumide}

Sur la figure 2.2, cela correspond aux zones de climat «tropical subhumide à subsec et chaud» et «tropical subhumide à subsec et frais».

Sous climat tropical subhumide, la saison sèche dure près de quatre à six mois; elle alterne avec la saison des pluies (mousson) et les précipitations peuvent aller de 900 à $1500 \mathrm{~mm}$ par an, parfois davantage. Les températures moyennes mensuelles varient entre 25 et $30^{\circ} \mathrm{C}$ pour le climat soudanien.

Les types de végétation sont la savane, riche en arbres, et les prairies humides.

Les principales espèces cultivées sous ce climat sont :

- les graminées. Panicum maximum, Brachiaria ruziziensis (photo 2.3), Brachiaria decumbens, Brachiaria humidicola, Andropogon gayanus, Digitaria decumbens pour les prairies permanentes;

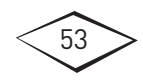


- les légumineuses herbacées. Centrosema pubescens, Pueraria phaseoloides, Stylosanthes guianensis et Stylosanthes hamata, ces deux dernières étant très souvent associées à Panicum maximum;

- l'arbuste Leucaena leucocephala et l'arbre Pithecellobium dulce.

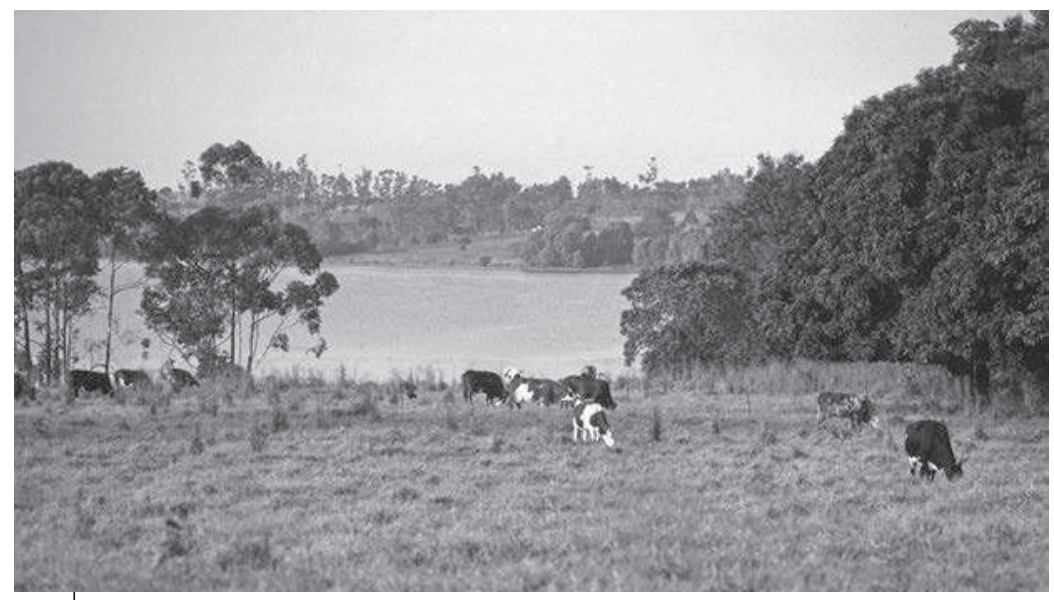

Photo 2.3.

Prairies défrichées implantées en Brachiaria ruziziensis et gérées en rotation pour les vaches laitières à la station fourragère de Wakwa, N'Gaoundéré, Adamaoua, Cameroun. (৫ H. Guérin)

\section{II) Climat tropical sec}

La saison sèche dure de six à huit mois et les précipitations annuelles sont comprises entre 400 et $900 \mathrm{~mm}$ par an. Les moyennes de température et d'humidité sont très variables au cours de ces saisons, avec des variations de température sensibles entre le jour et la nuit et au cours de la saison sèche, par exemple de 24 à $36^{\circ} \mathrm{C}$ pour le climat sahélo-soudanien.

Les régions concernées sont l'Afrique occidentale, centrale, orientale et septentrionale, l'Amérique du Sud (Campos, Cerrados et Llanos), l'Asie du Sud-Est continentale, les Antilles, une grande partie de l'Inde et du Nord de l'Australie, la côte ouest de Nouvelle-Calédonie (photo 2.4) et les îles Fidji.

La végétation appartient aux types steppe (herbage de moins de $80 \mathrm{~cm}$ de hauteur) et savane (herbage de plus de $80 \mathrm{~cm}$ de hauteur) avec de nombreuses graminées fourragères qui sont adaptées à ces climats

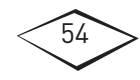


chauds, alternativement secs et humides. C'est le cas d'Andropogon gayanus, Brachiaria ruziziensis, Brachiaria decumbens, Chloris gayana, Cenchrus ciliaris, Bothriochloa pertusa, Urochloa mosambicensis, et dans les terrains bien alimentés en eau Sorghum almum. On trouve aussi des céréales telles que le sorgho (Sorghum bicolor) et le maïs (Zea mays). Parmi les légumineuses sont présentes Macroptilium atropurpureum, Stylosanthes hamata, et l'arbuste Leucaena leucocephala.

Sous climats secs, voire subhumides, où la saison sèche dure plus de la moitié de l'année, les fourrages sont généralement cultivés en saison des pluies pour améliorer l'alimentation en saison sèche, sous forme de foin ou en utilisant des légumineuses qui se dégradent moins vite que les graminées naturelles au cours de la saison sèche.

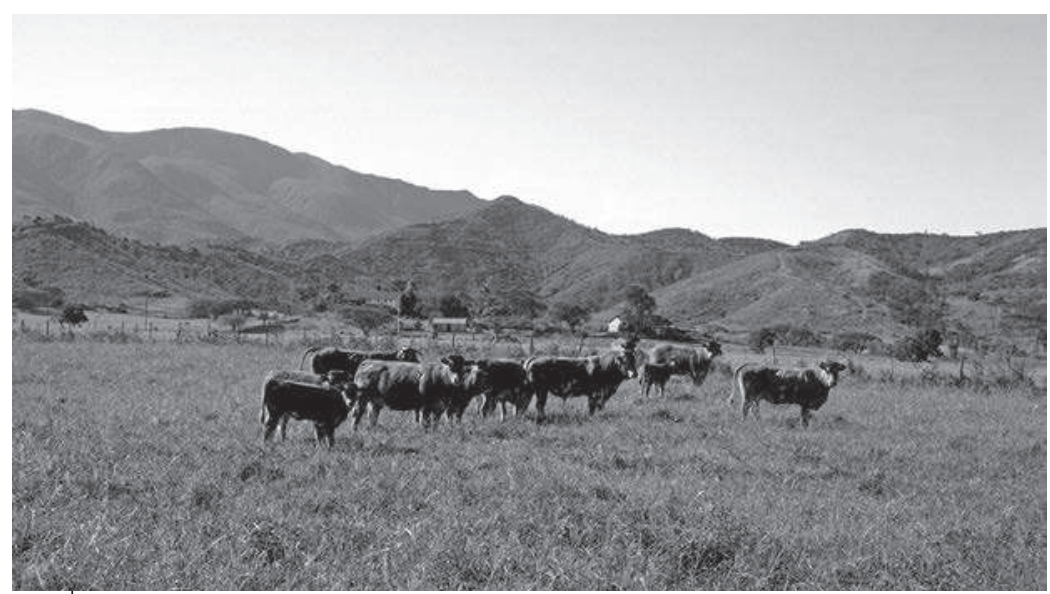

Photo 2.4.

Prairie à Chloris gayana et à Brachiaria decumbens pâturée par des bovins de race limousine, côte ouest sèche, Nouvelle-Calédonie. (๑ B. Toutain)

\section{IID Climat tropical subdésertique}

Sur la figure 2.2, cela correspond à la partie la plus humide de la zone «désertique et semi-désertique».

Les précipitations sont groupées sur une courte saison des pluies et représentent entre 100 et $400 \mathrm{~mm}$ par an. La variabilité interannuelle est forte. Les écarts de température entre le jour et la nuit sont importants. Les températures moyennes mensuelles sont souvent très chaudes, entre 18 et $33^{\circ} \mathrm{C}$ au Sahel, mais plus fraîches en Asie.

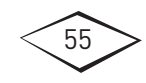




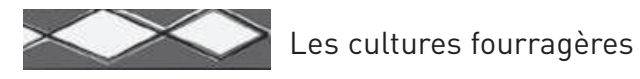

Ce sont des régions de steppes herbeuses et arbustives. Elles concernent de vastes étendues en Afrique (le Sahel de Dakar à la Somalie), au Moyen-Orient, au nord de l'Inde, en Asie centrale, en Australie, en Amérique du Nord, au Nordeste du Brésil et le long de la côte pacifique de l'Amérique du Sud.

On pratique encore peu la culture fourragère pluviale sous ce climat, en se contentant d'exploiter la végétation naturelle, les résidus de culture, l'association avec des cultures vivrières et la plantation d'arbres par endroits :

- les graminées Cenchrus ciliaris et Eragrostis curvula dans les sols profonds et bien alimentés en eau;

- les cultures vivrières de graminées telles que le mil (Pennisetum coloratum), le tef (Eragrostis tef) et le fonio (Digitaria exilis) et de légumineuses telles que l'arachide, le niébé (Vigna sinensis), le pois d'Angole (Cajanus cajan), qui peuvent être cultivées pures ou associées. Les cannes de graminées et les fanes de légumineuses sont conservées pour l'alimentation du bétail;

- les arbustes (Atriplex spp.);

- les arbres pour apporter de l'ombre et très souvent du fourrage. À titre d'exemple en Afrique de l'Ouest, Faidherbia albida (s'il trouve de l'eau en profondeur), Acacia raddiana, Prosopis juliflora, Moringa oleifera, et en Inde Acacia indica;

- les cultures fourragères irriguées sont rares et destinées presque exclusivement aux animaux en production laitière (photo 2.5).

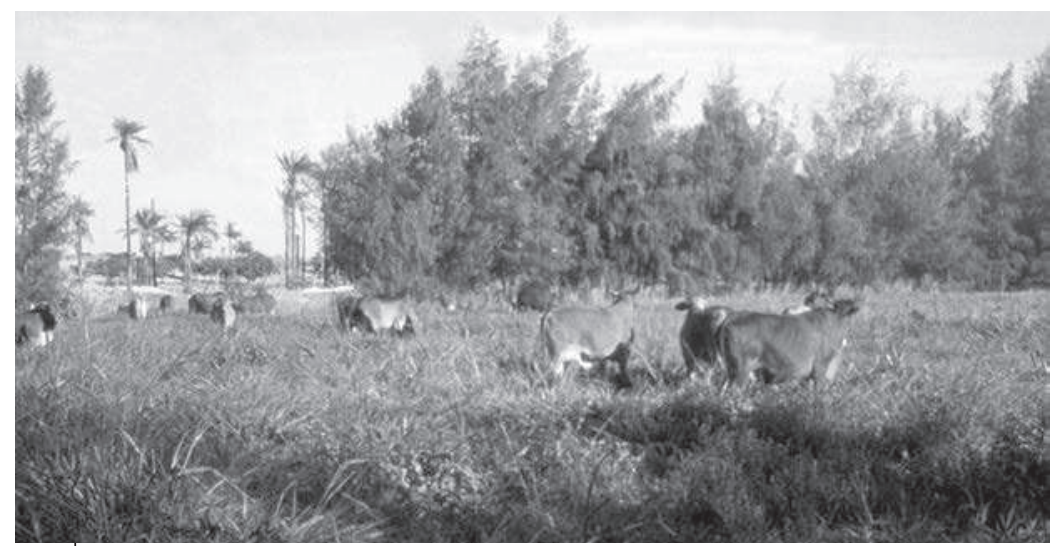

Photo 2.5.

Prairie de Panicum maximum irriguée et pâturée par des bovins à Sangalkam, région de Dakar, Sénégal. ( $\odot$ G. Roberge)

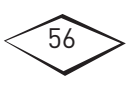




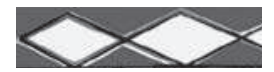

\section{ID Climat désertique}

Sur la figure 2.2 cela correspond à la partie la plus sèche de la zone «désertique et semi-désertique».

Les précipitations sont erratiques et rares, inférieures à $100 \mathrm{~mm}$. Les moyennes mensuelles de température sont plutôt élevées, entre 16 et $37^{\circ} \mathrm{C}$ au Sahara, et les écarts de température entre le jour et la nuit sont importants (parfois jusqu'à $50^{\circ} \mathrm{C}$ ). La vie rurale se concentre dans les oasis et les zones irrigables, où la luzerne (Medicago sativa) est cultivée depuis longtemps en irrigué pour l'alimentation des animaux. Parmi les arbres ayant un intérêt fourrager, on plante à Djibouti Acacia nilotica et Conocarpus erectus, ainsi que les arbustes (Atriplex spp., Suaeda fruticosa) et des palmiers (Hyphaene thebaica, Phoenix dactylifera).

\section{II) Climat tropical d'altitude}

Sur la figure 2.2, cette zone correspond au «faciès de haute montagne».

Du fait de l'altitude (au-dessus de 1000 mètres), les températures et l'évapotranspiration sont plus faibles qu'au niveau de la mer, avec des minima atteignant $5^{\circ} \mathrm{C}$ ou moins. Les précipitations sont plus élevées qu'en zones limitrophes plus basses. Ce climat concerne une partie de la région des Grands Lacs en Afrique de l'Est et du Sud (de l'Éthiopie à l'Afrique du Sud), le Fouta-Djalon en Guinée, l'Adamaoua au Cameroun, les hauts-plateaux malgaches, l'île de la Réunion (photo 2.6), le Yémen, l'Amérique andine, le Laos et le nord du Vietnam, etc.

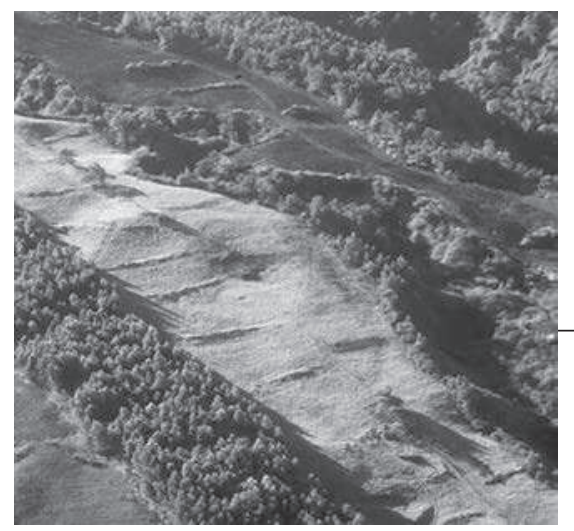

\section{Photo 2.6.}

Prairie d'altitude en lanières des Hauts de l'Ouest, appartenant à une exploitation d'élevage allaitant, la Réunion. (๑ V. Blanfort) 
À la Réunion, le choix des espèces fourragères prend en compte l'objectif de la culture (pâturage, fauche), les caractéristiques physiques du foncier, et le climat qui dépend beaucoup de l'altitude et de l'orientation des versants.

Le schéma général réunionnais de répartition des principales graminées fourragères est décrit à la figure 2.3 .

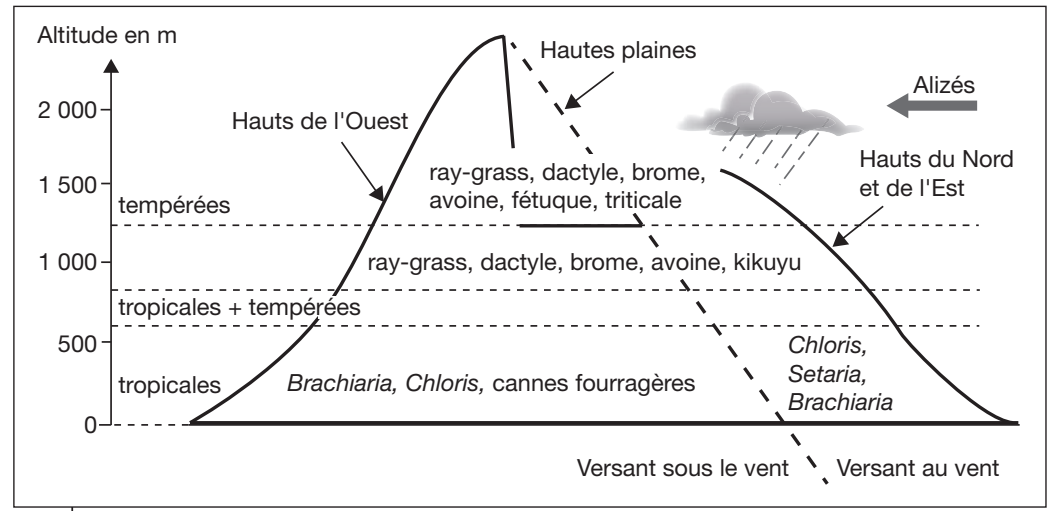

Figure 2.3.

Répartition en fonction de l'altitude et de l'orientation des graminées fourragères utilisées dans les systèmes prairiaux réunionnais. (d'après Grimaud et Thomas, 2002)

À basse altitude, jusqu'à 600, voire 800 mètres, les graminées utilisées sont toutes tropicales : Brachiaria humidicola, Brachiaria ruziziensis, Chloris gayana, Setaria anceps, Pennisetum purpureum et Tripsacum laxum.

À moyenne altitude, de 600 à 1200 mètres d'altitude, les prairies de kikuyu (Pennisetum clandestinum) prédominent, associées au Chloris et aux cannes fourragères, qui sont progressivement remplacées en montant en altitude par des graminées tempérées. Au dessus de 1200 mètres d'altitude, les graminées tempérées dominent (Lolium multiflorum, Dactylis glomerata, Festuca elatior), avec quelques légumineuses (Trifolium repens, Medicago sativa).

\section{Les grands types de sol}

Le sol dépend surtout de la nature des roches sous-jacentes, mais aussi du modelé du terrain et de la situation topographique; la nature du climat joue aussi un rôle important sur la pédogénèse. Tous ces facteurs conditionnent le bilan de l'eau, résultant des possibilités d'écoulement des eaux de surface. La connaissance de la nature géologique du terrain fournit des indications sur les roches, le relief et l'hydrographie, ainsi que les ressources en eau profonde qui permettront l'abreuvement ou

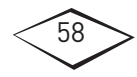


l'irrigation. Les formations géologiques, particulièrement variées dans les zones tropicales, ne seront pas abordées ici.

La morphologie joue un très grand rôle dans la pédogénèse en raison de l'entraînement d'un grand nombre d'éléments du sol et de l'eau le long des pentes :

- les points hauts sont décapés et les sols y sont donc peu épais et peu évolués;

- les points bas et les cuvettes favorisent au contraire l'accumulation et l'épaississement du sol ainsi que l'accumulation ou la stagnation de l'eau.

En raison de cette diversité, l'aptitude des sols pour le pâturage ou la mise en culture dépend beaucoup de leur position dans le paysage. Les aménagements sont adaptés aux potentialités de chaque parcelle ou de chaque portion de territoire. Il faut plusieurs milliers d'années pour faire un sol, il en faut moins de cinquante, et parfois seulement deux ou trois, pour le détruire par des mauvaises pratiques. À l'opposé, de bonnes pratiques peuvent conserver et même améliorer les qualités agronomiques des sols. Le sol comprend une fraction minérale, une fraction organique, de l'air dans les pores et de l'eau plus ou moins fixée à ces composants.

La fraction minérale du sol est la composante la plus importante du sol. La granulométrie des sols est répartie en cinq grandes catégories : les argiles $(0-2 \mu \mathrm{m})$, les limons fins $(2-20 \mu \mathrm{m})$, les limons grossiers $(20-50 \mu \mathrm{m})$, les sables fins $(50-200 \mu \mathrm{m})$ et les sables grossiers $(200-2000 \mu \mathrm{m})$.

La fraction organique du sol comprend les débris végétaux en cours d'humification, l'humus, et tous les organismes vivants. L'humus désigne des substances organiques qui résultent de la décomposition de matières organiques variées d'origine végétale. Le rôle de l'humus dans le sol est très important : il améliore les propriétés physiques, notamment la structure des agrégats et des mottes, ce qui permet un bon enracinement et une bonne circulation de l'eau et de l'air. Il améliore la capacité de rétention du sol en eau et augmente la capacité d'échange des cations. Par la minéralisation, il constitue une réserve de nutriments pour les plantes. Enfin, il sert de support à l'activité biologique du sol. Les cultures fourragères pérennes produisent plus de matière organique et d'humus qu'il ne s'en minéralise, leur bilan organique à long terme est donc positif pour le sol.

Le choix des espèces fourragères doit donc tenir compte des caractéristiques pédologiques de la région considérée et même de la nature des sols des parcelles dans lesquelles les cultures seront implantées.

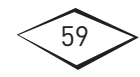




\section{ID Les sols sableux}

Ils favorisent généralement un enracinement profond qui permet de bien utiliser l'eau et les éléments minéraux disponibles en profondeur. Ils sont généralement pauvres en matière organique. Lamélioration de ces sols est réalisable par un apport important de fumier et d'autres matières organiques (sous-produits de culture). Il faut surveiller les risques de carences en phosphore, en soufre, en cuivre et en zinc.

Presque toutes les plantes fourragères sont possibles :

- en région subdésertique, Lasiurus hirsutus;

- si la saison sèche est marquée, Cenchrus ciliaris, Eragrostis curvula, Urochloa mosambicensis, Lablab purpureus, Macroptilium atropurpureum, Stylosanthes hamata, Stylosanthes humilis;

- si le climat est humide, Andropogon gayanus, Brachiaria decumbens, Brachiaria ruziziensis, Chloris gayana, Cynodon dactylon, Panicum maximum, Aeschynomenehistrix, Arachispintoi, Calopogoniummucunoides, Desmodium intortum, Mucuna pruriens, Stylosanthes guianensis.

Les plantes cultivées possibles sont l'arachide, le niébé, le petit mil, le pois d'Angole.

\section{II) Les sols argileux noirs ou vertisols}

Ils sont riches en éléments minéraux et très fertiles à l'état humide. Néanmoins les argiles gonflantes qui les composent risquent de comprimer les racines et de gêner leur fonctionnement; mais surtout elles provoquent la cassure des racines en se rétractant lors de l'assèchement. Le travail du sol et l'enrichissement progressif en matière organique (enfouissement d'engrais verts) permettent d'améliorer ce sol. On peut aussi améliorer l'état hydrique par des haies ou des petits barrages en terre qui favorisent l'infiltration. Il est parfois utile de vérifier qu'il n'y a pas de carence, ni d'excès en magnésium.

Les plantes fourragères possibles sont Bothriochloa pertusa, Brachiaria decumbens, Brachiaria humidicola, Panicum coloratum, Setaria anceps, Sorghum sudanense, Clitoria ternatea, Desmanthus virgatus, Macroptilium lathyroides, Neonotonia wightii, et les cultures de maïs et sorgho.

En région semi-aride : Sporobolus helvolus.

Les plantes cultivées possibles sont le maïs et le sorgho.

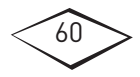




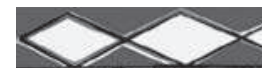

\section{Des sols rouges}

Très répandus, généralement bien drainés, parfois argileux et lourds, et de fertilité médiocre, ces sols très acides ( $\mathrm{pH}$ compris entre 3 et 7 ) sont carencés en phosphore, en potassium, en magnésium, parfois en calcium, et présentent une toxicité aluminique pour les plantes. Si on applique une fertilisation azotée sur des sols acides, il faut utiliser un engrais qui n'accentue pas cette acidité, comme l'urée.

Il faut choisir les espèces fourragères tolérantes : Brachiaria decumbens, Digitaria swazilandensis, Melinis minutiflora, Paspalum plicatulum, Setaria anceps, Stylosanthes guianensis. Le Ciat développe en Colombie des cultivars à fort enracinement (nouveaux génotypes et hybrides de Brachiaria) pour les adapter à ce type de sol.

Sont également utilisés : Brachiaria brizantha, Hyparrhenia rufa, Panicum maximum, Setaria anceps, Aeschynomene histrix, Calopogonium mucunoides, Centrosema pubescens, Chamaechrista rotundifolia, Macroptilium atropurpureum, Macroptilium lathyroides, Pueraria thunbergiana.

\section{IID Les sols neutres et légèrement basiques}

Ils conviennent à toutes les espèces fourragères s'ils sont profonds, bien drainés et bien alimentés en eau. Ils sont notamment favorables aux légumineuses dans la mesure où ils ne comportent pas de carences en minéraux comme le calcium, le magnésium, le soufre, et en oligoéléments, comme le bore et le molybdène.

Les plantes fourragères sont choisies en fonction des niveaux de fertilité et d'alimentation hydrique. Sont possibles Andropogon gayanus, Brachiaria brizantha, Brachiaria ruziziensis, Chloris gayana, Digitaria decumbens, Pennisetum clandestinum, Pennisetum purpureum, Tripsacum laxum, Calopogonium mucunoides, Lablab purpureus, Leucaena leucocephala, Medicago sativa, Mucuna pruriens, Stylosanthes guianensis.

Les plantes cultivées possibles sont en particulier le maïs, le soja, le sorgho, le pois d'Angole, le niébé.

\section{Les sols calcaires}

Ils sont toxiques pour certaines plantes en raison d'antagonismes qui s'exercent entre le calcium et le potassium, le fer ou le zinc. Ils sont parfois desséchants car très bien drainés.

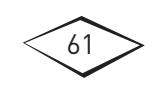




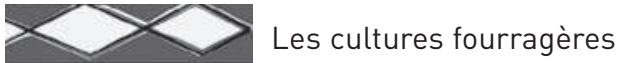

Les plantes fourragères possibles sont Cenchrus ciliaris, Panicum maximum, Pennisetum purpureum, Leucaena leucocephala, Medicago sativa.

\section{ID Les sols salés, sodiques ou halomorphes}

La présence de sel $(\mathrm{NaCl})$ ou de l'ion sodium $\left(\mathrm{Na}^{+}\right)$est toxique pour les plantes. Laccumulation du sel peut résulter de mauvaises pratiques culturales (par exemple de l'irrigation avec un réseau de drainage insuffisant). En périmètre irrigué, on peut favoriser le lessivage du sel par une amélioration du drainage. Les sols naturellement salés des régions arides (exemples à Djibouti) ou des bords de mer sont difficiles à mettre en valeur.

Certaines espèces fourragères sont tolérantes au sel, à des degrés divers :

- sur un sol de faible salinité en zone aride, des cultivars sélectionnés (Pakistan) de Panicum antidotale, Cenchrus ciliaris, Lasiurus hirsutus;

- sur un sol de salinité marquée en zone aride, on peut utiliser des Cyperaceae fourragères (essais conduits dans le désert du Néguev);

- en zone littorale, Stenotaphrum dimidiatum, Paspalum vaginatum;

- en steppe subdésertique, Artemisia herba-alba, Atriplex nummularia, Atriplex semibaccata (Australie), Atriplex halimus;

- en terrain agricole légèrement salinisé, Chloris gayana.

\section{IID Les sols hydromorphes}

L'excès d'eau, temporaire ou permanent, naturel ou volontaire (basfonds, bords de mare ou rizière) est peu favorable à la croissance de la plupart des plantes fourragères, particulièrement des légumineuses, par asphyxie au niveau des racines.

Certaines espèces fourragères résistent bien à l'inondation temporaire ou à l'excès d'humidité, comme Brachiaria humidicola, Brachiaria mutica, Echinochloa stagnina, Hyparrhenia rufa, Leersia hexandra, Paspalum notatum, Setaria anceps, Stenotaphrum dimidiatum, le riz cultivé. 


\section{La diversité des usages et des fonctions}

Les fourrages sont d'abord destinés à alimenter, exclusivement ou en grande partie, les herbivores domestiques. La gestion de leur valeur alimentaire en adéquation avec les besoins des animaux est guidée par des objectifs de production animale. Outre leur rôle alimentaire pour le bétail, les plantes fourragères peuvent aussi avoir d'autres fonctions et usages : l'alimentation humaine, la protection du sol (couverture végétale), l'amélioration de la fertilité des sols, la séquestration du carbone, le marquage du foncier et la délimitation de l'espace (figure 3.1). Certaines plantes dites «à deux fins » sont à la fois alimentaires pour l'homme et fourragères pour l'animal. Elles peuvent aussi avoir des fonctions médicinales tant pour l'homme que pour l'animal.

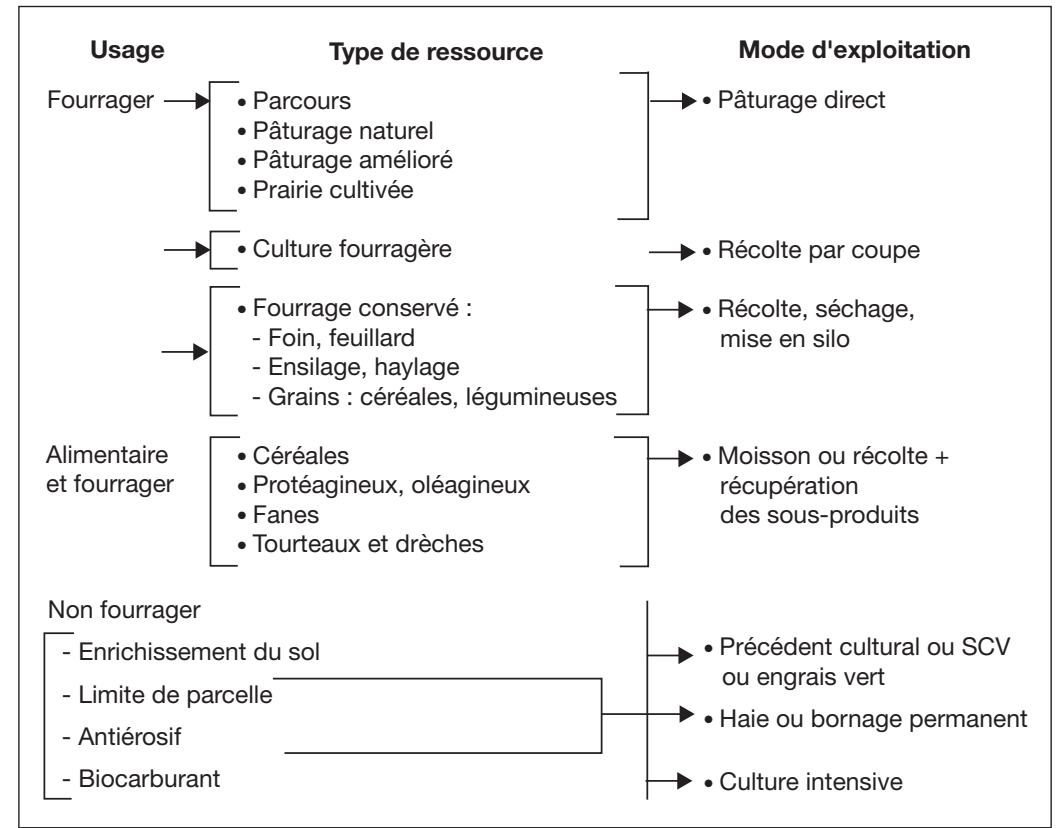

Figure 3.1. Ressources, modes d'exploitation et principaux usages des plantes fourragères et non fourragères.

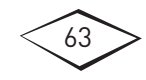




\section{L'usage fourrager pour alimenter les animaux}

La conduite de l'alimentation des ruminants doit leur assurer des apports nutritionnels en énergie, en matières azotées, en minéraux et en vitamines correspondant à leurs besoins, tant pour leur entretien et leurs déplacements, que pour leur production (croissance et production de viande, gestation, production de lait, de cuir, de laine, de travail, etc.).

Les herbivores ont la capacité de digérer les constituants fibreux des végétaux en les transformant en énergie assimilable et de synthétiser des protéines à partir des divers constituants azotés, protéiques ou non, apportés par l'alimentation. C'est principalement le cas des ruminants par l'intermédiaire de la flore microbienne de leur rumen (ou panse), et, dans une moindre mesure, des herbivores monogastriques, comme les chevaux, les ânes, les lapins, chez qui l'opération se produit surtout dans le caecum (portion du gros intestin).

\section{IID Quantité, qualité : des critères antagonistes}

Les cultures fourragères sont globalement appréciées sur le plan quantitatif par des critères de productivité et sur le plan qualitatif par des critères de valeur alimentaire. La quantité est exprimée en kilogrammes ou en tonnes de matière sèche par hectare $(\mathrm{kg} \mathrm{MS} / \mathrm{ha}$ ou t MS/ha). La qualité est décrite de façon globale sous le terme de valeur alimentaire, qui intègre les concentrations en nutriments (unités fourragères, matières azotées digestibles) et la capacité des fourrages à être consommés (quantités de matière sèche ingérées).

En général, la valeur alimentaire diminue quand la quantité produite s'accroît, du fait de la durée du cycle de végétation (semaines, mois) et du fait de la vitesse de croissance ( $\mathrm{kg}$ de matière sèche par ha et par jour) qui dépend en particulier des conditions hydriques, de la fertilité et de la température (figure 3.2).

Ces deux paramètres (la qualité et la quantité) sont primordiaux et contribuent au choix des espèces fourragères et des systèmes techniques pour les cultiver et les exploiter.

Léleveur doit donc arbitrer des compromis entre quantité et qualité pour ajuster le pilotage agronomique de son système fourrager et la conduite zootechnique et alimentaire de son troupeau (figure 3.3).

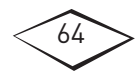




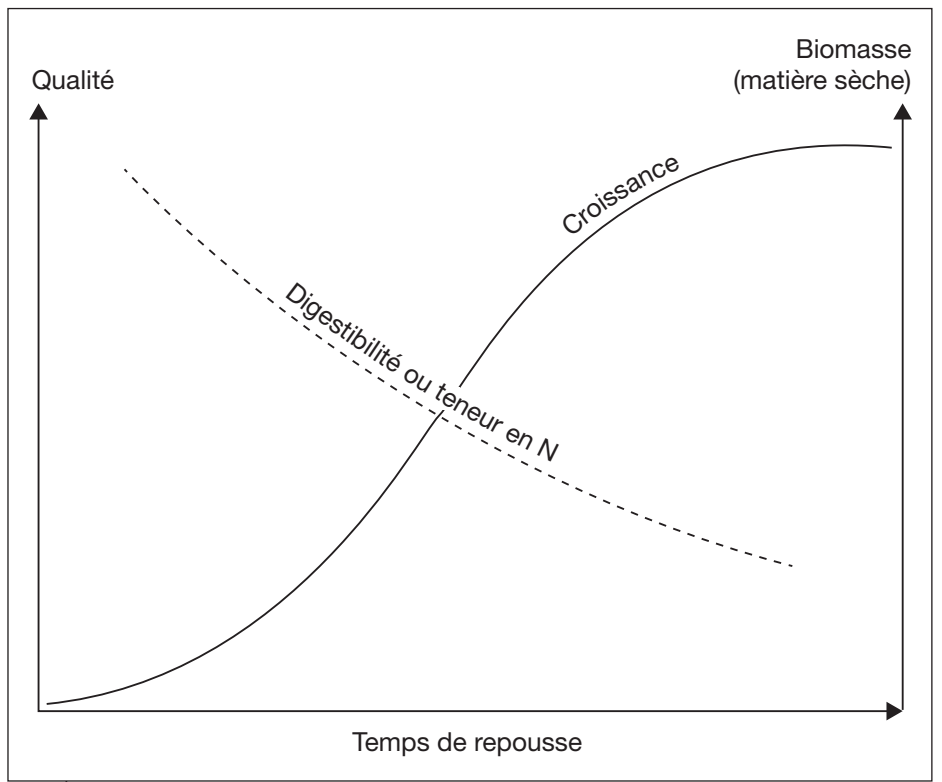

Figure 3.2.

Variations relatives de la quantité et de la qualité d'un fourrage au cours d'un cycle de croissance.

(Roberge et Toutain, 1999)

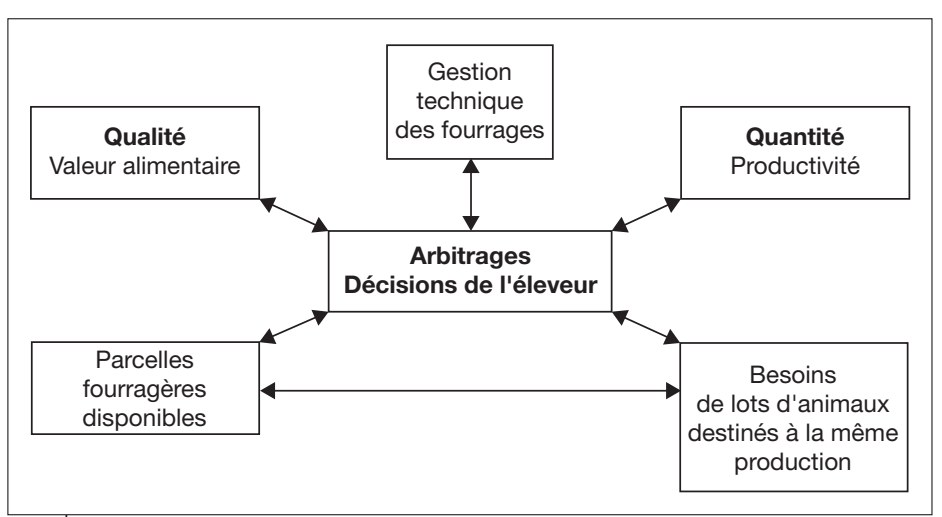

Figure 3.3.

Arbitrages à faire par l'éleveur entre qualité et quantité des plantes fourragères cultivées, besoins des animaux et surfaces fourragères disponibles. 


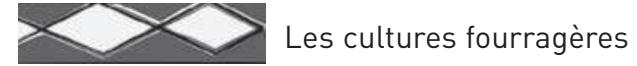

\section{Valeur alimentaire des fourrages}

La valeur alimentaire des fourrages conditionne les performances zootechniques. Dans les systèmes herbagers les apports nutritionnels dépendent strictement de la qualité de l'herbe; dans les systèmes agropastoraux, ou agrosylvopastoraux, les apports alimentaires sont fonction des associations de fourrages qui constituent le régime alimentaire des animaux. Plus le système de production animale est intensif et donc exigeant au plan des apports nutritionnels, plus la valeur alimentaire des fourrages doit être maîtrisée et optimisée.

\section{Définitions de la valeur alimentaire, combinaison de l'ingestibilité et de la valeur nutritive}

La «valeur alimentaire» mesure la capacité d'un aliment à couvrir les besoins nutritionnels de l'animal. Elle intègre la concentration en nutriments énergétiques, azotés et minéraux effectivement disponibles pour l'organisme, exprimée synthétiquement par la «valeur nutritive». Laptitude du fourrage à être consommé par les herbivores est dénommée «ingestibilité» (figure 3.4).

La première étape de caractérisation de la valeur nutritive est l'évaluation des teneurs en constituants organiques et en éléments minéraux dans les fourrages.

La teneur en matière organique $(\mathrm{MO})$ correspond à celle en matière sèche (MS) diminuée de la teneur en matière minérale (MM), cendres obtenues par calcination à partir d'une quantité connue de matière sèche : $\mathrm{MO}=\mathrm{MS}$ - MM.

Les principaux constituants organiques sont les glucides (principalement fibreux) et les matières azotées. Ils sont les précurseurs des nutriments. Leur disponibilité pour l'organisme est principalement fonction de leur digestibilité exprimant la part (\%) des aliments digérés, rapportée aux aliments ingérés. La fraction digérée est calculée par différence entre les quantités ingérées et celles excrétées dans les matières fécales.

Les concentrations en éléments nutritifs effectivement disponibles pour l'animal sont exprimées en unités rendant compte de leur utilisation digestive puis métabolique, par exemple l'énergie digestible (ED), l'énergie métabolisable (EM) et l'énergie nette $(\mathrm{EN})$; cette dernière est convertie en unités fourragères par rapport à un fourrage de référence. La valeur protéique des fourrages est exprimée en matières

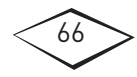




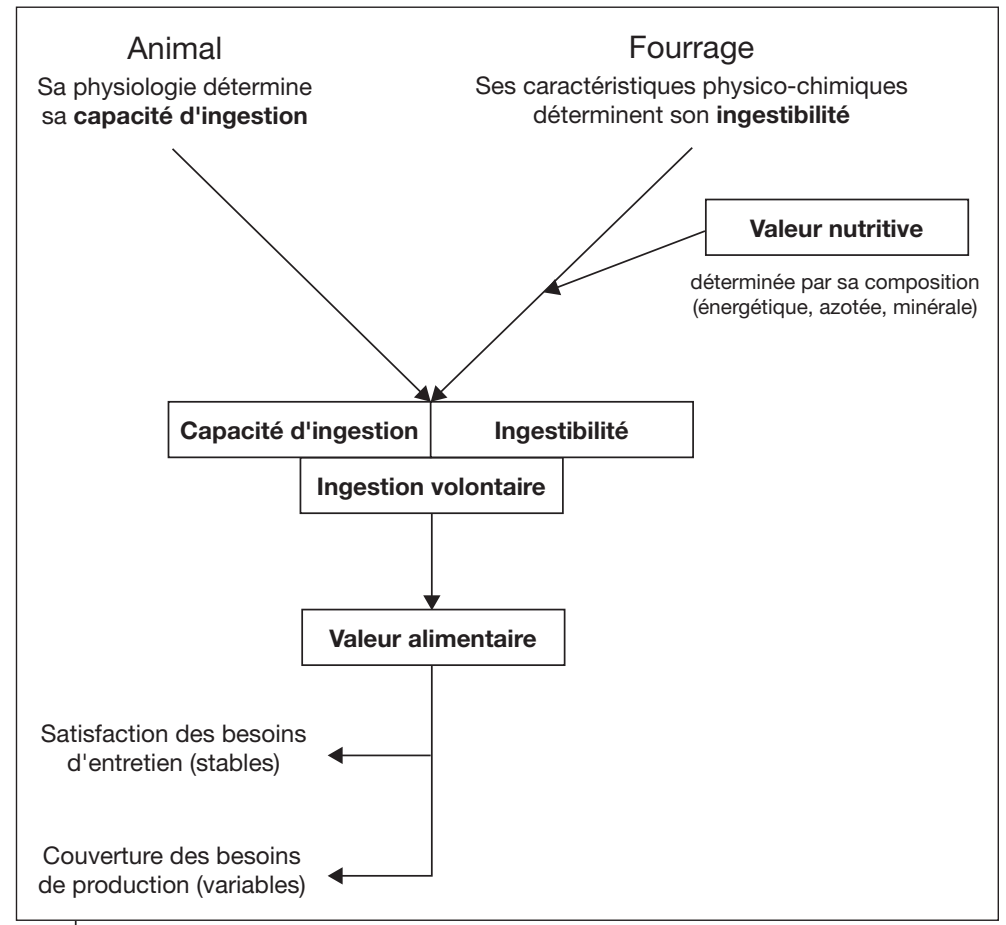

Figure 3.4.

Valeur nutritive, ingestion et valeur alimentaire des aliments : besoins d'entretien et de production des animaux.

azotées totales (MAT) ou encore en matières azotées (apparemment) digestibles (MAD), ou protéines digestibles dans l'intestin (PDI)².

Lingestibilité est un paramètre quantitatif qui intègre l'appétibilité ou appétence et la quantité ingérée exprimée par la matière sèche volontairement ingérée (MSVI). Lingestibilité est très variable selon la teneur en fibres, celles-ci ayant un effet d'encombrement sur le tube digestif. Cet effet d'encombrement est d'autant plus important que le fourrage est peu et lentement digestible. Il y a donc une forte liaison entre digestibilité et ingestibilité. Lingestibilité des fourrages tropicaux est globalement plus faible que celle des graminées tempérées en

2. Les paramètres nécessaires à l'évaluation des teneurs en PDI des fourrages sont difficiles à mesurer et exigent d'importants moyens expérimentaux. Ce système a été conçu pour des élevages très intensifs ne correspondant pas aux objectifs de cet ouvrage. La définition et l'usage de ce critère de valeur alimentaire ne sont donc pas davantage développés.

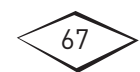


raison de leurs plus fortes teneurs en fibres. C'est une caractéristique essentielle et très variable de leur valeur alimentaire sur laquelle il est nécessaire d'influer pour améliorer leur efficacité zootechnique.

Lingestion effective de nutriments est elle-même contrôlée par la capacité d'ingestion des animaux, fonction de l'espèce animale, de l'âge, du stade physiologique, etc. L'ingestion est en premier lieu exprimée par unité de poids animal : par exemple en kilos de matière sèche par 100 kilos de poids vif $(\mathrm{PV})$ ou encore en grammes de matière sèche par kilo de poids métabolique $\left(\mathrm{PV}^{0.75}\right)$ - cette unité représente plus précisément la relation entre le poids et le besoin énergétique des animaux.

L'expression des quantités ingérées en Unités d'encombrement (UE) s'appuie sur la notion d'encombrement évoquée ci-dessus. Les unités d'encombrement ne peuvent être utilisées pour le calcul du rationnement que si l'ingestibilité des fourrages et la capacité d'ingestion des animaux sont exprimées avec cette unité ${ }^{3}$. Cette expression de l'ingestion étant encore peu utilisée en régions tropicales pour le calcul et la gestion des rations, elle n'est pas retenue dans la suite de cet ouvrage.

D’une façon générale, on adapte la précision des estimations de la valeur alimentaire aux objectifs de performances zootechniques : plus les objectifs sont élevés, plus il faut être précis. Le mode d'évaluation dépend aussi des possibilités d'observation et de mesure au champ, des capacités d'analyse et de la documentation. En fait, le plus souvent on se réfère à des tables de valeurs alimentaires, quand elles existent dans les conditions locales ou dans des contextes comparables.

\section{Variations de la valeur alimentaire}

La valeur alimentaire diminue au cours du développement des plantes; la baisse de la proportion de feuilles par rapport aux tiges et la lignification progressive de celles-ci affectent à la fois la valeur énergétique, la valeur azotée, la valeur minérale (phosphore en particulier) et l'ingestibilité. Cette diminution est d'autant plus rapide que la croissance est rapide. Elle est influencée par l'intensité de l'activité photosynthétique, elle-même fonction des variations des températures saisonnières et de l'éclairement.

3. L'ingestibilité d'un fourrage exprimée en Unités d'encombrement (UE) est évaluée par la comparaison du fourrage utilisé et d'un fourrage de référence distribué à un animal standard, également de référence. De même, la capacité d'ingestion d'un animal, caractérisée par l'espèce, l'âge et la production exprimée en UE, est évaluée en comparant cet animal à un animal de référence recevant le même fourrage. 
Ces variations sont illustrées par les valeurs mesurées en Afrique tropicale subsaharienne pour les repousses végétatives de plusieurs graminées à cycle photosynthétique en C4, cultivées sous irrigation et fertilisées, à plusieurs âges et selon la saison. Les graminées à port dressé (Panicum maximum, Pennisetum purpureum), qui ont une croissance très rapide, jusqu'à $180 \mathrm{~kg}$ de matière sèche par hectare et par jour avec irrigation, fertilisation et sous des températures élevées, évoluent plus rapidement que celles à port étalé (Brachiaria sp. par exemple), qui ont une croissance plus lente produisant 30 à $40 \mathrm{~kg}$ de matière sèche par hectare et par jour suivant les conditions agronomiques (tableau 3.1).

Les légumineuses ont une valeur alimentaire plus stable que les graminées.

\section{Variations de la valeur énergétique}

La valeur énergétique dépend principalement de la teneur en matière organique (MO) et de la digestibilité de celle-ci (exprimée en\%). La teneur en matière organique est assez constante, mais sa digestibilité est très variable, allant de $80 \%$ pour les fourrages jeunes à $40 \%$ pour les pailles.

La digestibilité dépend de nombreux facteurs :

- des qualités propres des fourrages selon l'espèce ${ }^{4}$, la variété, l'âge, l'organe de la plante (figure 3.5);

- des conditions environnementales dans lesquelles a poussé la plante (nature du sol, alimentation en eau, fertilité et fertilisation, température, évaporation);

- des conditions d'exploitation qui permettent plus ou moins aux animaux de trier les parties des fourrages les plus appétentes (souvent les plus digestibles), soit au pâturage avec des niveaux de charges animales variables, soit à l'auge selon le niveau de refus que l'on accepte.

La teneur en matière organique et la digestibilité de la matière organique déterminent la teneur en énergie digestible (ED). Lénergie digestible est le principal facteur de variation de la teneur en énergie nette (EN), ultime paramètre d'évaluation de la valeur énergétique : c'est le rapport entre la teneur en énergie nette (EN) du fourrage étudié et celle d'un fourrage de référence, exprimé en unités fourragères.

4. Les graminées possèdent généralement une valeur énergétique plus élevée que les légumineuses, ces dernières étant en revanche plus riches en matières azotées.

5. Les rendements de transformation de l'énergie digestible en énergie métabolisable, puis en énergie nette, varient dans des proportions moindres que la digestibilité évoquée ci-dessus. Pour leur signification biologique et les principes de leur évaluation nécessaire à l'expression de la valeur énergétique en unités fourragères voir Roberge et Toutain, 1999 (p. 96-97).

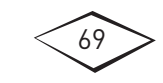




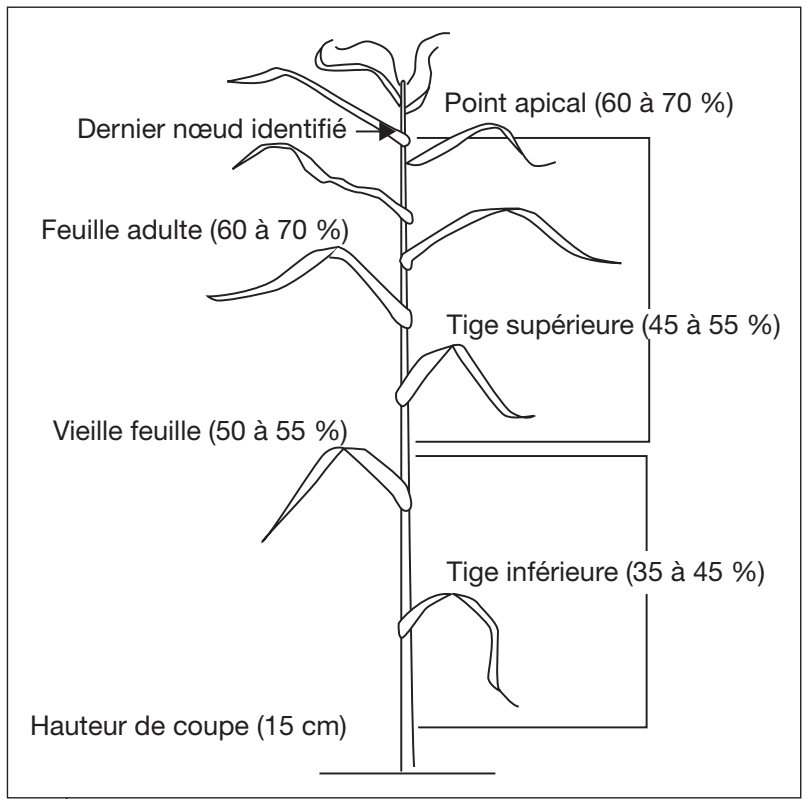

\section{Figure 3.5.}

Digestibilité des différents organes (en pourcentage) d'une graminée à port dressé. (d'après Mac Dowell, 1972)

Le système, tel qu'il a été développé par l'Inra et adapté à des fourrages tropicaux (Jarrige, 1989), distingue :

- les UFL ou Unités fourragères «lait», appliquées aux animaux à l'entretien et en production laitière. Elles sont également utilisées pour tous les autres types de ruminants dont les besoins totaux ne dépassent pas le double du besoin d'entretien (en croissance, à l'engraissement modéré [300 à $600 \mathrm{~g} /$ jour], en gestation, animaux de traction), soit la plupart des situations en élevage tropical;

- les UFV ou Unités fourragères «viande», réservées aux animaux en croissance et en engraissement dont les besoins énergétiques totaux sont supérieurs au double du besoin d'entretien (par exemple des bovins de $300 \mathrm{~kg}$ en embouche ayant un gain moyen quotidien supérieur à $600 \mathrm{~g} / \mathrm{jour}$ ) (feedlots industriels).

\section{Variations de la valeur azotée}

La valeur azotée dépend avant tout de la teneur en matières azotées totales (MAT) du fourrage. Celle-ci dépend des conditions agronomiques (teneur en azote du sol pour les graminées) et des proportions

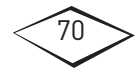


relatives des tissus fibreux surtout dans les tiges, et des tissus parenchymateux jeunes surtout dans les feuilles. Comme pour les autres critères de la valeur nutritive, le rapport feuilles/tiges est donc un paramètre précieux d'appréciation de la qualité des fourrages. En résumé, le fourrage jeune et feuillu est plus riche en azote qu'un fourrage plutôt âgé, ayant une forte proportion de tiges.

Dans la plupart des situations, la teneur en matières azotées digestibles (MAD) est suffisante pour apprécier la valeur des fourrages. Elle correspond à la teneur en matières azotées totales $($ MAT $=$ Ntotal x 6,25), diminuée de la teneur en matières azotées non digestibles (MAND) retrouvées dans les matières fécales (MAD $=$ MAT - MAND).

Pour les graminées et de nombreuses légumineuses herbacées, les fractions de matières azotées apparemment non digestibles (MAND) sont assez stables, proches de $40 \mathrm{~g}$ par kilo de matière sèche. La teneur en MAT est donc un prédicteur suffisant de la valeur azotée.

En revanche, pour les légumineuses contenant des tanins, la teneur en MAD est relativement indépendante de la teneur en MAT. Il faut alors l'estimer par diverses méthodes de laboratoire ou directement sur l'animal. Le dosage des tanins par des laboratoires spécialisés permet de comprendre ces variations de la digestibilité des matières azotées. C'est le cas en particulier pour les fourrages ligneux.

\section{Variations des teneurs en minéraux}

Ces valeurs sont estimées directement à partir des données analytiques. Leurs variations au cours des cycles de végétation sont rapportées dans les tables pour les principaux éléments tels que le calcium et le phosphore. En régions chaudes, en l'absence de fertilisation, ce sont surtout les teneurs en phosphore qui diminuent au cours de la croissance des plantes, elles sont insuffisantes comparativement aux besoins des animaux. Les faibles teneurs en zinc et en cuivre sont aussi à l'origine de carences fréquentes.

\section{Variations des quantités ingérées de fourrages}

Lingestion des fourrages, très variable, est aussi difficile à évaluer, en particulier au pâturage. En conséquence, les références sont insuffisantes au regard de la grande diversité des fourrages et des systèmes d'élevage. C'est pourtant l'un des paramètres de la valeur alimentaire les plus variables et donc avec un fort impact sur les apports de nutriments. Sur le plan de l'énergie par exemple, une variation de

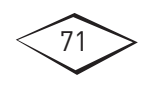


$10 \%$ des quantités ingérées peut induire une variation de $30 \%$ de l'énergie disponible pour couvrir les besoins de production, parce que les besoins d'entretien sont satisfaits en priorité.

Les quantités ingérées exprimées par la «matière sèche volontairement ingérée» (MSVI) varient avec la valeur nutritive (concentration en nutriments dans la matière sèche) mais pas seulement; les jeunes fourrages (moins de quatre semaines de repousse) très riches en eau (80 à $85 \%$ ) peuvent exercer un effet d'encombrement dans la panse qui limite leur ingestion. La capacité d'ingestion des animaux dépend de leur type zootechnique (espèce, âge, production) et du climat, les fortes chaleurs diminuant sensiblement la capacité d'ingestion surtout en milieu humide. Les valeurs de matière sèche volontairement ingérée (MSVI) rapportées dans le tableau 3.1 intègrent l'ensemble de ces facteurs pour des conditions de distribution standardisées avec des taux de refus généralement compris entre 10 et $20 \%$ des fourrages distribués.

Cette notion de «taux de refus» est importante car elle exprime la faculté laissée à l'animal, tant à l'auge qu'au pâturage, de choisir les espèces et les organes des plantes qu'il apprécie le plus, globalement ceux ayant la meilleure valeur nutritive et les plus consommés. À la ferme, on peut seulement estimer, sur la base de l'expérience et de l'observation, le niveau d'ingestion du fourrage rendu disponible aux animaux. Lappréciation la plus précise possible est cependant nécessaire pour repérer les conséquences sur la production de tout changement dans les quantités ingérées, dès lors que les fourrages sont distribués en principe «à volonté», mais avec des «taux de refus » autorisés et donc des possibilités de tri variables. De même, au pâturage, l'état du couvert (régularité, etc.) influence grandement la consommation.

Pour illustrer cette diversité, des valeurs moyennes de productivité et de valeur alimentaire sont rapportées à titre d'exemples relatifs à quelques espèces fourragères dans le tableau 3.1. Elles sont déduites de mesures effectuées en Afrique et aux Antilles françaises dans des conditions agroclimatiques contrastées ${ }^{6}$. Les tables de valeurs alimentaires contenues dans ces documents contiennent davantage de données (catégories de fourrages, espèces, teneurs en minéraux, etc).

6. Feeds of the humid tropics (West Indies) (Xandé et al., 1993); Alimentation des ruminants (Guérin, 1991 in [Cirad, Gret, MAE, 2002]); Feeds of the dry tropics (Sénégal) (Richard et al., 1993); Valeur alimentaire des fourrages cultivés (Guérin, 1999 in [Roberge et Toutain, 1999]).

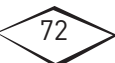


Les caractéristiques des grandes régions climatiques où sont produits ces fourrages (présentées dans le tableau 3.1) sont les suivantes :

- en région tropicale humide, les températures sont homogènes tout au long de l'année, alors qu'en région tropicale aride, les températures sont fraîches pendant une partie de la saison sèche ce qui ralentit la croissance des plantes fourragères irriguées. En région tropicale humide, les fourrages appartiennent plutôt à des systèmes herbagers, notamment en ranching, mais ils peuvent aussi être distribués à l'auge dans les petites exploitations familiales; on préfère alors des espèces à port dressé à croissance rapide donc plus productives;

- en milieu tropical sec, des fourrages cultivés sont introduits pour intensifier les systèmes d'élevage notamment pendant la saison sèche; ils sont comparés aux pailles sèches des parcours naturels et aux résidus de cultures, en particulier aux pailles de céréales et aux fanes de légumineuses. Pour ces régions, les valeurs des fourrages traditionnels sont présentées pour mettre en évidence la supériorité nutritionnelle des fourrages cultivés en saison sèche. Les fourrages sont généralement cultivés en saison des pluies (culture pluviale) pour alimenter les animaux en saison sèche sous forme de foin ou de pâture en utilisant des espèces qui restent vertes plus longtemps en début de saison sèche. La capacité des plantes à repousser spontanément à la saison des pluies suivante est aussi un critère apprécié; le genre Brachiaria, du fait de sa diversité avec des espèces et variétés souples d'utilisation et rustiques, répond bien à ces critères. Sous climat tropical sec, certaines cultures fourragères peuvent bénéficier de l'humidité des bas-fonds ou de l'irrigation (rives des fleuves, nappe phréatique peu profonde). Le facteur limitant des productions est alors la température en saison sèche fraîche, notamment pour les plantes en C4. Dans ces situations, les espèces les plus productives sont souvent identiques à celles de zones tropicales humides.

\section{IID Les particularités des fourrages ligneux}

Les fourrages ligneux sont principalement les feuillages d'arbres de prairies et de haies vives. Leurs feuilles tombées au sol, leurs fruits, dont les gousses de légumineuses, et même leurs fleurs, sont aussi considérés comme des fourrages ligneux.

Les espèces ligneuses les plus cultivées sont pour la plupart originaires d'Amérique centrale (Calliandra calothyrsus, Gliricidia sepium,

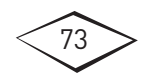


Tableau 3.1. Valeurs moyennes de rendements et de valeurs alimentaires de graminées et de légumineuses fourragères très répandues en fonction du milieu, du système de culture et de l'âge des repousses. Comparaison avec des fourrages pauvres de systèmes agropastoraux.

Les paramètres moyens rassemblés dans le tableau 3.1 sont :

- la productivité annuelle qui exprime le potentiel de disponibilité fourragère pour le bétail;

- le rythme de coupe est exprimé par l'âge des repousses (en semaines) lors de leur exploitation. Il rend compte de la disponibilité instantanée pour la gestion du système fourrager;

\begin{tabular}{|c|c|c|c|c|}
\hline Climat & $\begin{array}{l}\text { Type de } \\
\text { culture }\end{array}$ & $\begin{array}{l}\text { Type de } \\
\text { fourrage }\end{array}$ & $\begin{array}{l}\text { Productivité } \\
\text { (t MS/ha/an) }\end{array}$ & $\begin{array}{l}\text { Périodes } \\
\text { Âge (semaines-S) } \\
\text { Stade de } \\
\text { développement }\end{array}$ \\
\hline \multirow{4}{*}{$\begin{array}{l}\text { Milieu } \\
\text { tropical } \\
\text { humide } \\
900 \\
\text { à } 1800 \mathrm{~mm} \\
\text { en } 6 \text { à } \\
10 \text { mois }\end{array}$} & \multirow[t]{4}{*}{$\begin{array}{l}\text { Cultures } \\
\text { pluviales }\end{array}$} & \multirow[t]{4}{*}{$\begin{array}{l}\text { Fourrages } \\
\text { verts pâturés } \\
\text { ou distribués } \\
\text { à l'auge }\end{array}$} & $\begin{array}{l}\text { Graminées } \\
\text { à port dressé } \\
\text { Panicum maximum, } \\
\text { Pennisetum purpureum } \\
20 \text { à } 30\end{array}$ & $\begin{array}{l}\text { Année } \\
4 \text { à } 10 \mathrm{~S} \\
\text { Végétatif }\end{array}$ \\
\hline & & & $\begin{array}{l}\text { Graminées } \\
\text { à port étalé } \\
\text { Brachiaria } \text { sp., } \\
\text { Cencrus ciliaris, } \\
\text { Cynodon dactylon, } \\
\text { Digitaria } \text { sp. } \\
15 \text { à } 25\end{array}$ & $\begin{array}{l}\text { Année } \\
4 \text { à } 10 \mathrm{~S} \\
\text { Végétatif }\end{array}$ \\
\hline & & & $\begin{array}{l}\text { Légumineuses } \\
\text { Stylosanthes guyanensis, } \\
\text { Calpogonium sp., } \\
\text { Desmodium sp. } \\
10 \text { à } 15\end{array}$ & $\begin{array}{l}\text { Année } \\
6 \text { à } 12 \mathrm{~S} \\
\mathrm{~V}+\mathrm{F}+\mathrm{G}\end{array}$ \\
\hline & & & Foin de légumineuses & $\begin{array}{l}6 \text { à } 12 S \\
V+F+G\end{array}$ \\
\hline
\end{tabular}


- la vitesse de croissance en relation avec l'évolution de la valeur alimentaire. Plus la croissance est rapide, plus la valeur alimentaire diminue vite;

- la teneur en matière sèche. Elle permet de convertir le poids des fourrages bruts en nutriments produits et effectivement ingérés;

- l'expression des valeurs énergétiques en UFL / $\mathrm{kg}$ de MS est adaptée au rationnement des animaux à l'entretien, en lactation et en croissance modérée. [Les UFV ne sont pas présentées, car réservées aux animaux en croissance et en engraissement intensif pour l'embouche bovine ou ovine];

- la teneur en matières azotées digestibles (MAD). C'est la plus simple expression de la valeur azotée; - les matières sèches volontairement ingérées (MSVI) sont exprimées en $\mathrm{kg}$ de matière sèche par $100 \mathrm{~kg}$ de poids vif. Elles sont mesurées sur des moutons de $30 \mathrm{~kg}$ de poids vif et estimées par calcul pour les bovins en appliquant une relation étroite entre MSVI-ovin et MSVI-bovin établies expérimentalement sur de nombreux fourrages.

\begin{tabular}{|c|c|c|c|c|c|c|}
\hline \multirow{2}{*}{$\begin{array}{l}\text { Production } \\
\text { par coupe } \\
\text { (t MS/ha) }\end{array}$} & \multirow{2}{*}{$\begin{array}{l}\text { Vitesse de } \\
\text { croissance } \\
\text { (kg MS/ha/j) }\end{array}$} & \multirow{2}{*}{$\begin{array}{l}\text { Teneur } \\
\text { MS (\% du } \\
\text { fourrage } \\
\text { brut) }\end{array}$} & \multirow{2}{*}{$\begin{array}{l}\text { Valeur } \\
\text { énergétique } \\
\text { (UFL/kg MS) }\end{array}$} & \multirow[t]{2}{*}{$\begin{array}{l}\text { Valeur azotée } \\
\text { (MAD/kg MS) }\end{array}$} & \multicolumn{2}{|c|}{$\begin{array}{l}\text { Quantités ingérées } \\
\text { (kg MS/100 kg PV) }\end{array}$} \\
\hline & & & & & Bovins & Ovins \\
\hline 5 à 6 & 100 à 120 & 21 à 27 & 0,45 à 0,70 & 20 à 65 & 1,5 à 2,4 & 1,7 à 3,3 \\
\hline 4 à 5 & $\begin{array}{l}\text { Jusqu'à } 100 \\
\text { en SP }\end{array}$ & 19 à 30 & 0,60 à 0,80 & 30 à 95 & 1,7 à 2,2 & 2,1 à 3,0 \\
\hline 3 à 4 & $\begin{array}{l}50 \text { à } 100 \\
\text { Croissance } \\
\text { prolongée } \\
\text { en SS par } \\
\text { rapport aux } \\
\text { graminées }\end{array}$ & 23 à 28 & 0,57 à 0,72 & 55 à 135 & 1,5 à 2,4 & 1,7 à 3,3 \\
\hline 3 à 4 & $\begin{array}{l}50 \text { à } 100 \\
\text { Croissance } \\
\text { prolongée } \\
\text { en SS par } \\
\text { rapport aux } \\
\text { graminées }\end{array}$ & 85 à-90 & 0,5 à 0,6 & 50 à 90 & 2,5 & 3,4 \\
\hline
\end{tabular}




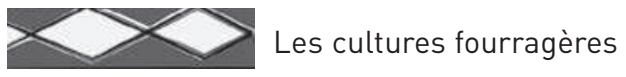

Tableau 3.1. (suite)

\begin{tabular}{|c|c|c|c|c|}
\hline Climat & $\begin{array}{l}\text { Type de } \\
\text { culture }\end{array}$ & $\begin{array}{l}\text { Type de } \\
\text { fourrage }\end{array}$ & $\begin{array}{l}\text { Productivité } \\
\text { (t MS/ha/an) }\end{array}$ & $\begin{array}{l}\text { Périodes } \\
\text { Âge (semaines-S) } \\
\text { Stade de } \\
\text { développement }\end{array}$ \\
\hline \multirow{5}{*}{$\begin{array}{l}\text { Milieu } \\
\text { tropical sec } \\
400 \text { à } \\
900 \text { mm en } \\
2 \text { à } 4 \text { mois }\end{array}$} & \multirow[t]{5}{*}{$\begin{array}{l}\text { Végétation } \\
\text { naturelle } \\
\text { et cultures } \\
\text { pluviales }\end{array}$} & $\begin{array}{l}\text { Fourrages } \\
\text { verts de } \\
\text { parcours } \\
\text { naturels }\end{array}$ & $\begin{array}{l}\text { Graminées et } \\
\text { légumineuses annuelles }\end{array}$ & Milieu SP \\
\hline & & \multirow[t]{2}{*}{$\begin{array}{l}\text { Foins et } \\
\text { pailles de } \\
\text { parcours } \\
\text { naturels et } \\
\text { jachères }\end{array}$} & $\begin{array}{l}\text { Foins distribués } \\
\text { en fin SS } \\
1 \text { à } 3\end{array}$ & $\begin{array}{l}\text { Coupe début SS } \\
2 \text { à } 4 \text { mois } \\
\text { Floraison- } \\
\text { Grenaison }\end{array}$ \\
\hline & & & $\begin{array}{l}\text { Pailles sur pied } \\
\text { et pâturées } \\
\text { de parcours naturels } \\
0,5 \text { à } 3\end{array}$ & $\begin{array}{l}\text { Milieu et fin SS } \\
\text { Grenaison }\end{array}$ \\
\hline & & \multirow[t]{2}{*}{$\begin{array}{l}\text { Résidus de } \\
\text { récoltes }\end{array}$} & $\begin{array}{l}\text { Pailles de céréales } \\
\text { riz, mil mais sorgho } \\
1 \text { à } 4\end{array}$ & $\begin{array}{l}\text { Début SS } \\
\text { Graines récoltées }\end{array}$ \\
\hline & & & $\begin{array}{l}\text { Fane de légumineuses } \\
\text { arachide, dolique, } \\
\text { niébé, pois, } \\
1 \text { à } 4\end{array}$ & $\begin{array}{l}\text { Début SS } \\
\text { Graines récoltées }\end{array}$ \\
\hline \multirow[t]{5}{*}{$\begin{array}{l}\text { Milieu } \\
\text { tropical sec } \\
400 \text { à } \\
900 \mathrm{~mm}\end{array}$} & \multirow{4}{*}{$\begin{array}{l}\text { Cultures } \\
\text { irriguées } \\
\text { en saison } \\
\text { sèche fraîche } \\
\left(10-25^{\circ} \mathrm{C}\right) \\
\text { et en saison } \\
\text { chaude } \\
\left(20 \text { à } 40^{\circ} \mathrm{C}\right)\end{array}$} & \multirow[t]{2}{*}{$\begin{array}{l}\text { Fourrage vert } \\
\text { irrigué } \\
\text { Panicum } \\
\text { maximum, } \\
\text { Pennisetum } \\
\text { purpureum }\end{array}$} & $\begin{array}{l}\text { Graminées } \\
\text { à port dressé } \\
\text { Saison chaude } \\
\left(25-40{ }^{\circ} \mathrm{C}\right) \\
25 \text { à } 35\end{array}$ & $\begin{array}{l}4 \text { à } 9 \mathrm{~S} \\
\text { Végétatif }\end{array}$ \\
\hline & & & $\begin{array}{l}\text { Graminées } \\
\text { à port dressé } \\
\text { Saison fraîche } \\
\left(10-25^{\circ} \mathrm{C}\right) \\
25 \text { à } 35\end{array}$ & $\begin{array}{l}5 \text { à } 9 \mathrm{~S} \\
\text { Végétatif }\end{array}$ \\
\hline & & \multirow[t]{2}{*}{$\begin{array}{l}\text { Fourrage vert } \\
\text { irrigué } \\
\text { Brachiaria } \\
\text { mutica }\end{array}$} & $\begin{array}{l}\text { Graminées à port étalé } \\
\text { Saison chaude } \\
\left(25-40{ }^{\circ} \mathrm{C}\right) \\
15 \text { à } 25\end{array}$ & $\begin{array}{l}4 \text { à } 9 \mathrm{~S} \\
\text { Végétatif }\end{array}$ \\
\hline & & & $\begin{array}{l}\text { Graminées à port étalé } \\
\text { Saison fraîche }\left(10-25^{\circ} \mathrm{C}\right) \\
15 \text { à } 25\end{array}$ & $\begin{array}{l}4 \text { à } 9 \mathrm{~S} \\
\text { Végétatif }\end{array}$ \\
\hline & $\begin{array}{l}\text { Culture } \\
\text { irriguée ou } \\
\text { pluviale } \\
\text { suivant la } \\
\text { période de } \\
\text { récolte }\end{array}$ & $\begin{array}{l}\text { Foin graminée } \\
\text { irriguée }\end{array}$ & $\begin{array}{l}\text { Graminées à port étalé } \\
\text { Panicum maximum } \mathrm{C} 1 \text {, } \\
\text { Chloris gayana }\end{array}$ & $\begin{array}{l}4 \text { à } 9 \mathrm{~S} \\
\text { Végétatif }\end{array}$ \\
\hline
\end{tabular}

Saison $: \mathrm{SP}=$ Saison des pluies, $\mathrm{SS}=$ Saison sèche, Stades $: \mathrm{V}=$ Végétatif, $\mathrm{F}=$ Floraison, $\mathrm{G}=$ Graines

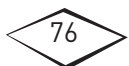




\begin{tabular}{|c|c|c|c|c|c|c|}
\hline \multirow{2}{*}{$\begin{array}{l}\text { Production } \\
\text { par coupe } \\
\text { (t MS/ha) }\end{array}$} & \multirow{2}{*}{$\begin{array}{l}\text { Vitesse de } \\
\text { croissance } \\
(\text { kg MS/ha/j) }\end{array}$} & \multirow{2}{*}{$\begin{array}{l}\text { Teneur } \\
\text { MS (\% du } \\
\text { fourrage } \\
\text { brut) }\end{array}$} & \multirow{2}{*}{$\begin{array}{l}\text { Valeur } \\
\text { énergétique } \\
\text { (UFL/kg MS) }\end{array}$} & \multirow[t]{2}{*}{$\begin{array}{l}\text { Valeur azotée } \\
\text { (MAD/kg MS) }\end{array}$} & \multicolumn{2}{|c|}{$\begin{array}{l}\text { Quantités ingérées } \\
\text { (kg MS/100 kg PV) }\end{array}$} \\
\hline & & & & & Bovins & Ovins \\
\hline 1 à 3 & $\begin{array}{l}10 \text { à } 40 \\
\text { en SP }\end{array}$ & 15 à 30 & 0,70 à 0,85 & 50 à 90 & 2,0 à 2,2 & 2,5 à 3,0 \\
\hline 1 à 3 & $\begin{array}{l}10 \text { à } 40 \\
\text { en SP }\end{array}$ & 85 à 90 & 0,48 à 0,56 & 20 à 85 & 1,6 à 2 & 1,9 à 2,7 \\
\hline 0,5 à 3 & $\begin{array}{l}10 \text { à } 40 \\
\text { en SP }\end{array}$ & 90 à 95 & 0,3 à 0,5 & 0 à 50 & 1,6 à 1,7 & 1,9 à 2,1 \\
\hline 1 à 4 & $\begin{array}{l}10 \text { à } 40 \\
\text { en SP }\end{array}$ & 85 à 90 & 0,34 à 0,51 & 0 à 30 & 1,3 à 1,7 & 1,4 à 2,2 \\
\hline 1 à 4 & $\begin{array}{l}10 \text { à } 40 \\
\text { en SP }\end{array}$ & 85 à 90 & 0,6 à 0,8 & 60 à 130 & 2,2 à 2,5 & 3,0 à 3,4 \\
\hline 5 à 8 & 100 à 150 & 13 à 25 & 0,55 à 0,75 & 35 à 90 & 1,8 à 2,1 & 1,7 à 3,0 \\
\hline 2 à 5 & 30 à 50 & 17 à 25 & 0,65 à 0,85 & 75 à 100 & 2,1 à 2,5 & 3,0 à 3,4 \\
\hline & 60 à 100 & 17 à 23 & 0,55 à 0,70 & 55 à 95 & 1,7 à 2,0 & 2,1 à 2,8 \\
\hline & 30 à 50 & 22 à 27 & 0,70 à 0,72 & 75 à 85 & 1,9 à 2,2 & 2,5 à 3,0 \\
\hline & & 85 à 90 & 0,6 à 0,7 & 30 à 85 & 1,8 à 2,3 & 2,3 à 3,2 \\
\hline
\end{tabular}


Leucaena leucocephala), et ont fait leurs preuves sur les plans agroforestier et fourrager. Cependant, elles ne sont pas adaptées à tous les contextes, en particulier aux régions subhumides et arides, même en système irrigué. Dans ces régions, de nombreuses espèces naturelles sont traditionnellement considérées comme fourragères et certaines sont domestiquées et sont gérées pour leur préservation, leur régénération et l'exploitation de leur fourrage. Parmi les plus courantes, c'est le cas de certaines espèces d'Acacia, de Combretum, de Ficus, etc.

Les fourrages ligneux sont le plus souvent directement broutés au pâturage. Parfois les bergers procèdent à un émondage pour les rendre accessibles aux animaux. Ils sont aussi récoltés pour être distribués en stabulation, à des vaches laitières par exemple. Ils peuvent encore être commercialisés pour approvisionner les élevages urbains, notamment pour l'engraissement de moutons à l'approche des fêtes. Sur les plans technique et économique ces usages peuvent être comparés avec l'emploi d'aliments de complément destinés à améliorer la valeur de la ration de base (fourrages à haute valeur nutritive, sous-produits agro-industriels, tels que son de céréales, mélasse, tourteaux, fruits abîmés, etc.).

La contribution des fourrages ligneux aux régimes des ruminants domestiques est d'autant plus utile que les autres fourrages herbacés et les résidus de récolte sont peu abondants et de mauvaise qualité en particulier du fait de leurs faibles teneurs en matières azotées. Les ligneux ont alors un effet remarquable sur la nutrition des animaux, carencés en protéines et en minéraux, mais aussi sur la flore microbienne de leur panse, elle-même carencée.

En effet, lorsque la ration de base est constituée de pailles grossières, l'azote apporté par les ligneux, s'il est lui-même digestible, améliore l'efficacité de la digestion microbienne. La ration totale est alors plus rapidement et plus complètement digérée. En conséquence, la panse est alors moins «encombrée » et la quantité totale de fourrage consommé, y compris de paille, augmente. Les rations totales, ainsi enrichies au plan quantitatif et au plan qualitatif, permettent une amélioration significative de l'état des animaux et aussi des productions.

Le tableau 3.2 permet de comparer la composition et la valeur nutritive (digestibilité, valeur énergétique, valeur azotée) de fourrages ligneux à celles de fourrages herbacés cultivés ou naturels en régions tropicales sèches. Ce tableau montre ainsi tant la diversité des fourrages traditionnels que celle des ligneux.

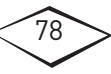


Tableau 3.2. Variations de la composition et de la valeur nutritive (digestibilité, valeur énergétique, valeur azotée) de fourrages ligneux comparées à celles des fourrages herbacés cultivés ou naturels en régions tropicales sèches. (données Cirad)

\begin{tabular}{|c|c|c|c|c|}
\hline \multirow{2}{*}{$\begin{array}{l}\text { Composition } \\
\text { et valeur nutritive }\end{array}$} & \multicolumn{2}{|c|}{ Fourrages cultivés verts } & \multirow{2}{*}{$\begin{array}{c}\text { Pailles sèches } \\
\text { de saison sèche / } \\
\text { parcours naturels } \\
\text { ou céréales cultivées }\end{array}$} & \multirow{2}{*}{$\begin{array}{l}\text { Fourrages } \\
\text { ligneux }\end{array}$} \\
\hline & Graminées & Légumineuses & & \\
\hline $\begin{array}{l}\text { Matières azotées } \\
\text { totales (g/kg de MS) }\end{array}$ & 40 à 140 & 80 à 175 & 30 à 60 & 70 à 220 \\
\hline $\begin{array}{l}\text { Ligno-celluloses } \\
\text { (g/kg de MS) }\end{array}$ & 360 à 480 & 380 à 450 & 460 à 500 & 130 à 480 \\
\hline $\begin{array}{l}\text { Lignine } \\
\text { (g/kg de MS) }\end{array}$ & 40 à 80 & 80 à 100 & 70 à 90 & 60 à 230 \\
\hline $\begin{array}{l}\text { Tanins } \\
\text { (g/kg de MS) }\end{array}$ & - & - & - & 0 à 80 \\
\hline $\begin{array}{l}\text { Digestibilité } \\
\text { matière organique } \\
\text { (DMO \%) }\end{array}$ & 40 à 75 & 50 à 75 & 40 à 55 & 30 à 75 \\
\hline $\begin{array}{l}\text { Valeur énergétique } \\
\text { (UFL/kg MS) }\end{array}$ & 0,4 à 0,8 & 0,5 à 0,8 & 0,30 à 0,45 & 0,3 à 0,8 \\
\hline $\begin{array}{l}\text { Matières azotées } \\
\text { digestibles } \\
\text { (MAD g/kg de MS) }\end{array}$ & 30 à 100 & 50 à 130 & 0 à 5 & 15 à 180 \\
\hline
\end{tabular}

Ainsi, par exemple, la complémentation par un ligneux de bonne qualité d'une graminée jeune contenant $14 \%$ de MAT est sans effet sur les performances. En revanche, pour la même graminée à un stade plus avancé contenant seulement $5 \%$ de MAT, on observe un effet significatif de la complémentation sur l'état et le gain de poids de moutons en croissance-engraissement. L'effet positif peut être comparé à celui d'un tourteau à apport protéique équivalent : en moyenne il faut environ $3 \mathrm{~kg}$ de matière sèche de ligneux (soit 9 à $10 \mathrm{~kg}$ de feuillage vert) de bonne qualité pour remplacer $1 \mathrm{~kg}$ de tourteau. Cette substitution est limitée par l'appétibilité des ligneux et par la capacité des animaux à les consommer; dans la pratique elle dépasse rarement $30 \%$ de la matière sèche totale ingérée pour les bovins et $50 \%$ pour les moutons; pour les caprins elle atteint facilement $70 \%$.

Lutilisation rationnelle des fourrages ligneux nécessite donc de pouvoir apprécier leur valeur nutritive, très variable, comparativement à celle des fourrages auxquels ils sont associés. Cependant leurs teneurs en

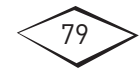


matières azotées digestibles (MAD) et leurs valeurs énergétiques (UFL) sont très variables et difficiles à prévoir en fonction de critères analytiques simples comme la teneur en cellulose brute (CB) ou la teneur en matières azotées totales (MAT). Leur valeur nutritive doit être estimée par des critères plus complexes, afin de rendre compte de la lignification des fibres et de ses effets sur la digestibilité de la matière organique, donc sur la valeur énergétique. La lignification affecte aussi la digestibilité des matières azotées qui sont en quelque sorte prisonnières des fibres; cet effet physique se conjugue avec l'effet biochimique des tanins.

Certains fourrages ligneux très riches en MAT peuvent ainsi avoir des valeurs nutritives très faibles.

Des approches globales des critères de la digestibilité par des méthodes de laboratoire in vitro, par voie microbienne ou avec des enzymes de synthèse, permettent aussi de prévoir les valeurs nutritives et de comparer les espèces entre elles. Les résultats de ces analyses complexes permettent de comprendre la diversité des performances nutritionnelles et zootechniques obtenues avec les fourrages ligneux.

Dans des contextes où de nombreuses espèces dites fourragères sont disponibles, ces comparaisons sont importantes pour concevoir des options d'aménagements agroforestiers et aussi des plans d'affouragements. Toutefois, les arbitrages entre espèces dépendront surtout des préférences des agriculteurs et des éleveurs en fonction des autres usages (bois de feu, bois d'œuvre, alimentation humaine, pharmacopées) et aussi des aptitudes des espèces à être domestiquées en pépinière, puis cultivées pour des aménagements de terroirs.

Ainsi, en zones tropicales humides on peut utiliser des espèces très répandues, sélectionnées et expérimentées comme Gliricidia sepium, Calliandra calothyrsus qui contiennent jusqu'à 0,7 à $0,8 \mathrm{UFL} / \mathrm{kg}$ MS et $150 \mathrm{~g} \mathrm{MAD} / \mathrm{kg}$ MS. Leucaena leucocephala a une valeur équivalente, voire supérieure pour les MAD, mais doit être utilisé avec précaution en particulier pour les petits ruminants et les chevaux car il contient une substance toxique, la mimosine. Il peut aussi se multiplier et donner lieu à des envahissements dans les prairies de graminées environnantes.

Cependant certaines espèces cultivées et diffusées à travers le monde sont sans réel intérêt fourrager. C'est le cas de Flemingia macrophylla dont la faible valeur azotée s'explique par d'importantes teneurs en

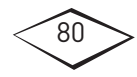


lignine et en tanins. C'est aussi le cas pour certains acacias cultivés (Acacia mangium par exemple). Il faut préciser toutefois que leur faible valeur fourragère n'affecte en rien leurs autres fonctions agroforestières; au contraire, une lente dégradation de l'azote et des fibres des feuilles dans les litières et le sol est plus favorable aux processus d'humification.

Pour l'élevage, on préférera donc à ces espèces introduites, des ligneux autochtones, comme par exemple Ficus exasperata, Pterocarpus erinaceus, ou encore Morinda lucida, bien connus des populations qui les récoltent, notamment pour alimenter les petits ruminants de certaines régions d'Afrique de l'Ouest. Ces espèces ont des teneurs en UFL et en MAT comparables aux valeurs des meilleures espèces introduites. À noter cependant que certaines espèces locales sont réputées fourragères mais qu'elles ont des valeurs nutritives faibles (parfois 0,3 à $0,5 \mathrm{UFL}$ et moins de $50 \mathrm{~g} \mathrm{MAD} / \mathrm{kg} \mathrm{MS}$ ) et ont peu ou pas d'effet zootechnique. C'est le cas par exemple de Afzelia africana, Albizzia zygia, Pericopsis laxiflora et même de Piliostigma thonningii dont les gousses sont parfois récoltées.

En zones tropicales sèches, les espèces citées ci-dessus (Calliandra spp., Gliricidia spp., Flemingia spp., Leucaena spp.) ont été abondamment expérimentées de même que certains acacias exotiques, souvent de provenance australienne. Malgré d'importants travaux de sélection et de diffusion, ces espèces ont été peu adoptées par les éleveurs, dans la mesure où sur le plan agroforestier, les espèces locales étaient souvent mieux adaptées à la fois au milieu et aux usages souhaités. En effet, en régions sèches, les espèces les plus utiles pour le fourrage sont celles qui émettent leurs feuilles en fin de saison sèche, en période de soudure, ce qui n'est pas le cas des espèces introduites.

Pour évaluer le rôle des ligneux dans les systèmes fourragers, ainsi que les avantages et les inconvénients des espèces introduites par rapport aux espèces locales, il est donc utile de connaître les caractéristiques des espèces locales notamment leurs cycles de production (cycles phénologiques), leur appétibilité et leur valeur nutritive.

Parmi les nombreux acacias, souvent considérés comme la panacée en régions sèches, il y a le meilleur et le pire en matière de valeur alimentaire. Les feuilles d'Acacia albida (alias Faidherbia albida qui a l'avantage de porter ses feuilles en saison sèche), Acacia nilotica, Acacia senegal, Acacia seyal ont des teneurs en énergie de 0,6 à $0,8 \mathrm{UFL} / \mathrm{kg}$ MS et des teneurs en MAD comprises entre de 80 à $150 \mathrm{~g} / \mathrm{kg}$ MS. Ces espèces

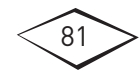


produisent aussi des gousses qui peuvent être directement consommées sous les arbres par les animaux ou récoltées, transportées, stockées, vendues. Leurs valeurs nutritives ne sont pas directement liées à celles des feuillages. Elles dépendent aussi des teneurs en azote, en fibres lignifiées et en tanins. Ainsi, le feuillage d'Acacia nilotica a une meilleure valeur nutritive que celui de Faidherbia albida, mais c'est l'inverse pour les gousses.

En revanche, certaines espèces comme Acacia ataxacantha, Acacia linearoides, Acacia macrostachya, ont une végétation luxuriante et des teneurs en matières azotées totales élevées (jusqu'à $20 \%$ de la matière sèche voire plus), mais des valeurs nutritives très faibles - d'ailleurs les animaux les consomment très peu.

Parmi les autres espèces ligneuses des régions sèches certaines ont des valeurs nutritives remarquables et sont très appétées par le bétail :

- pour les bovins, ce sont surtout des espèces faciles d'accès et de préhensibilité, comme Ficus sycomorus, Ficus gnaphalocarpa, Pterocarpus lucens, Boscia senegalensis;

- pour les petits ruminants, ce sont des espèces plus épineuses ou de petite taille, parfois du fait d'un abroutissement sévère, comme Balanites aegyptiaca, Ziziphus mauritiana.

Certaines espèces ont une valeur nutritive moyenne, voire faible $(0,4$ à 0,6 UFL, 40 à $70 \mathrm{~g} \mathrm{MAD} / \mathrm{kg}$ de MS). Pourtant, si les espèces de bonne qualité citées précédemment sont absentes ou raréfiées, les espèces de valeur moyenne ont un rôle stratégique très important car elles assurent aux animaux le minimum de complémentation, azotée en particulier, pendant la période de soudure. C'est le cas, par exemple, des Combretaceae, comme Guiera senegalensis, abondant dans les systèmes agrosylvopastoraux d'Afrique subsaharienne.

Ces espèces locales ne sont pas cultivées au sens strict mais sont intégrées dans les systèmes de gestion durable des ressources agroforestières. Elles peuvent alors jouer un rôle important dans des systèmes alimentaires qui associent cultures fourragères, herbes naturelles et résidus de récolte. Cela justifie de connaître leurs caractéristiques biologiques et techniques et de définir des pratiques de gestion qui les valorisent économiquement tout en assurant leur pérennité dans les paysages et les systèmes de production. Pour une région donnée, il est donc nécessaire de réunir l'information disponible sur la valeur fourragère des espèces utilisées en élevage, et en particulier celles utilisées par les acteurs du monde rural.

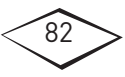




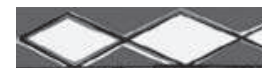

\section{Pour d'autres usages et fonctions}

Outre leur usage fourrager, les plantes fourragères peuvent avoir des usages alimentaires et en pharmacopée pour l'homme et le bétail et des usages agronomiques et environnementaux. Ces autres fonctions peuvent être mises en ouvre simultanément ou non avec la fonction fourragère. Mais le plus souvent, plusieurs fonctions coexistent et on parle de plantes ou de cultures à usages multiples; quand la fonction est strictement alimentaire, pour les hommes et les animaux, on parle de plantes ou de cultures à deux fins.

\section{IID Alimentation humaine et animale : plantes à deux fins}

Beaucoup de plantes cultivées fournissent, outre la récolte principale dédiée à l'alimentation humaine ou à son emploi comme matière première industrielle, des sous-produits (ou coproduits) utilisés pour alimenter les animaux :

- soit les résidus de récolte (pailles de céréales, fanes et cosses de légumineuses); les surfaces de culture dédiées à ces plantes doivent être comptabilisées dans les surfaces fourragères;

- soit des sous-produits résultant des procédés de transformation, comme les sons de céréales, les tourteaux d'oléagineux, les graines de coton, les drèches de brasseries, la bagasse et la mélasse de canne à sucre, etc.

Certaines variétés de plantes alimentaires sont sélectionnées - parfois choisies par les agro-éleveurs - pour fournir des graines alimentaires et pour la bonne valeur fourragère de leur feuillage après la récolte. C'est pourquoi ces plantes figurent dans les listes des plantes fourragères. C'est le cas de beaucoup de variétés locales de niébé (Vigna unguiculata), d'arachide (Arachis hypogea) et dans une moindre mesure de dolique (Dolichos lablab, photo 3.1) en Afrique, en Inde et en Amérique du Sud. Les pois d'Angole (Cajanus cajan, photo 3.2) ont aussi cette double qualité, mais ils sont plutôt localisés en Inde et dans les îles du Pacifique. La sélection du sorgho intègre très souvent des critères de qualité comme la valeur alimentaire des feuilles et des tiges.

La culture de ces espèces est d'ailleurs bien maîtrisée par les producteurs de ces régions, contrairement aux espèces uniquement fourragères et encore peu connues des paysans comme Panicum, Pennisetum,

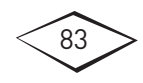



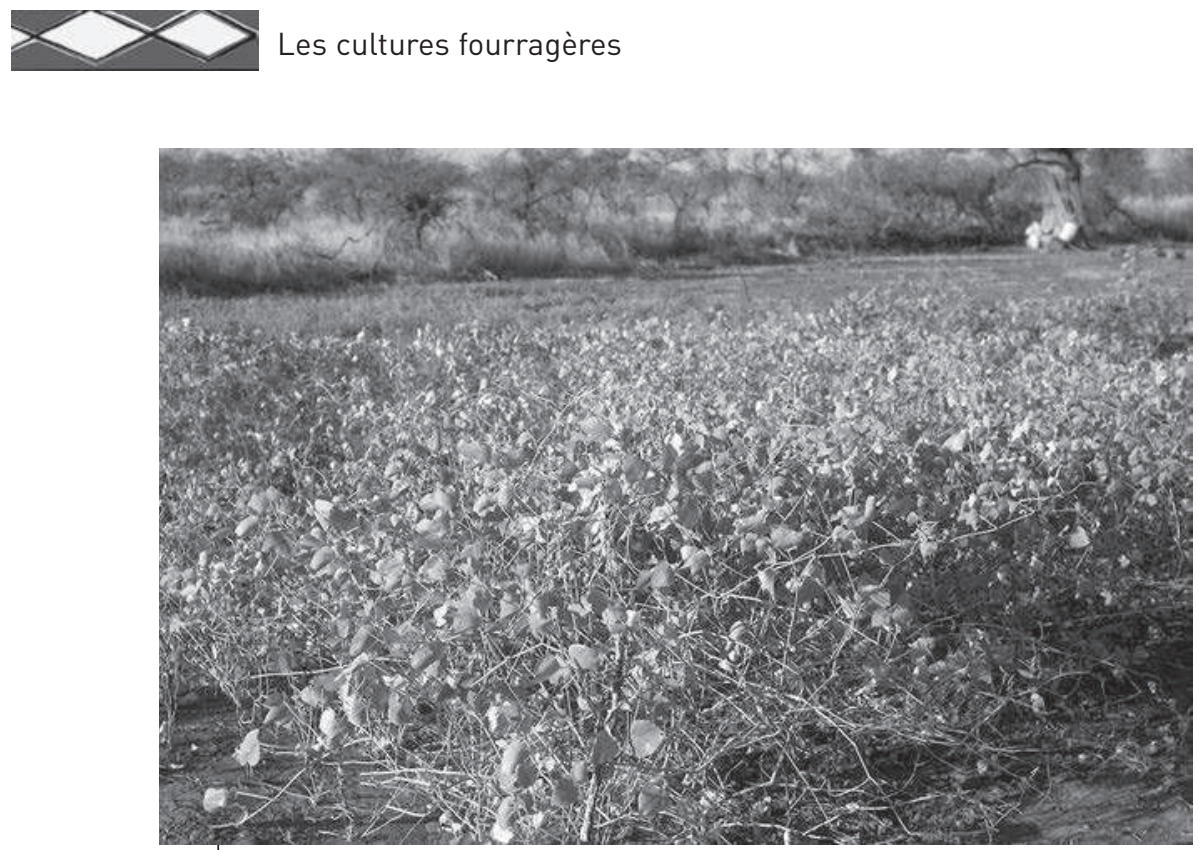

Photo 3.1.

Dolichos lablab (dolique), légumineuse à deux fins (fourragère et alimentaire) à Bané au sud de Tenkodogo, au centre du Burkina Faso. (@ H.D. Klein)

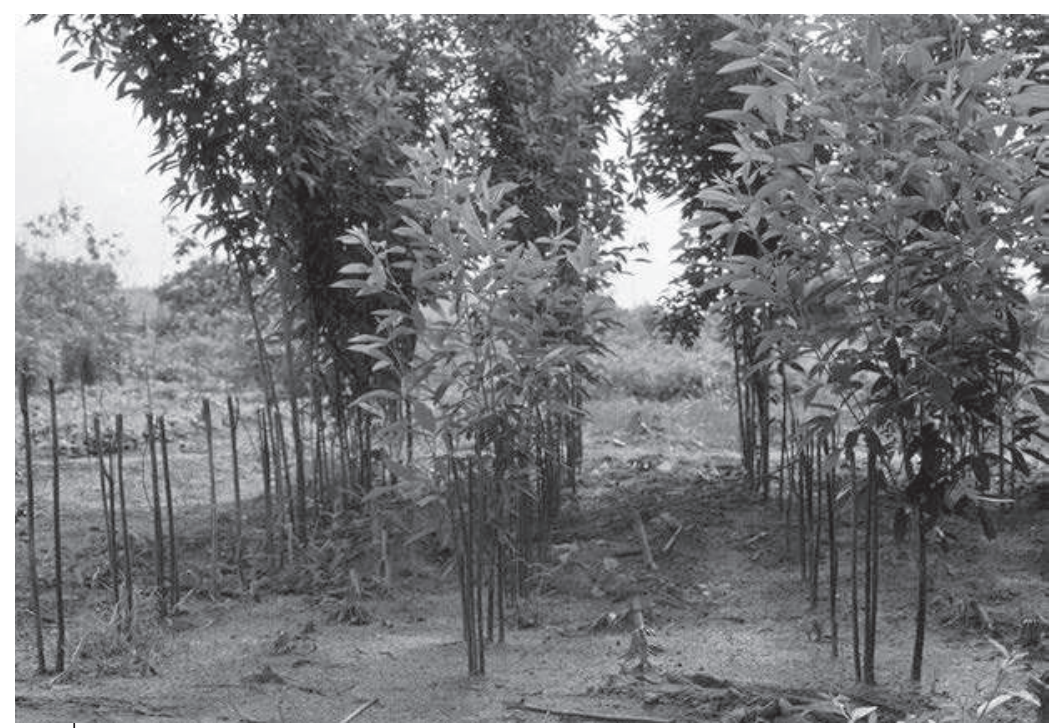

Photo 3.2.

Jachère améliorée de Cajanus cajan (pois d'Angole), légumineuse à deux fins, alimentaire et fourragère, implantés un an avant en dérobé et en intercalaire dans un champ de maïs à Touboro au Nord Cameroun. (๑ H. D. Klein)

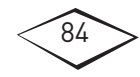


Andropogon, Stylosanthes, etc. Elles permettent très souvent aux éleveurs de s'initier à l'utilisation des plantes fourragères, avant le passage à la culture fourragère proprement dite. Toutefois, dans la plupart des pays tropicaux, les objectifs de sécurité alimentaire pour l'homme priment toujours par rapport à celui de la production fourragère.

\section{II) Effets agronomiques}

Les effets agronomiques qui peuvent être apportés par de nombreuses plantes fourragères en zones tropicales sont pour l'essentiel les qualités recherchées également pour les plantes de couverture : une protection contre l'érosion, une amélioration de la fertilité minérale, un enrichissement en matière organique, une amélioration de la capacité de rétention en eau et un contrôle des mauvaises herbes.

De fait, la plupart des plantes de couverture utilisées actuellement pour les cultures tropicales sont des plantes fourragères. C'est à la fois une qualité, car elles peuvent être à usage mixte (plantes fourragères et plantes de couverture), et un défaut, car elles peuvent être pâturées accidentellement.

\section{Protection contre l'érosion et contre le dessèchement}

Beaucoup de plantes fourragères herbacées, installées pour une longue période, développent un couvert végétal dense qui est généralement amélioré par les coupes ou les pâtures. Ce couvert végétal a un rôle protecteur contre les agents érosifs et la lumière directe, par divers effets :

- diminution de l'impact des gouttes de pluie sur le sol, réduisant ainsi le phénomène de battance;

- frein des écoulements superficiels de l'eau lors des pluies, réduisant ainsi l'érosion en nappe et améliorant la pénétration de l'eau dans le sol;

- constitution de la litière (débris de végétaux morts), réduisant ainsi les effets du vent, du ruissellement et de l'évaporation;

- protection de la surface du rayonnement direct du soleil donc de ses effets, car en pays tropical, la température ambiante accélère les réactions chimiques, notamment la nitrification et l'évaporation;

- réduction des écarts de température de surface entre le jour et la nuit et création d'un microclimat favorable aux activités biologiques.

Certaines espèces de graminées à port étalé couvrent bien le sol et supportent d'être coupées régulièrement. Elles sont choisies comme

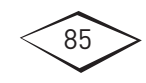


plantes couvre-sol, assurant une couverture de faible épaisseur et dense sur laquelle on peut marcher.

Les espèces utilisables à la fois comme plantes fourragères et comme couvre-sol sont les graminées Stenotaphrum dimidiatum, Paspalum vaginatum, Axonopus compressus, Pennisetum clandestinum (kikuyu), Cynodon dactylon (chiendent ou couch grass), Paspalum notatum, et des légumineuses rampantes à fort développement comme Desmodium uncinatum, Pueraria phaseoloides et Arachis pintoi. Ces plantes de couverture peuvent garder cependant une fonction fourragère pendant une partie de l'année.

\section{Effets sur la fertilité minérale}

Les cultures fourragères annuelles présentent généralement les mêmes inconvénients pour le sol que les autres plantes cultivées annuelles (effet du labour préjudiciable à l'activité biologique, exposition du sol nu à l'air et au soleil, affaiblissement de la fertilité par exportation de nutriments dans les récoltes), à moins qu'une part importante de la biomasse produite ne soit incorporée au sol après la culture.

La gestion de la fertilité du sol, telle qu'elle est souvent pratiquée dans les régions tropicales, est fondée uniquement sur la fertilisation minérale. Elle entraîne fréquemment une acidification des sols en l'absence de chaulage, une baisse rapide du taux de matière organique, voire même une toxicité aluminique. L'application de ce mode de gestion aux cultures fourragères peut induire les mêmes effets, à moins d'apporter des engrais riches en phosphore et en calcium comme les scories et les phosphates naturels, qui jouent également un rôle de chaulage.

Il existe cependant des modes d'utilisation des plantes fourragères qui tendent à restaurer une certaine fertilité au sol :

- les graminées fourragères exploitent intensément les horizons superficiels du sol et leur croissance est exigeante en nutriments, notamment en azote et en potassium. Lorsque le fourrage est récolté sans restitution (foin, ensilage), les nutriments contenus dans la récolte sont exportés et doivent être restitués par des apports d'engrais organiques (fumier, compost) ou minéraux;

- en conduite de jachère avec certaines graminées et en l'absence d'utilisation fourragère, la fertilité initiale du sol peut être restaurée en quelques années. Divers mécanismes contribuent à cet effet de jachère. Certaines graminées comme Andropogon gayanus, Panicum maximum et Paspalum notatum parviennent aussi à mobiliser annuellement

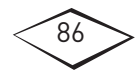


quelques kilos d'azote par hectare, grâce à la présence de rhizobactéries fixatrices d'azote dans l'environnement de leurs racines;

- les légumineuses fourragères peuvent améliorer le bilan azoté du sol grâce à la fixation symbiotique de l'azote atmosphérique. La quantité d'azote fixée varie beaucoup selon les conditions locales et peut représenter jusqu'à 20 ou $25 \mathrm{~kg}$ par hectare chaque année, parfois davantage. Cet enrichissement en azote provient de la matière organique des racines et des feuilles mortes recyclées dans le sol et du prélèvement en profondeur des nutriments vers les couches superficielles grâce à l'enracinement profond des légumineuses;

- les ligneux, par leur enracinement à la fois superficiel et profond, ont une action mécanique et biologique importante sur le sol, complémentaire de celle du couvert herbacé. Beaucoup d'espèces ligneuses sont associées à des bactéries ou à des champignons symbiotiques qui permettent de mobiliser des nutriments tels que l'azote atmosphérique ou le phosphore peu assimilable du sol. Les racines profondes puisent des éléments chimiques qui se retrouvent dans la litière morte des feuilles sèches.

\section{Enrichissement en matière organique}

La structure du sol, résultant de l'agrégation de ses composants, détermine ses propriétés physiques. Le sol est un support pour les végétaux et un habitat pour tous les organismes qui y vivent. La matière organique joue un rôle essentiel dans la constitution des agrégats, dans la stabilité structurale, donc dans le maintien des propriétés physiques du sol, sa porosité (micro et macroporosité), l'aération, la capacité d'infiltration et la capacité de stockage de l'eau.

Lenrichissement en matière organique améliore la vie biologique du sol en permettant l'activité et la prolifération des vers de terre, des arthropodes, des bactéries et même des termites. La faune du sol effectue un véritable travail mécanique, en le remuant et en l'aérant, et participe à la minéralisation de cette matière organique et à son humification. Le retournement d'une vieille prairie donne un sol fertile, apte à être cultivé, qui bénéficie de l'enrichissement organique obtenu peu à peu par la prairie et de l'enfouissement des restes de plantes fourragères, principalement de leurs racines.

La biomasse provenant des résidus de récolte ou d'une culture à base de plantes fourragères (engrais vert) peut être soit enfouie pour accélérer les processus d'humification et enrichir le sol en matière organique, soit laissée en surface pour former une couverture permanente du sol. Ces

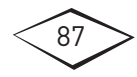


techniques utilisées dans les zones tropicales permettent d'améliorer le taux de matière organique. Les refus laissés par les animaux alimentés en stabulation contribuent également à la composition des fumiers.

\section{Effets sur la capacité de rétention en eau}

De nombreux facteurs induits par les plantes de couverture et les plantes fourragères, améliorent le bilan hydrique :

- amélioration de l'infiltration à la suite de la diminution du ruissellement au moment des pluies;

- augmentation de la réserve utile par leur contribution à la structure du sol et à l'enrichissement en matière organique;

- rétention de l'eau par la création en surface d'un microclimat ombragé, d'une baisse de la température de surface et une diminution des déplacements d'air.

Les arbres utilisent beaucoup d'eau et sont donc de forts compétiteurs pour les plantes herbacées. C'est pourquoi certains éleveurs (par exemple, en Australie, en Amérique centrale et en Amérique du Sud) préfèrent éliminer les arbres de leurs prairies pour favoriser la production de l'herbe; mais cette pratique, peu soucieuse de l'impact environnemental, présente très souvent plus d'inconvénients que d'avantages.

Le maintien d'un nombre limité d'arbres isolés dans les parcelles (20 à 40 arbres/ha) limite l'érosion hydrique, car leur présence réduit localement l'impact des gouttes de pluie et participe au maintien de la fertilité des sols. Au moment du défrichement, il est donc important de conserver des arbres qui concurrencent le moins les cultures (par exemple, Faidherbia albida en Afrique sèche) et des arbres à usages multiples notamment fruitiers et médicinaux.

\section{Aide au contrôle des mauvaises herbes dans les terres de culture}

En Afrique tropicale, dans le contexte actuel de durée de jachère de plus en plus courte, les cultures sont envahies par des adventices herbacées et subligneuses. Cette tendance devient préoccupante, car faute de traitements adéquats, cet envahissement est de plus en plus une cause d'abandon de ces parcelles. En semant en intercalaire des plantes de couverture, on empêche la germination des mauvaises herbes par l'ombrage créé, ou par un phénomène de répulsion chimique au niveau du sol (allélopathie).

Généralement implantées en association aux cultures vivrières ou industrielles, les plantes de couverture doivent être de port bas ou étalé et moins consommatrices d'eau et de nutriments que les mauvaises

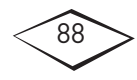


herbes pour ne pas entrer en concurrence avec la culture; on les choisit en général pour qu'elles servent de fourrage après la récolte des cultures principales ou pour qu'elles enrichissent le sol en azote. On les utilise en particulier dans les techniques de culture sans labour (semis sous couvert végétal), très pratiquées en Amérique tropicale. Elles doivent être faciles à détruire par voie chimique, afin qu'elles ne deviennent pas elles-mêmes des «pestes végétales». Les plus courantes sont les légumineuses Stylosanthes guianensis, Stylosanthes hamata, Mucuna spp., Arachis pintoi, et des graminées, essentiellement des céréales à double usage, et Cynodon dactylon, Brachiaria ruziziensis, etc.

En régions humides dans certaines plantations de cocotiers et de palmiers à huile d'Asie, d'Océanie et d'Afrique, des graminées basses ou des légumineuses ont été plantées ou semées après la plantation des jeunes arbres pour couvrir rapidement le sol et empêcher les mauvaises herbes de s'installer. Ce sont en général des légumineuses lianescentes comme Centrosema pubescens, Pueraria phaseoloides, Calopogonium mucunoides, Arachis pintoi. Elles protègent aussi la surface du sol des rayons solaires directs, de l'évaporation, des agents érosifs et procurent au sol de l'azote et de la matière organique. En fin de cycle, elles sont pâturées par les animaux qui contribuent au nettoyage des plantations.

\section{Effets sur l'environnement global et la biodiversité}

\section{Risques de dissémination des plantes envahissantes}

Des introductions anciennes de plantes pour des objectifs fourragers ont amélioré les ressources fourragères, mais aussi importé des espèces qui envahissent les cultures, déstabilisent l'équilibre entre les espèces de l'écosystème et menacent la survie d'espèces autochtones. Les dommages causés par ces plantes sont très pénalisants et coûteux, surtout pour les agriculteurs.

De très nombreux exemples peuvent être cités :

- Panicum maximum (herbe de Guinée), dans des champs du centre de la Côte d'Ivoire;

- Pennisetum clandestinum (kikuyu), devenu adventice des cultures dans certains pays, par exemple en Nouvelle-Zélande;

- Paspalum dilatatum, disgracieuse adventice des gazons en pays chauds;

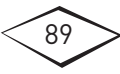


- Leucaena leucocephala (leucène), très envahissant dans certains archipels du Pacifique;

- Mimosa pudica (petite sensitive), envahissant les prairies de l'Amérique tropicale et des archipels du Pacifique.

Létude de la répartition dans l'espace et de la progression dans les milieux naturels des principales espèces envahissantes permet d'apprécier dans quelle mesure les activités d'élevage sont compatibles avec la préservation de la biodiversité. Les nouvelles introductions font l'objet d'une évaluation des risques avant d'être autorisées, par exemple en Australie. Par ailleurs, il arrive que les semences commerciales contiennent comme impuretés quelques graines d'autres espèces, ce qui est souvent sans conséquence.

\section{Rénovation de pâturages dégradés}

Dans les régions tropicales subhumides et humides, les prairies semées ou implantées sont toutes menacées par l'embroussaillement, soit par des espèces ligneuses natives (recrû forestier), soit par des espèces exotiques envahissantes, telles que Chromolaena odorata en Afrique équatoriale (introduite comme plante de couverture dans les plantations d'hévéas), Psidium goyava dans les archipels du Pacifique, Lantana camara dans de nombreuses régions, la vigne maronne (Rubus spp.) à la Réunion, Mimosa pudica, Spermacoce verticillata en Guyane. Le remplacement par une nouvelle flore fourragère suffisamment compétitive, l'adoption de pratiques de conduite du bétail adaptées et éventuellement l'emploi d'autres modes d'entretien de la prairie (gyrobroyage, feu dirigé) permettent de réhabiliter des prairies dégradées.

Dans les régions arides, la dégradation du sol par surpâturage, avec tassement superficiel, et réduction des capacités de pénétration des eaux de pluies, entraîne le dépérissement des arbres, puis la disparition du tapis herbacé. De tels exemples abondent au Sahel, notamment dans les environs des mares et des points d'eau très fréquentés. La rénovation des pâturages dégradés consiste souvent à réintroduire des espèces ligneuses fourragères. Citons par exemple la plantation d'espèces d'arbrisseaux de steppe, natives ou introduites, telles Atriplex nummularia ou Artemisia herba-alba, au Moyen-Orient, en Afrique du Nord et en Australie, ou d'arbustes Haloxylon aphyllum sur sols sodiques et Haloxylon persicum sur sols sableux en Asie centrale.

\section{Protection des berges et des cours d'eau}

Linstallation ou le maintien d'une végétation dense le long des canaux d'irrigation, des fossés de drainage naturels ou creusés, des rivières,

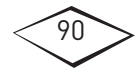


des fleuves et de tout axe où s'écoule l'eau, en continu ou de façon occasionnelle, stabilise le sol et retient les limons transportés des versants par le ruissellement superficiel. À défaut de la forêt galerie ou ripicole - végétation la plus souhaitable -, une large bande enherbée et/ou une haie jouent ce rôle.

De nombreux canaux d'irrigation ont été plantés en Brachiaria mutica pour stabiliser le sol et fournir occasionnellement du fourrage. En Asie tropicale, Leucaena leucocephala est parfois planté en bordure de terrasses irriguées; le feuillage est alors récolté pour enrichir l'alimentation des buffles utilisés comme animaux de trait.

\section{II) Usages et fonctions propres aux ligneux}

Comme nous l'avons vu, les ligneux offrent de multiples usages : bois de feu, bois d'œuvre (poutres, piquets, bois à sculpter), fruits comestibles, gousses pour tanner le cuir, colorants de teinturerie, graines oléagineuses ou riches en protéines, feuilles consommées en cuisine, médecine humaine et vétérinaire, etc. La gomme arabique exsudée par certaines espèces (Acacia senegal et Acacia seyal) fait aussi l'objet d'un commerce important et parfois de plantations commerciales.

\section{Fonctions écologiques}

Les arbres du bocage constituent une rupture brutale dans le paysage agricole et pâturé. Ils induisent des modifications micro-écologiques importantes dans lesquelles microclimat, sol et activités biologiques interagissent. L'effet brise-vent, la modification de l'évapotranspiration et l'ombrage sont les trois facteurs principaux de l'effet du bocage sur le microclimat.

En zones très arides le ralentissement de la vitesse du vent en saison chaude augmente les températures au niveau du sol. En revanche, la présence des arbres réduit les risques d'érosion, liés notamment aux vents violents de saison des pluies et aux vents érosifs de saison sèche. Piégées par les ligneux, les particules transportées par le vent enrichissent les sols qui reçoivent également les débris végétaux (feuilles, fleurs, fruits, bois).

Le microclimat créé par des arbres de grande taille apporte du confort au bétail : il n'est pas rare de voir les bovins ruminer à l'ombre aux heures chaudes, ou de se protéger des bourrasques auprès des haies. En Asie tropicale humide, Samanea saman, en

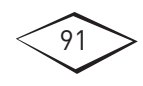


Afrique, Khaya senegalensis ou le baobab Adansonia digitata, ou en zones subarides Balanites aegyptiaca et Acacia raddiana, par leur taille et leur ombre, ou en Amérique latine Gliricidia et Erythrina, sont fréquents dans les pâturages.

Tous ces facteurs militent en faveur du maintien d'un couvert arboré d'au moins $5 \%$ de la surface agricole et pastorale.

\section{Marquage du foncier et gestion de l'espace}

Certaines plantes d'intérêt fourrager sont utilisées aussi pour affirmer l'usage du sol, dans les limites des coutumes locales. Par sa longévité, l'arbre est très souvent utilisé par certaines sociétés rurales pour marquer les limites de parcelles, de champs, de propriétés. Dans les régions d'élevage, ces arbres sont souvent fourragers. Par exemple, dans certaines régions sèches de l'Inde (Rajasthan) et en Amérique latine, des arbres sont préservés en bord de champs pour borner les parcelles, et leur feuillage est coupé régulièrement pour être distribué aux petits ruminants; le droit de plantation, la propriété de l'arbre et les droits d'usage du feuillage sont soigneusement définis. Mais les bords des champs peuvent être également bornés par des touffes de graminées pérennes comme Andropogon gayanus dans l'Ouest du Burkina Faso.

Des arbustes plantés à forte densité $(50 \mathrm{~cm}$ entre deux pieds) protègent les parcelles de la pénétration du bétail ou, inversement, permettent de contenir le bétail dans un espace clos. Clôturer les parcelles à l'aide d'arbres permet de délimiter la propriété foncière, de mieux gérer les pâturages et de limiter la divagation du bétail, donc de réduire les conflits. Des arbres et des buissons peuvent être utilisés pour créer ces clôtures, soit sous forme de piquets classiques (bois mort), soit sous forme de piquets vifs, soit sous forme de haies vives.

\section{Séquestration du carbone}

La réduction des émissions de gaz à effet de serre (GES) est un enjeu majeur de la lutte contre le réchauffement climatique; l'agriculture et l'élevage sont directement concernés. Trois gaz à effet de serre sont principalement produits par les activités agricoles : le méthane $\left(\mathrm{CH}_{4}\right)$, le protoxyde d'azote $\left(\mathrm{N}_{2} \mathrm{O}\right)$ et le dioxyde de carbone $\left(\mathrm{CO}_{2}\right)$. Selon les méthodes de calcul du Groupe d'experts intergouvernemental sur l'évolution du climat (GIEC-IPCC, $2007 \mathrm{a}$ et b) qui n'intègrent que

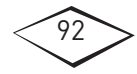


les émissions directement imputables au secteur agricole, celles-ci seraient responsables de $14 \%$ des émissions mondiales de gaz à effet de serre (GES), dont $31 \%$ seraient imputables au seul sous-secteur de l'élevage.

Deux types d'actions sont à envisager : diminuer le niveau des émissions de gaz à effet de serre et favoriser le transfert et le stockage de carbone dans des compartiments terrestres sous une forme stabilisée. À ce titre, les systèmes herbagers tropicaux apparaissent comme des puits de carbone potentiels très importants et jusqu'ici encore peu pris en compte.

\section{Carbone, plantes fourragères et élevage}

En première approche, les productions animales n'apparaissent pas comme un puits direct de carbone (C) et pourtant elles peuvent contribuer à son stockage notamment lorsque les systèmes de production utilisent des pâturages et des cultures fourragères avec un couvert de végétation permanent, pâturé ou récolté.

Laptitude des sols à séquestrer du carbone varie selon les régions écologiques (Sahel, Corne de l'Afrique, Amazonie, etc.), les modalités d'implantation d'un couvert fourrager (déforestation ou non, méthode de déboisement) et les modes de conduite des animaux en pâture (niveau de chargement, rythme de rotation, temps de passage). En plus des variations climatiques, les modifications de l'usage des terres et de l'itinéraire technique des systèmes agricoles induisent des variations du stock de carbone dans les sols. Ces variations sont dues à des processus biologiques comme la modification des apports de matière organique au sol, le transfert de carbone sous forme solide (récoltes, érosion) ou soluble (lixiviation et ruissellement), les pertes par minéralisation $\left(\mathrm{CO}_{2}, \mathrm{CH}_{4}\right)$ de la matière organique des sols et aux pratiques des éleveurs (labour des prairies, niveau d'utilisation, fertilisation...). La gestion des sols apparait ainsi comme un point clef du contrôle des stocks et flux de carbone.

Globalement les surfaces totales de pâturages permanents (3,5 milliards d'ha) se caractérisent par un stockage de carbone très important estimé à $30 \%$ du carbone des sols du monde. Relativement stable car souterrain, le potentiel de séquestration annuel (jusqu'à 0,3 milliard t/ an de carbone organique) pourrait compenser jusqu'à $4 \%$ des émissions globales de gaz à effet de serre. Les pâturages des régions chaudes représentent un pool de stockage de carbone de $326 \mathrm{Gt}$ soit 1,8 fois celui des prairies des zones tempérées.

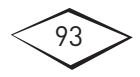


En zone tempérée, le stock de carbone immobilisé sous une prairie est en moyenne de $65 \mathrm{t} / \mathrm{ha}$ contre 40 sous une culture annuelle et 70 sous forêt. En plus de ce stock de carbone immobilisé, la prairie est capable de stocker du carbone supplémentaire provenant de l'écart entre les apports de carbone dans les sols (turnover des racines, des litières, déjections) et les émissions de $\mathrm{CO}_{2}$ liées à la respiration au niveau du sol et des animaux. À l'échelle de la parcelle, le bilan des gaz à effet de serre attribué aux prairies est en moyenne de $0,5 \mathrm{t} / \mathrm{ha} / \mathrm{an}$ dans les prairies permanentes, mais des résultats récents de recherches en Europe montrent qu'il peut atteindre $1 \mathrm{t}$ de carbone- $\mathrm{CO}_{2} / \mathrm{ha} / \mathrm{an}$.

Les zones tropicales humides ont des potentiels de stockage de carbone très élevés. La forêt amazonienne est l'écosystème qui stocke le plus de carbone avec plus de $100 \mathrm{t}$ dans les sols et une biomasse aérienne pouvant dépasser $350 \mathrm{t}$ dans certaines zones de Guyane (Blanfort et al., 2010). Certaines études montrent qu'après une chute brutale suite à la déforestation pour la mise en place de prairies, ces pertes peuvent en partie être compensées après mise en place d'un pâturage bien géré. Dans certaines conditions de gestion, les stocks de carbone dans le sol peuvent se reconstituer peu à peu pour égaler, voire dépasser, celles des sols forestiers après 88 ans.

Au-delà de l'effet de la déforestation et du changement du mode d'occupation des sols sur les pertes de carbone, les recherches en Amazonie montrent que les pâturages issus de déforestation peuvent sous certaines pratiques continuer à stocker du carbone dans le sol tout en fournissant une production fourragère importante (figure 3.6).

Des recherches en cours en Amazonie française visent à préciser ces processus en s'appuyant sur de nombreux sites de prairie indépendants, d'âges différents et de sites de forêt témoins. Les résultats montrent que les stocks en carbone du sol sous prairies augmentent pendant une vingtaine d'années après déforestation jusqu'à dépasser celui des forêts d'origine, surtout sur les vingt premiers centimètres de profondeur (de 0 à $20 \mathrm{~cm}$ ) : de 130 à 141 t/ha de carbone sous prairies de plus de trente ans, contre 80 à $112 \mathrm{t} / \mathrm{ha}$ de carbone dans les sols des forêts témoins (sols ferralitiques). Le mode de déforestation a un effet sur le stock en carbone du sol sous prairie. Ce carbone est majoritairement séquestré sous forme de matière organique dans le sol des prairies (litière et MO récalcitrante), alors que la forêt accumule le carbone majoritairement dans la biomasse végétale aérienne (150 et $250 \mathrm{t} /$ ha en Guyane).

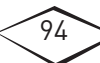




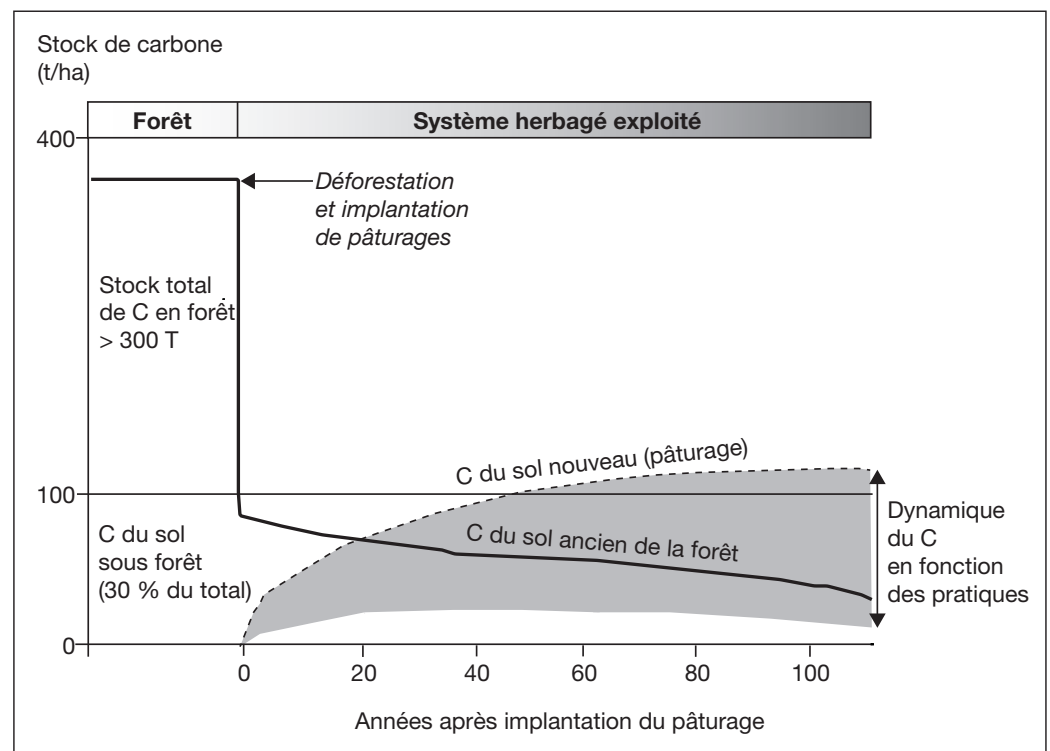

Figure 3.6.

Dynamique du carbone organique du sol (SOC) après déforestation et mise en place d'un pâturage. (@ Blanfort et al., 2010)

Sans cautionner la déforestation et ses conséquences très négatives sur la biodiversité et sur l'effet de serre, cela laisse augurer qu'une gestion plus durable des surfaces déforestées transformées en pâturage peut s'envisager. Lobjectif est alors la mise en place des systèmes herbagers capables d'assurer des productions fourragères et des services environnementaux.

Le carbone organique étant un des facteurs qui conditionne la fertilité des sols, une gestion des prairies favorisant le stockage net de carbone constitue un facteur de durabilité des terres déforestées. Ces résultats sont intéressants dans un contexte amazonien où la durabilité de la fertilité des sols après déforestation et donc des productions agricoles et de fourrages est très incertaine.

Fabrication des agrocarburants à partir des plantes fourragères

Un biocarburant est un produit issu de matériaux organiques renouvelables, non fossiles, provenant de la biomasse végétale naturelle ou cultivée. S'il provient de biomasse cultivée, il est appelé agrocarburant. Il existe actuellement deux filières principales de traitement de la

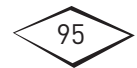


biomasse : la filière huile et dérivés (biodiesel); la filière alcool à partir d'amidon, de cellulose ou de lignine hydrolysés.

On distingue trois générations de bio- ou agrocarburants. Ceux de première génération sont issus de produits alimentaires, d'espèces végétales oléifères comme le palmier à huile, le tournesol ou le colza ou de plantes «à sucre» comme la canne à sucre, la betterave sucrière, le maïs, le sorgho et le blé. Ils sont utilisés pour être transformés en alcool via un processus de fermentation des sucres. Ils n'utilisent généralement pas de plantes fourragères, sauf, de façon marginale, les espèces à deux fins (alimentaire et fourragère), comme la canne à sucre, le maïs et le sorgho.

Les biocarburants de deuxième génération proviennent d'une source ligno-cellulosique (herbe, bois, feuilles, pailles). Ils utilisent principalement Panicum virgatum et Miscanthus sacchariflorus. Des recherches sont actuellement en cours sur des espèces fourragères prairiales de zones tempérées, notamment les Lolium pérennes (projet Grassohol de l'Institute of Biological, Environmental and Rural Sciences, Royaume-Uni). Une hydrolyse enzymatique appliquée à la biomasse transforme les produits ligneux en sucres plus simples, qui sont ensuite fermentés pour donner de l'éthanol; dans la deuxième génération, la biomasse est transformée en gaz de synthèse, qui est lui-même transformé en gazole suivant le procédé Fischer-Tropsch (développé par l'Institut français des Pétroles pour la filière gaz : GtL : Gas to Liquid).

Les biocarburants de troisième génération sont encore en cours d'étude. Ils proviennent principalement des algues et des microorganismes qui produisent de l'hydrogène sous l'effet de la lumière et de contraintes chimiques.

Les biocarburants ou agrocarburants de deuxième génération produits à partir de fourrages peuvent entrer en concurrence avec les ressources fourragères. À terme, le développement des cultures dédiées aux seuls biocarburants pourrait faire resurgir des conflits d'usage avec l'élevage. Lautre danger potentiel porte sur la fertilité des sols, qui risque de diminuer si tous les résidus, qui jusqu'ici enrichissent la terre, sont récupérés pour la production des biocarburants. Enfin, les espèces utilisées pour ces biocarburants étant déjà très résistantes aux herbicides, leur dissémination pourrait en faire des espèces invasives difficilement contrôlables. 


\section{La diversité des systèmes de production}

Le chef d'exploitation doit inscrire son projet fourrager dans un projet global d'élevage, en tenant compte du milieu agroclimatique et plus encore du système d'élevage, qui déterminera les niveaux d'intensification. Il devra définir les caractéristiques techniques et socio-économiques de systèmes fourragers adaptés aux besoins du troupeau dans son ensemble ou à ceux de lots spécifiques d'animaux, et à la gestion globale de son exploitation souvent pluriactive.

\section{Les systèmes fourragers dans les systèmes d'alimentation}

Voici quelques exemples de systèmes fourragers en fonction des objectifs de l'élevage :

- la production de fourrages de qualité pour affourager avec régularité des vaches laitières;

- la mise en place et la gestion de prairies pour l'engraissement de bovins destinés à la production de viande;

- la culture de fourrages pour assurer un complément dans l'alimentation de bœufs de trait en période de travail;

- la constitution de réserves pour la période de faible production fourragère;

- la mise en place de prairies permanentes gérées en rotation pour alimenter un élevage naisseur.

Pour concevoir de tels systèmes, il faut d'abord prévoir les productions en quantité et en qualité de diverses catégories de fourrages présents ou adaptables aux conditions des exploitations, puis comparer les productions de fourrage aux besoins des animaux en matière sèche, énergie, azote, prévoir les besoins en intrants pour la culture fourragère, et élaborer un calendrier fourrager par saison pour tenir compte des rythmes de production et des utilisations.

L'éleveur doit donc anticiper et évaluer les besoins des animaux et se fixer un objectif global de production fourragère pour les saisons

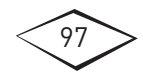


successives et même les années suivantes. Il doit faire appel à des innovations tant en termes de gestion des ressources que de nouvelles productions.

De nombreuses introductions expérimentales de fourrages, réalisées en station ou dans des terroirs très encadrés avec les moyens de projets temporaires, se sont révélées techniquement efficaces et prometteuses. Pourtant, les résultats de leur diffusion sont variables et les cultures n'ont pas toujours survécu aux projets qui ont permis leur introduction. Ce fut notamment le cas en Afrique subsaharienne, quand les paysans n'ont pas été associés au choix des espèces et lorsque les modes de cultures se sont révélés trop exigeants en temps de travail et en intrants dans le contexte technico-économique des exploitations.

Les cultures fourragères qui s'implantent durablement en milieu rural sont celles qui satisfont aux projets des producteurs notamment sur les plans zootechniques et de la gestion de la fertilité des sols. C'est par exemple le cas pour la production laitière dans certaines régions d'altitude d'Afrique de l'Est, ou encore pour le ranching ou les élevages mixtes latino-américains. Ces conditions techniques et économiques sont analysées et présentées chapitre 7 .

\section{Comment ajuster l'offre fourragère et les besoins des animaux?}

D’une façon générale, les ressources fourragères varient selon les saisons. Les écarts saisonniers sont particulièrement accentués en régions tropicales arides et semi-arides. En saison des pluies, les ressources sont abondantes avec des valeurs fourragères moyennes (du fait des fortes croissances) à bonnes, si elles sont utilisées à un stade précoce. En saison sèche, les ressources agropastorales sont réduites et de moindre qualité; de plus elles sont variables d'une année à l'autre en fonction des aléas climatiques. Notons qu'en zones équatoriales ou subéquatoriales, la saison sèche est très réduite, voire inexistante.

Pour atténuer les écarts importants entre l'offre fourragère et les besoins des animaux, les éleveurs utilisent différentes stratégies (savoirfaire et techniques) selon les saisons, les climats, les performances attendues des troupeaux et les systèmes de production.

Ces stratégies (Lhoste et al., 1993) ont été reportées sur la figure 4.1.

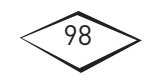




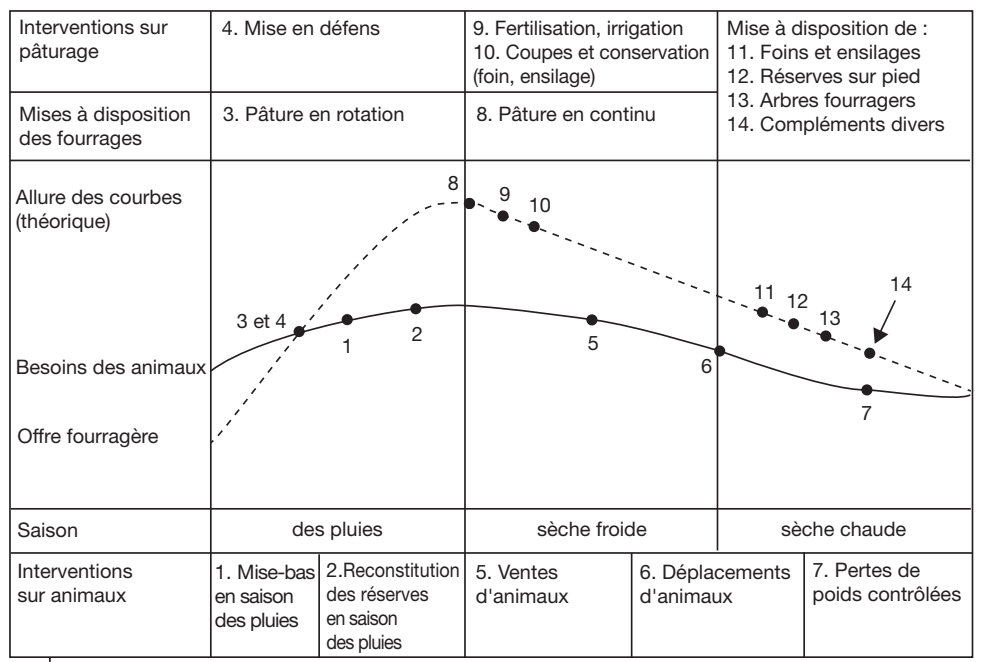

Figure 4.1.

Allures théoriques des courbes permettant de prévoir l'ajustement des besoins des animaux aux ressources végétales de leur territoire. (d'après Lhoste et al., 1993)

En saison des pluies les éleveurs peuvent :

- faire coïncider les périodes de grands besoins aux périodes de fortes productions, en déplaçant la saison de mise-bas (période de forte demande) en saison des pluies;

- favoriser la reconstitution des réserves de l'animal pendant cette période favorable;

- mieux répartir la production fourragère au cours de l'année par l'introduction de rotations, la pratique du déprimage, les mises en défens temporaires;

- mettre en défens pendant toute la saison des pluies pour reporter la production fourragère de la période excédentaire (saison des pluies) à la période déficitaire (saison sèche), sous forme de réserves (foin, ensilage, report sur pied).

En saison sèche les éleveurs peuvent :

- diminuer la demande en vendant des animaux avant qu'ils ne perdent du poids;

- diminuer la demande en déplaçant les animaux vers des zones plus favorables;

- tirer parti des possibilités de l'animal à mobiliser ses réserves corporelles en le laissant perdre du poids, mais sans excès;

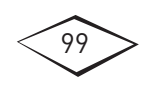




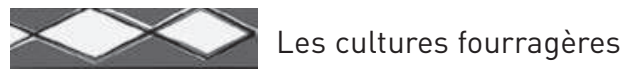

- pâturer en continu, parcelle après parcelle pour réduire au maximum les refus;

- augmenter la production végétale en fertilisant, en irriguant ou en utilisant des plantes fourragères plus productives;

- augmenter la quantité de fourrage consommable en récoltant du fourrage sous forme de foin ou d'ensilage;

- distribuer le foin ou l'ensilage en deuxième moitié de saison sèche;

- faire pâturer le fourrage conservé sur pied dans les parcelles mises en défens pendant une grande partie de l'année;

- augmenter la production végétale en introduisant des ligneux dans les parcours ou dans les zones cultivées;

- faire appel à des compléments alimentaires très souvent produits à l'extérieur et achetés.

\section{II Élaborer un système fourrager}

Le projet zootechnique, à l'origine de tout projet fourrager, est calibré suivant :

- les besoins des animaux correspondant aux objectifs de la production animale;

- les productions fourragères annuelles et saisonnières et leur potentiel d'intensification;

- la recherche d'un équilibre entre les besoins des animaux et le potentiel fourrager;

- le système global d'exploitation, y compris les productions agricoles vivrières d'autoconsommation ou commerciales (maraîchage, arboriculture fruitière, etc.).

Des questions complémentaires ne tardent pas à se poser : l'exploitant dispose-t-il des surfaces nécessaires pour cette culture fourragère? Les distances des parcelles à l'exploitation sont-elles compatibles avec l'objectif? Quel matériel et quelle main-d'œuvre faudra-t-il mobiliser? La mise en œuvre d'une culture fourragère est-elle économiquement justifiée?

Il faut aussi prendre en compte les fonctions non fourragères comme l'impact sur la fertilité des sols, la fourniture d'énergie, l'amélioration du paysage, pour conforter les arguments d'une amélioration fourragère, mais aussi pour orienter le choix des espèces utilisées.

La compréhension globale des systèmes d'alimentation est un préalable au diagnostic quantitatif des ressources en termes de productivité,

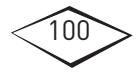


de disponibilité saisonnière et de valeur fourragère. Pour obtenir une analyse plus fine, proche d'un bilan fourrager, il faut évaluer quantitativement par année et par saison :

- les plantes herbacées des parcours sylvopastoraux, des jachères, des espaces résiduels dont les bas-fonds, de plus en plus occupés par du maraîchage, donc devenus inaccessibles au bétail;

- les sous-produits de récolte, tels que pailles de céréales, fanes de légumineuses, tiges de coton;

- les adventices herbacées;

- les arbres et arbustes des parcours sylvopastoraux et des espaces cultivés, y compris les recrus annuels.

Pour cela on doit faire appel à des données très rarement estimées ou mesurées, ce qui rend l'évaluation très imprécise, sauf pour des situations extrêmes d'excédent ou de disette. Il est donc souvent plus facile de rechercher les facteurs limitants et de s'efforcer de les corriger. Les indicateurs des contraintes à rechercher sont :

- pour les ressources alimentaires, les savoirs locaux sur l'état des couverts végétaux, les charges, les espaces disponibles;

- pour les animaux, leur comportement sur les parcours, leur production (le lait), leur état corporel et sanitaire, et la mortalité des jeunes.

Dans certains systèmes très intensifs, il est parfois possible d'approcher un véritable bilan fourrager quantitatif et qualitatif. Chacune des ressources en fourrage est évaluée par sa productivité, sa répartition au cours de l'année et la qualité du fourrage. Pour chaque pâturage, sont estimés la capacité de charge animale et le rythme optimal d'exploitation. Les ressources fourragères sont alors caractérisées par les productions de matière sèche, d'unités fourragères et de matières azotées et les équilibres entre ces caractères en quantités effectivement disponibles pour chaque groupe d'animaux, et en qualités nutritionnelles.

La priorité est donnée aux besoins alimentaires et à la faisabilité technique et économique des différentes options de cultures fourragères. La taille du projet fourrager et le niveau d'intensification requis pour atteindre les objectifs de production seront déterminés d'après le projet zootechnique et la faisabilité technico-socio-économique de la production fourragère. À cette étape, l'éleveur est au seuil d'un processus d'intensification. Le choix du niveau technique s'appuiera sur des prévisions de production simulées dans la région ou un contexte analogue et sur une analyse économique intégrant les risques techniques et commerciaux.

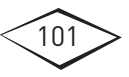


À ce niveau global de compréhension des systèmes fourragers, d'élevage et de production, des modifications techniques du système fourrager (changement d'espèces, intensification, etc.) et des introductions de plantes adaptées à chaque type de parcelle et aux besoins spécifiques des troupeaux peuvent être décidées.

\section{ID Comment élaborer un calendrier fourrager}

Le calendrier fourrager décrit la succession et la combinaison des ressources produites et leur emploi par le cheptel. Il est fractionné en saisons, ou en périodes plus courtes. Il décrit les reports d'utilisation des fourrages conservés. Les animaux sont considérés par catégorie homogène selon les besoins : classe d'âge, stade physiologique, production, état corporel visé. Létat corporel optimum n'est pas systématiquement recherché sous les tropiques, la mobilisation et la reconstitution saisonnière des réserves corporelles faisant traditionnellement partie des pratiques de gestion.

Les éleveurs utilisent le plus souvent plusieurs types de ressources fourragères provenant des pâturages (naturels ou cultivés) et les éleveursagriculteurs utilisent également des terres cultivées. Ils essaient de tirer profit de toutes les ressources disponibles à un moment donné, variables selon les saisons et les années, et d'intégrer l'élevage à l'agriculture.

Le diagnostic des ressources disponibles à l'échelle de l'exploitation est donc la synthèse des bilans et des diagnostics établis pour chaque unité de ressources en tenant compte des gradients morphopédologiques, qui conditionnent les potentiels de production végétale, l'occupation des sols (cultures, etc.), les modalités d'accès aux ressources fourragères et leurs modes de gestion (vaine pâture, pâture contrôlée, coupe et transport, distribution et stockage).

Léleveur peut ajuster le fourrage disponible saisonnier en effectuant des récoltes et du stock et il peut influer sur la vitesse de croissance par la fertilisation, l'irrigation et, parfois, le déprimage. Ces informations, dont la précision dépend des données disponibles dans la région agroclimatique, de la complexité du système de production et de l'expérience de l'éleveur, permettent d'élaborer un calendrier fourrager.

Après avoir comparé les productions aux besoins des animaux et après avoir analysé les effets des déficits ou des excédents sur la végétation ou sur le cheptel, des solutions peuvent être proposées pour

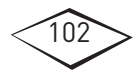


compenser les déséquilibres. Cette démarche constitue un premier niveau d'intensification. L'étape suivante consiste à augmenter et à améliorer les productions fourragères par unité de surface avec de nouvelles cultures fourragères. Cet objectif et les moyens pour l'atteindre doivent s'inscrire dans des projets d'élevage compatibles avec le fonctionnement global de l'exploitation et de sa place dans le territoire.

\section{Les systèmes fourragers dans l'exploitation}

\section{ID Les facteurs d'intégration d'un système fourrager dans une exploitation laitière}

L'éleveur ou l'agro-éleveur qui a l'ambition, par exemple, de créer un élevage laitier valorisant des fourrages cultivés en zone de savane subhumide en Afrique de l'Ouest doit, en préalable à l'analyse de faisabilité technique, analyser le contexte socio-économique de son exploitation. Il doit notamment vérifier l'existence d'un débouché commercial pour les produits animaux, le statut foncier des parcelles qu'il veut mettre en valeur, sa capacité d'investissement en équipements et intrants, la main-d'œuvre mobilisable pour de nouvelles activités. Le niveau d'intensification dépendra des besoins en fourrage, des potentiels agronomiques et de la comparaison des coûts et des bénéfices des diverses options.

\section{Opportunités commerciales et financières}

L'exemple analysé est celui d'une exploitation d'élevage laitier en zone subhumide au Burkina Faso.

Sur le plan du marché, le village est doté d'une mini-laiterie qui approvisionne la ville voisine. Le prix du lait payé aux éleveurs est soumis à la concurrence du lait des éleveurs transhumants, en particulier en saison des pluies. Il est aussi soumis à des normes de qualité qui augmentent sous la pression de la concurrence des produits laitiers transformés importés.

Toutefois, le projet a pour objectif de produire du lait toute l'année grâce à un contrat d'approvisionnement et à des prix négociés entre l'organisation des éleveurs et la filière de commercialisation. Il faut donc assurer au cheptel une alimentation assez régulière sur les plans quantitatif et qualitatif.

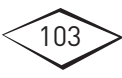




\section{Sécurité foncière pour l'accès aux ressources agrosylvopastorales}

Mettre en place des parcelles de fourrage cultivé suppose une sécurité foncière sur plusieurs années et un contrôle de la production fourragère toute l'année. Léleveur doit pouvoir exploiter son terrain en toute sécurité, c'est-à-dire avoir un droit sur son terrain (public, communautaire ou privé) pour cultiver et exploiter sans perturbations.

Sur le plan foncier, les parcelles d'une exploitation peuvent avoir des statuts différents et donc des opportunités d'aménagement différentes. Ainsi, l'exploitant peut être :

- propriétaire d'une parcelle (il s'agit le plus souvent de règles d'usage, par exemple un droit d'usage exclusif sur des terres qui appartiennent à l'État ou à la communauté), ce qui permet d'envisager des investissements en irrigation (en zone irrigable) et l'implantation de plantes pérennes;

- utilisateur de ses champs de proximité, dénommés parfois «champs de case», pouvant accueillir des aménagements agroforestiers et des améliorations fourragères sur des bordures de parcelles et éventuellement sur des parcelles entières;

- attributaire par le chef de terre de parcelles éloignées. En général, le droit d'exploitation est limité à des cultures annuelles. Toutefois un chef de terre ou une communauté d'agro-éleveurs peut, le plus souvent sous l'impulsion de projets, envisager des actions d'aménagement du foncier par des arbres, des haies et plus rarement par des cultures fourragères;

- simple co-utilisateur des parcours avec d'autres agro-éleveurs, soumis parfois à la concurrence des troupeaux transhumants. Dans le meilleur des cas, la communauté des utilisateurs adopte une gestion des parcours raisonnée collectivement telle que la mise en défens, l'exploitation patrimoniale des arbres, etc., mais sans améliorations avec des plantes fourragères; c'est le cas des systèmes agropastoraux de la région du Fouta-Djalon en Guinée.

\section{Capacité à mobiliser de la main-d'œuvre}

En système de cultures pluviales, l'organisation du travail est très saisonnière, avec des périodes de tension forte sur la main-d'œuvre familiale en saison des pluies. Linstallation et la gestion des cultures fourragères, herbacées ou arbustives, coïncident souvent avec ces périodes. Il est donc nécessaire d'évaluer la capacité de travail des exploitations, qui constitue souvent un frein à l'extension des cultures fourragères.

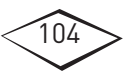


Pour simplifier la démarche, on considérera qu'à proximité d'une ville, qui constitue un réservoir de main-d'œuvre et favorise l'accès à un marché, la force de travail familial peut être complétée par de l'emploi salarié selon les capacités financières des éleveurs. Cette analyse prévisionnelle doit être faite à l'échelle de toutes les activités de l'exploitation sur les plans de l'organisation du travail, des charges et des recettes, afin d'aboutir à un équilibre technique et économique.

\section{Arbitrage entre les productions fourragères et animales et d'autres productions}

Quelle que soit l'opportunité commerciale à l'origine d'un investissement fourrager, elle doit être mise en balance avec d'autres spéculations comme le maraîchage ou la production fruitière.

\section{ID Les niveaux d'intensification}

Pour chaque niveau d'intensification de la production fourragère, on détermine les principales caractéristiques, les charges et la productivité; à chaque niveau correspondent les plantes et les modes de production adaptés, ainsi que des technologies et des équipements. En schématisant, Guy Roberge (1988) a distingué cinq niveaux d'intensification des cultures fourragères (tableau 4.1) :

- niveau 0. Savanes naturelles et élevages traditionnels, sans aucune intensification;

- niveau 1. Amélioration du pâturage naturel par l'introduction d'espèces fourragères améliorantes sur une petite proportion des surfaces (plantes herbacées ou ligneuses), avec ou sans travail du sol (sursemis); - niveau 2. Culture fourragère proprement dite avec de faibles niveaux d'intrants; le travail du sol avec de faibles moyens (manuel ou culture attelée), le semis ou le bouturage, pas ou peu de fertilisation;

- niveau 3 (variante du niveau 2). Culture fourragère, avec des intrants plus importants : travail mécanisé, semis ou bouturage, fertilisation élevée, travaux d'entretien;

- niveau 4. Au niveau 3 est ajoutée la maîtrise de l'eau (irrigation), facteur de production très important en milieu tropical sec.

\section{ID Les limites à l'intensification}

Le processus d'intensification repose sur l'amélioration du rendement des facteurs limitants du système considéré; il ne faut pas considérer seulement l'efficience à l'unité de surface. Par exemple, un élevage

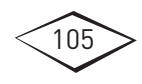


Tableau 4.1. Cinq niveaux d'intensification associés à des caractéristiques techniques, des chargements et des productions végétales. (d'après Roberge, 1988)

\begin{tabular}{|c|c|c|c|}
\hline $\begin{array}{l}\text { Niveaux } \\
\text { intensification } \\
\text { Systèmes d'élevage }\end{array}$ & $\begin{array}{l}\text { Caractéristiques } \\
\text { techniques }\end{array}$ & $\begin{array}{l}\text { Charge } \\
\text { et production }\end{array}$ & $\begin{array}{l}\text { Exemples } \\
\text { de fourrages } \\
\text { Types d'exploitation }\end{array}$ \\
\hline $\begin{array}{l}\mathbf{0} \\
\text { Extensif pur } \\
\text { Investissements } \\
\text { très faibles } \\
\text { Systèmes pastoraux }\end{array}$ & $\begin{array}{l}\text { Équilibre naturel } \\
\text { Animal/pâturage/ } \\
\text { homme }\end{array}$ & $\begin{array}{l}0,1 \text { à } 0,4 \mathrm{UBT} / \mathrm{ha} / \mathrm{an} \\
0 \text { à } 2 \mathrm{t} \mathrm{MS} / \mathrm{ha} / \mathrm{an}\end{array}$ & $\begin{array}{l}\text { Savanes naturelles } \\
\text { Élevages } \\
\text { traditionnels : } \\
\text { sahélien, soudanien }\end{array}$ \\
\hline $\begin{array}{l}1 \\
\text { Semi-extensif } \\
\text { Investissements } \\
\text { faibles } \\
\text { Systèmes pastoraux } \\
\text { et prairiaux }\end{array}$ & $\begin{array}{l}\text { Facteurs légers } \\
\text { préexistants : gestion } \\
\text { des parcours et des } \\
\text { animaux, contrôle } \\
\text { des feux, actions sur } \\
\text { les animaux }\end{array}$ & $\begin{array}{l}1 \text { à } 2 \mathrm{UBT} / \mathrm{ha} / \mathrm{an} \\
1 \text { à } 3 \mathrm{t} \mathrm{MS/ha/an}\end{array}$ & $\begin{array}{l}\text { Savanes naturelles } \\
\text { aménagées } \\
\text { Ranching en zones } \\
\text { sèches }\end{array}$ \\
\hline $\begin{array}{l}2 \\
\text { Semi intensif } \\
\text { Investissements } \\
\text { moyens } \\
\text { Systèmes pastoraux }\end{array}$ & $\begin{array}{l}\text { Facteurs externes } \\
\text { légers : travail léger } \\
\text { du sol, } \\
\text { enrichissement } \\
\text { (flore introduite), } \\
\text { pas de fertilisation, } \\
\text { feux et ligneux } \\
\text { contrôlés }\end{array}$ & $\begin{array}{l}1 \text { à } 2 \mathrm{UBT} / \mathrm{ha} / \mathrm{an} \\
2 \text { à } 5 \mathrm{t} \mathrm{MS} / \mathrm{ha} / \mathrm{an}\end{array}$ & $\begin{array}{l}\text { Savanes améliorées } \\
\text { Ranching en zones } \\
\text { humides }\end{array}$ \\
\hline $\begin{array}{l}3 \\
\text { Intensif } \\
\text { Investissements } \\
\text { forts } \\
\text { Systèmes } \\
\text { agropastoraux } \\
\text { Systèmes mixtes } \\
\text { Polyculture-élevage }\end{array}$ & $\begin{array}{l}\text { Facteurs externes } \\
\text { plus importants : } \\
\text { cultures fourragères } \\
\text { fertilisation, } \\
\text { plantes introduites } \\
\text { sélectionnées, } \\
\text { entretien des } \\
\text { pâturages } \\
\text { (gyrobroyage), } \\
\text { élimination des refus } \\
\text { et des ligneux }\end{array}$ & $\begin{array}{l}2 \text { à } 4 \mathrm{UBT} / \mathrm{ha} / \mathrm{an} \\
10 \text { à } 15 \mathrm{t} \mathrm{MS/ha/an} \\
5 \text { à } 10 \mathrm{t} \mathrm{MS/ha/an}\end{array}$ & $\begin{array}{l}\text { Cultures fourragères : } \\
\text { Graminées } \\
\text { Légumineuses } \\
\text { Associations } \\
\text { graminées et } \\
\text { légumineuses } \\
\text { Vergers fourragers }\end{array}$ \\
\hline $\begin{array}{l}4 \\
\text { Très intensif } \\
\text { Investissements } \\
\text { conséquents } \\
\text { Systèmes laitiers }\end{array}$ & $\begin{array}{l}\text { Maîtrise des facteurs } \\
\text { de production : } \\
\text { irrigation jusqu'à } \\
4 \text { mm par jour, } \\
\text { fertilisation jusqu'à } \\
500 \text { unités N/an, } \\
\text { plantes à hauts } \\
\text { rendements } \\
\text { coupées et } \\
\text { distribuées en vert, } \\
\text { gestion exigeante }\end{array}$ & $\begin{array}{l}>5 \mathrm{UBT} / \mathrm{ha} / \mathrm{an} \\
15 \text { à } 30 \mathrm{t} \mathrm{MS/ha/an}\end{array}$ & $\begin{array}{l}\text { Graminées (cannes) } \\
\text { de grandes tailles } \\
\text { Fermes intensifiées } \\
\text { irriguées }\end{array}$ \\
\hline
\end{tabular}

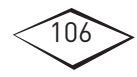


dont le pâturage supporte 3 têtes/ha est généralement considéré comme plus intensif que celui qui présente un chargement de 1 tête/ha; pourtant si le facteur limitant du premier élevage est le temps de travail, une charge plus faible lui conviendrait mieux.

En agronomie, la loi des facteurs limitant la fertilité du sol a été démontrée pour trois principaux nutriments des plantes, azote, phosphore, potasse. Le niveau de rendement est déterminé par la disponibilité en l'élément le plus faiblement pourvu. Il ne sert à rien d'apporter beaucoup d'azote si le phosphore est déficient. Laugmentation de la productivité souhaitée via des processus d'intensification est soumise à des règles comparables à celles des facteurs limitant, car elle relève de processus biologiques.

Lintensification est limitée par d'autres facteurs :

- le climat. Sous des précipitations de $500 \mathrm{~mm}$ sans irrigation, l'intensification est difficile et réduite, la production peut atteindre $3 \mathrm{t} \mathrm{MS} / \mathrm{ha}$, correspondant à un niveau 2 (tableau 4.1). Avec une pluviosité de $1000 \mathrm{~mm}$, la production peut atteindre 10 à $15 \mathrm{t} \mathrm{MS} / \mathrm{ha}$, soit un niveau 3 d'intensification, voire le niveau 4 avec 25 à $30 \mathrm{t} \mathrm{MS/ha.} \mathrm{Il} \mathrm{ne}$ faut cependant pas confondre productivité en valeur absolue et niveau d'intensification;

- l'accès aux technologies. Les possibilités d'accès aux matériels, aux sources d'énergie et de travail, aux ressources génétiques et aux semences, aux autres intrants (engrais), aux connaissances techniques et pratiques d'organisation et d'action influent sur le niveau d'intensification que peut atteindre un éleveur;

- le résultat économique. De l'adoption d'un niveau d'intensification dépendent les résultats économiques attendus, c'est-à-dire des dépenses et des profits. Le meilleur résultat économique n'est pas toujours lié à la plus forte intensification. On doit aussi s'assurer que le projet ne génère pas de conséquences défavorables (érosion, difficultés économiques, etc.).

Il ne faut jamais oublier que la production fourragère est une production «primaire» destinée, en élevage, à être transformée en lait, en viande ou en travail. Intensifier engendre des coûts plus élevés pour l'installation des plantes fourragères, puis en intrants, en matériel de récolte et d'entretien. C'est la valeur marchande des productions animales obtenues qui permet de financer et d'accentuer l'intensification. Cependant, l'objectif d'une production maximale déterminée par les potentiels génétiques des fourrages et du cheptel ne correspond pas forcément à l'optimum économique.

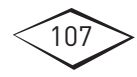




\section{Places et usages des cultures fourragères dans les systèmes d'élevage}

On se réfère aux quatre principaux systèmes d'élevage pratiqués dans le monde tropical : les systèmes pastoraux et agropastoraux, les systèmes prairiaux, les systèmes mixtes agriculture-élevage et de polyculture élevage, et les systèmes hors sol pour l'engraissement ou la production laitière.

\section{ID Dans les systèmes pastoraux et agropastoraux}

Les systèmes d'élevage pastoraux relèvent tous ou presque des systèmes extensifs. Dans ces conditions, l'éleveur tire parti à moindres coûts des ressources naturelles et compense la productivité relativement faible de son bétail par un nombre de têtes important. Les pasteurs ajustent l'offre fourragère aux besoins de leurs troupeaux en étant mobiles et en se déplaçant sur de vastes surfaces; ils font évoluer leur système de production en allongeant les transhumances et en se déplaçant de plus en plus en zones agricoles où les troupeaux exploitent les espaces naturels non cultivés, les jachères et les champs après les récoltes. Ils pratiquent alors un peu d'agriculture de subsistance, ce qui les amène à sédentariser une partie de la famille et à garder quelques animaux près de leur campement. Ils récoltent très souvent les résidus de culture (cannes de céréales, fanes de niébé et d'arachide), mais cultivent rarement des cultures fourragères.

Les pasteurs qui se mettent à cultiver évoluent vers les systèmes mixtes agriculture-élevage. On peut distinguer, en fonction des groupes ethniques : l'agropasteur, éleveur pour qui l'objectif principal est la production animale, même s'il cultive (agriculture de subsistance); l'agro-éleveur, agriculteur qui utilise la traction animale et/ou qui investit les revenus de l'agriculture dans l'achat de bétail.

Toutes les nuances existent entre le pastoralisme et l'agriculture et des transitions entre ces systèmes ont lieu dans les deux sens au gré des circonstances (prix et marché des produits, débouchés, conditions climatiques, évolutions foncières, etc.).

\section{Dans les systèmes prairiaux}

Les systèmes sur prairies ou systèmes herbagers reposent sur une alimentation essentiellement à base d'herbe, tantôt pâturée (le plus

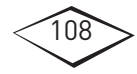


souvent), tantôt récoltée en période de surplus, conservée et distribuée en saison de repos végétatif et de déficit (figure 4.1). Les prairies ou herbages sont des végétations herbeuses naturelles ou cultivées (pâturages améliorés avec, par exemple, des Brachiaria), pâturées par des animaux.

L'exploitation se fait par pâture libre, dans des parcs, une grande partie de l'année, avec possibilité de faucher les surplus de production et de faire du foin, ou plus rarement de l'ensilage, sous forme de report pour la saison de repos végétatif. Dans certains systèmes herbagers, en zones d'altitude, de savanes herbeuses par exemple, les prairies naturelles composent l'essentiel des ressources fourragères, et les cultures fourragères au sens strict ne sont souvent qu'un appoint.

Les niveaux d'intensification, qui dépendent de l'importance des investissements consentis et du degré de maîtrise de la ressource fourragère, sont le plus souvent intermédiaires. Ces systèmes bénéficient de beaucoup d'espaces, et aussi d'investissements importants faits dans la durée. Les exploitations familiales spécialisées en élevage et les ranches relèvent souvent de ces systèmes à fort investissement. Ils sont présents surtout sur le continent sud-américain, en Australie, mais aussi en Afrique centrale, orientale et australe.

Dans les régions les plus humides, au-delà de 1800 à $2000 \mathrm{~mm}$ de pluie par an, la végétation naturelle, essentiellement ligneuse, n'est pas pâturable et les rancheros sont obligés d'implanter leurs prairies avec des plantes fourragères cultivées (par exemple en Amérique tropicale) qui doivent être réinstallées tous les quatre à cinq ans pour maintenir la ressource fourragère à un niveau de production acceptable.

En revanche, dans les zones plus sèches, où la pluviométrie est inférieure à $1800 \mathrm{~mm}$ de pluie par an, les pâturages naturels de type savane sont largement pâturés. Des prairies sont parfois implantées sur les meilleures terres pour améliorer la qualité et la régularité de la production d'herbe par rapport aux savanes naturelles. Des pâturages dégradés peuvent être également restaurés en introduisant des fourrages cultivés sur une partie de leur surface avec des modes d'exploitation proches de ceux de l'Australie (par exemple en Nouvelle-Calédonie).

Le maintien de la ressource fourragère dépend de la façon dont sont régulés les effectifs et les niveaux de charge animale pour éviter des processus de dégradation. L'organisation de ces chargements nécessite une sectorisation des zones de pâtures pour pouvoir effectuer

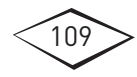


des rotations. Les animaux sont déplacés de parc en parc selon des logiques de rotation, en fonction de la vitesse de repousse de la végétation et des effets saisonniers. Sans recours à des intrants, la productivité de ces prairies se situe entre 7 et $14 \mathrm{t}$ MS/ha.

Les cultures d'herbe sous forme de prairies sont parfois complétées par des cultures fourragères semées avec des légumineuses (Pueraria phaseoloides, Calopogonium mucunoides, Arachis pintoi, etc.) ou par des haies vives et des arbres en prairies qui jouent aussi le rôle de complément alimentaire lorsque la saison sèche influe sur la production fourragère.

\section{ID Dans les systèmes mixtes agriculture-élevage}

À l'échelle de l'exploitation, les systèmes mixtes associant l'agriculture et l'élevage représentent une première étape d'intensification de l'élevage, puisque l'agro-éleveur y consacre une part de ses investissements. Parmi ces investissements, la production fourragère peut tenir une bonne place. Au sein de l'exploitation s'établit une sorte d'échange de services entre l'agriculture et l'élevage : les plantes cultivées procurent les résidus de culture, éventuellement des sous-produits agro-industriels; les cultures fourragères sont pâturées, distribuées en vert ou stockées pour les périodes de soudure quand les parcours ne suffisent plus. Les animaux d'élevage consomment les résidus de culture, les adventices, les sous-produits agricoles et de plus en plus de plantes fourragères cultivées. Ils apportent l'énergie utile pour le travail attelé (travail du sol, transport) et participent au nettoyage des parcelles et à la fertilisation organique des sols (déjections et fumier).

Quelques exemples sont présentés ci-après (ils sont développés dans le cédérom).

Les légumineuses et les céréales à deux fins produisent à la fois des graines pour l'alimentation humaine et des fanes ou des pailles pour le bétail. C'est le cas en Afrique de l'Ouest avec les variétés d'arachide et de niébé à deux fins pour constituer des réserves de fourrage, et avec la culture de sorghos dont les feuilles et la moelle des tiges servent de fourrage de réserve après la récolte des épis, notamment pour alimenter les animaux de trait au moment des labours, alors que l'herbe n'a pas encore repoussé.

Les jardins fourragers sur des parcelles adjacentes aux champs et souvent clôturées sont des réserves de fourrage de qualité destinées

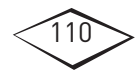


à un petit nombre de vaches laitières élevées sur l'exploitation. L'investissement consenti et le travail sont valorisés par la commercialisation du lait.

Les banques fourragères permanentes (fodder banks) semées avec des légumineuses (Pueraria phaseoloides, Calopogonium mucunoides, Arachis pintoi) pâturées quelques heures par jour permettent de complémenter en matières azotées les rations quotidiennes des animaux.

Les jachères améliorées avec des légumineuses ou parfois des graminées comme Andropogon gayanus, en début de période de jachère, permettent, en plus de la production de fourrages, de restaurer la fertilité des sols, à condition que le pâturage ne soit pas trop intense au cours des premières années.

Les assolements fourragers sont composés d'une culture fourragère (annuelle ou bisannuelle) introduite entre deux cultures vivrières ou industrielles, en utilisant des plantes fourragères strictes ou des plantes à deux fins.

Des associations de plantes, principalement dans le cas de cultures sous couvert végétal (culture sans labour), sont mises en place dans le sud-ouest de Madagascar et en Amérique du Sud. Des cultures fourragères de décrue sont implantées après la saison d'inondation au Nordeste du Brésil.

Des haies vives et des arbres sur prairies jouent aussi le rôle de compléments alimentaires lorsque la saison sèche réduit significativement la production fourragère.

\section{IID Dans les systèmes hors sol}

Les systèmes d'élevage les plus intensifs au sens économique ont recours à des achats d'importantes quantités d'aliments pour le bétail. C'est le cas des élevages industriels de volailles et de porc, à base de céréales, de sous-produits agro-industriels et de compléments minéraux et vitaminiques. Les élevages hors sol comprennent aussi les élevages de ruminants élevés dans des enclos ou à l'étable, sans surface pâturée.

Ces systèmes sont associés à des objectifs spécifiques de production, l'engraissement et/ou la production laitière. La dimension des ateliers va de l'animal unique, élevé dans une cour ou attaché, à l'atelier de production, à un nombre relativement important d'animaux (atelier d'embouche, étable laitière).

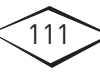


Plus largement, sont inclus dans ces systèmes les exploitations dans lesquelles l'alimentation des animaux n'est pas exclusivement basée sur les fourrages qui peuvent être produits par l'éleveur, mais aussi complémentée avec des aliments concentrés achetés.

Les ateliers intensifs sont soit intégrés dans une exploitation agricole ou d'agro-élevage, soit indépendants et spécifiques.

Voici quelques exemples :

- les moutons ou les bœufs de case, élevés pour obtenir des animaux gras à forte valeur ajoutée, par exemple, l'élevage spéculatif des moutons de Tabaski (fête musulmane) en Afrique de l'Ouest, du Centre ou de l'Est (Corne de l'Afrique), ou celui des bœufs de fosse de Madagascar;

- les fermes laitières aux alentours des villes et des capitales en Afrique (ceinture laitière autour de Ndjamena, d'Addis-Abeba, de Dakar, etc.) et les fermes de chamelles laitières autour de Nouakchott; - les étables laitières (livestock units) de quelques têtes en Afrique de l'Est, permettant un revenu d'appoint à des personnes ayant aussi d'autres activités, ou leur équivalent à Madagascar.

Les cultures fourragères, composantes essentielles de ces systèmes, doivent apporter des biomasses suffisantes et de qualité adéquate. Elles doivent être installées sur des sols agricoles fertiles et entretenues avec soin, parfois même fertilisées et irriguées. Les plantes les plus cultivées sont des graminées, essentiellement la canne fourragère ou herbe à éléphant (Pennisetum purpureum), ainsi que Tripsacum laxum, Panicum maximum ou Brachiaria decumbens. Des légumineuses fourragères sont également cultivées, Medicago sativa (luzerne), Centrosema pubescens, Macroptilium atropurpureum.

Le maïs fourrage, récolté avant maturité, est envisageable, mais cet usage entre en concurrence avec la production de grains. Les fourrages sont coupés et apportés aux animaux à l'état vert (cut and carry). Selon les climats, les productions de foin, de haylage et d'ensilage permettent de constituer des réserves de qualité. Au Brésil, des jardins fourragers ou capineira ont ce rôle d'affouragement en vert.

Des fourrages et d'autres aliments sont aussi achetés à des agriculteurs ou à des industries agro-alimentaires, notamment les fanes d'arachide, les tourteaux de coton ou de soja, les sons de blé et les issues de riz, des feuillages, etc., ou même du foin.

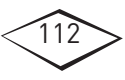




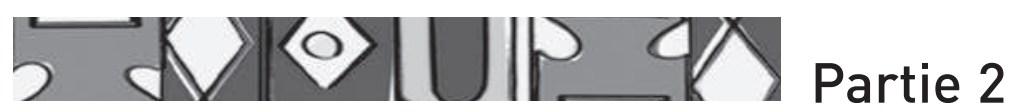

\section{Comment cultiver, exploiter et entretenir les plantes fourragères?}

Les exploitations pratiquant l'élevage disposent généralement de surfaces fourragères très diverses plus ou moins aménagées. Des surfaces permanentes aux cultures annuelles, ce sont :

- les prairies cultivées permanentes avec des fourrages spontanés pérennes, des prairies naturelles permanentes, des parcours avec ou sans ligneux fourragers;

- les herbages installés ayant vocation à se pérenniser comme les prairies permanentes. La durée nécessaire à une prairie temporaire pour reconstituer un stock carbone équivalent au stock présent avant labour et pour mettre en place des cultures fourragères est d'au moins cinq ans; - les banques fourragères pour assurer un complément pour certaines périodes;

- les soles fourragères annuelles, en cultures pures, associées, voire dérobées sous une culture incluse dans un plan d'assolement.

- les prairies temporaires (moins de six ans), dites «artificielles» lorsqu'elles ne comportent que des légumineuses.

Ces surfaces très variées nécessitent des techniques particulières échelonnées, regroupées au sein d'«itinéraires techniques».

Les itinéraires techniques dépendent du contexte économique et du niveau d'intensification du système d'élevage. Le système de production extensif est basé sur des modes de culture traditionnels, la traction animale ou la culture manuelle; le système de production intensif mobilise un capital important et des moyens mécaniques. Sont présentés tout d'abord les itinéraires techniques complexes qui relèvent de systèmes plutôt intensifs, motorisés, tels qu'ils sont pratiqués par exemple à la Réunion ou en Guyane. Ils sont complétés par les itinéraires techniques des systèmes plus traditionnels, plus simples, mais aussi plus communs en zones tropicales (figure 5.1).

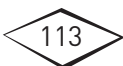


Les étapes techniques d'une culture fourragère : mise en place, installation, gestion de l'exploitation, entretien

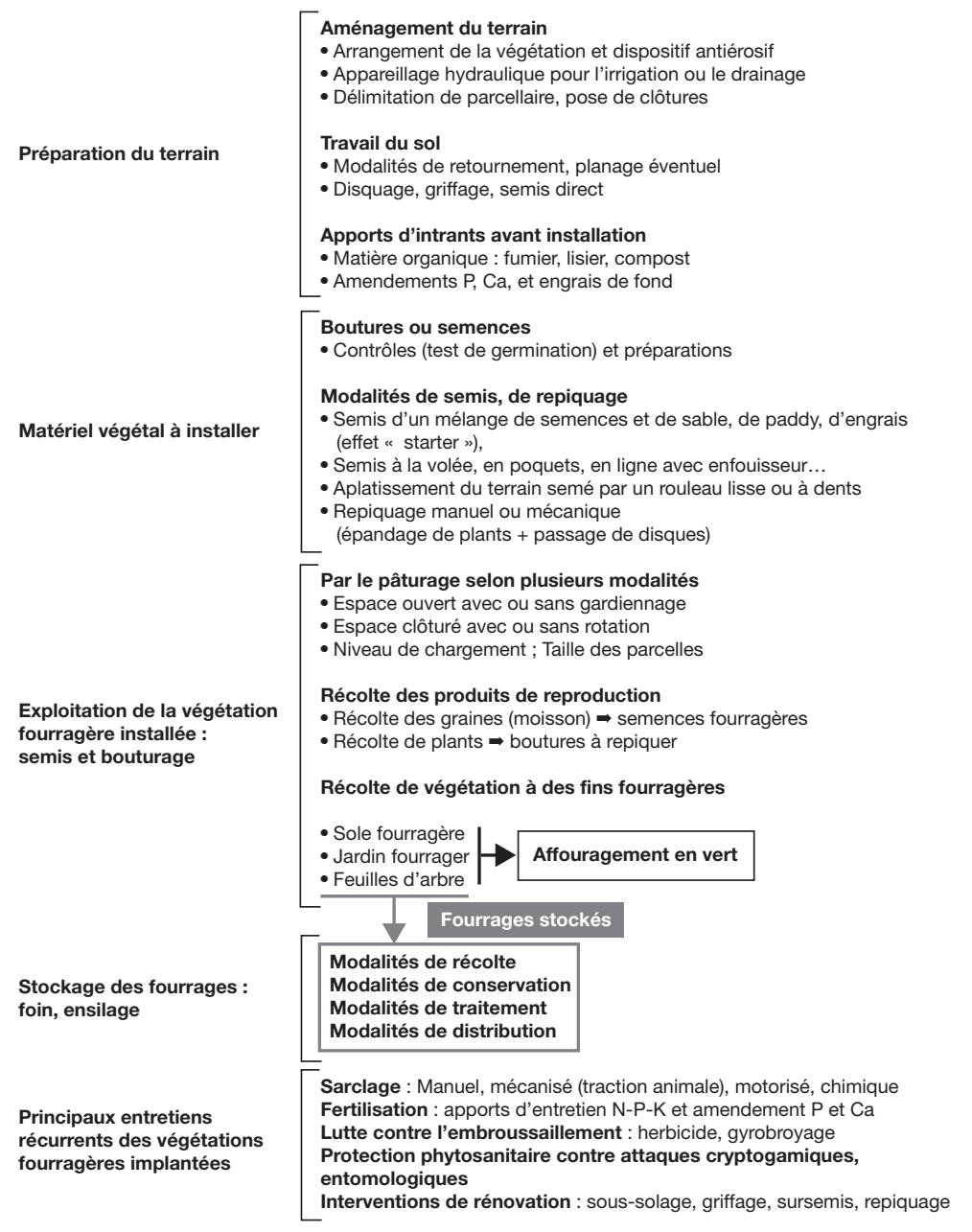

Figure 5.1.

Itinéraires techniques pour la mise en place, l'installation, l'exploitation et l'entretien des cultures fourragères.

Un itinéraire technique doit donc être raisonné :

- pour un ensemble (un espace, un terrain) qui doit être le plus cohérent possible pour maintenir des conditions optimales pour les plantes tout au long de leur cycle et pour préparer la saison suivante;

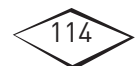


- en prenant en compte les possibilités, les contraintes et les besoins des différentes opérations culturales en matière d'organisation du travail, de mécanisation, d'intrants (fertilisation et phytosanitaire);

- en s'ajustant en permanence à l'évolution des conditions dans la parcelle (sécheresse, inondation, adventices, bioagresseurs) et en choisissant les espèces en fonction de tous les autres facteurs.

Les modes de culture et d'exploitation des fourrages sont le plus souvent regroupés en trois phases : l'installation, l'exploitation et l'entretien. Les itinéraires techniques pour les plantes ligneuses sont différents de ceux conçus pour les herbacées. La production des semences fourragères et une méthode de calcul des coûts sont présentées au chapitres 9 et 10 . 



\section{La culture}

\section{des plantes fourragères}

Le mode d'installation des cultures fourragères dépend de la végétation en place (forêts, parcours, terres de culture), des conditions édaphiques, des espèces choisies, du niveau d'intensification, des assolements, du système d'élevage et de la place de ces ressources dans le système. En prenant en compte tous ces facteurs, l'éleveur doit définir la date et les conditions du semis ou du bouturage, ainsi que les moyens engagés pour l'entretien de la culture fourragère, par exemple le niveau de fertilisation.

Les plantes choisies déterminent également les itinéraires techniques, en raison notamment de leurs caractéristiques physiologiques :

- la taille des graines et leur capacité germinative;

- la vigueur des plantules;

- le cycle, le port (érigé, volubile, rampant) et la taille de la plante;

- la possibilité d'implantation par boutures qui permettent un démarrage plus rapide que le semis;

- la compétitivité des plantes choisies par rapport aux adventices, qui est liée aux caractéristiques précédentes et à d'éventuelles aptitudes allélopathiques.

Les différents travaux à entreprendre sont la préparation de la surface, la préparation du sol, l'acquisition et la préparation des semences et des plants et le semis ou la mise en place des boutures.

\section{La préparation de la surface cultivée}

Les travaux préliminaires à la mise en place d'une culture fourragère dépendent de la localisation de la parcelle choisie, de ses antécédents, de son voisinage : un terrain déjà utilisé pour des cultures annuelles ne se prépare pas comme une nouvelle parcelle que l'on vient de défricher. La préparation du terrain comporte :

- le défrichement de la végétation en place si nécessaire;

- les aménagements antiérosifs;

- le planage et les aménagements hydrauliques pour le drainage et l'irrigation;

- l'amendement du sol.

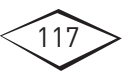




\section{$>$ Les cultures fourragères}

\section{IID Le défrichement}

Le défrichement consiste à éliminer la végétation en place sur une parcelle de forêt ou de friche pour la rendre apte à la culture. Nous abordons dans cet ouvrage seulement le cas des défrichements forestiers mécanisés en zones tropicales humides, ces derniers commencent fréquemment par un déboisement.

Les méthodes et les outils utilisés sont multiples : tracteur, bulldozer, lame, chaîne, dent, arrache-souche, tronçonneuse, outils manuels. Le feu est également très utilisé, aussi bien en Afrique qu'en Amazonie et en Asie du Sud-Est (photo 5.1), mais ce procédé est de en plus critiqué en raison des émissions de dioxyde de carbone $\left(\mathrm{CO}_{2}\right)$ et des risques accrus d'érosion qu'il engendre.

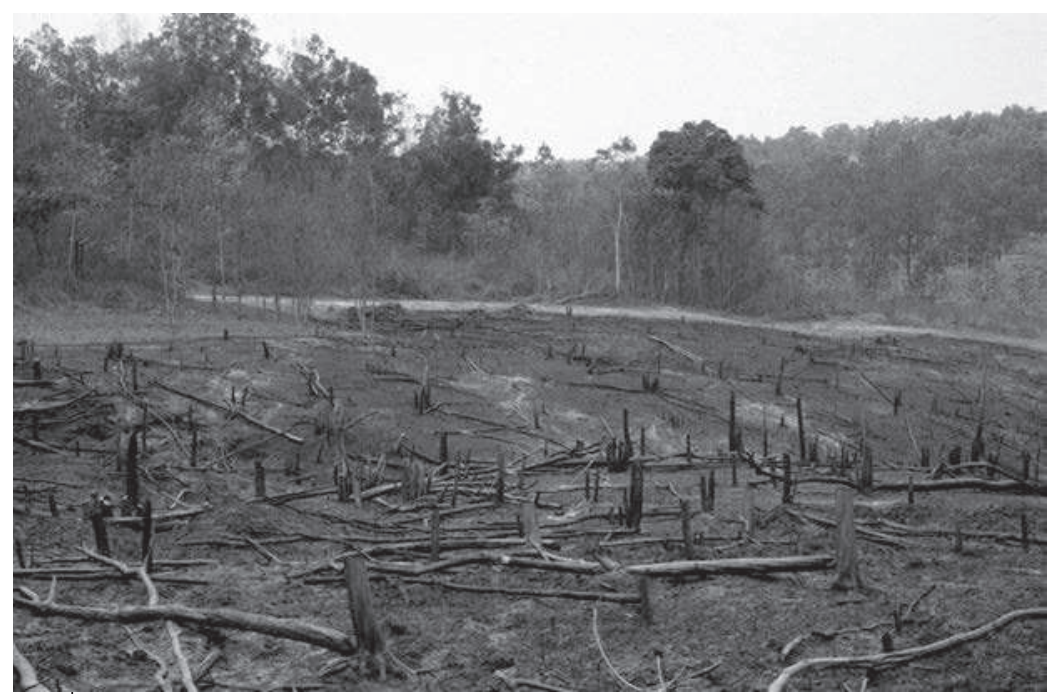

Photo 5.1.

Défrichement par le feu dans une forêt tropicale humide, avant la mise en culture (culture sur brûlis), Sumatra, Indonésie. (๑ B. Toutain)

La pratique du déboisement total, autrefois généralisée, n'est plus recommandée actuellement car elle induit une dégradation de l'environnement (sols nus très sensibles à l'érosion) et réduit la biodiversité animale et végétale. Pour mettre en place une prairie permanente, différentes améliorations ont été apportées : abattage manuel, défrichement progressif, reforestation.

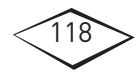




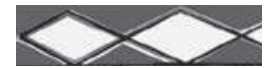

Labattage manuel préserve mieux les sols et permet de laisser des arbres, mais il ne convient pas à toutes les situations, par exemple une grande surface à défricher exige une main-d'œuvre coûteuse.

Le défrichement progressif en deux temps est pratiqué en Guyane et dans certains États du Brésil. En premier, est mis en œuvre l'abattage des arbres sans brûlage et la récupération du bois comme poteaux, bois d'œuvre et bois de feu, l'andainage des rémanents, puis le nettoyage et le planage du sol entre les andains. Il est suivi aussitôt de l'implantation d'un pâturage artificiel; ensuite le terrain est dessouché après trois à cinq ans d'exploitation du pâturage. L'avantage de cette méthode est de pratiquer le dessouchage ultérieurement, sur un sol enherbé, moins sensible à l'érosion, quand une grande partie des racines des arbres ont pourri. Le matériel utilisé est alors moins lourd et moins dégradant pour le sol, mais l'implantation de la végétation fourragère est plus difficile que sur un sol totalement défriché et propre et doit être faite préférentiellement de façon manuelle.

La réhabilitation des milieux dégradés, par la reforestation ou la création d'un pâturage permanent amélioré agroforestier, permet d'apporter un fourrage ligneux complémentaire et de l'ombrage aux animaux.

\section{Les aménagements antiérosifs}

Lérosion correspond au transport et à l'accumulation de particules de sol par l'eau et par le vent. Dans les régions tropicales les plus sèches, l'érosion causée par le vent (éolienne) domine, alors que dans les zones plus humides, le risque le plus élevé est lié à l'érosion par l'eau (hydrique) en raison de l'abondance des pluies et d'un ruissellement très abondant. L'érosion hydrique étant la plus importante dans les zones cultivées, nous aborderons ici surtout ce qui permet de la limiter ou de la contrôler.

Linstallation d'un pâturage permanent contribue à limiter les risques d'érosion à partir du moment où les plantes assurent une bonne couverture. Le couvert prairial s'avère la meilleure culture de cicatrisation après déforestation, mais le passage des instruments aratoires pendant le défrichement et l'implantation peut avoir des effets dégradants (encadré 5.1). Les aménagements antiérosifs relèvent toujours des mêmes principes : ralentir le ruissellement en créant des obstacles, favoriser l'infiltration en travaillant le sol et évacuer les eaux

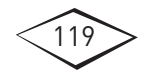


excédentaires en aménageant des canaux. Les techniques antiérosives varient en fonction de la surface à aménager, de l'échelle de la parcelle et de celle du bassin versant, des moyens disponibles en main-d'œuvre et en financement, des matériaux présents (pierres), du climat, des pentes, mais aussi de la végétation en place.

Pour créer un obstacle sur une surface de quelques hectares et pour de petits aménagements en pente faible ou modérée, il peut être recommandé de construire des cordons pierreux : ils sont composés de blocs de pierre disposés en courbes de niveau, mais cela suppose de disposer de blocs de latérite ou de roche à proximité. En ralentissant le ruissellement, le cordon pierreux favorise le dépôt des matériaux entrânés (sable, particules plus fines et matière organique) et la pénétration de l'eau en amont. Des terrasses à très faible pente sont aménagées lorsque les cordons pierreux sont suffisamment hauts. Dans les régions où les pierres ne sont pas disponibles, des diguettes en terre peuvent être construites en début de saison des pluies lorsque le sol est ameubli. Les cordons et diguettes peuvent aussi être plantés de graminées, d'arbustes ou d'arbres pérennes pour améliorer la pérennité et l'efficacité de ces aménagements (figure 5.2). Lorsqu'il n'y a pas de pierres dans la région, on peut construire des bandes enherbées, de 1 à $3 \mathrm{~m}$ de large en fonction de la pente et des disponibilités en terre. Cette technique, qui fonctionne comme un filtre, est bien adaptée aux zones de savanes humides et forestières, où les graminées pérennes s'installent naturellement. Dans les zones sèches, où l'installation spontanée de graminées pérennes est plus longue et plus difficile, le semis ou le repiquage des graminées permet d'accélérer l'installation des bandes enherbées.

\section{Encadré 5.1. Utilisation d'Andropogon gayanus pour les bandes enherbées}

La technique du repiquage d'Andropogon gayanus à partir d'anciennes touffes est bien connue des paysans des régions soudaniennes, mais ses résultats sont aléatoires si une période sèche suit la phase de repiquage. Le semis de cette graminée pérenne donne de bons résultats même en zone semi-aride. Il faut préparer le sol où l'on souhaite semer Andropogon. Un semis au flanc d'une diguette en terre ou en amont d'un cordon pierreux a de bonnes chances de réussir. Les semences sont mélangées à du sable 12 à 24 heures avant le semis, brassées avec le sable humide pour éliminer les poils hydrophobes et laissées en tas ou dans un sac pour faire pénétrer l'eau dans les graines. Ce mélange semences et sable est déposé au fond d'une rainure de $1 \mathrm{~cm}$ de profondeur et tassé au pied. La levée a lieu cinq à huit jours plus tard.

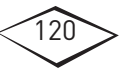



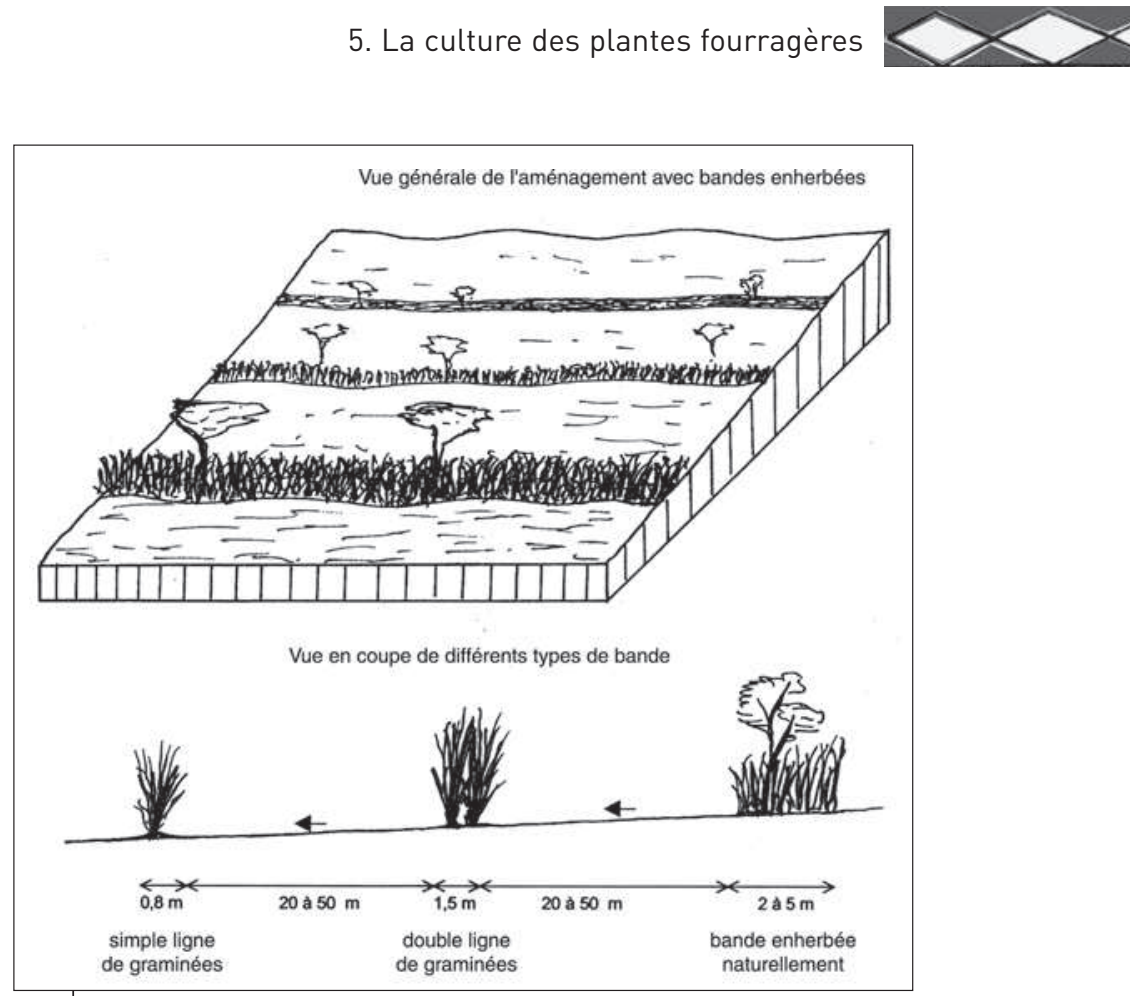

Figure 5.2.

Aménagement antiérosif avec bandes enherbées de graminées.

(๔ Mémento de l'agronome, 2002)

Des lignes d'arbres ou d'arbustes sont implantées autour des champs pour constituer des brise-vent ou des haies vives afin d'empêcher le bétail d'y pénétrer. Ces haies vives d'arbustes plantés à forte densité (50 $\mathrm{cm}$ entre deux pieds) constituent des barrières filtrantes qui ralentissent aussi le ruissellement.

Il est préférable d'associer les aménagements physiques et biologiques lorsque cela est possible. La végétalisation des diguettes en terre avec des lignes de touffes de graminées pérennes en amont des ouvrages et la plantation d'arbustes pour consolider les berges augmentent la pérennité des aménagements. Lintérêt fourrager de cette végétation constitue très souvent un atout supplémentaire.

\section{IID Les aménagements hydrauliques}

La maîtrise de l'eau par des aménagements qui permettent de protéger les sols contre l'érosion, de drainer, d'irriguer ou de contrôler la

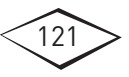


salinisation peut relever de décisions individuelles des agriculteurs, mais s'inscrit généralement dans un réseau d'aménagement collectif.

\section{Le drainage et l'assainissement des sols}

Ils sont particulièrement importants dans trois situations :

- en climat humide pour éviter l'asphyxie des plantes par excès d'eau;

- en zone de bas-fonds pour évacuer les eaux de pluie en excès;

- en zone aride pour lutter contre la salinisation en assurant le lessivage des sols.

L'objectif du drainage est d'évacuer les eaux excédentaires qui pourraient entraîner l'hydromorphie du sol, l'asphyxie des racines, la salinisation, etc. Les systèmes de drainage doivent être adaptés aux besoins, aux couverts végétaux et aux caractéristiques pédologiques et hydrauliques de chaque périmètre. Le drainage superficiel peut suffire pour évacuer l'eau dans une culture de riz, mais le drainage profond est nécessaire pour lutter contre la remontée de la nappe phréatique. De plus, le décompactage et le sous-solage peuvent améliorer l'infiltration de l'eau dans un sol tassé par le bétail.

Le drainage est conçu à l'échelle parcellaire, mais il doit être intégré dans une infrastructure hydraulique d'évacuation des eaux excédentaires au sein d'un bassin versant élémentaire.

Les techniques de drainage sont variées et requièrent des compétences spécifiques. Les ouvrages à ciel ouvert consistant à creuser des fossés et/ou à modeler la surface en ados séparés par des rigoles débouchant sur des fossés sont réalisés par des machines, voire manuellement. Les poses des drains enterrés (en PVC ou en poterie) pour les drainages souterrains sont des aménagements lourds réalisés le plus souvent par des entreprises disposant de sous-soleuses.

\section{L'irrigation}

Lirrigation permet de sécuriser et d'augmenter la production agricole dans les zones de climat aride, semi-aride, ou même dans les régions bien arrosées pour réaliser deux cultures par an, plus rarement trois, ou pour réduire les risques dus à la variabilité des précipitations.

Lirrigation demande des investissements financiers importants à l'installation, puis pour assurer le fonctionnement annuel, les achats d'intrants et les travaux d'entretien. Les revenus générés par les cultures irriguées doivent donc être à la hauteur des coûts. Dans le cas des cultures fourragères, la commercialisation des productions animales devra couvrir

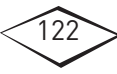


à la fois les frais de la production de fourrage et les frais de l'élevage. Le choix d'aménager un périmètre irrigué est donc lourd de conséquences pour tous les usagers et doit être envisagé en concertation à tous les stades, depuis sa conception jusqu'à sa gestion (encadré 5.2).

\section{Encadré 5.2. Diagnostic d’un périmètre irrigué}

Le diagnostic doit permettre de répondre aux questions suivantes :

Comment les cultures fourragères s'intègrent-elles dans les systèmes de production?

Y a-t-il concurrence avec d'autres productions ou activités au cours du calendrier?

Quel est le coût de l'entretien et du fonctionnement du périmètre irrigué par hectare ou par mètre cube d'eau d'irrigation?

Que représente ce coût par rapport aux rendements moyens attendus?

Y a-t-il risque de dégradation de la fertilité des terres irriguées?

Observe-t-on une baisse du taux de matière organique, une baisse de la fertilité chimique, des phénomènes de salinisation, la prolifération d'adventices, des problèmes de drainage?

Y a-t-il conflit entre les irrigants et d'autres usagers du terroir?

Quel est le statut foncier des parcelles irriguées?

Quelle est la capacité de renouvellement de la nappe phréatique?

Le planage, opération indispensable en rizière irriguée inondée, est très rare pour les cultures fourragères; il a été pratiqué dans la région nord de la Côte d'Ivoire dans les années 1980 afin de pouvoir utiliser un semoir en ligne semi-porté.

Les méthodes d'irrigation utilisées pour des cultures fourragères sont classiques :

- l'irrigation par gravité. L'ouverture d'une vanne sur le canal d'irrigation permet l'accès de l'eau, qui s'écoule sur l'ensemble de la parcelle parfaitement aplanie ou en très légère pente. Lexcès d'eau s'évacue dans des canaux de drainage;

- l'irrigation par calants, une variante de l'irrigation par gravité. Sur une surface plane en pente uniforme, on fait couler une lame d'eau régulière jusqu'à ce que l'ensemble de la planche soit couverte;

- l'irrigation à la raie, qui fournit une quantité d'eau à peu près constante à chaque raie entre deux billons. Cependant, plus la raie est longue, moins on arrive à contrôler la répartition de l'eau entre le début et la fin de la raie, en principe réalisée avec une légère pente;

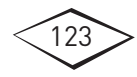


- l'irrigation par aspersion (asperseurs sous pression) permet de mieux répartir l'eau, en comparaison des autres techniques citées. Le coût élevé de l'investissement pour l'aspersion sous pression et de la main-d'œuvre pour l'arrosage manuel limite l'usage de ces techniques d'irrigation aux situations économiquement intéressantes.

Les cultures de décrue en saison sèche le long des rivières ou autour des mares sont un mode de valorisation de l'humidité du sol sans investissement.

Dans le Nordeste du Brésil, une importante filière laitière bovine s'est développée depuis les années 2000. Les éleveurs ont mis en œuvre des systèmes de contrôle hydraulique très diversifiés et des techniques de précision par l'irrigation au goutte à goutte pour des cultures destinées à l'affouragement.

\section{La lutte contre la salinisation}

Dans les pays chauds, la surface de terres irriguées abandonnées chaque année à la suite de la dégradation des réseaux ou de la perte de fertilité des sols, notamment du fait de la salinité, est approximativement égale à celle des périmètres nouvellement aménagés. La lutte contre la salinisation ne doit donc pas être oubliée.

Le phénomène de salinisation est lié à la différence qui existe entre les quantités de sel apportées par l'eau d'irrigation et la quantité exportée par l'eau de drainage. En climat chaud et sec, l'évapotranspiration des cultures joue comme un mécanisme de concentration du sel dans la solution du sol. En climat plus humide, les pluies d'hivernage lessivent une partie du sel accumulé en saison sèche, permettant d'équilibrer la salinisation moyenne du sol.

Les périmètres irrigués sont menacés par la salinisation lorsque les eaux d'irrigation sont salées. Ce risque s'accroît en régions arides à cause de la forte évaporation. La salinisation, facteur de désertification, a été pour une grande part responsable du déclin de la Mésopotamie. Il est donc important de mesurer et de limiter ce risque, par exemple en favorisant le lessivage.

\section{Les apports d'amendements et de fumier}

La fertilité du terrain au moment de la mise en place de prairies, ou d'autres cultures fourragères, conditionne leur productivité et leur pérennité. L'amendement d'un sol cultivé permet de corriger et d'améliorer la fertilité du sol généralement sur plusieurs années; mais il n'est

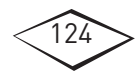




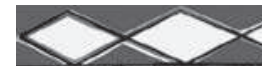

effectué que dans les exploitations où l'élevage assure un revenu suffisant pour rentabiliser ce type d'investissement. Beaucoup de cultures fourragères tropicales ne bénéficient d'aucune fertilisation.

Lamendement d'un sol cultivé peut comprendre la correction de l'acidité et l'apport de calcium (amendements calciques), l'enrichissement en matières organiques et en éléments minéraux majeurs par l'incorporation de fumier, de compost et de lisier, et l'apport d'engrais phosphaté, dont les effets durent plusieurs années (fumure dite de fond). Ces amendements sont épandus au sol avant la mise en place de la culture fourragère. Les apports en cours de végétation viseront à stimuler la production à des moments déterminés et à compenser les pertes en nutriments.

Les amendements calciques, par apport de chaux ou de marne au sol, corrigent partiellement l'acidité des sols ( $\mathrm{pH}$ compris entre 3 et 6). Le principal effet attendu du chaulage est d'éviter la toxicité aluminique pour les espèces les plus sensibles dans les sols très acides, ayant un $\mathrm{pH}$ nettement inférieur à 5,5 et pauvres en matière organique. Lorsque le taux de matière organique est élevé, celle-ci se lie à l'aluminium, supprimant la toxicité. Le pH de l'horizon superficiel (jusqu'à $5 \mathrm{~cm}$ de profondeur) est souvent le plus acide en raison de l'effet acidifiant de l'azote organique, il sert de référence pour raisonner les apports d'amendements.

Les amendements organiques sont excellents, parce qu'ils recyclent des éléments minéraux majeurs (azote, phosphore, potassium) rejetés par l'élevage dans le fumier et le lisier. Le fumier contient tous les éléments indispensables à la croissance des végétaux, mais sous des formes plus ou moins rapidement disponibles.

Les amendements phosphatés sont très importants à prendre en compte. En pays tropicaux, le phosphore se révèle fréquemment le premier facteur limitant de la fertilité, notamment pour l'installation des légumineuses dans les sols très acides, le phosphore étant immobilisé dans le sol. Les phosphates naturels (par exemple ceux du Maghreb) ou les scories (du type scorie Thomas) sont recommandés avec un niveau d'apport de l'ordre de 80 à 120 unités de $\mathrm{P}_{2} \mathrm{O}_{5} / \mathrm{ha} / \mathrm{an}$.

\section{La préparation du sol}

La préparation du sol est fonction de la nature du sol, de l'état du couvert, des outils disponibles et des plantes que l'on veut établir. Pour planter des boutures, la finition est plus grossière que pour semer de

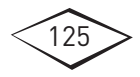


petites graines (par exemple, Brachiaria, Andropogon, Paspalum) pour lesquelles le lit de semences doit être très soigneusement préparé avec un bon nivellement et un bon émiettement. Dans les terrains destinés à la fauche, il faut enlever les pierres, les souches et les termitières pour permettre le passage de la faucheuse.

Le labour mécanique ameublit le sol en même temps qu'il enfouit, au moins partiellement, la végétation vive ou morte. Dans de nombreuses situations, un disquage avec un pulvériseur à disques est moins perturbant pour le sol et peut suffire. Au contraire en sol lourd (argileux) et mal drainé, il peut être nécessaire de pratiquer au préalable un sous-solage avec un décompacteur. Un lit de semences fin et régulier s'obtient avec un passage croisé de disques (covercrop, pulvériseur ou herse lourde).

En culture attelée, les outils sont adaptés au type d'attelage choisi. Le travail comprend un labour superficiel, un disquage, puis un hersage pour affiner le lit de semences. Pour éviter d'endommager le matériel, un dessouchage systématique des ligneux doit être effectué.

En culture manuelle, l'ameublissement de la terre à la houe reste superficiel, l'impact sur la structure du sol est proche de celui du semis sans labour. Ensuite les graines sont enfouies dans des trous réalisés avec un bâton ou une canne planteuse à intervalles réguliers, ou semées à la volée.

Sur les terrains en pente en régions semi-arides la durée pour obtenir le recouvrement du sol après semis étant assez longue, le travail doit être réalisé selon les courbes de niveau. Une fois installées, la plupart des plantes fourragères fixent bien le sol, mais la période pendant et juste après semis est particulièrement critique.

\section{L'implantation des semences ou des plants}

La mise en place d'une culture fourragère étant longue et coûteuse, il est recommandé d'utiliser des semences propres et saines, conservées dans les meilleures conditions.

Avant tout achat, il est recommandé de consulter sur Internet les sites de nombreux producteurs de semences fourragères tropicales, notamment en Australie et au Brésil, ou de demander conseil. Pour choisir des semences et connaître leur disponibilité sur le marché international, voici deux sources d'information en ligne sur les plantes fourragères tropicales :

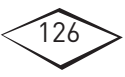




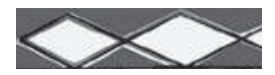

- Tropical Forages, an interactive selection tool :

www.tropicalforages.info/

- FAO Grassland Index by Latin names :

www.fao.org/ag/AGP/AGPC/doc/Gbase/latinsearch.htm

\section{||D L'acquisition des semences}

Dans de nombreux pays tropicaux le marché des semences fourragères est peu développé et la disponibilité est limitée à une gamme réduite d'espèces et de cultivars, voire uniquement à des semences de céréales ou de légumineuses; ces dernières peuvent être utilisées secondairement comme fourrages, mais elles ne conviennent pas pour des prairies. Le marché international des semences fourragères tropicales est dominé par les pays ayant une demande interne conséquente : l'Australie, l'Afrique du Sud et le Brésil. Dans les autres pays, les marchés locaux peuvent être organisés à partir de réseaux entre petits producteurs.

Il faut par ailleurs bien s'assurer de la fiabilité des semenciers, notamment en matière d'acheminement des commandes, les semences de graminées fourragères étant particulièrement sensibles aux conditions de température pendant leur transport et leur stockage. Les graines maintenues quelques jours à plus de $25^{\circ} \mathrm{C}$ perdent rapidement leur pouvoir germinatif. Il faut aussi considérer les règlements phytosanitaires des pays exportateurs et importateurs.

Les espèces fourragères communément utilisées dans un pays peuvent souvent être obtenues chez les fermiers qui les produisent à partir de plantes non sélectionnées. Certaines stations de recherche et d'expérimentation qui utilisent des espèces fourragères importées peuvent fournir de petites quantités de semences ou de plants. Lintroduction d'une nouvelle espèce ou d'une nouvelle variété qui a réussi dans des conditions agro-écologiques similaires comporte toujours un risque d'échec, notamment du fait des maladies et des parasites locaux différents; à titre d'exemple les sorghos fourragers sélectionnés à l'étranger et importés en Afrique réussissent assez mal.

\section{ID Le contrôle des semences}

Une fois les semences acquises, on procède d'abord à leur observation, pour déceler la présence éventuelle d'insectes (charançons, bruches, etc.) ou de moisissures, surtout si les semences ont été stockées sans protection insecticide et/ou fongicide depuis un certain temps.

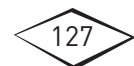




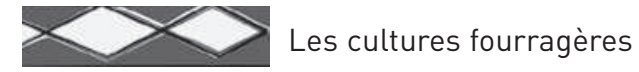

La qualité germinative peut être testée facilement; ce contrôle permet de calculer la quantité de semences nécessaire par unité de surface. Le test de germination est réalisé dans des boîtes de Petri (ou équivalent), garnies de papier filtre ou de papier buvard humidifié dans lesquelles on dispose un nombre déterminé de graines (jusqu'à 100). La boîte est fermée, pour prévenir le dessèchement, réhumidifiée si nécessaire et placée à la lumière. Chaque jour, les graines qui ont germé sont enlevées et comptabilisées; pour certaines semences (Brachiaria humidicola) il faut attendre 15 jours (figure 5.3). Au terme de l'essai, on calcule le taux de germination, c'est-à-dire le rapport entre le nombre de graines ayant germé et le nombre de graines total, ramené à 100 graines et exprimé en $\%$.

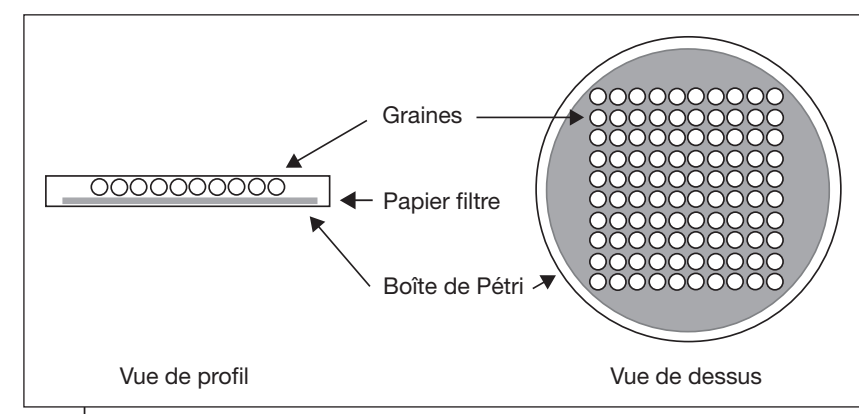

Figure 5.3.

Boîte de Petri ensemencée pour tester la germination de graines fourragères.

\section{ID La levée de la dormance}

Pour les espèces qui présentent des phénomènes de dormance (repos végétatif des graines), on doit respecter un intervalle de temps entre la récolte des semences et le semis, tout en maintenant de bonnes conditions de conservation, généralement au froid; il faut par exemple entre trois et six mois pour Panicum maximum. La levée de dormance est parfois abrégée par une conservation en chambre froide (Cenchrus ciliaris).

Chez les légumineuses on trouve deux types de graines, des «graines tendres» qui germent immédiatement, et des «graines dures» qui germent plus tard, protégées par un tégument plus dur. Par exemple, chez Stylosanthes guianensis des graines «tendres» de couleur blanchebeige germent tout de suite, et des graines «dures» marron foncé sont dormantes.

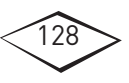


Pour obtenir un semis homogène, il faut lever la dormance des graines dures en blessant le tégument par scarification avec un polisseur à riz ou en effectuant un traitement à l'eau chaude ou à l'acide sulfurique : - traitement à l'eau chaude. Les semences sont versées 25 à 30 minutes dans de l'eau à $55^{\circ} \mathrm{C}(1$ volume d'eau bouillante et 1 volume d'eau froide) ou 10 minutes à $70^{\circ} \mathrm{C}(2$ volumes d'eau bouillante dans 1 volume d'eau froide) puis soigneusement séchées.

- traitement à l'acide sulfurique. On utilise de l'acide de batterie peu concentré, mais cette technique peut être dangereuse pour les exécutants et pour les semences lorsque la concentration de l'acide n'est pas connue.

\section{IID L'inoculation des légumineuses}

En zone tropicale, les légumineuses cultivées, qui sont généralement originaires d'autres continents (la plupart d'Amérique centrale et du Sud) ne trouvent pas forcément dans le sol le Rhizobium symbiotique adéquat (encadré 5.3). Lors de l'introduction d'une nouvelle espèce, surtout si la plante manque de vigueur, il faut vérifier, un mois après le semis, que les racines présentent bien des nodulations, en faisant une coupe transversale : la racine principale et les plus grosses racines latérales doivent présenter dans les deux ou trois premiers centimètres du sol des nodules actifs roses.

En l'absence de nodules, cette espèce devra être inoculée avec un Rhizobium adéquat lors du prochain semis. Linoculation consiste à enrober les semences au moment du semis avec le Rhizobium pour stimuler une nodulation rapide et efficace. Il est préférable d'utiliser des souches pures, sélectionnées pour leur efficience, isolées localement ou commercialisées par les laboratoires spécialisés en prenant toutes les précautions phytosanitaires nécessaires.

Le plus pratique est d'associer l'inoculation et l'enrobage des semences: utiliser un adhésif pour coller Rhizobium et maintenir la bactérie en vie jusqu'à ce qu'elle infecte la plantule.

Pour une simple inoculation, de nombreux adhésifs sont efficaces : eau sucrée (10 à $25 \%$ ), amidon (de blé, maïs, riz en même quantité que l'inoculum), miel (10\%), huile de table (10 ml $/ \mathrm{kg}$ de semences), ainsi que la gomme arabique et la méthylcellulose recommandées pour l'enrobage des semences. La méthylcellulose est fabriquée à partir de la cellulose du bois et se comporte comme des fibres solubles.

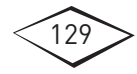


Elle donne des solutions très visqueuses une fois diluée dans l'eau. La méthylcellulose est un additif alimentaire.

Pour réaliser l'enrobage, mélanger l'inoculant et l'adhésif, puis les semences comme décrit précédemment, puis ajouter la quantité de produit recommandée pour l'enrobage en une seule fois et mélanger rapidement jusqu'à ce que les graines se séparent et paraissent toutes enrobées ( 2 min environ).

\section{Encadré 5.3. Que sont les Rhizobium?}

Les Rhizobium sont des bactéries principalement associées aux légumineuses.

Cultivés sur un milieu à base de mannitol et d'eau de levure au laboratoire, les Rhizobium peuvent survivre quelques temps dans le sol. En présence de la légumineuse appropriée, ils colonisent la racine. La pénétration se fait par l'extrémité de poils absorbants, sous forme d'un cordon d'infection contenant les bactéries qui pénètrent les tissus jusqu'à l'intérieur des cellules du cortex racinaire.

Deux grands types de Rhizobium peuvent être distingués :

- à croissance lente $\left(8\right.$ à 24 heures entre chaque génération à $\left.30^{\circ} \mathrm{C}\right)$, ils présentent une réaction alcaline en milieu mannitol-levure;

- à croissance rapide ( 3 à 5 heures entre chaque génération à $30^{\circ} \mathrm{C}$ ), ils présentent une réaction acide en milieu mannitol-levure.

Parmi les espèces de Rhizobium à croissance lente se trouvent les Rhizobium des légumineuses tropicales (Stylosanthes, Aeschynomene), mais aussi quelques cas particuliers de légumineuses tempérées (Lupinus, Lotononis). Parmi les espèces de Rhizobium à croissance rapide se trouvent celles nodulant avec les légumineuses tempérées (Trifolium, Vicia) et quelques cas particuliers, tels que les Rhizobium spécifiques de Leucaena ou de Sesbania.

Les fournisseurs de semences de légumineuses fourragères sont habituellement en mesure de fournir le Rhizobium adapté.

\section{Semis ou plantations?}

Partout où les semences sont disponibles, le semis, plus rapide à réaliser et moins coûteux, est très souvent préféré à la plantation de boutures. Au contraire, la plantation de boutures est nécessaire pour les espèces produisant peu ou pas de semences (par exemple Digitaria swazilandensis) ou lorsque l'approvisionnement est mal assuré. Ces contraintes influencent le choix des espèces.

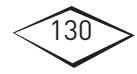


Les caractéristiques des plantes fourragères à cultiver permettent de déterminer le type et les modalités de leur implantation : semis, plantation, date, densité.

\section{IID Les semis}

Il faut semer sur un sol humidifié après une pluie (au moins $50 \mathrm{~mm}$ d'eau) et quand de nouvelles pluies sont attendues peu après. Un épisode sec peu après la levée compromet le semis car les plantules sont très fragiles.

La taille des semences varie beaucoup, avec généralement des semences de graminées fourragères très petites $(1$ à $2 \mathrm{~mm})$ et des semences de légumineuses plus grosses, mais de taille variable selon les espèces. Sachant qu'une semence ne doit généralement pas être enfouie à plus de 1,5 fois sa taille, le semis d'une graminée doit être fait presque à la surface, mais pas totalement, pour éviter l'entraînement des graines par les eaux de ruissellement dès la première pluie. Le tassement par un passage de rouleau après le semis permet de limiter ce risque.

Le semis peut se faire en ligne ou à la volée sur un sol bien préparé, ou en poquets sur un sol plus grossièrement préparé :

- le semis en ligne est recommandé pour faciliter tous les traitements ultérieurs, notamment les sarclages avant que la plante ne couvre le sol; - le semis à la volée, généralisé pour des raisons de temps et de coûts, peut être réalisé manuellement, ou à l'aide d'un semoir à la volée à manivelle ou plus fréquemment avec un épandeur à engrais. Dans ce cas, le mélange de sable ou de son aux semences facilite l'épandage. Dans la pratique, les éleveurs sèment en mélangeant les semences avec des engrais ou du paddy, cela permet d'obtenir une levée plus régulière qu'avec le semis des graminées seules;

- le semis en poquet est effectué manuellement pour les grosses graines.

D'autres techniques existent comme le sursemis : le semis est effectué sans travail préalable du sol, sur un sol nu ou le plus souvent sur une végétation déjà en place.

\section{Les plantations de boutures ou d'éclats de souche}

Plusieurs espèces de graminées tropicales sont multipliées par voie végétative, selon trois techniques.

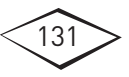


Les fortes tiges ou tiges longues plus ou moins étalées (Andropogon gayanus, Pennisetum purpureum, Brachiaria mutica) sont plantées par voie végétative en utilisant des boutures enterrées sur la moitié de leur longueur, selon un angle de $45^{\circ}$ avec l'horizontale. On peut aussi creuser des sillons peu profonds $(10 \mathrm{~cm})$, disposer les boutures au fond du sillon et le refermer. L'écartement de plantation doit être adapté à l'espèce choisie. Les boutures sont des portions de tige comportant au moins trois nœuds, elles sont mises en terre peu de temps après la coupe pour conserver leur vitalité.

Les graminées à fortes touffes qui produisent peu de semences viables ou des semences difficiles à semer, comme Panicum maximum, peuvent être multipliées végétativement par division de la souche en éclats de souche. Un éclat comporte des racines dont les bouts sont coupés, le collet et un bouquet de feuilles de 2 à 4 talles sectionnées à quelques centimètres au-dessus du plateau de tallage. Ils sont plantés dans un sol fraîchement préparé, en lignes distantes de 40 à $60 \mathrm{~cm}$ tous les 40 à $60 \mathrm{~cm}$ sur la ligne, après avoir été trempés si possible dans une solution insecticide. Le collet doit être placé à ras du sol (ni trop enfoui, ni à l'air). La préparation et la plantation demandant du temps et de la main-d'œuvre, il faut pouvoir compter sur l'entraide ou sur l'emploi de personnel en nombre suffisant.

Les tiges fines des plantes stolonifères (Brachiaria humidicola, Digitaria decumbens, Digitaria swazilandensis, Pennisetum clandestinum) sont faciles à obtenir. Elles sont coupées, dispersées sur le sol, puis intégrées partiellement au sol par un passage croisé de disques lisses, ou parfois par le piétinement de bovins lâchés sur la parcelle.

\section{Les modes d'implantation et les types de couverts installés}

Différents modes d'implantation existent : culture pure, association de plusieurs plantes, culture dérobée, culture sous couvert, semis direct sur couverture végétale.

\section{IID Les cultures pures}

La forme de culture fourragère la plus simple est monospécifique; à une surface fourragère correspond une espèce fourragère. Toutes les

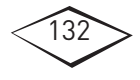


plantes poussent au même rythme et ont la même valeur fourragère en même temps. Les décisions d'utilisation et opérations d'entretien sont simples. Mais ce type de couvert a l'inconvénient de présenter les mêmes défauts ou les mêmes faiblesses en même temps, par exemple, les périodes de faible production, ou les périodes de floraison avec perte de qualité fourragère, ou de vieillissement, ou de problème sanitaire, etc. Il est alors recommandé de diversifier les surfaces fourragères pour disposer de surfaces avec des espèces différentes qui auront ainsi des qualités et des usages complémentaires. On peut aussi combiner des surfaces de graminées et des surfaces de légumineuses.

\section{II) Les cultures associées}

Les plantes associées sont très souvent des mélanges de deux espèces, parfois beaucoup plus, soit uniquement de graminées, soit de légumineuses et de graminées.

En semant en même temps plusieurs espèces de graminées, l'éleveur souhaite profiter de la capacité de production de ces graminées en combinant leurs qualités : certaines vont s'installer plus vite que d'autres, certaines vont avoir une persistance plus grande que d'autres dans le temps, certaines vont avoir des valeurs alimentaires meilleures que d'autres, etc. L'ensemble doit être plus performant que chacune d'elle séparément.

Le choix du mélange doit être raisonné. Par exemple, mêler Chloris gayana, qui pousse vite (environ trois mois) mais ne persiste guère plus de trois ans (production maximale la première année), à Panicum ou à certains Brachiaria (Brachiaria humidicola), dont l'installation est plus longue (six à huit mois) mais qui peuvent durer cinq à dix ans, est une stratégie qui favorise la bonne implantation d'une prairie permanente. Dans des conditions de sol ou de climat un peu difficiles, en l'absence d'expérimentation antérieure, semer un mélange de graminées est une stratégie de sécurité.

Lobjectif d'associer des graminées et des légumineuses herbacées est double, fournir un fourrage équilibré en énergie et en matières azotées pour l'alimentation des animaux et économiser la fertilisation azotée. Les graminées sont productives, riches en cellulose et en sucres, mais s'appauvrissent en matières azotées avec l'âge, et sont plus exigeantes en matières organiques et en minéraux. Les légumineuses sont moins productives, mais plus riches en matières azotées (certaines ont des

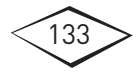


tanins qui diminuent leur digestibilité), et du fait de leur capacité à fixer l'azote atmosphérique, elles libèrent dans le sol de l'azote qui est récupérable par les graminées.

Le choix des espèces doit être raisonné en fonction de leur physiologie. Une graminée produisant de fortes touffes espacées, comme certains Panicum, peut être associée à des légumineuses grimpantes, mais pas étouffantes, comme Macroptilium atropurpureum ou Centrosema pubescens, ou encore une petite plante très dynamique comme Stylosanthes hamata qui se resème chaque année dans les espaces entre les touffes. En région méditerranéenne, le mélange annuel de la vesce et de l'avoine en est un exemple.

Une graminée gazonnante peut être associée à une légumineuse basse comme Arachis pintoi, comme l'association du ray-grass et du trèfle blanc, très connue en région tempérée. Voici quelques autres exemples ayant une bonne longévité :

- en Guyane et au Brésil, Brachiaria ruziziensis et Calopogonium mucunoides, Brachiaria humidicola, Desmodium ovalifolium (Brachiaria ruziziensis et Calopogonium mucunoides étant des espèces pionnières); - au Cameroun et en Côte d'Ivoire, Stylosanthes hamata ou Stylosanthes guianensis et Panicum maximum.

Ce système présente beaucoup d'avantages, mais il est plus délicat à gérer, car en saison humide, les graminées tropicales se développent plus vite que les légumineuses (et inversement en saison sèche). Le maintien de l'équilibre entre graminées et légumineuses dépend des modes d'utilisation et de gestion. Léleveur peut jouer sur :

- le type de fertilisation. Le phosphore favorise les légumineuses et l'azote les graminées. De plus, la graminée profitant de la fourniture d'azote par la légumineuse, sa croissance est rapide;

- la période et l'intensité d'exploitation. Les légumineuses se développent mieux en saison sèche et sont préférentiellement consommées en saison sèche et en début de saison des pluies. La fauche tend à réduire la dominance des graminées.

\section{ID La culture dérobée, implantée ou non sous couvert}

La culture dérobée est très souvent une culture fourragère, introduite entre deux cultures principales (très souvent céréales) au cours de l'année. Elle peut être mise en place après la récolte de la première culture, après la récolte de la culture précédente, ou «sous couvert», dans la culture précédente toujours en place.

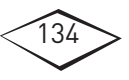




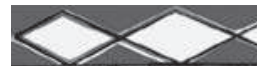

On peut ainsi semer une légumineuse fourragère dans une céréale en place (riz, maïs) après le premier sarclage de celle-ci (photo 5.2) : c'est une culture «dérobée sous couvert». Cette technique permet de cultiver sur la même parcelle deux plantes dans des zones où la saison des pluies est trop courte pour deux implantations successives.

Ainsi, il est possible d'installer à moindre frais une culture fourragère, certes peu productive au cours de la première saison sèche, mais qui peut devenir beaucoup plus productive dès la deuxième année, sans aucune intervention, si la légumineuse arrive à se maintenir ou à se resemer naturellement comme Stylosanthes hamata et Calopogonium mucunoides (photo 5.2).

En régions tropicales, la saison froide, qui ne permet plus la croissance de plantes tropicales, est parfois suffisamment humide pour convenir à la culture de plantes tempérées, moins exigeantes en chaleur. Le choix de la culture dérobée se porte souvent sur des céréales comme l'avoine ou le triticale qui sont ensuite fauchées en vert et fanées. On peut utiliser aussi des légumineuses comme le pois fourrager ou la féverole, mais très souvent leurs rendements sont faibles, en raison de la trop forte évaporation en journée, et le parasitisme est difficile à contrôler.

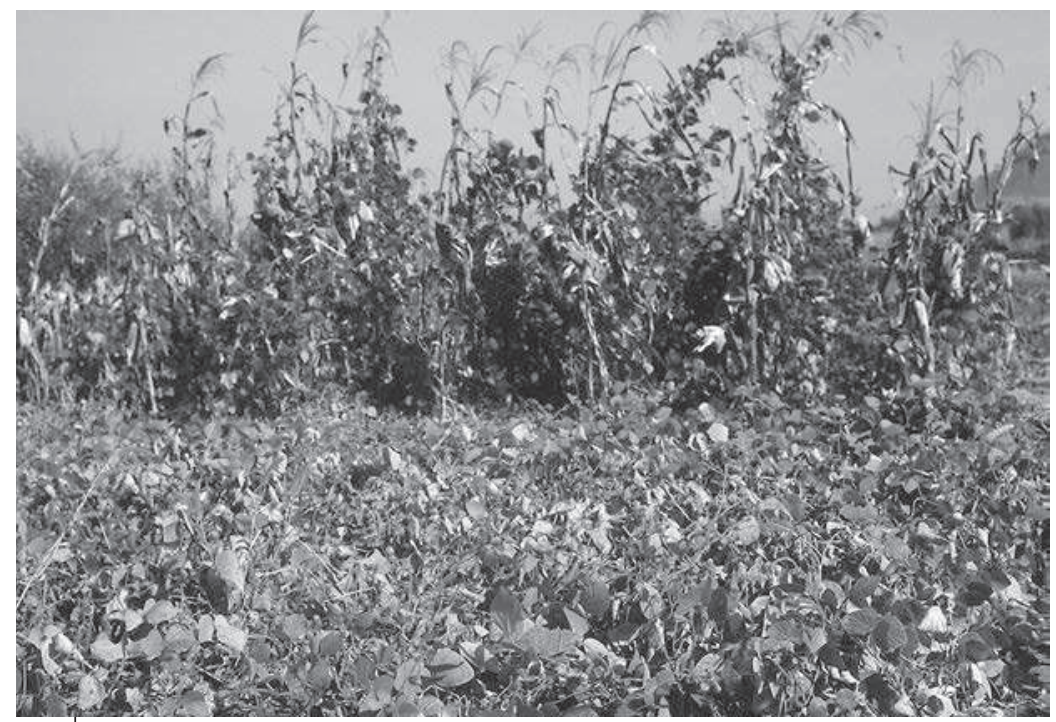

Photo 5.2.

Jachère de Calopogonium mucunoides (parcelle en avant) implantée un an avant en dérobé et en intercalaire dans un maïs, tout comme la parcelle en arrière-plan à Garoua, Nord-Cameroun. (@ H. D. Klein)

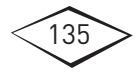




\section{IID Le semis direct sur couverture végétale}

Les semis directs pour installer des fourrages et régénérer des pâturages dégradés en régions tropicales sont utilisés à grande échelle en Australie et au Brésil. Ces techniques très extensives, rapides et peu coûteuses sont réalisées avec des semoirs spéciaux fabriqués sur place. Ces outils assurent en un seul passage et successivement - sur des lignes très espacées (band seeder) ou non (chisel seeder) (photos 5.3 à 5.6) - l'épandage d'un herbicide à faible rémanence, l'ouverture du sillon, l'épandage d'un mélange de semences différentes, l'épandage d'engrais et la fermeture du sillon.

Ces outils sont également utilisés sur la côte ouest (sèche) de Nouvelle-Calédonie pour améliorer les pâturages à base d'Heteropogon contortus, graminée subspontanée - introduite puis disséminée spontanément, comme une plante indigène. Ces pâturages sont exploités seulement durant quelques mois de l'année, au stade jeune en début de saison des pluies et après la chute des graines en fin de saison sèche. Les éleveurs sèment un mélange complexe de cinq plantes, une graminée (Panicum maximum) et quatre légumineuses (Stylosanthes guianensis et Stylosanthes hamata, Cassia rotundifolia et Desmanthus virgatus). Après une mise en défens de quatre à six mois, pour permettre l'établissement d'une partie ou de la totalité de ces plantes, une exploitation modérée et régulière permet aux plantes fourragères semées de coloniser une grande partie de la surface en quelques années. Peu à peu s'établit un pâturage de bien meilleure qualité que la végétation naturelle et exploitable plus longtemps dans l'année.

La technique de semis direct a été étendue aux terres de culture, avec de nouvelles façons culturales apparues au cours des années 19601970, d'abord en Amérique du Nord, puis en Amérique du Sud, avant d'être diffusées dans de nombreuses régions tropicales. Le semis direct consiste à travailler le sol le moins possible, uniquement sur la ligne de semis (minimum tillage), voire pas du tout (zero tillage) et à semer une plante alimentaire (céréale) ou industrielle (coton) directement sur un sol nu ou sur une couverture végétale; on parle alors de semis direct sur couverture végétale $(\mathrm{SCV})$. Si la plupart des plantes de couverture sont déjà connues comme plantes fourragères, les deux usages conjoints (plante de couverture et plante fourragère) ne sont pas toujours compatibles, une plante pâturée ne pouvant assurer aussi bien la fonction de couverture.

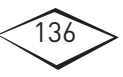



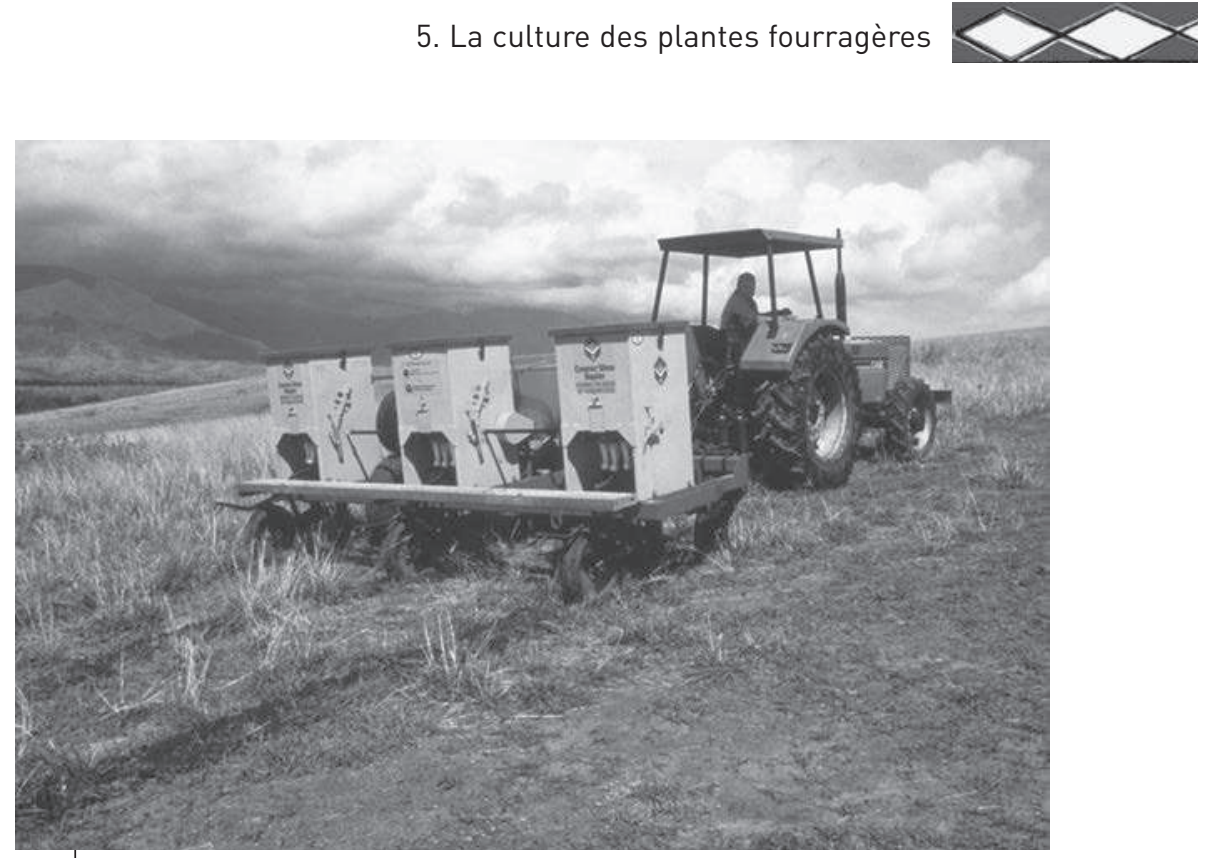

Photo 5.3.

Sursemoir australien à trois bandes (band seeder) pour améliorer un pâturage dégradé, Nouvelle-Calédonie. (๑ H. D. Klein)

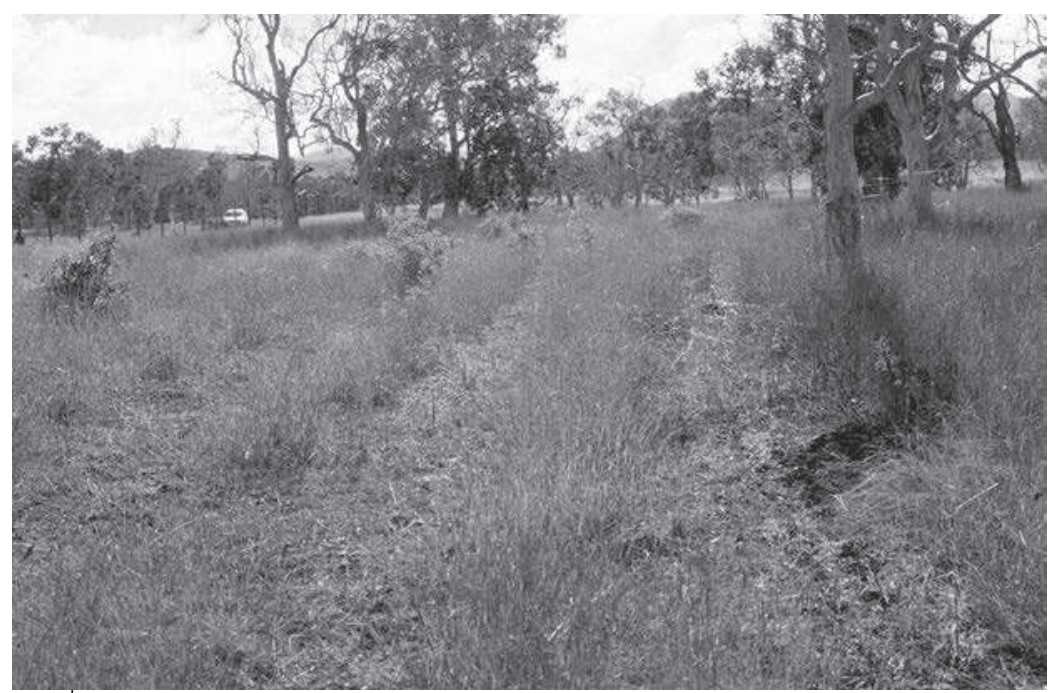

Photo 5.4.

Bandes sursemées avec le band seeder dans un pâturage naturel à Heteropogon contortus et niaoulis,

côte ouest de Nouvelle-Calédonie. (๑ H. D. Klein)

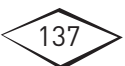



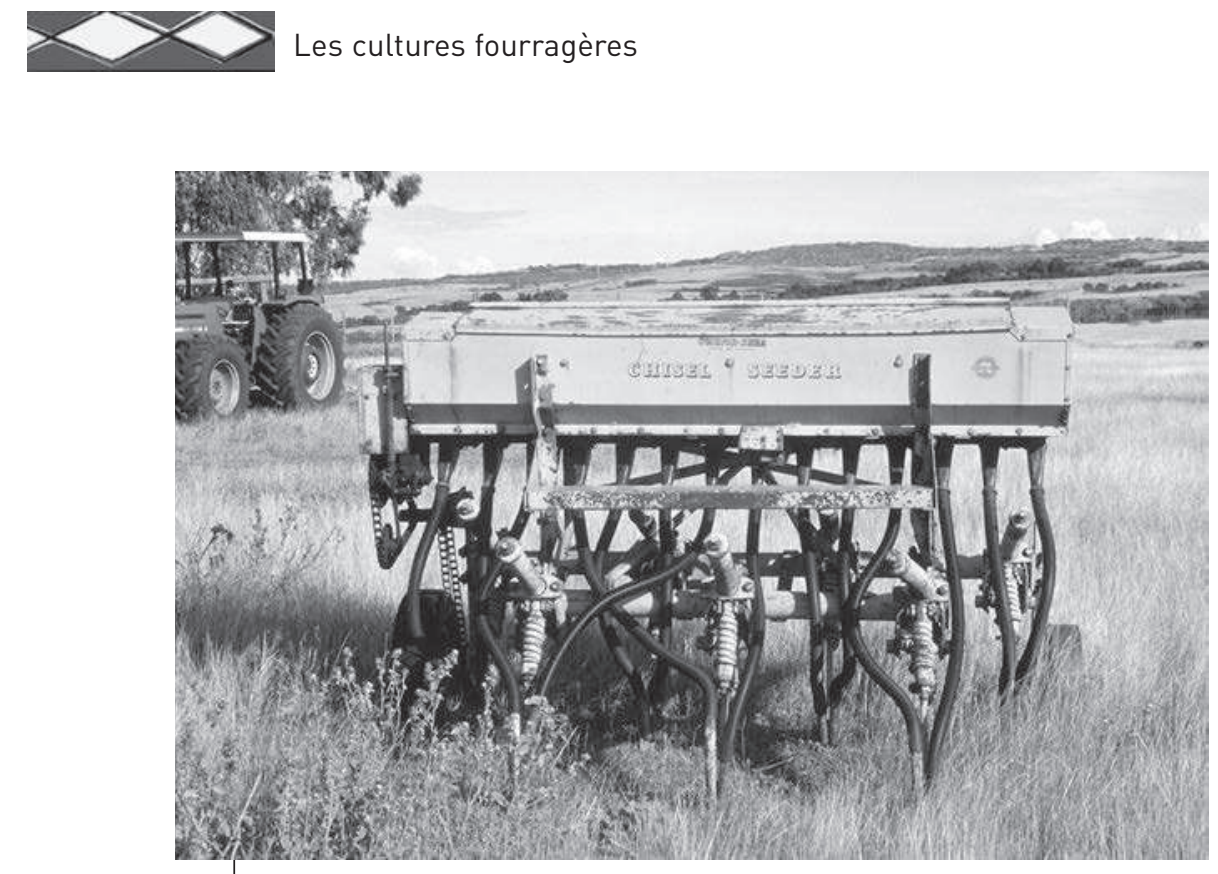

Photo 5.5.

Sursemoir australien (Chisel seeder), côte ouest de Nouvelle-Calédonie. (๑ H. D. Klein)

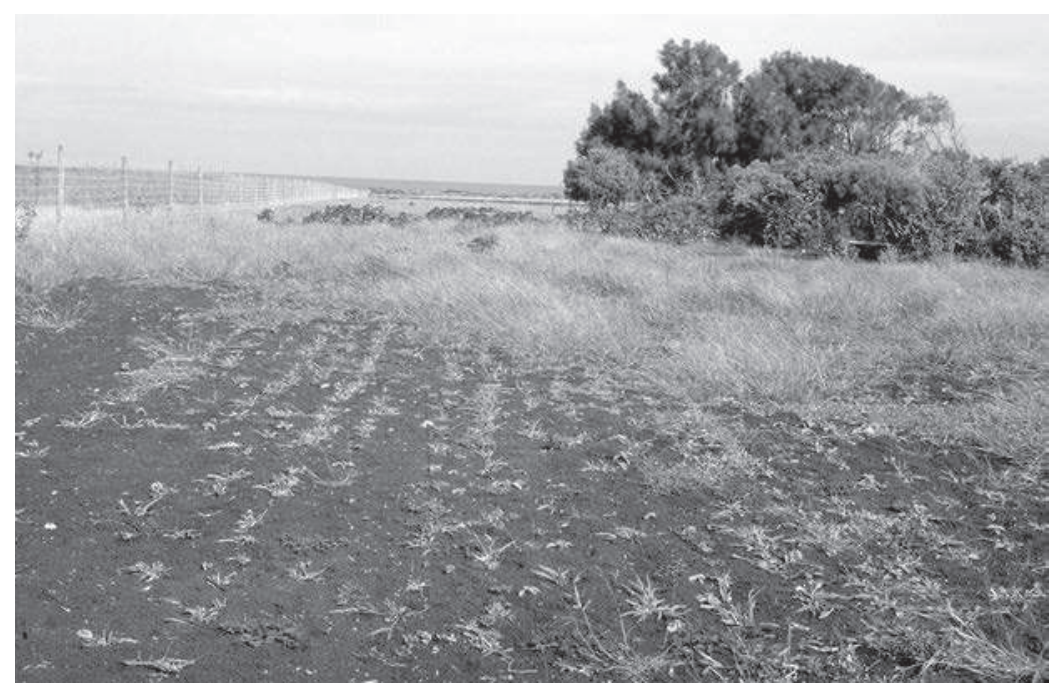

Photo 5.6.

Sursemis avec le chisel seeder de deux graminées et de trois légumineuses à Ouaco, côte ouest de Nouvelle-Calédonie. (৫ H. D. Klein)

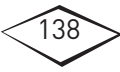




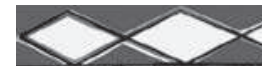

Pour un travail manuel, on peut s'aider d'un semoir manuel, avec ouverture puis fermeture de la ligne de semis, ou d'une canne planteuse brésilienne (photo 5.7) qui injecte à chaque opération un petit nombre de graines et éventuellement de l'engrais dans le sol.

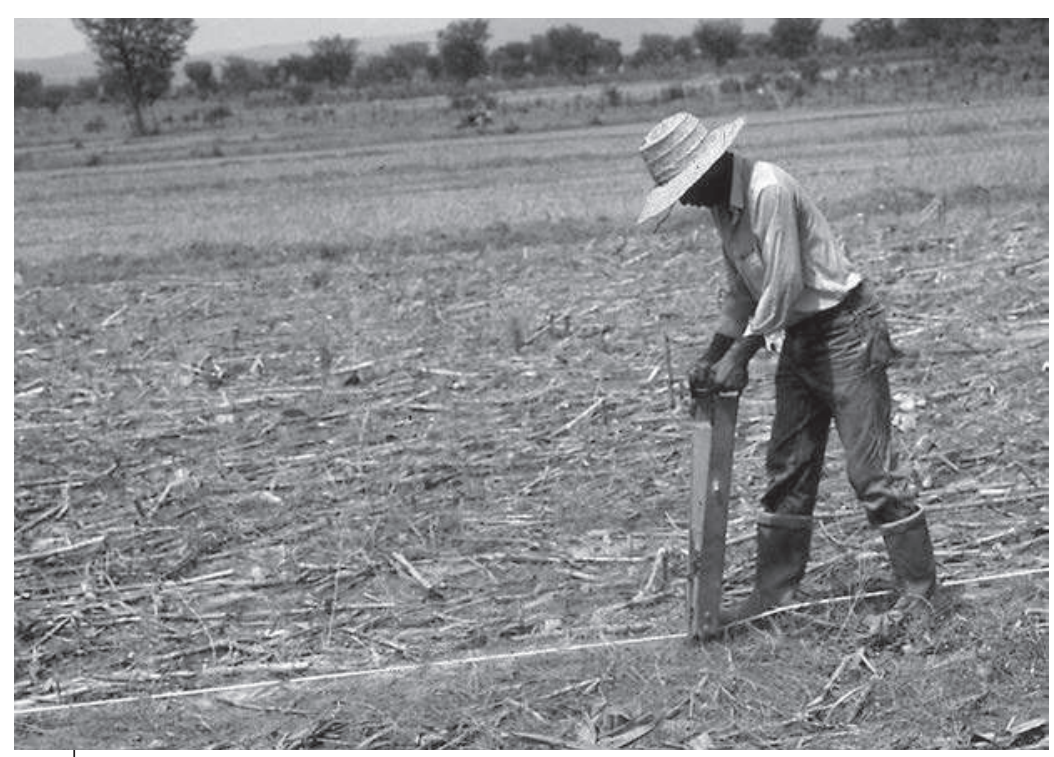

Photo 5.7.

Sursemis manuel sur des résidus de Maïs avec une canne planteuse (origine Brésil), à Touboro, Nord-Cameroun. (@ H. D. Klein)

Pour réduire ou annuler la compétition entre la plante de couverture et la culture nouvellement semée, il est préférable de semer sur une couverture morte (photo 5.8). Celle-ci résulte soit d'une plante annuelle à la fin de son cycle, soit d'une plante vivace détruite à l'aide d'un herbicide juste avant le semis direct. La technique du semis direct s'est développée avec l'apparition en 1956 d'un herbicide total peu rémanent (Roundup ${ }^{\circledR}$ ) et des premiers semoirs utilisables sans travail du sol.

Une plante de couverture doit être facile à établir, capable de couvrir rapidement le sol et de croître rapidement pour limiter la compétition des adventices. Soit elle sert simplement de support à un semis direct, soit elle est maintenue un grand nombre d'années pour assurer une couverture permanente dans des plantations pérennes comme le palmier à huile ou les fruitiers; il faut bien sûr que la couverture reste efficace plusieurs années, ce qui suppose que la plante de couverture n'ait pas disparu (pâturée, brûlée ou désagrégée).

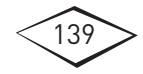



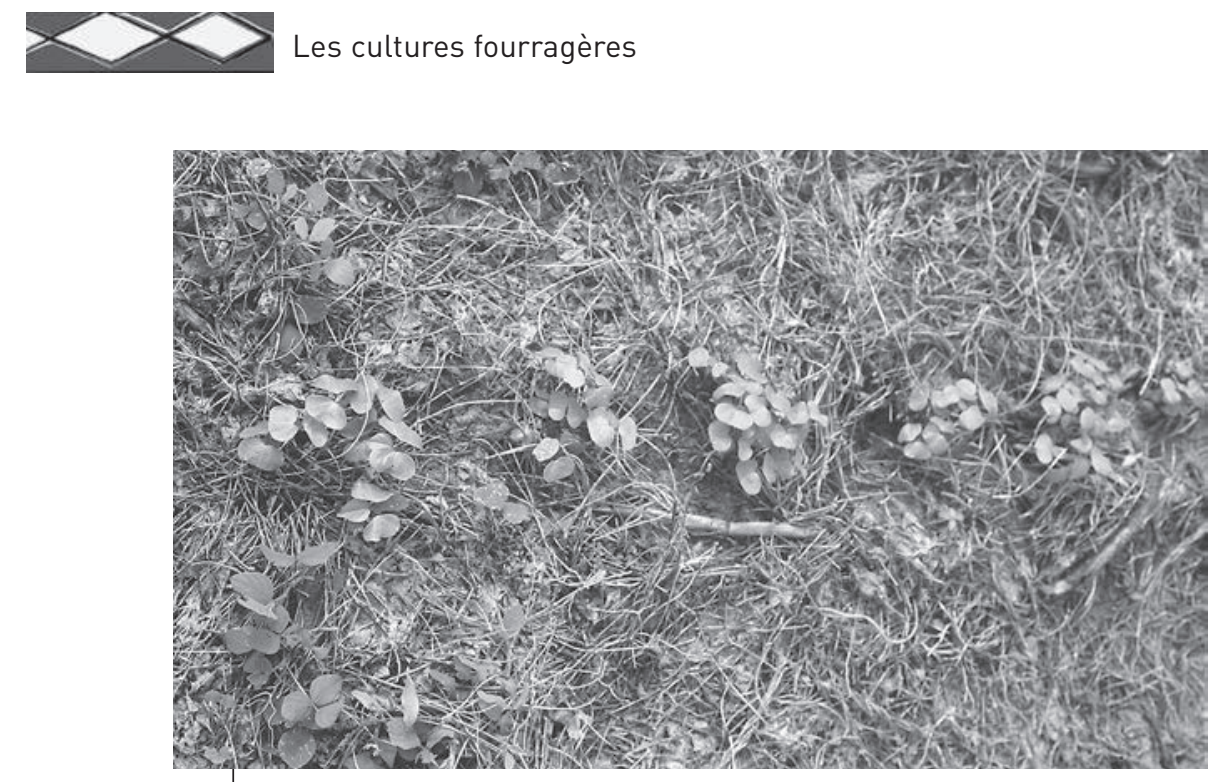

Photo 5.8.

Levée de plants de cotonniers après semis direct dans un mulch de Calopogonium mucunoides sans traitement herbicide, Garoua (nord Cameroun). (๑ H. D. Klein)

Le semis direct de la plante principale peut avoir lieu la même année que l'installation de la couverture végétale ou l'année suivante.

- les successions intra-annuelles des deux cultures au cours de l'année ne sont possibles que si la disponibilité en eau et les températures le permettent, par exemple en zone tropicale humide avec une saison des pluies suffisamment longue, à condition que l'altitude ne soit pas trop élevée;

- les successions interannuelles permettent d'utiliser la technique du semis direct dans des zones où les successions intra-annuelles ou les associations ne sont pas possibles. Ces semis directs incluent dans les rotations des plantes d'intérêts agronomiques et/ou économiques variés pour faire évoluer favorablement les sols et augmenter le revenu des agriculteurs;

- les associations de deux plantes sur une même parcelle permettent d'utiliser la technique du semis direct dans des zones où les successions ne sont pas possibles. Ces associations sont plus ou moins faciles à gérer, la plante de couverture doit concurrencer le moins possible (lumière, eau, nutriments) la culture principale source de revenus.

En zone tropicale, le semis direct sur couverture végétale a été utilisé, d'abord au sud-ouest du Brésil en zone humide sur de grandes exploitations mécanisées (Mato Grosso), surtout pour la production agricole,

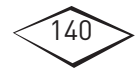




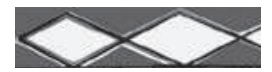

puis beaucoup plus modestement pour l'agriculture et l'élevage (usage mixte). Ces systèmes ont été remaniés et ajustés à des zones plus sèches pour les petites agricultures paysannes familiales peu motorisées au Paraná (sud-est du Brésil), pour des exploitations manuelles à Madagascar et pour des exploitations en traction animale dans les zones cotonnières des savanes africaines.

Parmi la large gamme de systèmes de semis direct sur couverture végétale adaptés aux différents milieux, trois systèmes simples peuvent être recommandés pour un usage mixte sans risque. Ils permettent d'intégrer l'agriculture et l'élevage et de répondre techniquement aux principales contraintes physiques et socio-économiques des petites agricultures du Sud, notamment sans intrants chimiques, même sur sols dégradés :

- en système irrigué, la succession intra-annuelle de riz et de vesces dans les rizières (Madagascar);

- en système pluvial (en région sèche), l'association de maïs et d'une légumineuse alimentaire et fourragère (Vigna unguiculata et Vigna umbellata, Cajanus cajan), voire de Dolichos lablab (dolique) beaucoup moins répandue;

- pour les zones plus sèches, des systèmes variés en alternance ou en association à base de Stylosanthes guianensis (précipitations inférieures à $1200 \mathrm{~mm}$ ) ou de Stylosanthes hamata (précipitations inférieures à $800 \mathrm{~mm}$ ), capables de régénérer le potentiel des sols avec un minimum d'intrants, tout en fournissant un apport fourrager aux systèmes d'élevage. Stylosanthes hamata présente en plus l'avantage de coloniser les zones dégradées alentours grâce à d'abondants resemis naturels.

La graminée Brachiaria ruziziensis et les légumineuses Mucuna spp., capables de régénérer le potentiel des sols avec un minimum d'intrants, tout en fournissant un apport fourrager aux systèmes d'élevage, sont malheureusement plus difficiles à associer aux cultures principales en raison de leur fort développement.

La compatibilité entre le semis direct sur couverture végétale et l'usage fourrager pour l'élevage n'est viable que si l'éleveur maîtrise l'espace et les ressources. C'est le cas par exemple au Mato Grosso et au Paraná, au Brésil où beaucoup d'éleveurs gèrent de façon individuelle des propriétés privées. Il en va différemment dans les systèmes agraires où la gestion et l'utilisation de l'espace et des ressources est en grande partie collective, comme dans toutes les zones sahéliennes et soudaniennes d'Afrique (par exemple à Madagascar et au nord Cameroun). 


\section{Les fertilisations de fond au semis}

Il est parfois nécessaire d'appliquer une fertilisation de fond au moment du labour car les sols tropicaux présentent généralement des carences en phosphore et en azote, et le potassium est un élément indispensable à l'assimilation chlorophyllienne de la plante. Il peut être recommandé d'apporter :

- du phosphore pour compenser l'insuffisance du sol, avec 50 unités d'acide phosphorique $\left(\mathrm{P}_{2} \mathrm{O}_{5}\right)$, jusqu'à 100 unités pour assurer une fertilisation pendant cinq années environ;

- de la potasse pour compenser la forte consommation des plantes fourragères, de l'ordre de 50 unités sous forme de potasse $\left(\mathrm{K}_{2} \mathrm{O}\right)$.

Lapport d'azote, s'il est effectué, sera appliqué aux graminées plus tard, sur des plants bien implantés et capables de consommer utilement l'azote, avec des apports fractionnés pendant la durée du cycle de végétation. Le fractionnement des apports permet de limiter le lessivage des engrais par l'eau. La quantité totale épandue peut être considérable, tant les graminées sont gourmandes en azote; le seuil économique fixe la dose maximale à épandre. Lépandage de 50 à 150 unités d'azote sur une graminée fourragère sans irrigation au cours d'une année représente une bonne fertilisation.

Au semis, la dose choisie aura pour objectif de stimuler les jeunes plantes. Mais il ne faut pas oublier que cet engrais favorisera aussi les mauvaises herbes.

Si on sème des légumineuses, l'apport d'azote peut être utile au départ pour permettre à la légumineuse de se développer, avant qu'elle ne soit capable de fixer elle-même l'azote. Un épandage de chaux $(\mathrm{CaO})$ favorise la nodulation car les légumineuses sont adaptées aux sols neutres ou légèrement basiques. Des doses de plusieurs tonnes par hectare (selon la nature de la matière brute : calcaire, marnes, craie, chaux vive ou éteinte, etc.) sont très souvent nécessaires pour modifier le $\mathrm{pH}$.

Les carences doivent être prévenues, et il faut les déterminer à l'aide d'une analyse chimique du sol ou de l'œil expert d'un professionnel. Dans les sols tropicaux acides ou sableux, on constate souvent des carences en magnésium $(\mathrm{Mg})$, élément indispensable pour la constitution de la chlorophylle, et en soufre dans les sols ferrugineux. 
Une fois le site de la culture déterminé et les espèces fourragères choisies mises en place, le producteur doit gérer au mieux l'utilisation de la production de fourrage, de façon à obtenir, sans dégradation du milieu, une production animale rentable et durable. distribués frais à l'auge immédiatement après la coupe (affouragement en vert ou zéro pâturage), ou conservés et distribués sous forme essentiellement de foin ou d'ensilage (figure 6.1). Le choix des différentes formes d'utilisation dépend du climat, des sols, des espèces cultivées, des espèces animales et du système de production (type de production, taille de l'exploitation, capacité technique, moyens financiers).

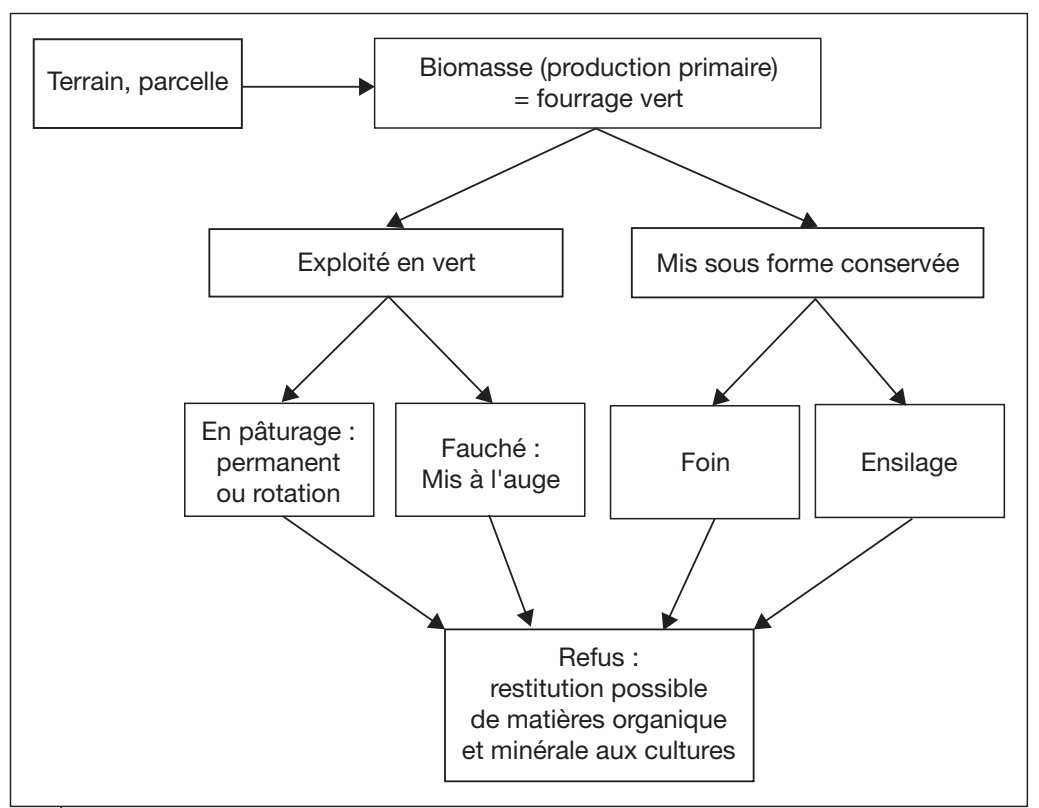

Figure 6.1.

Les différents modes d'exploitation des plantes fourragères.

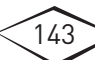




\section{Des productions de fourrages très variables}

La production de fourrage est évaluée généralement en mesurant, par des coupes au ras du sol, sur une surface connue, la biomasse présente. Ces coupes donnent une estimation de la biomasse verte (ou appelée biomasse brute) de la production aérienne du fourrage. Pour la comparer à d'autres productions, il est nécessaire d'obtenir une biomasse sèche exprimée en matière sèche (MS), c'est-à-dire pratiquement sans eau, par un séchage au soleil, ou mieux, après passage dans une étuve (jusqu'à ce que l'eau soit complètement évaporée, c'est-à-dire jusqu'à l'obtention d'un poids constant de l'échantillon). Elle est exprimée en gramme de MS par mètre carré ou en kilogramme ou tonne de MS par hectare. Pour prendre en compte les variations saisonnières, on peut aussi exprimer cette production pour une période donnée ( $\mathrm{g} \mathrm{MS} / \mathrm{m}^{2}$ par jour, par mois ou par saison); c'est une bonne expression de la productivité.

Les productions annuelles de fourrages sont extrêmement variables selon les familles de plantes, les structures du couvert, les zones agro-écologiques, les modes d'exploitation, etc. Elles sont également variables selon la saison, car elles dépendent à la fois du cycle biologique des espèces, du climat (précipitations, températures, ensoleillement et évapotranspiration) et du sol (conservation de l'humidité). La qualité du fourrage varie pour des raisons sensiblement identiques, mais inversement, la valeur fourragère, notamment des graminées, diminue rapidement avec l'évolution des stades biologiques ou avec l'augmentation des temps de repousse.

\section{IID Variation selon les plantes: type morphologique et famille}

Laugmentation de la biomasse d'un peuplement fourrager dans le temps suit une courbe d'allure sigmoïde, appelée courbe de croissance, dont la dynamique dépend des conditions du milieu (température, rayonnement, alimentation hydrique et nutrition minérale) et dont l'allure est caractéristique de l'espèce. La courbe de croissance est caractérisée par l'enchaînement de trois phases de développement pour chaque cycle de végétation :

- une croissance initiale exponentielle pendant la reconstitution de l'appareil foliaire;

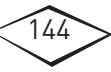


- une phase intermédiaire linéaire pendant laquelle l'élongation des organes est maximale;

- une phase finale de ralentissement jusqu'à la biomasse maximale correspondant à l'accumulation de la matière sèche produite.

La vitesse de croissance maximale (représentée par la pente de la phase linéaire) varie peu pour une région donnée, quels que soient la famille et le type morphologique, alors que les différences sont beaucoup plus importantes dans la phase initiale exponentielle et dans la phase finale d'amortissement. Ces écarts de croissance s'expliquent en partie par les différences morphogénétiques qui déterminent la structure des couverts et influencent l'utilisation et la répartition des assimilats pour la croissance des différents organes constitutifs du peuplement.

Dans un même milieu, trois types différents de courbes de croissance correspondent aux trois types morphologiques, cespiteux à fort développement, cespiteux et gazonnants (stolonifères) (figure 6.2).

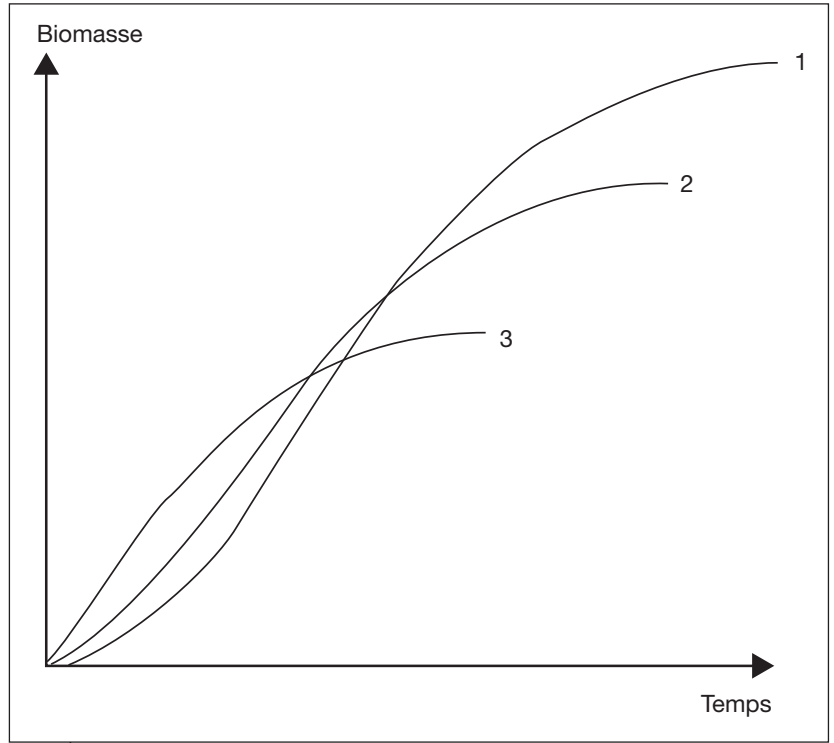

Figure 6.2.

Dynamique de croissance de la biomasse aérienne pour trois types morphologiques d'espèces.

(d'après Lemaire et al., 1999)

1. cespiteux à fort développement : graminée, Pennisetum purpureum; légumineuse, Leucaena leucocephala

2. cespiteux : graminée, Panicum maximum; légumineuse, Stylosanthes guianensis

3. gazonnant : graminée, Digitaria swazilandensis; légumineuse, Arachis pintoi

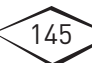


Ces différences s'expliquent aussi par l'appartenance des plantes fourragères tropicales à deux grandes familles botaniques : les graminées au groupe $\mathrm{C} 4$ et les légumineuses au groupe $\mathrm{C} 3$. En plus d'un métabolisme carboné en $\mathrm{C} 4$ plus efficace, les graminées sont, pour la plupart, morphologiquement mieux adaptées au pâturage que les légumineuses, ces deux caractères leur conférant toujours un avantage compétitif très important. En revanche, les légumineuses, par leur aptitude à fixer l'azote atmosphérique, jouent un rôle primordial en enrichissant les sols en azote, ce qui améliore la croissance des plantes.

La figure 6.3 montre l'écart de production entre les graminées tropicales en $\mathrm{C} 4$ et les légumineuses en $\mathrm{C} 3$, dans des conditions non limitantes. La même différence est observée entre des graminées en C4 (tropicales) et en C3 (tempérées).

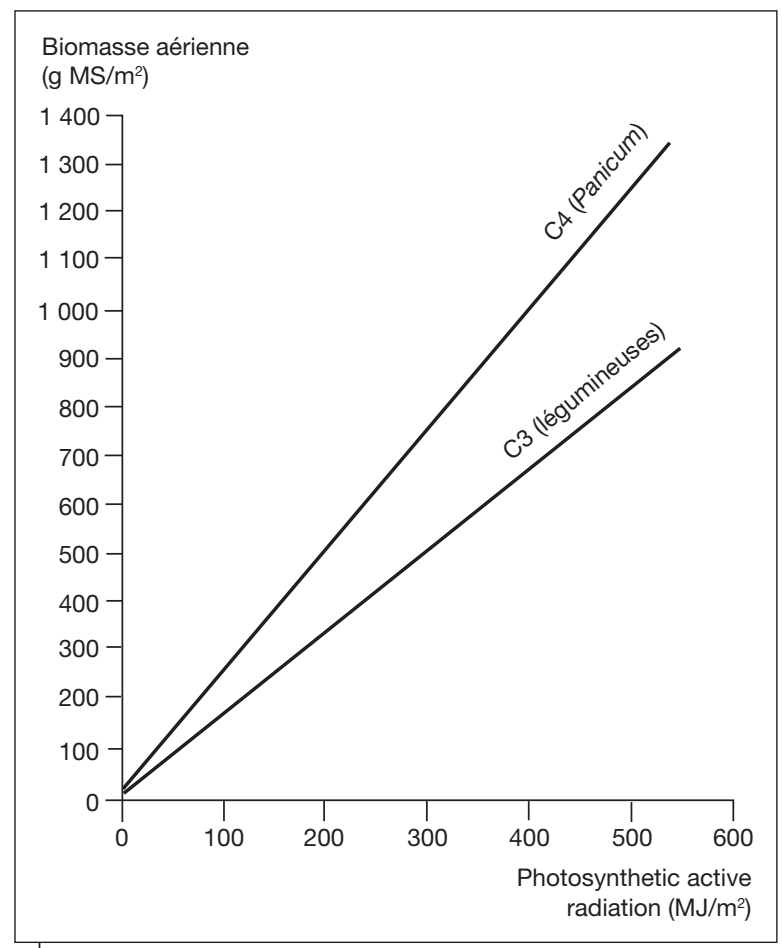

Figure 6.3.

Relation entre la production de biomasse aérienne et les quantités de rayonnement photosynthétique actif (RPA = PAR en anglais) absorbé des plantes de type C4 (graminées) et de type C3 (légumineuses). (d'après Lemaire et al., 1999)

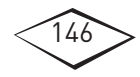




\section{ID Variation selon les conditions de milieu et les modes de production et d'exploitation}

Le niveau de production des cultures fourragères est influencé tant par les conditions du milieu (climatiques, sols) (voir chapitres 1 et 2) que par le choix des plantes et des pratiques agricoles utilisées pour la mise en place et les modes d'exploitation, d'entretien, de gestion et d'utilisation. La comparaison de systèmes intensifs en milieu sec sénégalais, sans irrigation (tableau 6.1) et avec irrigation (tableau 6.2), permet d'illustrer la diversité des productions.

Tableau 6.1. Rendements de quelques espèces fourragères cultivées en système intensif en régime pluvial dans différentes régions du Sénégal. (Roberge et Toutain, 1999)

\begin{tabular}{lll}
\hline $\begin{array}{l}\text { Précipitations } \\
\text { annuelles }\end{array}$ & $\begin{array}{l}\text { Culture fourragère } \\
\text { en pluvial }\end{array}$ & $\begin{array}{l}\text { Rendement } \\
\text { (t MS/ha/an) }\end{array}$ \\
\hline De 250 à $400 \mathrm{~mm}$ & Niébé (Vigna unguiculata) & 4 à 5 \\
\cline { 2 - 3 } & $\begin{array}{l}\text { Mil (Pennisetum americanum) } \\
\text { cultivé pour l'ensilage }\end{array}$ & 3 à 5 \\
\hline De 600 à $800 \mathrm{~mm}$ & Cenchrus ciliaris & 6 à 9 \\
\cline { 2 - 3 } & Eragrostis superba & 9 à 12 \\
\cline { 2 - 3 } & Panicum coloratum & 9 à 12 \\
\hline De 800 à $1200 \mathrm{~mm}$ & Pennisetum purpureum & 20 à 30 \\
\cline { 2 - 3 } & Panicum antidotale & 15 à 25 \\
\hline
\end{tabular}

En système irrigué, on implante soit des espèces pérennes valorisant bien l'eau et supportant les baisses de températures de saison froide (tableau 6.2), soit des espèces annuelles en saison chaude. Les quantités d'eau apportées varient en fonction du lieu : dans la région de Dakar un apport de $12000 \mathrm{~m}^{3}$ d'eau/ha/an est suffisant; plus au Nord sur le fleuve Sénégal, où les évaporations journalières sont plus fortes, les quantités requises varient de 12000 à 18000 m³/ha/an.

Les plantes fourragères destinées à l'alimentation animale sont soit directement pâturées par l'animal, soit coupées pour une distribution au bétail (affouragement en vert), ou pour la conservation, ensilage ou foin. La production de semences et de plants est traitée dans le chapitre 9.

Avec des graminées pérennes, il peut être avantageux d'alterner la fauche et la pâture pour maintenir les prairies en bon état de propreté.

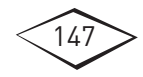


Tableau 6.2. Rendements des principales espèces fourragères cultivées avec irrigation dans la région de Dakar, Sénégal, de 1979 à 1984. (Roberge et Toutain, 1999)

\begin{tabular}{lll}
\hline Types de fourrage & Nom des plantes & Rendement (t MS/ha) \\
\hline Pérenne (toute l'année) & Panicum maximum & 20 à $30 /$ an \\
\hline En grande culture & Brachiaria mutica & 16 à 25 / an \\
\hline Annuel (saison chaude) & Stylosanthes guianensis & 8 à 12 / an \\
\cline { 2 - 3 } & Maïs fourrager & 7 à $10 /$ cycle \\
\cline { 2 - 3 } & Sorgho fourrager & $35 /$ cycle \\
\cline { 2 - 3 } & Mil fourrager & 6 à $7 /$ cycle \\
\cline { 2 - 3 } & Niébé & 3 à $5 /$ cycle \\
\hline Annuel (saison froide) & $\begin{array}{l}\text { Lolium italicum } \\
\text { (Ray grass d'Italie) }\end{array}$ & $\begin{array}{l}10 \text { à } 15 / 6 \text { mois } \\
\text { en } 5 \text { coupes }\end{array}$ \\
\cline { 2 - 3 } & $\begin{array}{l}\text { Medicago sativa } \\
\text { (Luzerne) }\end{array}$ & $\begin{array}{l}16 \text { / } 6 \text { mois } \\
\text { en } 4 \text { coupes }\end{array}$ \\
\hline
\end{tabular}

La fauche aide à contrôler les adventices et à éliminer les refus tout en constituant un stock de fourrage conservé, tandis que la pâture permet un retour de matière organique au sol. La fauche peut toutefois être déconseillée lorsque des espèces envahissantes à reproduction végétative sont présentes, car elle favorise l'augmentation des drageons et des tiges axillaires.

\section{L'exploitation par pâturage direct}

Lexploitation par la pâture réduit le temps de travail de l'exploitant, puisque la récolte est assurée directement par l'animal lui-même. De plus, une partie des nutriments ingérés est restituée au sol, mais l'exploitation directe présente aussi quelques inconvénients comme le gaspillage et la dégradation de la flore, que l'on peut toutefois limiter par une gestion du pâturage adaptée.

\section{Comment conduire les animaux?}

Faut-il conduire les animaux vers le fourrage, ou apporter le fourrage aux animaux? Les éleveurs ont le choix entre cinq modes de conduite, très souvent combinés entre eux selon les saisons et les systèmes.

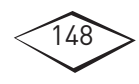


Le pâturage libre est répandu partout où les surfaces pâturables sont importantes et le plus souvent non attribuées et non clôturées, la mobilité des troupeaux est forte et la main-d'œuvre abondante et peu onéreuse. Les animaux se déplacent librement, en cherchant euxmêmes fourrage et eau, et reviennent éventuellement dans un enclos la nuit.

Le gardiennage est très souvent associé au pâturage libre partout où la mobilité est importante. Les animaux sont gardés par un berger qui choisit les lieux de pâture et d'abreuvement, rythme les différentes activités et empêche les animaux d'aller dans les champs cultivés.

Le pâturage en parcelles clôturées est répandu partout où les surfaces sont attribuées, avec des élevages suffisamment rémunérateurs pour rentabiliser l'investissement en clôtures qui varie selon la taille des parcelles, certaines parcelles en ranching couvrent plusieurs centaines d'hectares. Le parcellaire permet une délimitation nette, un contrôle de l'accès au pâturage et surtout des modes de gestion des pâturages favorables à une intensification des productions animales et végétales.

Le pâturage au piquet est pratiqué par des agriculteurs-éleveurs qui ne disposent pas de pâturages, ou qui utilisent des pâturages non clôturés, et qui ont un petit nombre d'animaux. Le piquet est déplacé chaque jour ou deux fois par jour sur une surface nouvelle et la longueur de la corde doit assurer l'accès à une quantité suffisante de fourrage. Cette technique, très utilisée notamment aux Antilles et à Mayotte, peut être considérée comme une forme intensive du pâturage en rotation.

Le zéro-pâturage est bien adapté aux productions intensives et aux élevages dans des zones périurbaines. Le fourrage et les alimentscompléments sont apportés aux animaux qui sont immobilisés dans un lieu fixe.

\section{ID Comment conduire le pâturage?}

Le rythme de pâturage détermine le schéma de l'exploitation de la surface fourragère. Il existe plusieurs modes d'exploitation des cultures fourragères pluriannuelles et des pâturages naturels : en continu (pâtures permanentes), avec des périodes de repos (pâtures en rotation) (figure 6.4).

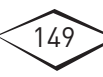




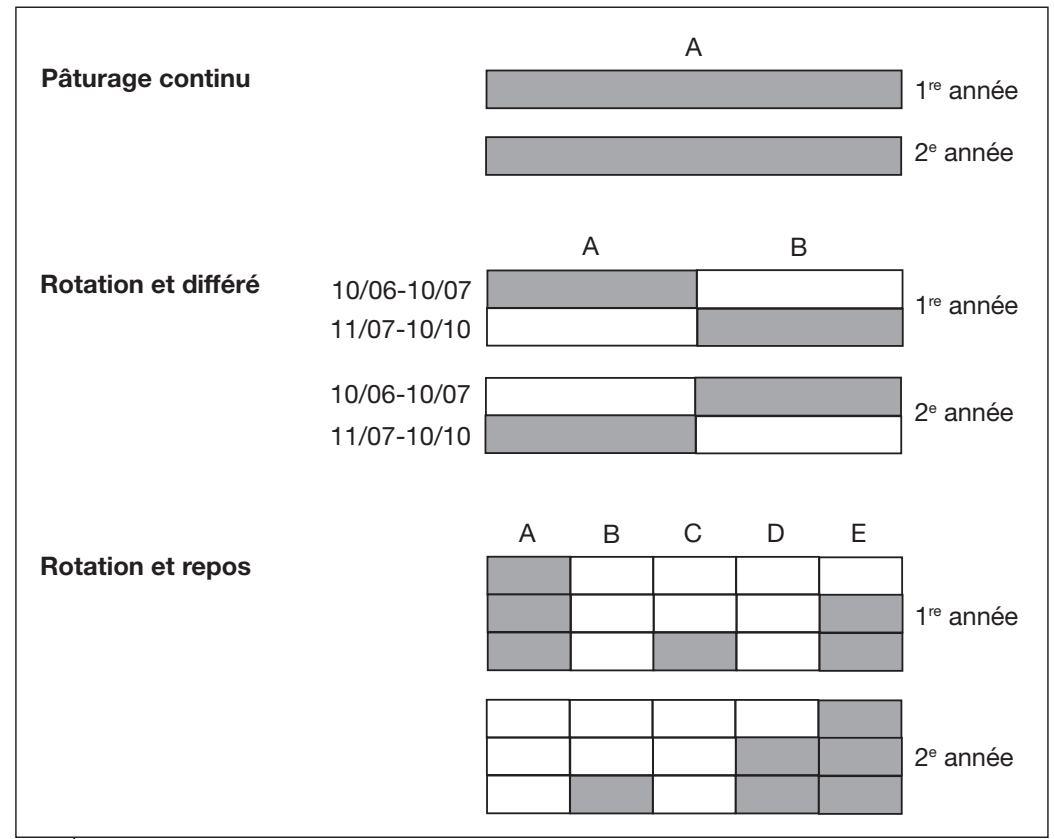

Figure 6.4.

Les principaux systèmes de pâturage. (d'après Daget et Godron, 1995)

\section{Le pâturage permanent ou continu}

Dans le système de pâturage continu le troupeau dispose de l'ensemble de la surface fourragère à pâturer, de jour comme de nuit, tout au long de la saison ou de l'année. Les animaux choisissent eux-mêmes les espèces et les zones à pâturer. Ce système convient à des troupeaux de taille limitée, avec des charges relativement faibles et dans des zones humides où la production d'herbe varie peu au cours de l'année, c'està-dire plutôt à des élevages extensifs; il est également pratiqué dans la plupart des ranches au cours de la saison sèche.

La pâture continue offre beaucoup d'avantages; d'abord du fait de la simplicité des aménagements, donc de faibles investissements, avec une clôture périphérique, un point d'abreuvement, de l'ombrage et des pierres à lécher. Les animaux étant contenus à l'intérieur des clôtures, il n'y a généralement pas de berger et la surveillance est limitée. Elle présente néanmoins des inconvénients en période de croissance de la végétation en raison de l'irrégularité d'exploitation à l'intérieur du parc, surpâturage dans certaines zones et sous-pâturage dans d'autres;

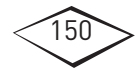


les animaux reviennent régulièrement sur les plus jeunes plantes et les repousses, ce qui peut épuiser la végétation et créer une certaine hétérogénéité dans le couvert. Dans les associations végétales, les animaux consomment plus volontiers les légumineuses que les graminées, ce qui provoque leur disparition. Ces inconvénients peuvent être partiellement corrigés par le déplacement dans les parcelles des pôles d'attraction comme les pierres à lécher, ce qui permet d'influencer les déplacements des animaux et de favoriser une exploitation plus homogène des parcelles.

Pour survivre à de fréquentes périodes de surpâturage, les espèces fourragères des prairies permanentes doivent être solidement enracinées pour ne pas être arrachées. En effet, la consommation des animaux étant difficile à ajuster à la production fourragère, le tapis végétal pérenne se dégrade et évolue vers une végétation spontanée hétérogène. Les tâches d'entretien consistent le plus souvent à éliminer mécaniquement les refus et à contrôler l'invasion par des plantes indésirables, notamment des ligneux. Le gyrobroyage ou la fauche de certaines plantes sont déconseillés car celles-ci peuvent se révéler envahissantes.

\section{Le pâturage en rotation}

Lalternative au pâturage continu est le pâturage en rotation sur plusieurs parcelles, dont les tailles et les compositions végétales peuvent être diverses. Le système repose sur quelques principes :

- exploiter un maximum d'herbe de qualité optimale, afin d'utiliser au mieux la charge animale (au bénéfice de la prairie) et le potentiel de production des animaux (au bénéfice des animaux). On évite ainsi le vieillissement des plantes donc leur perte de valeur et on limite les quantités de refus;

- respecter des niveaux de chargement stables et similaires lors des différents passages;

- conduire des rythmes de rotation régulière. Toute variation importante en temps de passage, rotation ou niveau de chargement se traduit par des perturbations du couvert fourrager;

- laisser aux plantes fourragères des périodes de repos indispensables à leur reconstitution après la consommation par les animaux. On améliore ainsi la durée de vie de la prairie;

- réduire la proportion de refus liés au vieillissement des organes végétaux, et en même temps contrôler l'envahissement par les plantes indésirables.

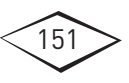


La gestion du pâturage en rotation repose sur un séjour aussi court que possible dans chaque parcelle (donc avec une forte charge instantanée) et un temps de repos optimal de plusieurs semaines entre deux passages du troupeau. On cherche à concilier la quantité et la qualité du fourrage offert aux animaux. Un séjour court évite en effet le gaspillage, par piétinement ou par écrasement de l'herbe, et par les souillures des déjections.

Lutilisation des cultures fourragères et des prairies est d'autant plus intensive que le nombre de parcelles est élevé. La parcellisation permet l'allotement du bétail, c'est-à-dire le groupement des animaux par catégories selon leurs besoins : vaches laitières ou allaitantes, mâles à l'engraissement, animaux à l'entretien (vaches sèches, génisses...). Selon le découpage choisi, chaque parc a ses particularités dont on tient compte dans le choix des rotations. Mais il nécessite un investissement important en clôtures, en couloirs entre parcelles et abreuvoirs, et des moyens en main-d'œuvre pour déplacer les animaux.

\section{ID Quand et comment exploiter les pâturages?}

La première exploitation d'une plante fourragère est particulièrement importante pour la survie d'une jeune plantation. Elle doit être effectuée de six à douze mois après son installation, avec soin, sans abîmer le sol (qui est meuble en saison des pluies), en fauchant les plantes à plus de $10 \mathrm{~cm}$ de hauteur, et en retirant l'herbe de la prairie. Il est aussi possible de faire pâturer avec une forte charge, mais rapidement en quelques jours, afin que les animaux n'arrachent pas les jeunes plantes encore peu enracinées. Ce passage, appelé déprimage, doit être contrôlé par l'éleveur afin d'éviter une concentration élevée d'animaux tassant le terrain.

Pour certaines espèces, l'exploitation de la prairie doit être peu intensive, voire inexistante en première année pendant toute la période végétative, pour obtenir un maximum de fleurs et surtout de graines. En climat équatorial (par exemple dans l'État du Pará au Brésil, en Guyane française), la plupart des espèces (Brachiaria brizantha, Brachiaria decumbens, Brachiaria ruziziensis) exprime, dès les premiers mois, un fort développement foliaire qui ne correspond pas à leur développement racinaire. En première année, six à neuf mois après le semis, une exploitation modérée est donc possible. Ceci nécessite une bonne connaissance de la physiologie de la plante, qui varie avec

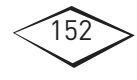


les conditions climatiques et aussi d'une plante à l'autre, voire d'un cultivar à l'autre.

Pour juger de la possibilité d'admission des animaux dans une parcelle ou de la nécessité de leur retrait il n'existe pas de règle absolue, l'habileté et l'expérience de l'éleveur étant décisives. En plus de l'évaluation «à l'œil» de la masse fourragère sur pied, l'éleveur peut utiliser un herbomètre ou le disque-herbe dans une végétation monospécifique basse, cette mesure fournit une évaluation de la quantité d'herbe disponible.

On se réfère habituellement à quelques repères usuels :

- sur une parcelle récemment semée en graminées (ou après plantation de boutures), on laisse la culture s'installer et couvrir le sol, en moyenne pendant six mois après le semis (voire plus de neuf mois en sol humide ou sableux). Le système racinaire, qui se développe plus lentement que le système foliaire, atteint généralement les deux tiers de la biomasse totale;

- en période de végétation active sur une parcelle déjà installée, le temps de repos minimum après la sortie des animaux ou une coupe est de trois à quatre semaines. Au-delà de six semaines de repos, la qualité des repousses baisse;

- on retire les animaux pour changer de parcelle quand on constate que le fourrage de meilleure qualité a été intégralement consommé. La durée de séjour peut être prolongée si l'on veut rabattre davantage les plantes et réduire l'importance des refus. Au contraire, on veillera à faire des rotations rapides si l'on vise la performance des animaux. La décision de retirer les animaux prend aussi en compte la bonne gestion de l'herbe; par exemple, on veille à ne pas affaiblir les plantes fourragères par une exploitation trop longue et trop intense si l'on craint la compétition de plantes adventices;

- en période de faible croissance des plantes fourragères (pleine saison des pluies, saison froide, saison sèche chaude), le temps de repos nécessaire est plus long et toutes les parcelles sont successivement pâturées. On peut inclure alors une parcelle de réserve, ou parcelle tampon, utilisée seulement à cette période, et non utilisée en période de végétation active;

- en période de repos végétatif (saison sèche froide), la rotation étant inutile, il est fréquent d'ouvrir et de faire communiquer toutes les parcelles; on passe d'un système en rotation à un système en pâturage continu jusqu'à la période de végétation active suivante. Au cours de cette période, l'herbe est peu sensible à la forte pâture;

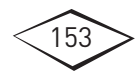


- en zone humide, pour mieux gérer la quantité et la qualité de l'herbe et les écarts de croissance entre saison des pluies et saison sèche, il faut limiter les apports d'azote en saison des pluies et les augmenter en saison sèche afin de stimuler la vitesse de croissance de l'herbe. Si nécessaire, des parcelles sont fauchées pour la production de réserves fourragères; le choix des parcelles à faucher tient compte de la quantité et de la qualité de l'herbe disponible et des conditions climatiques.

Dans des systèmes intensifs, l'éleveur peut définir une «fenêtre de pâturage». Les limites quantitatives maximale et minimale de cette période correspondent à des quantités d'herbe au-dessus et au-dessous de laquelle il n'est pas conseillé de pâturer la prairie, et la limite qualitative correspond à la date à partir de laquelle la qualité de l'herbe permettant une production animale individuelle satisfaisante n'est plus assurée.

Pour chaque espèce fourragère, il est possible de déterminer, à partir de l'allure de la courbe de croissance (quantité) et de la courbe de digestibilité ou de teneur en azote (qualité), les limites de bonne utilisation fourragère dans différentes conditions (sans ou avec intensification) (figure 6.5) :

- la limite quantitative minimale, pour éviter les risques de surpâturage et de dégradation de la prairie, correspond approximativement pour les graminées à une biomasse minimale de 0,75 à $1,5 \mathrm{t} \mathrm{MS} / \mathrm{ha}$;

- la limite quantitative maximale, pour éviter le gaspillage par piétinement et ne pas compromettre la repousse, correspond à une biomasse maximale de 2,5 à 4,5t MS/ha pour les graminées;

- la limite qualitative, pour permettre une production animale individuelle satisfaisante et éviter les refus dus à la lignification de l'herbe, correspond à un stade variable selon la plante et le type de repousses. Pour les graminées, c'est le stade épiaison avec une repousse reproductrice, ou le stade feuillu avant la sénescence des feuilles avec une repousse feuillue.

Sans apport d'engrais, la croissance étant lente, la mise à la pâture a lieu tardivement et le bon déroulement du pâturage est très souvent limité par une valeur alimentaire qui n'est plus satisfaisante. En revanche, avec apport d'engrais, la croissance étant plus importante et surtout plus rapide, la mise à la pâture peut être plus précoce et, très souvent, les limites quantitatives déterminent la décision d'arrêter la pâture, et non pas la valeur alimentaire de l'herbe. Dans la pratique, ces limites sont peu respectées, par négligence ou très souvent «faute de mieux».

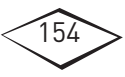




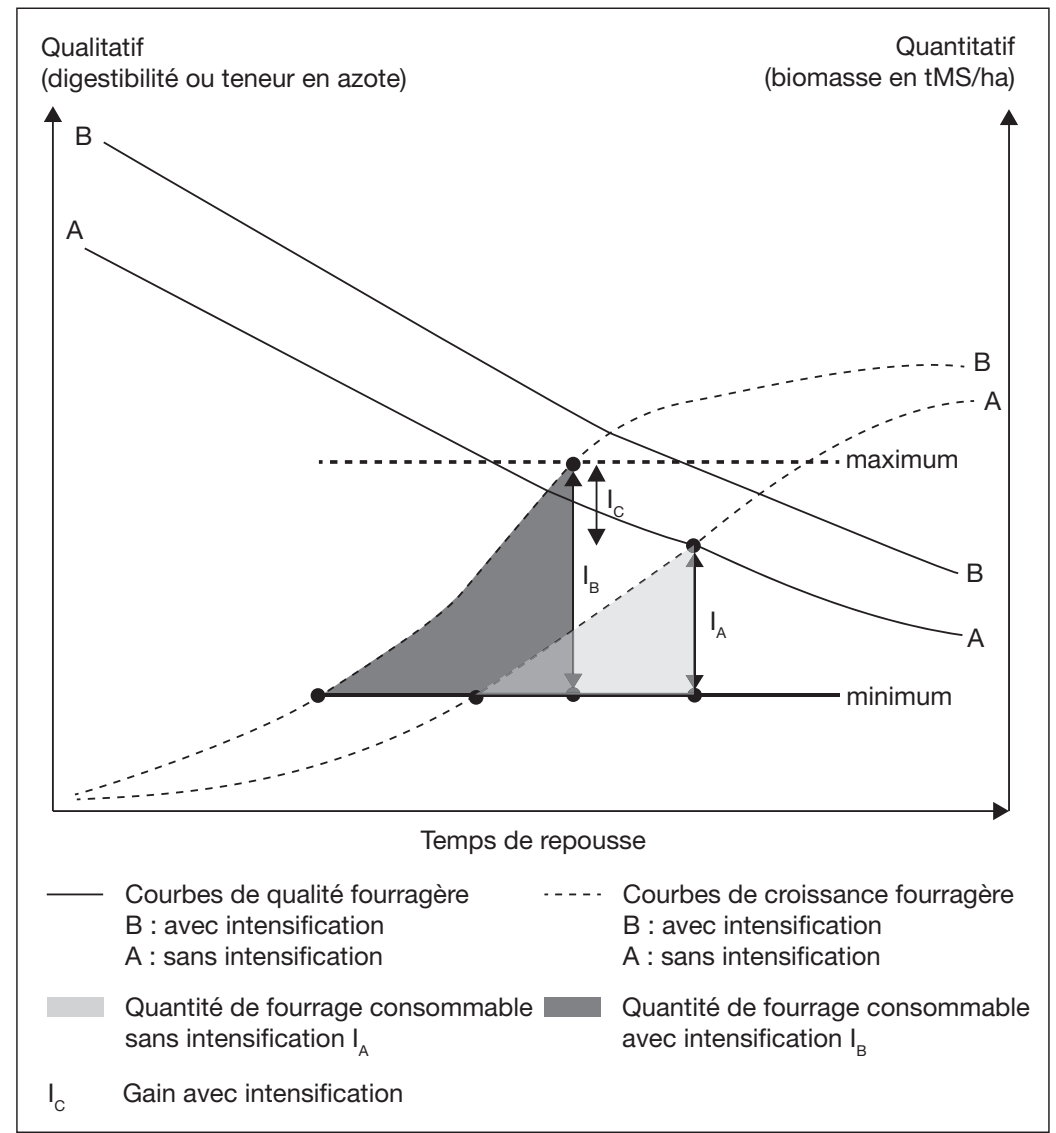

Figure 6.5.

Limites quantitatives et qualitatives déterminant les quantités de fourrages consommables pour une bonne utilisation des pâturages, avec et sans azote. (d'après Hnatyszyn et Guais, 1988)

En saison des pluies, on exploite les graminées tous les 30 à 45 jours et les légumineuses tous les 45 à 60 jours, du fait de leur croissance plus lente. En saison fraîche ou en système irrigué, la qualité diminuant moins vite, ces délais peuvent être rallongés d'une quinzaine de jours, soit 45 à 60 jours pour les graminées et 60 à 75 jours pour les légumineuses. Le nombre d'exploitations d'une culture fourragère au cours de l'année et le nombre d'années d'exploitation dépendent du type de cultures, des plantes, des modes d'exploitation et bien sûr des offres et des besoins en fourrage.

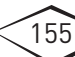




\section{IID Les différents types de rotation}

Selon le nombre de parcelles, le rythme de rotation et l'intensité du système fourrager, on distingue plusieurs types de rotation.

\section{Le pâturage alterné}

Le pâturage alterné est le plus simple des systèmes en rotation. Il consiste à faire pâturer les animaux en alternance sur deux parcelles, généralement de même dimension, en laissant les plantes au repos pendant au moins trois semaines. Les espèces mises au repos reconstituent ainsi leurs réserves et ne sont pas exploitées à un stade trop précoce. Les charges peuvent être plus élevées qu'en pâture continue et l'exploitation est mieux répartie dans l'espace, les engrais mieux utilisés et les animaux mieux surveillés. En revanche, l'investissement en clôtures et en pare-feu est plus élevé et la gestion demande un peu plus de travail.

Ce système est adapté aux espèces fourragères supportant de fortes charges, résistantes au piétinement, à vitesse de croissance rapide, présentes aussi bien sous les tropiques humides que subhumides.

\section{Le pâturage tournant}

Le pâturage tournant désigne plus spécifiquement la pâture en rotation en système relativement intensif avec des clôtures fixes, des parcelles comparables entre elles et d'une taille adéquate pour assurer une défoliation régulière. Le nombre de parcelles est compris en général entre deux et douze, l'objectif étant de mieux tirer parti de la vitesse de croissance de l'herbe et de sa qualité : le choix du temps de repos optimal est un compromis entre la qualité et la quantité. Le nombre de parcelles dépend aussi des moyens disponibles (maind'œuvre, moyens financiers et techniques), du type de production choisie (lait ou viande), de l'espèce cultivée et de l'allotement du bétail. Chaque parcelle est pourvue d'un point d'eau, d'une pierre à lécher (complément minéral) et éventuellement, d'un coin d'ombre.

Le temps de repos de l'herbe entre deux passages peut varier entre 20 et 50 jours selon la vitesse de croissance de l'herbe, l'espèce végétale et le type d'animal. En début de saison des pluies, la vitesse de croissance étant rapide, le temps de repos sera donc court. Le temps de séjour optimal par parcelle se situe entre quatre et cinq jours. On s'efforce d'équilibrer pour cela la charge animale à la taille de la parcelle.

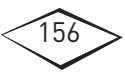




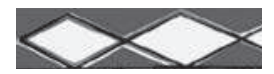

\section{Le pâturage rationné}

Le pâturage rationné est une forme intensive d'exploitation d'une culture fourragère. Le troupeau est confiné à l'une des extrémités de la parcelle et contenu par une clôture électrique mobile. Dans les systèmes très intensifs (le plus souvent pratiqués dans les pays du Nord), on avance cette clôture une ou deux fois par jour, de sorte que les animaux disposent ainsi d'herbe fraîche et consomment pratiquement tout le fourrage à leur disposition. Un autre fil à l'arrière limite les mouvements des animaux sur la parcelle pour empêcher le piétinement et surtout la pâture des jeunes repousses; on ne la déplace que tous les deux ou trois jours. Ce système très intensif a l'intérêt de réduire les pertes et les gaspillages grâce à une exploitation régulière, rapide et complète de l'herbe sur pied. Il oblige les animaux à ne pas faire de sélection et diminue ainsi les refus. Il évite aussi les variations de production laitière qui sont constatées avec des temps de passage de plus d'un jour. En revanche, il demande plus de main-d'œuvre et plus de technicité. Il faut en effet déplacer la clôture, dégager l'herbe sous le fil, adapter la quantité d'herbe aux besoins du troupeau, faucher des surfaces, assurer l'alimentation et la maintenance du système électrique, protéger le matériel du vol, etc.

Le pâturage rationné est surtout utilisé pour la production laitière, seule production permettant de rentabiliser un tel investissement.

Quand le nombre d'animaux est limité à quelques têtes, l'éleveur peut simplement les attacher à un piquet, et il organise la pâture rationnée en jouant sur la fréquence de changement de place et la longueur de la corde.

\section{Le pâturage de complément : les banques fourragères}

Le pâturage de complément est constitué de cultures fourragères de bonne qualité que l'on fait pâturer un court moment de la journée à certaines périodes de l'année, par exemple au retour du pâturage sur parcours, et pour des animaux choisis en fonction de leurs besoins (lactation, engraissement de finition).

On distingue :

- les banques fourragères énergétiques avec des graminées généralement pâturées;

- les banques fourragères de protéines avec des légumineuses herbacées, généralement pâturées;

- les banques fourragères de protéines avec des ligneux (photo 6.1), pâturées, ou coupées et portées aux animaux.

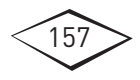



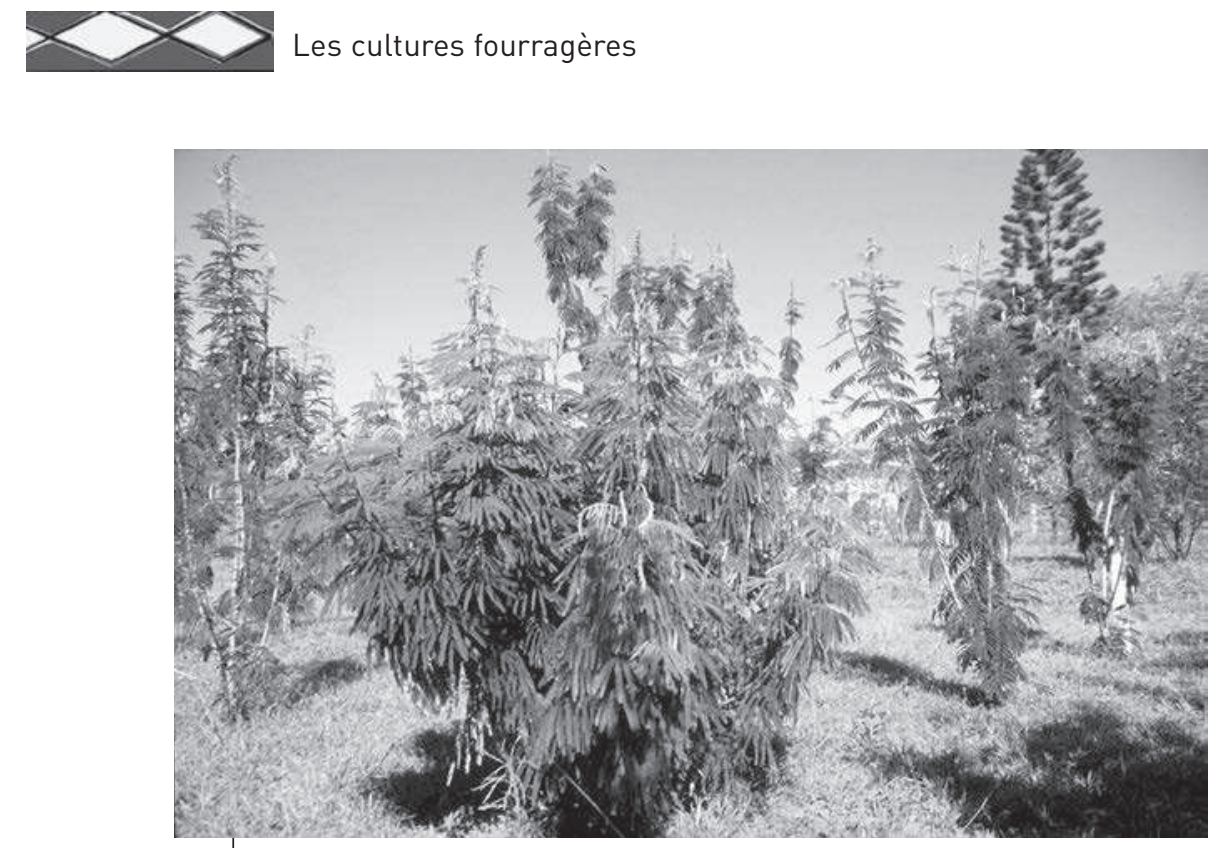

Photo 6.1.

Plantation de Calliandra calothyrsus servant de complément alimentaire aux cerfs d'élevage au pâturage, Port Laguerre, côte ouest de Nouvelle-Calédonie. (@ H. D. Klein)

Un dispositif un peu comparable est quelquefois utilisé en Australie en zone sèche : des pâturages naturels à base de graminées sont enrichis avec des légumineuses à forte capacité de resemis naturel comme Stylosanthes hamata semées sur des surfaces réduites. Ces dernières sont pâturées épisodiquement par des animaux, ce qui permet un resemis naturel des légumineuses sur tout le dispositif.

Ces parcelles ne nécessitent pas forcément de clôture, sauf si on a besoin de les protéger d'animaux extérieurs en divagation. Au cours de son déplacement quotidien, le berger fait séjourner le troupeau sur ces pâtures de complément. Le pâturage «mixte» avec des bovins, des ovins et/ou des équins permet de gérer le couvert herbacé en jouant sur les spécificités et les complémentarités de sélection et de besoins des différents herbivores.

\section{II) Les charges animales}

Tous les systèmes d'exploitation sont liés à la notion de charge qui traduit la relation entre les animaux (exprimée en nombre de têtes, en

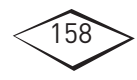


unité de bétail, en poids ou en gain de poids vif [PV]) et le pâturage (exprimé en unité de surface ou en biomasse).

Deux unités animales sont utilisées dans les zones tropicales francophones :

- l'Unité gros bétail (UGB), définie par une vache laitière de $600 \mathrm{~kg}$ PV produisant annuellement 30001 de lait, consommant $19 \mathrm{~kg} \mathrm{MS} /$ jour et ayant des besoins énergétiques annuels de $3000 \mathrm{UF}$;

- l'Unité bétail tropical (UBT), correspondant à une vache allaitante de $250 \mathrm{~kg}$ PV à l'entretien consommant 6,25 kg MS/jour.

Le taux de charge d'un pâturage est défini, pour une période donnée par le nombre d'animaux d'une certaine classe d'âge, ou mieux par le nombre d'unités animales par unité de surface (en général UBT/ha), ou le nombre de kilos de poids vif animal par unité de surface, ou par la surface disponible par unité animale (ha/UBT ou ha/100 kg de $\mathrm{PV}$ ). Il dépend à la fois de la quantité d'herbe présente, de sa vitesse de croissance, de la qualité et de la quantité d'herbe volontairement ingérée par l'animal.

La capacité de charge optimale, ou le taux de charge optimal, est la quantité de bétail que peut supporter le pâturage sans être détérioré, le bétail devant rester en bon état d'entretien, voire prendre du poids ou produire du lait pendant son séjour sur le pâturage. La capacité de charge dépend de la quantité de fourrage produit, mais aussi de la valeur du fourrage mis à la disposition du bétail, afin que celui-ci puisse extérioriser des performances économiquement satisfaisantes (Boudet, 1984).

Quand l'offre fourragère n'est plus assez abondante, ou de moindre valeur nutritive, ou moins appétible et plus difficile à brouter, ou que la charge animale est trop élevée, la consommation par tête diminue et devient inférieure à la capacité d'ingestion. Dans ces conditions, le gain de poids individuel diminue fortement et peut même devenir «négatif», c'est-à-dire que l'animal maigrit et que la végétation, surpâturée, risque de se dégrader. Ainsi avec une charge de plus en plus élevée, le gain de poids individuel, d'abord stable, diminue rapidement à partir d'un certain seuil, alors que le gain de poids par hectare augmente jusqu'à un seuil légèrement plus élevé, puis diminue très brutalement. La capacité de charge optimale est située à l'intersection de ces deux courbes et une zone optimale plus ou moins large est définie de part et d'autre de ce seuil (figure 6.6).

L'évolution et la durée de vie de la prairie dépendent beaucoup du taux de charge, de la stabilité des chargements en adéquation à la pression

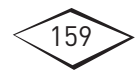




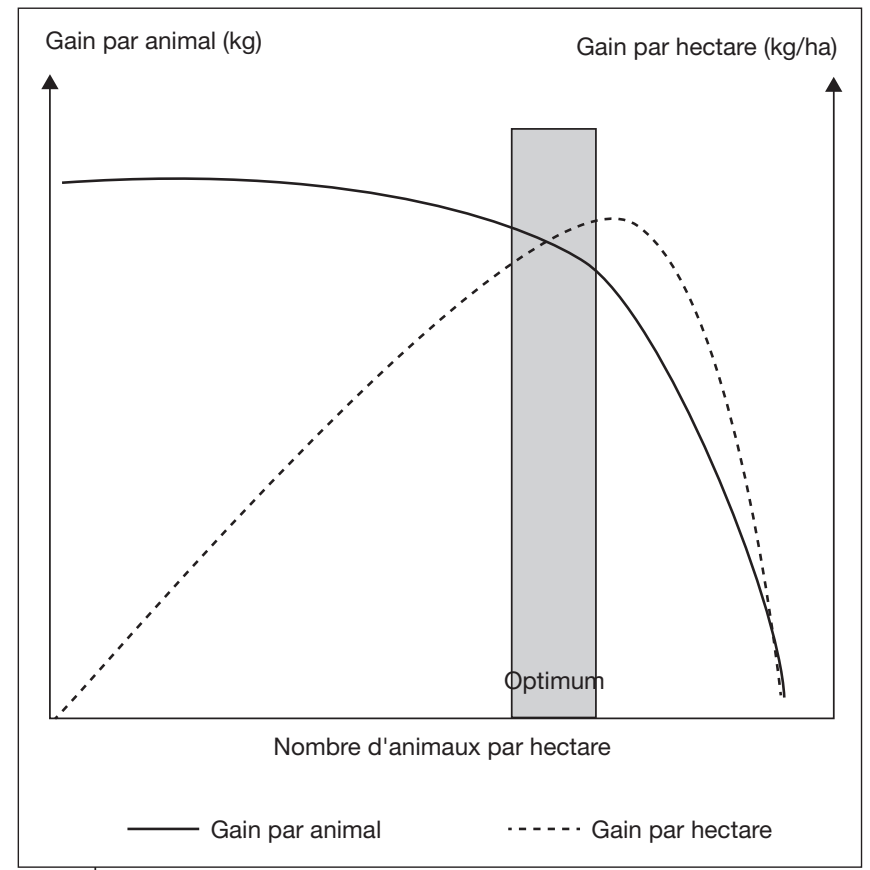

Figure 6.6.

Relations entre la production par animal,

la production par hectare et la charge animale

(d'après Mott, 1960)

réelle selon les saisons et des pratiques d'entretien et de fertilisation. Pour utiliser au mieux et de façon la plus durable possible la production de fourrage, l'éleveur doit trouver le bon ajustement entre la capacité de production du pâturage et le nombre d'animaux qui pâturent.

La sous-exploitation provoque du gaspillage, avec accumulation des refus et conduit à un accroissement du salissement, voire même de l'embroussaillement dans les zones de savanes humides.

L'exploitation excessive épuise et élimine les plantes les plus appétées. Les graminées pérennes broutées en permanence avec une charge annuelle forte (par exemple supérieure à 3 ha/UBT en zones de savanes) épuisent leurs réserves racinaires pour élaborer de nouvelles pousses et ne parviennent plus, dans ces conditions, à reconstituer leurs réserves souterraines. La biomasse racinaire, qui représente généralement le triple de la production aérienne de ces plantes, tend à se réduire et entretient de moins en moins le stock de matière

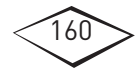


organique du sol. Elles sont progressivement remplacées par des graminées pérennes moins appétées, puis par des graminées annuelles spontanées moins productives et, pour finir, par des dicotylédones herbacées ou ligneuses non appétées.

De brusques fluctuations du niveau des charges animales instantanées produisent également des perturbations dans l'équilibre de compétition interspécifique du couvert herbagé. De telles perturbations se traduisent également par des végétaux de moins en moins pâturés et de plus en plus envahissants.

La végétation fourragère évolue sous l'influence de facteurs liés au milieu, mais également sous l'influence de facteurs liés aux modes d'exploitation. Dans les systèmes intensifs, l'effet des pratiques est très supérieur à celui des facteurs du milieu, alors que c'est l'inverse en systèmes extensifs. Néanmoins, on observe des dégradations du fait de l'embuissonnement par Chromolaena odorata résultant du surpâturage lié à des pratiques extensives en Afrique centrale.

\section{Utilisation des fourrages après la coupe et modes de conservation}

Outre le pâturage, mode de récolte le plus fréquent et le plus économique, le fourrage peut être coupé, puis soit distribué immédiatement après la coupe, affouragement en vert ou zéro pâturage, soit conservé et distribué sous forme de foin, d'ensilage ou d'herbe déshydratée.

\section{II) Les coupes en vert et l'affouragement à l'auge}

Lherbe est fauchée et éventuellement hachée s'il le faut (cannes de Pennisetum purpureum par exemple), puis transportée sur le lieu d'utilisation, avant d'être placée dans une auge pour qu'elle reste propre (photo 6.2). L'herbe verte est renouvelée chaque jour, les refus sont retirés et peuvent être compostés ou incorporés à la litière pour produire du fumier. En général, le sol est fertilisé par les apports de fumier.

Il est indispensable de respecter une hauteur optimale de coupe $(10 \mathrm{~cm}$ environ) et de sectionner les herbes avec netteté pour permettre à la plante de repousser immédiatement. Ce mode d'exploitation permet de réduire au minimum le gaspillage, l'éleveur choisissant les plantes

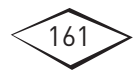




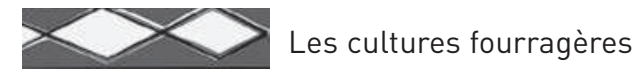

ou les parties de plantes qu'il récolte et les quantités distribuées. Mais couper du fourrage pour le porter aux animaux représente un travail quotidien considérable : à titre d'exemple, une unité bovin tropical (1 UBT) ingère chaque jour 25 à $30 \mathrm{~kg}$ de fourrage vert. Pour satisfaire ce mode d'alimentation, il faut cultiver sur des parcelles proches du lieu de distribution et exploiter des plantes fourragères de qualité, très productives et cultivées avec soin. Les plus utilisées sont Pennisetum purpureum et Tripsacum laxum, hautes et dressées, toutes deux appelées «cannes fourragères» du fait de leur ressemblance avec la canne à sucre.

Ce mode d'alimentation est réservé à des animaux gardés dans un espace confiné, une cour ou une étable, par exemple les vaches laitières élevées pour nourrir la famille ou pour la vente de lait à proximité, les animaux à l'engraissement, les bêtes de trait et, éventuellement, les animaux malades en cours de soin et les veaux au sevrage.

Si l'affouragement doit être assuré toute l'année, il faut une croissance permanente du fourrage ou disposer d'une surface supplémentaire réservée à la saison de faible végétation. De tels animaux reçoivent généralement des compléments alimentaires. Léleveur peut aussi avoir occasionnellement recours à des fourrages conservés.

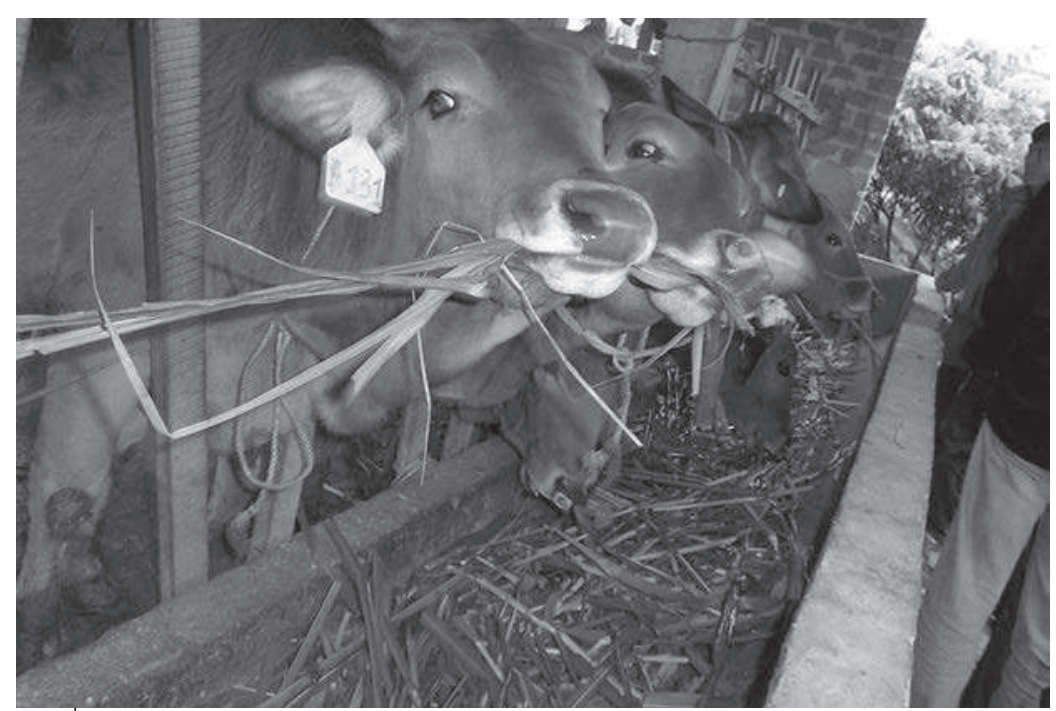

Photo 6.2.

Bovins en stabulation, affouragés en vert à l'auge avec des cannes de Pennisetum purpureum, Nord Vietnam. (๑ P. Salgado, Cirad)

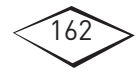




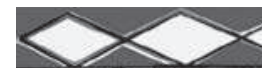

\section{IDD La récolte et la conservation des fourrages}

Le report d'une partie de la production sous forme de fourrage conservé permet de compenser la faible production de la saison sèche froide, par une récolte de l'excédent de production au moment du pic de croissance. On cherche à la fois à utiliser au mieux toute la biomasse produite et à préserver une bonne valeur alimentaire du fourrage apporté aux animaux.

En raison des variations de productivité et de qualité fourragère au cours de l'année, la pâture directe de l'herbe ne permet pas d'utiliser toujours le fourrage au meilleur moment, en particulier dans les régions où il existe une saison sèche. À cette période, l'herbe sur pied perd rapidement une partie de sa valeur alimentaire, en particulier sa teneur en matières azotées et son ingestibilité. Cette baisse de qualité concerne surtout les graminées et dans une moindre mesure les légumineuses.

Il existe trois grands modes de report de fourrages, par ordre de coût croissant :

- le report sur pied. Il consiste à mettre en défens un herbage ou un parcours, pour pouvoir en disposer au moment d'un déficit fourrager sur les autres parcelles. Cette pratique est facile et peu onéreuse par rapport aux autres formes de report fourrager, mais le fourrage sera de médiocre qualité;

- la fauche et le fanage sur place pour faire du foin. Les brins sont gardés longs pour faciliter l'aération lors du fanage. On peut faner de petites comme de grandes quantités d'herbe;

- l'ensilage. La coupe est accompagnée d'un hachage pour permettre un bon tassement lors de la mise en silo. On doit disposer d'une quantité suffisante d'herbe pour constituer et remplir un silo.

Pour avoir un fourrage de qualité, il faut le couper à un moment où il a encore une très bonne valeur fourragère et utiliser des méthodes de conservation qui protègent en grande partie cette valeur. Récolter du fourrage et le stocker est coûteux. On doit prendre garde de bien raisonner les volumes à traiter pour éviter les frais inutiles. Il est avantageux de tirer d'abord parti des restes de fourrage sur les parcelles et dans les endroits où il reste des regains (zone sous ombre, zone basse plus humide, etc.). Il faut également pouvoir disposer de la maind'œuvre suffisante et de matériel approprié pour réussir un chantier de fanage et plus encore d'ensilage.

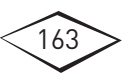




\section{Le foin}

Le fanage consiste à baisser rapidement la teneur en eau du fourrage en-dessous de $15 \%$, ce qui stoppe toute dégradation. Plus rapide sera le fanage, mieux seront conservés les constituants nutritifs.

Le fanage se fait très souvent au champ. Pour y parvenir, les conditions atmosphériques doivent être favorables : temps chaud et sec, soleil, vent léger. Chaque incident en cours de fanage, pluie, absence de soleil, forte humidité de l'air, vent trop fort, occasionne des pertes. En effet, tant que les tissus végétaux ne sont pas morts, ils continuent à consommer des sucres : les pluies lessivent les sucres solubles et une partie des minéraux; l'herbe humide fermente et moisit produisant des substances malodorantes et nocives; le vent disperse les feuilles légères. Un bon fanage est effectué en trois jours maximum. Pour faciliter le séchage régulier de toute la masse d'herbe coupée, il est nécessaire de retourner le foin et de l'aérer si possible tous les jours. On profite de ces retournements pour constituer des andains, c'est-àdire le regroupement en tas allongés, ce qui facilitera la récupération au moment de l'enlèvement.

Le ramassage du foin sec, produit volumineux, peut être suivi du compactage, soit manuel sous forme de bottes que l'on lie avec de la ficelle, soit mécanique avec une presse adéquate. La presse ramasse, tasse puis lie la botte (botte carrée de 10 à $20 \mathrm{~kg}$ ou balle ronde de 400 à $700 \mathrm{~kg}$ ). Les bottes ou le foin en vrac sont transportés jusqu'à une meule élevée en plein champ (photo 6.3) ou dans un grenier à foin; ce bâtiment doit être sain, bien abrité, un peu aéré pour éviter les condensations et permettre au foin d'achever son séchage; l'humidité ne doit pas remonter du sol.

En pays humide, le séchage peut être terminé dans un séchoir ventilé et chauffé. Le foin encore humide est déposé sur un plancher à clairevoie dans un local couvert pourvu d'une ventilation mécanique pour faire passer de l'air légèrement chauffé à travers le foin.

La qualité du foin dépend de la qualité du fourrage au moment de la coupe, de la qualité du séchage et des conditions de stockage. Les critères les plus pertinents de qualité sont la valeur alimentaire et les performances animales. Un bon foin s'apprécie à son degré de siccité, à sa composition botanique et à ses valeurs énergétique et azotée (qualité et quantité des espèces récoltées, pourcentage de légumineuses, présence ou non de mauvaises herbes), à sa couleur encore verte, à sa texture souple grâce à une proportion importante de feuilles

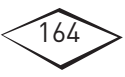




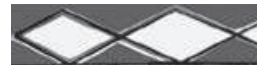

par rapport aux tiges. Il doit y avoir également peu de poussières et l'odeur doit être agréable sans aucun relent de moisi. Insuffisamment sec, le fourrage peut se mettre à chauffer et perdre ses qualités, voire même s'enflammer.

Pour faire un bon foin, il faut en principe faucher à un stade précoce, en début d'épiaison pour les graminées et au stade bourgeonnement pour les légumineuses. En zone tropicale, ces stades optima sont atteints en saison des pluies, période qui n'est pas favorable au séchage. On s'efforce alors de cultiver des espèces ou des variétés tardives, et de faner le regain en fin de saison, après avoir retardé la maturité de l'herbe en imposant une pâture à forte charge ou après avoir effectué une première fauche pour de l'affouragement en vert ou de l'ensilage.

Certaines espèces fourragères conviennent mieux que d'autres au fanage :

- les graminées à feuilles fines sèchent facilement (Chloris gayana);

- les grosses graminées (Pennisetum purpureum) sèchent mal. Après la fauche, il est parfois utile d'utiliser un éclateur, outil mécanique dont le martèlement des fléaux fracture les tiges;

- les légumineuses sèchent bien mais les petites feuilles tendent à se détacher des tiges, ce qui fait perdre les parties de la plante de

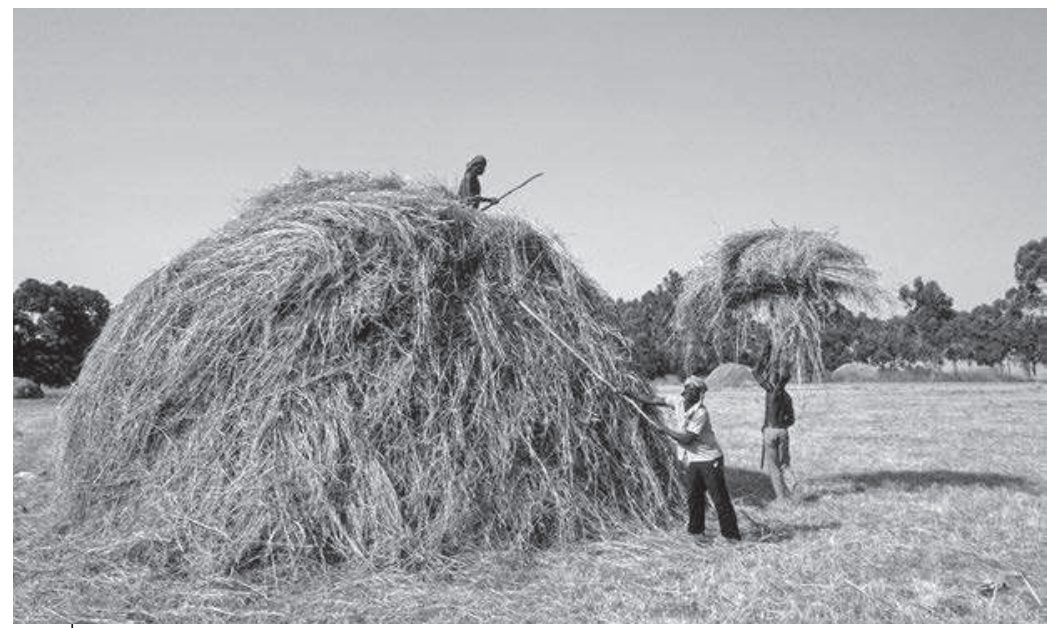

Photo 6.3.

Constitution d'une meule de foin dans un pâturage sur le ranch de N'Goundjel (Ex Compagnie La Pastorale), Adamaoua, Cameroun. (৫ H. D. Klein)

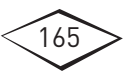


meilleure qualité au moment du ramassage. En revanche, les niébés et les doliques séchés et roulés en botte constituent d'excellents foins facilement transportables et stockables à proximité des étables.

Du fait qu'il est transportable, le foin peut être produit uniquement pour la vente par de petites exploitations dépourvues d'animaux; ces foins sont achetés par des exploitants ayant un effectif trop important d'animaux en regard de leur surface fourragère disponible, ou, comme en Afrique, par des citadins qui élèvent un animal dans leur cour. Des propriétaires de chevaux ou des clubs hippiques, ne disposant pas de production fourragère, achètent aussi des foins de bonne qualité.

Des fourrages sont aussi produits dans des périmètres irrigués et valorisés par la vente du foin à des producteurs laitiers proches des villes (bourgou, luzerne, Macroptilium atropurpureum). En termes d'environnement, la commercialisation des fourrages pose le problème du transfert de fertilité du terroir de production, qui exporte donc perd des nutriments, à la région de vente, par exemple la périphérie d'une ville, qui importe et accumule ces nutriments, source potentielle de pollution.

\section{L'ensilage}

Lensilage est une technique de conservation des fourrages humides, la qualité du produit étant proche de celle du fourrage avant la fauche. La conservation est obtenue par acidification contrôlée en conditions anaérobies (en absence d'air), au moyen de la transformation des sucres solubles du fourrage en acide lactique par des enzymes et des micro-organismes (bactéries). On peut stimuler la fermentation en inoculant le fourrage au moment du remplissage du silo avec des bactéries sélectionnées. Si la teneur en sucres solubles n'est pas suffisante, on peut augmenter artificiellement l'acidification du fourrage en ajoutant de petites quantités d'acides formiques du commerce.

Cette technique est moins tributaire des conditions climatiques (pluies en particulier) que le fanage, mais elle nécessite un important investissement en matériel, en main-d'œuvre et une forte technicité. Pour réussir un ensilage il faut réunir plusieurs conditions :

- un taux de matière sèche assez élevé (idéalement $35 \%$ ), car à un taux inférieur, l'ensilage produit des jus qui sont autant de pertes;

- un taux en sucres fermentescibles suffisant pour assurer une bonne fermentation;

- une production de fourrage dense et importante pour limiter les coûts de récolte et assurer le remplissage du silo. Pour les céréales,

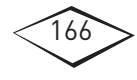


la densité de peuplement doit être supérieure à celle utilisée pour la production de grains;

- respecter les contraintes de mise en silo et les conditions d'anaérobiose (tassage, enveloppe bien hermétique).

Toutes ces conditions sont généralement réunies avec certaines céréales (maïs, sorgho) ou plus généralement avec certaines graminées à grosses cannes, à condition souvent de faire un préséchage préalable. La coupe est généralement mécanisée et faite avec des équipements spéciaux, les ensileuses, qui comprennent une partie faucheuse et une cheminée courbe évacuant le fourrage haché vers une benne tractée par un deuxième tracteur (photo 6.4). Lorsque la benne est pleine, elle est vidée dans le silo et revient au champ pour le chargement suivant.

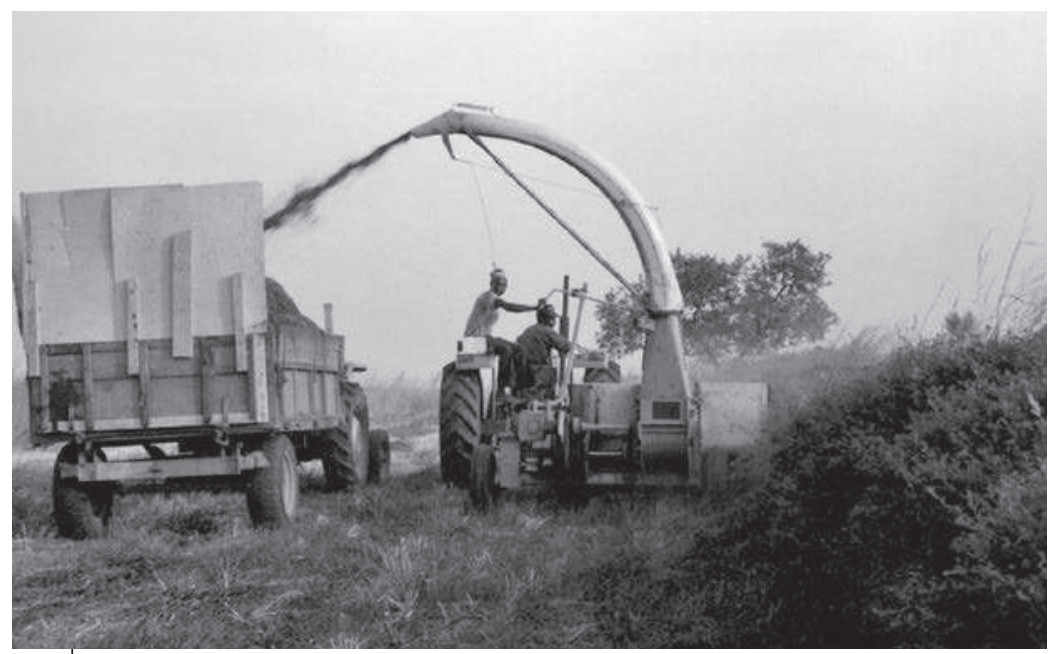

Photo 6.4.

Faucheuse-ensileuse en action, parcelle de Stylosanthes guianensis sur la station fourragère de Wakwa, N'Gaoundéré, Adamaoua, Cameroun. (๔ G. Rippstein)

La conception du silo varie : meule, tranchée, fosse, couloir. Il doit être complètement fermé, facile à charger avec le fourrage vert (qui est pesant), facile à tasser, avec une légère pente pour permettre aux jus de s'écouler, et facile à distribuer par tranches successives.

Pour un grand volume, le silo couloir délimité par des murs est le plus pratique (photo 6.5). Le fourrage est déposé le plus rapidement possible, tassé par un tracteur et recouvert de bâches plastiques étanches.

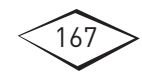




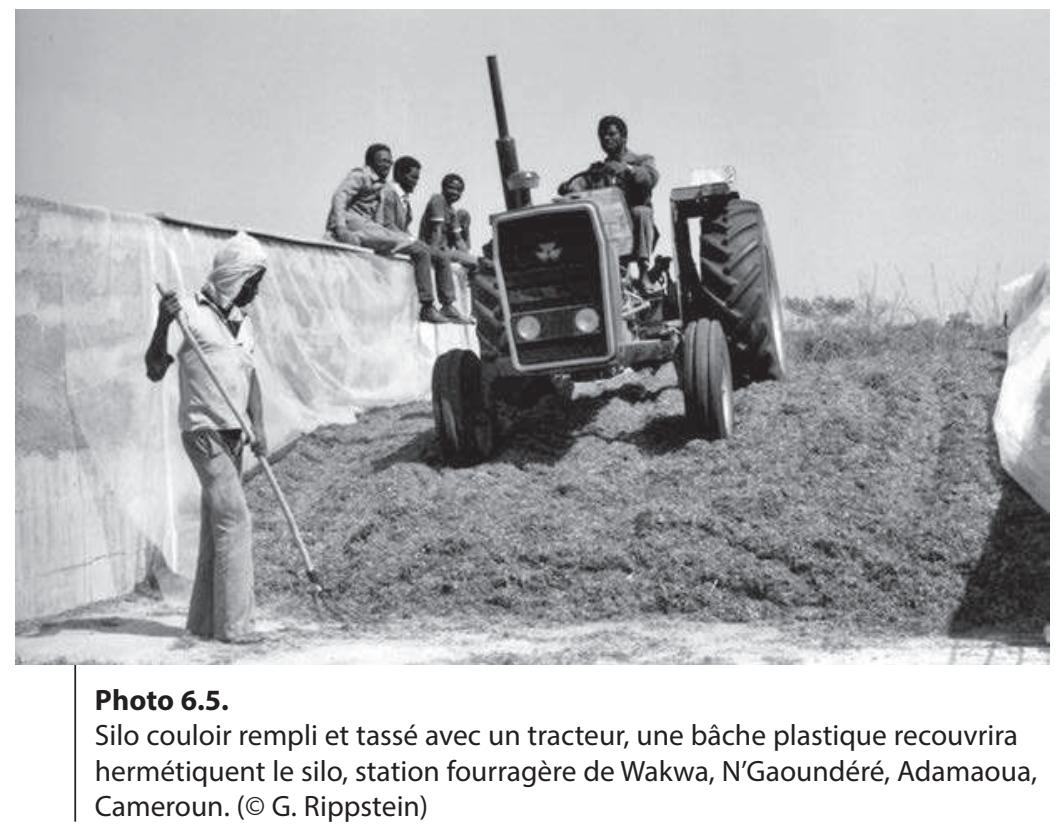

Il doit être rempli très rapidement (en moins de 24 heures) et quand il est plein il est hermétiquement fermé par une bâche plastique ajustée à la bâche inférieure. Après six semaines de fermentation au minimum, on ouvre le silo à une extrémité et on prélève l'ensilage au fur et à mesure des besoins; le temps de conservation peut dépasser l'année. Le produit prélevé dans le silo doit être consommé assez rapidement et le silo doit être bien refermé à chaque fois. Le silo se trouve donc près du lieu de distribution aux animaux.

Lensilage en balles rondes enrubannées est une forme différente ne comportant pas de silo fixe. Une masse de fourrage est compressée et emballée dans un film plastique épais à l'aide d'une machine. La balle terminée est étanche à l'air et peut être stockée au champ ou près du lieu d'utilisation. Elle peut être transportée bien que son enveloppe soit fragile. L'ouverture d'une balle n'expose à l'air que le contenu de la balle, ce qui facilite la conservation de tout le reste du fourrage. Les balles doivent être protégées des rongeurs et d'autres animaux qui consomment le plastique.

La voie de conservation du haylage est intermédiaire entre le fanage et l'ensilage; le fourrage est partiellement séché au sol jusqu'à un taux d'humidité compris entre 30 et $40 \%$, avant d'être mis en balle ronde et

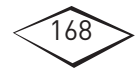


enrubanné. Il est donc moins lourd que l'ensilage et se transporte plus facilement. La fermentation lactique qui se développe ensuite dans la balle étanche bloque tout mécanisme de pourriture ou de moisissure. Le haylage doit être utilisé rapidement après l'ouverture de la balle, sinon le fourrage, encore humide, se met à moisir. Le haylage est produit en particulier pour les chevaux.

\section{Utilisation du foin et de l'ensilage}

Le fanage et l'ensilage ont été peu adoptés par les petits et moyens producteurs des pays tropicaux, à l'exception de quelques pays de l'Asie du Sud-Est comme le Vietnam et de quelques pays de l'Afrique subsaharienne, où la FAO a largement diffusé une technique d'ensilage en petits silos, pour un volume de quelques mètres cubes. En revanche, ils sont très utilisés dans les exploitations mécanisées, pour l'alimentation des vaches laitières et des bovins en embouche, aussi bien en pays tempérés qu'en pays tropicaux comme à la Réunion, en Guyane et dans une grande partie de l'Amérique latine.

En Afrique, ils sont utilisés dans les ranches plutôt en altitude; en Adamaoua au Cameroun, sous climat soudano-guinéen d'altitude, avec une saison sèche rigoureuse de quatre à cinq mois, et près de $1700 \mathrm{~mm}$ de pluies en sept à huit mois. Leur utilisation en station expérimentale est réservée aux vaches laitières toute l'année et aux jeunes mâles à l'engraissement au cours de la saison sèche.

\section{Les productions animales permises}

Les productions animales permises par les plantes fourragères cultivées sont très variables, mais conduisent la plupart du temps à des gains de poids (individuels ou par unité de surface) très supérieurs à ceux obtenus sur pâturages naturels. La relation entre l'état d'une prairie et sa productivité, d'une part et les gains de production des animaux, d'autre part, dépend de nombreux facteurs :

- le milieu (climat et sol), les espèces végétales, le couvert (hauteur et densité), la saison et l'âge de la repousse;

- la race, l'état physiologique des animaux, les conditions du sevrage et de l'allaitement, l'état sanitaire, la prophylaxie, les apports de sel et/ ou de compléments;

- le système d'élevage, notamment le rythme de pâturage, l'intervalle entre passages, le temps de repousses, le niveau de chargement et la taille des lots.

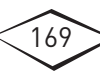


Dans un même contexte agro-écologique, plus la saison est climatiquement sévère, plus l'impact des cultures fourragères sur les performances animales est marqué.

Les références et les résultats issus de la littérature et des recherches menées, notamment par le Cirad sont extrêmement variables.

En milieu tropical sec, des fourrages irrigués (genres Panicum et Pennisetum), associés à de petites quantités de compléments de 0,5 à $1 \mathrm{~kg}$ de tourteau d'oléagineux pour équilibrer les rations, permettent des gains de poids vif sur zébus de 400 à $500 \mathrm{~g}$ par jour en pleine saison sèche, alors que le bétail conduit de façon traditionnelle maigrit à cette saison, par exemple dans les polders du lac Tchad.

En milieu subhumide, des performances équivalentes sont obtenues en systèmes mixtes agriculture-élevage avec des fanes de légumineuses récoltées à la fin du cycle de culture et stockées, alors que la croissance moyenne annuelle sur les parcours agropastoraux est de l'ordre de $200 \mathrm{~g}$ par jour, par exemple dans le bassin arachidier du Sénégal.

Dans des contextes comparables, des vaches laitières métisses recevant à l'auge du fourrage vert de prairies irriguées des genres Brachiaria, Panicum, Pennisetum, associé à une dose équivalente de concentrés, peuvent produire 6 à 8 , voire 10 litres de lait par jour. En Ouganda par exemple, de jeunes mâles peuvent gagner jusqu'à $100 \mathrm{~kg}$ PV/an avec des foins de graminées produits en milieu subhumide, avec une pluviométrie de $1400 \mathrm{~mm} / \mathrm{an}$.

En milieu tropical humide d'altitude, en Colombie, dans l'Adamaoua au Cameroun, en Guinée, les gains sous $2000 \mathrm{~mm}$ de pluie peuvent atteindre 150 à $200 \mathrm{~kg}$ PV/ha/an sur pâturages naturels, et atteindre 300 à $400 \mathrm{~kg} \mathrm{PV/ha/an} \mathrm{sur} \mathrm{fourrages} \mathrm{cultivés.}$

En milieu tropical humide, dans le centre de la Côte d'Ivoire par exemple, des graminées à port étalé du genre Brachiaria, associées à des légumineuses du genre Stylosanthes permettent des gains de poids vif de taurillons et de génisses de 150 à $200 \mathrm{~g} / \mathrm{j}$ our en moyenne sur l'année, alors que sur savane naturelle ces gains sont de l'ordre de 80 à $100 \mathrm{~g} /$ jour. À Wakwa, à proximité de N'Gaoundéré (Adamaoua, Cameroun), l'utilisation de foins de savanes naturelles et de cultures fourragères (Brachiaria ruziziensis, association de savanes et de Stylosanthes guianensis) a fait l'objet de très nombreux essais pour étudier les consommations de foin et les gains de poids obtenus, avec et sans tourteau de coton. Il apparaît que dans la grande majorité des cas le foin seul ne permet pas de gains de poids en pleine saison

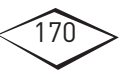


sèche et qu'en complémentant avec du tourteau de coton le gain de poids est important.

En milieu équatorial en Guyane, avec plus de $2000 \mathrm{~mm} / \mathrm{an}$ avec deux mois à moins $50 \mathrm{~mm} / \mathrm{mois}$ et deux mois à plus de $200 \mathrm{~mm} / \mathrm{mois}$, dans des prairies implantées en Digitaria swazilandensis ou Digitaria decumbens, monospécifiques ou en association de Brachiaria humidicola ou Brachiaria ruziziensis et Desmodium heterocarpon ou Calopogonium mисunoides, avec des animaux mâles de plus de 18 mois, les gains par animal varient de 300 à $600 \mathrm{~g} / \mathrm{jour}$, soit 100 à $200 \mathrm{~kg}$ PV/an, autrement dit un gain annuel de 300 à $500 \mathrm{~kg}$ PV/ha/an avec 2 à 3 têtes/ha.

$\mathrm{Au}$ Cameroun et également à la Réunion, l'ensilage de maïs, de manioc ou de graminées permet des gains du même ordre à condition de donner du tourteau de coton ou des grains de maïs. Ces résultats ont été regroupés dans le tableau 6.3.

Tableau 6.3. Résultats expérimentaux des consommations et des gains de poids de bovins alimentés en saison sèche chaude (deux à trois mois) avec du foin ou de l'ensilage et complémentés avec des tourteaux de coton en Adamaoua camerounais et sur l'île de la Réunion (Roberge et Toutain, 1999).

\begin{tabular}{|c|c|c|c|c|}
\hline $\begin{array}{l}\text { Nature } \\
\text { du } \\
\text { fourrage }\end{array}$ & $\begin{array}{l}\text { Types } \\
\text { d'animaux } \\
\text { Localisation } \\
\text { Auteur }\end{array}$ & $\begin{array}{l}\begin{array}{l}\text { Consommation } \\
\text { fourrage }\end{array} \\
(\mathrm{kg} \mathrm{MS} / 100 \mathrm{~kg} \\
\left.\mathrm{PV}^{(2)} / \text { jour}\right)\end{array}$ & $\begin{array}{l}\text { Distribution de } \\
\text { tourteau de coton } \\
\text { (kg/100 kg PV/jour) } \\
\text { ou autres }\end{array}$ & $\begin{array}{l}\text { Gain de poids } \\
\text { (GMQ) }^{(1)} \\
\text { (g/tête/jour) }\end{array}$ \\
\hline \multirow{3}{*}{$\begin{array}{l}\text { Foin Savane } \\
\text { Repousses } \\
200 \text { jours }\end{array}$} & \multirow{3}{*}{$\begin{array}{l}\text { Mâles zébus } \\
\text { de } 300 \text { kg PV } \\
\text { Wakwa } \\
\text { Brégeat (1978) }\end{array}$} & 2,0 & 0 & -66 \\
\hline & & 2,1 & 0,50 & +250 \\
\hline & & 2,0 & 1,00 & +732 \\
\hline \multirow{4}{*}{$\begin{array}{l}\text { Foin Savane } \\
\text { Repousses } \\
200 \text { jours }\end{array}$} & \multirow{4}{*}{$\begin{array}{l}\text { Mâles zébus } \\
\text { de } 300 \text { kg PV } \\
\text { Wakwa } \\
\text { Brégeat (1978) }\end{array}$} & 1,7 & 0 & -255 \\
\hline & & & & \\
\hline & & 2,1 & 0,50 & +539 \\
\hline & & 2,2 & 1,00 & +592 \\
\hline Pailles de blé & $\begin{array}{l}\text { Mâles zébus } \\
\text { de } 400 \text { kg PV } \\
\text { Wakwa } \\
\text { Brégeat (1978) }\end{array}$ & 1,6 & 0,125 & -54 \\
\hline Foin de & Génisses & 1,7 & 0 & -186 \\
\hline Stylosanthes & Wakwa & & & \\
\hline guianensis & Rippstein & & & \\
\hline 200 jours & (1983) & & & \\
\hline
\end{tabular}

(1) GMQ : gain moyen quotidien - (2) PV : poids vif

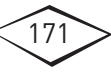


Tableau 6.3. Résultats expérimentaux des consommations et gains de poids de bovins alimentés en saison sèche (deux à trois mois) avec du foin ou de l'ensilage et complémentés avec des tourteaux de coton en Adamaoua camerounais et sur l'île de la Réunion. (suite)

\begin{tabular}{|c|c|c|c|c|}
\hline $\begin{array}{l}\text { Nature } \\
\text { du } \\
\text { fourrage }\end{array}$ & $\begin{array}{l}\text { Types } \\
\text { d'animaux } \\
\text { Localisation } \\
\text { Auteur }\end{array}$ & $\begin{array}{l}\text { Consommation } \\
\text { fourrage } \\
(\mathrm{kg} \mathrm{MS} / 100 \mathrm{~kg} \\
\mathrm{PV}^{(2)} / \text { jour) }\end{array}$ & $\begin{array}{l}\text { Distribution de } \\
\text { tourteau de coton } \\
\text { (kg/100 kg PV/jour) } \\
\text { ou autres }\end{array}$ & $\begin{array}{l}\text { Gain de poids } \\
\text { (GMQ) }^{(\mathbf{1})} \\
\text { (g/tête/jour) }^{\text {(g) }}\end{array}$ \\
\hline $\begin{array}{l}\text { Foin de } \\
\text { Brachiaria } \\
\text { ruziziensis } \\
(100 \mathrm{~N}-50 \mathrm{P}-50 \mathrm{~K})\end{array}$ & $\begin{array}{l}\text { Mâles zébus } \\
\text { de } 350 \text { kg PV } \\
\text { Wakwa } \\
\text { Brégeat (1978) }\end{array}$ & $\begin{array}{c}2,9 \\
?\end{array}$ & $\begin{array}{c}0,125 \\
0,30\end{array}$ & $\begin{array}{l}+402 \\
+650\end{array}$ \\
\hline $\begin{array}{l}\text { Foin de } \\
\text { Brachiaria } \\
\text { brizantha } \\
(100 \mathrm{~N}-50 \mathrm{P}-50 \mathrm{~K})\end{array}$ & $\begin{array}{l}\text { Mâles zébus } \\
\text { de } 350 \text { kg PV } \\
\text { Wakwa } \\
\text { Brégeat (1978) }\end{array}$ & $\begin{array}{l}3,1 \\
3,3 \\
2,5\end{array}$ & $\begin{array}{c}0 \\
0,50 \\
1,00 \\
\end{array}$ & $\begin{array}{l}+475 \\
+800 \\
+1200\end{array}$ \\
\hline Ensilage maïs & $\begin{array}{l}\text { Bœufs Foulbé } \\
\text { de } 350 \mathrm{~kg} \mathrm{PV} \\
\text { Wakwa } \\
\text { Rippstein } \\
(1975)\end{array}$ & 2,1 & 0,30 & +506 \\
\hline $\begin{array}{l}\text { Ensilage } \\
\text { de manioc }\end{array}$ & $\begin{array}{l}\text { Zébus } \\
\text { Goudalis } \\
\text { de } 8 \text { mois } \\
\text { Wakwa } \\
\text { Lhoste (1973) }\end{array}$ & $\begin{array}{c}85 \% \\
\text { (ad libitum) }\end{array}$ & $15 \%$ & +950 \\
\hline $\begin{array}{l}\text { Ensilage de } \\
\text { graminées } \\
\text { Tripsacum } \\
\text { laxum, } \\
\text { Panicum } \\
\text { maximum }\end{array}$ & $\begin{array}{l}\text { Vaches laitières } \\
\text { Montbéliard } \\
\text { Goudalis } \\
\text { Wakwa } \\
\text { Rippstein } \\
(1975)\end{array}$ & & $\begin{array}{c}1 \\
\text { maïs grain } \\
+ \text { tourteau } \\
\text { de coton, } \\
\text { sels minéraux }\end{array}$ & $\begin{array}{l}5,5 \text { à } 6,5 \mathrm{~kg} \\
\text { lait/tête }\end{array}$ \\
\hline Ensilage maïs & $\begin{array}{l}\text { Taurillons en } \\
\text { finition } \\
\text { la Réunion } \\
\text { Desvals (1991) }\end{array}$ & 1,3 & 0,470 & +1200 \\
\hline $\begin{array}{l}\text { Ensilage } \\
\text { graminées }\end{array}$ & $\begin{array}{l}\text { Génisses } \\
\text { la Réunion } \\
\text { Desvals (1991) }\end{array}$ & 1,4 & 0,59 & +650 \\
\hline $\begin{array}{l}\text { Cannes } \\
\text { fourragères } \\
\text { vertes } \\
\text { Pennisetum } \\
\text { purpureum }\end{array}$ & $\begin{array}{l}\text { La Réunion } \\
\text { Desvals (1992) } \\
\text { Taurillons en } \\
\text { finition } \\
\text { Génisses à } \\
\text { viande (Bigot) }\end{array}$ & $\begin{array}{l}0,7 \\
1,7\end{array}$ & $\begin{array}{c}1,20 \\
?\end{array}$ & $\begin{array}{l}+1071 \\
+570\end{array}$ \\
\hline
\end{tabular}

(1) GMQ : gain moyen quotidien - (2) PV : poids vif

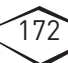




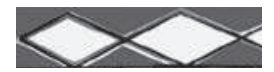

\section{Deux aliments particuliers}

\section{IID Les farines et les bouchons}

Quelques fourrages particulièrement riches, principalement des légumineuses, en premier la luzerne, sont, dès la récolte, séchés en séchoir ventilés et chauffés, puis le foin est réduit en farine conditionnée en sacs ou sous forme de bouchons ou pellets. Les farines et bouchons sont des fourrages secs de grande qualité, de fabrication industrielle, et leur coût est élevé en raison de la qualité du produit et des processus de transformation. Ils sont destinés aux élevages intensifs de vaches laitières, ou plus souvent aux élevages de volailles, pour apporter des carotènes et quelques protéines.

\section{IID Les résidus de culture}

Dans les pays tropicaux des zones sèches ou subhumides, où les fourrages sont rares en fin de saison sèche, les agriculteurs conservent également comme fourrage les résidus de culture, c'est-à-dire les pailles de céréales (maïs, sorgho) et les fanes de légumineuses (niébés, arachide) après la récolte. Les fanes sont encore riches en matières azotées, tandis que les pailles sont surtout riches en fibres. Très souvent, une grande partie des pailles et des fanes sont consommées au champ par les animaux du voisinage et les animaux transhumants. Mais pour disposer de ces résidus pour son propre usage, l'agriculteur doit transporter les pailles et les fanes du champ vers la maison ou le village (photo 6.6.) et les stocker de préférence en hauteur hors de portée du bétail (photo 6.7). Elles sont données en fin de saison sèche avec d'autres compléments pour assurer la ration de base à des animaux laitiers ou d'embouche (vaches, bœufs, moutons), ou encore aux animaux de trait (bœufs, dromadaires, ânes et chevaux). 

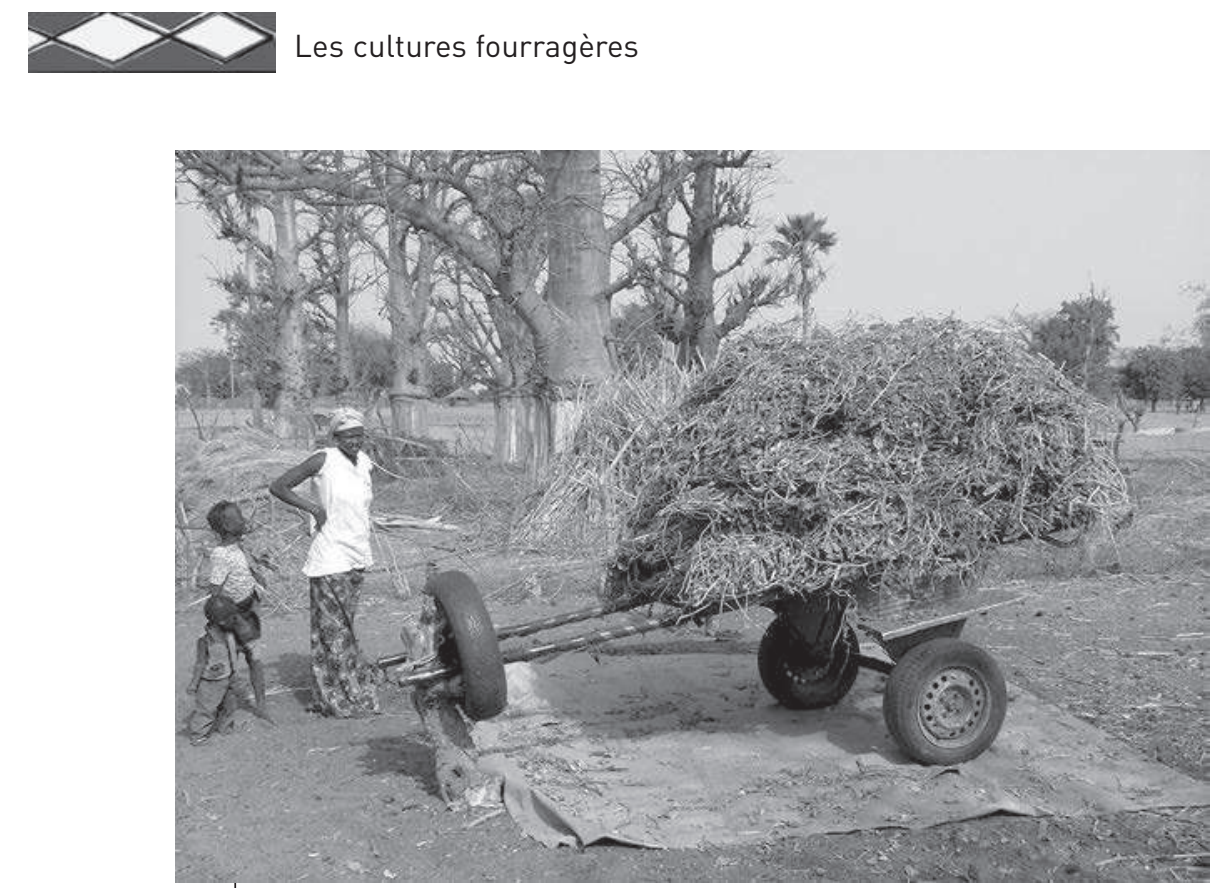

Photo 6.6.

Charrette transportant des bottes de niébé sec (Vigna unguiculata), Sénégal. (৫ G. Rippstein)

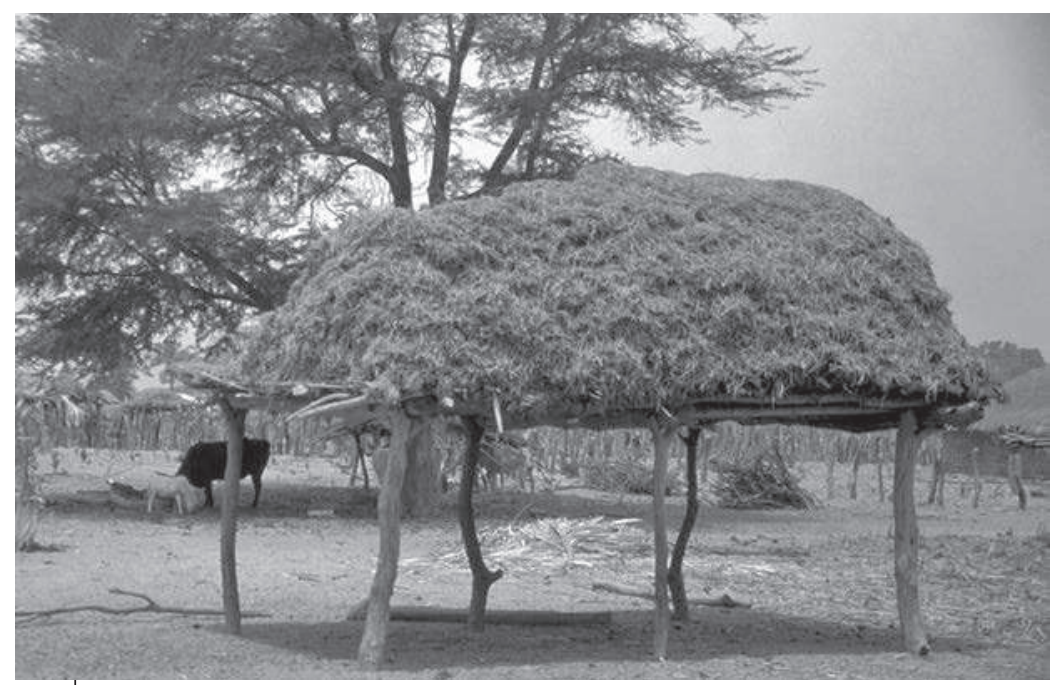

Photo 6.7.

Réserves de fanes d'arachide (fourrages) stockées en hauteur pour la complémentation des bovins en saison sèche, Sénégal.

(๑ P. Lhoste)

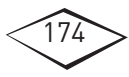




\section{L'entretien}

Les pratiques d'entretien visent à soutenir la production des cultures fourragères annuelles, et à maintenir la production des prairies et des herbages cultivés sur plusieurs années. Les plantes fourragères ont besoin de soins adaptés à leur nature, aux modes d'exploitation et aux productions attendues. À ces usages, sont associées des techniques d'entretien pour maintenir l'alimentation en éléments minéraux et en eau des plantes fourragères, et pour lutter contre les plantes indésirables et contre les maladies, en fonction du type de cultures, annuelle ou pluriannuelle. Si l'entretien est faible ou déficient, les espèces fourragères valorisent imparfaitement les investissements consentis pour leur mise en place. Leur production n'atteint pas le meilleur niveau possible et diminue au fil des années car le couvert herbacé se dégrade peu à peu et sa qualité diminue. Finalement, la production animale en subit les conséquences.

Le principe pour maintenir plusieurs années les qualités d'une prairie est simple :

- respecter un temps de repos adéquat entre chaque période de pâture;

- adopter un chargement animal raisonnable;

- limiter les charges et les rythmes de rotation;

- apporter éventuellement des quantités limitées d'engrais à la reprise de végétation;

- plus rarement procéder à un entretien mécanique (rotobroyage) et/ ou chimique quand les refus deviennent trop abondants.

Cependant, les éleveurs évoquent rarement le «rendement» d'une pâture, comme le fait un agriculteur pour une culture de mil ou de maïs. Pour le pâturage, le rendement (production en poids de MS/ha) n'est généralement pas raisonné comme un objectif par l'éleveur, sauf s'il s'agit d'herbages destinés à la fauche pour l'ensilage ou le foin.

Lobjectif de l'éleveur est de satisfaire les besoins du troupeau et d'obtenir une production satisfaisante : une disponibilité d'herbe dans la durée, une régularité de production, une qualité de l'herbe adaptée à la performance et à la santé du troupeau. Les potentialités d'une prairie sont souvent très supérieures aux productions réellement obtenues.

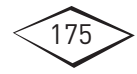


Les stratégies des agriculteurs pour atténuer les conséquences de la variabilité de la production sont multiples :

- valoriser la diversité des parcelles disponibles;

- favoriser les rotations du bétail;

- prévoir des stocks de fourrages.

L'éleveur doit en outre tenir compte des irrégularités prévisibles ou imprévisibles telles que les aléas climatiques, le pic de production, les attaques de parasites (insectes, champignons), la période de repos végétatif, la gestion des refus, le piétinement, ce qui l'amène à prendre des décisions rapides de gestion du pâturage et d'entretien. D'où la notion de pilotage, essentielle pour une bonne gestion des prairies.

\section{La conduite des prairies favorable à leur maintien}

Lors des premières phases d'exploitation, les plantes semées sont encore très sensibles à la compétition des mauvaises herbes. Il faut limiter à des passages rapides des animaux avec une faible charge. Une pâture trop précoce peut gêner le développement racinaire des plantes et amoindrir le développement végétatif. En terrain léger, les plantes peuvent être facilement arrachées. Les erreurs de conduite à ce stade risquent d'aboutir à des prairies peu productives, non pérennes, qui se dégradent rapidement.

En région amazonienne, les premières exploitations (déprimage) sur des prairies de graminées (par exemple Brachiaria) sont pratiquées avec de légers passages d'animaux ou par une fauche tardive sept à neuf mois après le semis (cinq à sept mois après un bouturage). Lexploitation «de croisière» en pâture ne commence qu'après douze mois avec une charge globale de $900 \mathrm{~kg}$ de $\mathrm{PV} / \mathrm{ha} /$ an et avec des charges instantanées autour de $3000 \mathrm{~kg}$ de PV/ha sur des repousses de quatre à six semaines suivant les saisons.

Au cours des années suivantes, la pérennité de la prairie dépend de la dynamique des espèces fourragères. Les pratiques des éleveurs pour l'exploitation et pour l'entretien des prairies sont essentielles pour assurer une longue utilisation. Le rythme de pâture est un élément de gestion déterminant la pérennité de la prairie.

Lévolution floristique des prairies pâturées dépend de plusieurs facteurs :

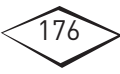


- la longévité des espèces fourragères. La graminée Chloris gayana n'est exploitable en prairie que deux ou trois ans, tandis que Panicum maximum peut persister plus de dix ans;

- la nature du sol. Par exemple, en terrain périodiquement très humide et engorgé, les graminées Brachiaria decumbens et Brachiaria ruziziensis ont une longévité médiocre (deux à trois ans). En revanche, ces espèces restent compétitives vis-à-vis des mauvaises herbes sur des sols pauvres qui se ressuient correctement. La toxicité aluminique se révèle défavorable à la pérennité de Digitaria swazilandensis et Digitaria decumbens. Les teneurs en phosphore influencent aussi la pérennité des plantes fourragères, plus particulièrement des légumineuses;

- les variations climatiques. En période de fortes pluies, la croissance de la plupart des graminées fourragères est stoppée, à quelques exceptions près (comme Echinochloa spp., Ischaemum spp., Brachiaria mutica, Brachiaria humidicola, Hemarthria altissima), alors que des plantes indésirables comme les Cyperaceae peuvent se développer. En période sèche, les espèces fourragères s'arrêtent progressivement de pousser mais continuent à être exploitées, par conséquent si la couverture du sol par les plantes fourragères s'éclaircit, des adventices à croissance rapide peuvent émerger dès la reprise des pluies.

Les adventices représentent très souvent des indicateurs écologiques signalant un déséquilibre ou une perturbation du milieu comme l'asphyxie du sol (les Cyperaceae), l'acidification ou un déséquilibre minéral ou le plus souvent un problème de gestion (Sida spp., Solanum spp., Chromolaena odorata, Mimosa pigra, Mimosa pudica, Spermacoce spp., etc.). En terrains très humides, par exemple, les Cyperaceae, herbes peu ou pas appétées, se développent souvent très bien parce qu'en valorisant mieux que les autres les faibles teneurs en phosphore de ces sols, elles parviennent alors à étouffer les autres plantes, notamment les graminées fourragères.

L'esprit d'observation et l'expérience acquise peu à peu permettent à l'éleveur d'améliorer ses pratiques d'utilisation des prairies. Voici quelques éléments clés de bonne gestion.

Rythme de pâture. La conduite des troupeaux, qui engendre de fortes variations de la charge instantanée des pâturages, tend à rompre l'équilibre entre prélèvement et pousse de l'herbe. Lirrégularité des temps de pâture et de repos s'avère peu propice à la constitution d'un couvert dense et épais dans les premiers centimètres au-dessus du sol. Au contraire, la pratique raisonnée du pâturage constitue le principal outil de régulation de la végétation et de la flore des prairies et des

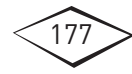


herbages pâturés. Lorganisation d'une pâture régulière reste malgré tout délicate à réaliser sur tous les parcours d'un élevage. Léleveur doit contrôler l'état du couvert fourrager et la présence d'espèces potentiellement dégradantes.

Limiter la pâture en saison sèche permet de garder une hauteur suffisante d'herbe pour assurer une bonne reprise aux premières pluies. Dans les systèmes pratiquant la fertilisation, un apport de 15 à 30 unités d'azote par hectare stimule la reprise des graminées fourragères. La combinaison d'espèces s'avère également efficace, comme le mélange d'espèces à croissance moyenne même en période plus sèche et d'espèces à reprise rapide, par exemple en zone amazonienne Brachiaria humidicola et Digitaria heterocarpon.

Intensité de l'exploitation. Choisir la hauteur de l'herbe au retrait des animaux d'une parcelle permet de jouer sur la compétition entre espèces herbacées. Par exemple, en faisant brouter assez ras les espèces stolonifères, les stolons se trouvent renforcés et deviennent denses à la surface du sol, ce qui gêne les mauvaises herbes. La fertilisation azotée agit dans le même sens. À l'inverse, pour gêner des monocotylédones indésirables sensibles à l'ombre (graminées du genre Sporobolus, Cyperaceae), il est parfois nécessaire de laisser monter le couvert sans pâture pendant 8 à 10 semaines.

Choix des espèces animales. Suivant les milieux, plusieurs espèces animales peuvent être combinées. Par exemple, la pâture mixte de bovins et de caprins peut limiter considérablement la repousse des ligneux sans endommager le couvert herbacé. Mais parfois la présence de plusieurs espèces animales peut accentuer les perturbations de la végétation : ainsi, la pâture par des chevaux après (ou avec) celle des bovins accentue souvent la formation de plages surpâturées.

\section{Les fertilisations organique et minérale}

Le raisonnement de la fertilisation est fondé sur un bilan dans lequel est recherché l'équilibre entre les entrées et les sorties d'éléments fertilisants pour une période donnée. Les animaux d'élevage prélèvent dans leur ration alimentaire les éléments nutritifs qui leur sont nécessaires, mais une partie de ces éléments n'est pas absorbée et se trouve excrétée dans les déjections, celles-ci reviennent au sol ou sont concentrées et transformées dans les fumiers. Ces restitutions sur les prairies contribuent au bilan. 
Lapport d'amendements organiques, compostés ou pas, ou toute autre matière organique éligible, présente des avantages agronomiques indéniables. Leur utilisation entraîne une amélioration de la stabilité structurale (enjeu contre l'érosion hydrique et éolienne) et une augmentation de la capacité d'échange cationique qui se traduit par un meilleur stockage des éléments minéraux nutritifs.

\section{Intérêt et raisonnement de la fertilisation}

La fertilisation a pour but essentiel d'entretenir la fertilité du sol pour satisfaire les besoins des cultures. Voici quelques repères pour l'apport des éléments majeurs : azote, phosphore, potasse et calcium.

\section{L'azote}

Lazote a essentiellement une action sur la production en accélérant la croissance des plantes, surtout celle des graminées à productivité élevée (par exemple Panicum maximum, variété $\mathrm{C} 1$ ). Cette pratique a deux conséquences pour l'exploitation des plantes (figure 7.1) :

- une production donnée est atteinte plus tôt. C'est un effet de gain de temps qui tend à accélérer le rythme de gestion des prairies;

- la production est plus importante à un stade ou à une date donnée. C'est l'effet de gain de production.

Lapport d'azote peut rendre certaines espèces plus vulnérables aux attaques d'insectes comme les noctuelles.

Cependant, de fortes doses régulières d'azote font diminuer la proportion des légumineuses dans les associations prairiales de graminées et de légumineuses. Une faible dose d'azote peut néanmoins s'avérer nécessaire au bon démarrage de la légumineuse lors de l'implantation d'une association.

Après la saison sèche, il faut attendre une pluie efficace $(50 \mathrm{~mm})$ afin d'éviter les pertes d'azote par volatilisation. Sur les repousses, des apports peuvent être effectués après chaque exploitation, quelques jours après la coupe ou dès la sortie des animaux, ou encore dès qu'il y a suffisamment de parties vertes pour permettre l'assimilation chlorophyllienne. En pâture continue, on peut sans danger épandre de petites quantités d'azote en présence des animaux.

Dans les régions à forte pluviosité, des apports fréquents fractionnés réduisent les pertes par ruissellement et par lessivage et permettent

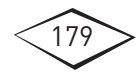




\section{Les cultures fourragères}

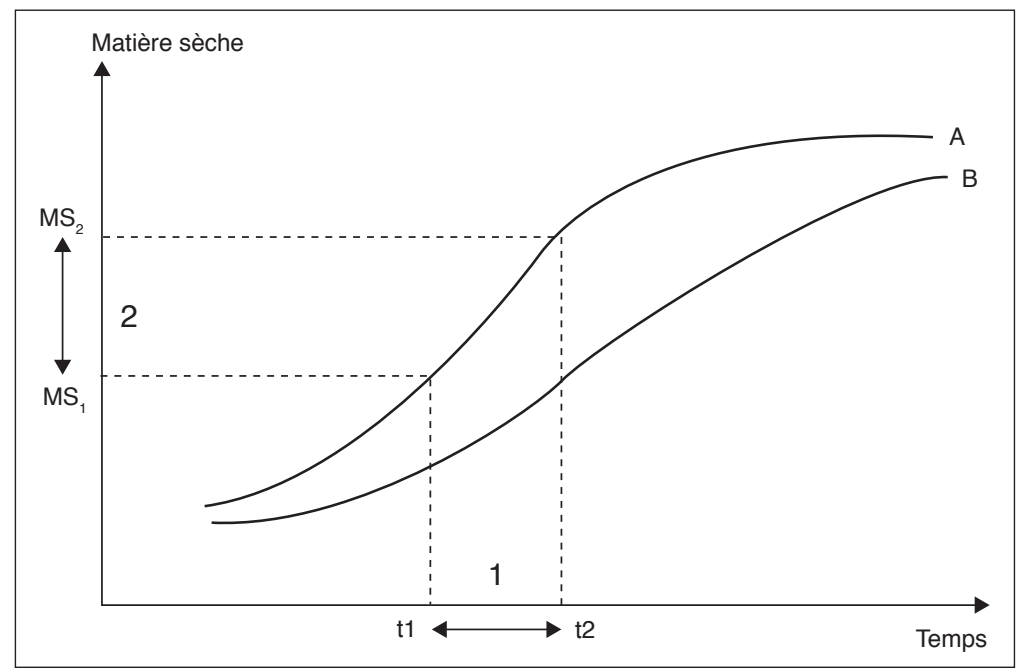

Figure 7.1.

Effet de l'azote sur la croissance fourragère des prairies.

(d'après Hnatyszyn et Guais, 1988)

A. croissance obtenue avec une forte fertilisation azotée

$B$. croissance fourragère obtenue avec une faible fertilisation azotée

1. gain de temps pour obtenir une production équivalente $(\mathrm{t} 2-\mathrm{t} 1)$

2. gain de production à un stade ou à une date donnée $\left(\mathrm{MS}_{2}-\mathrm{MS}_{1}\right)$

d'augmenter le coefficient réel d'utilisation de l'azote. Sur culture annuelle, deux à trois apports sont conseillés, avec un dernier apport indispensable au stade montaison ou début épiaison.

À la Réunion, en saison des pluies, une fertilisation moins riche en azote, l'ensilage des excédents et les pluies tardives permettent d'amoindrir et de décaler vers la fin de la saison des pluies le pic de production fourragère. En saison fraîche, la stimulation de la pousse de l'herbe avec des apports fractionnés d'engrais plus fortement dosés en azote assurent le maintien d'une production herbagère suffisante. Par contre, en Guyane, la saison sèche étant marquée, la fertilisation n'est pas utile et peut même être dangereuse pour la plante qui subit un déficit hydrique.

La forme sous laquelle l'azote minéral est apporté peut être importante dans les pays tropicaux à sols acides, voire très acides. Les formes ammoniacales (ammoniaque anhydride, nitrate, sulfate et phosphate d'ammoniaque, urée) sont les plus accessibles sur les marchés africains, mais elles provoquent une acidification du sol lors

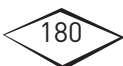


de la nitrification $\left(\mathrm{NH}_{4}+3 / 2 \mathrm{O}_{2} \rightarrow \mathrm{NO}_{2}+\mathrm{H}_{2} \mathrm{O}+2 \mathrm{H}_{+}\right)$. En revanche, les formes cyanamide ou nitrique (nitrate de potasse ou de soude) ont plutôt un effet neutralisant, mais elles sont moins accessibles pour plusieurs raisons : en période humide sa conservation est difficile, le produit ayant tendance à prendre en masse; de plus son coût à l'unité est moins élevé, mais l'effet acidifiant de l'urée est de courte durée.

\section{Le phosphore}

Par leur $\mathrm{pH}$ bas, leur faible teneur en matière organique et des taux d'alumine élevés, la plupart des sols tropicaux doivent faire l'objet d'attention particulière pour éviter que le phosphore ne soit bloqué. Le phosphore joue en effet un rôle majeur dans l'évolution des sols tropicaux et dans celui des écosystèmes microbiens pour l'établissement, la production et la persistance des légumineuses. La déficience en phosphore de nombreux sols tropicaux nécessite un apport important, généralement en une seule fois, lors de la mise en place de la culture. Quelquefois, une faible dose suffit, 20 à $40 \mathrm{~kg} / \mathrm{ha}$ de phosphore. Il en faut davantage pour les sols très acides et les sols d'origine volcanique, ou pour la rénovation ou l'entretien des prairies. Les formes les plus communes d'engrais phosphoriques minéraux sont les phosphates naturels (peu solubles, mais les moins coûteux) et les superphosphates simples ou triples, qui ont l'avantage de contenir aussi du soufre.

\section{La potasse}

La potasse a un effet direct sur la production des prairies et on constate une interaction positive avec l'azote mais il y a un risque de surconsommation si les apports sont trop importants. La fertilisation potassique est particulièrement recommandée lorsque le fourrage est récolté, car au pâturage, les animaux restituent une grande partie $(90 \%)$ de cet élément par les fèces et les urines. Le niveau souhaitable dépend de la proportion des divers constituants de la texture du sol (argile, limon). Généralement, des doses de 20 à $50 \mathrm{~kg} / \mathrm{ha}$, sous forme de chlorure ou de sulfate de potassium, peuvent être appliquées à la mise en place de la prairie. Loptimum, pour de nombreuses légumineuses, se situe autour de $110 \mathrm{~kg} / \mathrm{ha} /$ an de potassium, appliqués en plusieurs fois.

C'est un élément majeur pour la production de graines. En conséquence, dans les prairies comprenant des légumineuses qui doivent se maintenir par leur grenaison, l'apport de potasse est précieux, par exemple sur Stylosanthes hamata.

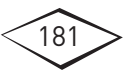




\section{Le calcium}

Le calcium est généralement présent dans les sols. Dans les sols très acides et pour certaines espèces sensibles à la toxicité de l'aluminium de ces sols, on peut relever le $\mathrm{pH}$ en apportant du calcium. Lamendement calcaire peut être la chaux, vive ou éteinte, mais son action est brutale et peut affecter certains équilibres chimiques du sol; il est préférable d'utiliser du calcaire broyé, magnésien ou non, en choisissant le degré de finesse. Les doses à apporter dépendent de l'acidité du sol à amender. Dès que le sol atteint le pH de 5,5, les toxicités disparaissent.

\section{ID Les plans de fertilisation}

La fertilisation mérite d'être bien raisonnée pour éviter les dépenses inutiles et les pertes polluantes dans l'environnement. Le plan de fertilisation ou plan de fumure consiste à prévoir l'ensemble des apports d'engrais et d'amendements sur les différentes cultures et parcelles de l'exploitation, ainsi que les modalités et les dates d'apport (encadrés 7.1 et 7.2).

Deux grands types de fertilisation sont présentés, ceux des cultures fourragères intensives et ceux des prairies.

\section{La fertilisation des cultures fourragères intensives}

La fertilisation des cultures de graminées fourragères suit une logique proche de celle des cultures de céréales. Par contre, celle des légumineuses porte principalement sur le phosphore et la potasse. Le plus souvent les apports d'azote sont à éviter car ils peuvent nuire au développement des nodosités qui rendent les plantes autosuffisantes en azote. Seuls de légers apports au semis (15 à 20 unités/ha) peuvent être conseillés pour favoriser le développement initial du système racinaire.

Voici quelques exemples de niveaux de fertilisation pratiqués en zone de savane humide pour les graminées et en zone de savane sèche pour les légumineuses.

Cannes fourragères, graminées utilisées pour l'affouragement en vert dans les petits élevages laitiers (Pennisetum purpureum, Tripsacum laxum, hybride de Pennisetum purpureum et Saccharum officinarum). Lentretien de la fertilité se fait le plus souvent sous forme d'engrais

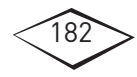


organique. Le fumier est restitué quotidiennement à chaque pied de canne coupée et mélangé à des déjections fraîches. Avec une fertilisation chimique, les besoins en intrants par tonne de MS produite sont de : 10 à $30 \mathrm{~kg}$ d'azote; 2 à $3 \mathrm{~kg}$ de $\mathrm{P}_{2} \mathrm{O}_{5} ; 30$ à $50 \mathrm{~kg}$ de $\mathrm{K}_{2} \mathrm{O}, 3$ à $6 \mathrm{~kg}$ de $\mathrm{CaO}$. Ces espèces peuvent produire plus de $30 \mathrm{t} \mathrm{MS/ha/an} \mathrm{avec} \mathrm{une}$ alimentation en eau toute l'année.

Niébé (Vigna unguiculata), légumineuse utilisée pour l'affouragement en sec en fin de saison sèche aux animaux de trait. En fumure organique, on apporte $10 \mathrm{à} 20 \mathrm{t} / \mathrm{ha}$ de fumier tous les trois ans. À l'implantation, on apporte essentiellement du phosphore et de la potasse (50 unités de $\mathrm{P}_{2} \mathrm{O}_{5}, 75$ à 100 unités de $\mathrm{K}_{2} \mathrm{O}$, c'est-à-dire $100 \mathrm{~kg} /$ ha de supertriple et 100 à $150 \mathrm{~kg}$ de $\mathrm{KCl}$ ), et pas ou peu d'azote car au-delà de 40 unités la nodulation est inhibée.

\section{Encadré 7.1. Un exemple dans le nord de la Côte d'Ivoire}

Létablissement de pâturages sur des sols à horizons superficiels très appauvris a fait l'objet d'un projet de développement, avec un niveau d'intensification intermédiaire. Plus de 1500 ha de pâturages ont été mis en place, composés en association d'une graminée (Panicum maximum cv C1) et d'une légumineuse (Stylosanthes hamata cv Verano) (Dulieu, 1982).

Lapport d'engrais était nécessaire pour lever les carences minérales et permettre une exploitation prolongée : un apport initial de 150 à 200 unités/ha de $\mathrm{P}_{2} \mathrm{O}_{5}$ et de 30 unités/ha de $\mathrm{N}$ a été appliqué pour accélérer la mise en place des légumineuses, suivi d'un autre apport de 30 unités/ha de $\mathrm{N}$, au stade 3 feuilles pour accélérer le démarrage et l'enracinement des Panicum. Puis chaque année, en début de saison des pluies, après $50 \mathrm{~mm}$ de pluies utiles, un apport starter d'azote pouvait être apporté à raison de 30 unités/ha de N. Lurée avait été choisie comme engrais azoté en raison de son prix avantageux. Exploitées essentiellement en pâture, ces prairies n'ont pas reçu d'engrais potassique, car la potasse était en grande partie recyclée par les urines des animaux.

\section{La fertilisation des prairies améliorées}

Sur les prairies exploitées en pâturage et par coupe plusieurs fois par an on pratique essentiellement une fumure de «couverture». Lalimentation minérale des plantes est liée à leur alimentation hydrique (régime des pluies et nature des sols) et à leur composition floristique (densité du couvert et stade physiologique). En conséquence, le mode d'utilisation de la prairie guide la fertilisation autant que le type de pâturage. 
Influencé par la révolution fourragère dans les pays industrialisés et notamment en Europe (1960-1980), le pilotage des pâturages avec de forts niveaux de fertilisation a été adopté dans certaines régions tropicales, par exemple aux Antilles françaises (Xandé, 1989). Mais depuis les années 1990, les agropédologues et les agropastoralistes ont plutôt cherché à stimuler les sols tropicaux pour éviter que le phosphore ne soit bloqué, avant de subvenir aux besoins de la plante elle-même.

\section{Encadré 7.2. Un exemple en Guyane}

En adoptant des mises en place de couverts mixtes (2 légumineuses et 2 graminées), certains éleveurs sont parvenus à maintenir leurs prairies en bon état pendant plus de vingt ans. La fertilisation initiale consistait en un apport d'engrais organique avec 10 à $20 \mathrm{t}$ de fumier/ha et 120 unités de phosphore sous forme de scories Thomas ou de phosphate naturel. Pour l'entretien annuel, seul un apport de 80 unités/ha de $\mathrm{P}_{2} \mathrm{O}_{5}$ sous forme de phosphate naturel est pratiqué.

\section{Le contrôle des mauvaises herbes}

Les plantes fourragères cultivées sont exposées comme toutes les cultures à l'envahissement et à la concurrence d'autres espèces dites adventices ou «mauvaises herbes». Certaines de ces plantes envahissantes peuvent être tolérées dans les pâturages, d'autres sont en revanche très gênantes pour l'exploitation. Aucune plante n'est mauvaise dans l'absolu, cette appréciation n'est faite que par rapport à un contexte particulier.

Pour porter un jugement sur une situation de salissement, il faut connaître de façon précise les facteurs écologiques et agronomiques qui influencent le développement des espèces et des communautés adventices. Ainsi, il devient possible d'agir sur ces facteurs pour maintenir l'enherbement d'une parcelle en dessous d'un seuil de nuisibilité globale. Pour ce faire, on doit être capable d'identifier de façon précise les espèces concernées à tous les stades de leur développement. La mise en œuvre du désherbage sera décidée si son coût est compatible avec les gains escomptés.

Trois situations sont présentées : le désherbage des cultures fourragères annuelles, le contrôle des adventices dans les prairies permanentes, le désherbage des prairies de fauche.

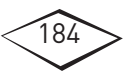




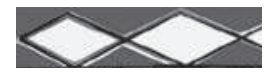

\section{IID Le désherbage des cultures fourragères annuelles}

La lutte contre les mauvaises herbes ne pose pas de problème si l'on dispose de la main-d'œuvre suffisante pour désherber manuellement. Cependant, sur de grandes parcelles ou dans un contexte d'abandon des jachères à fonction nettoyante, le travail manuel ne permet plus de maîriser le salissement.

Au cours d'une saison de culture, la composition floristique et l'abondance des mauvaises herbes évoluent. Ainsi, les espèces de début de cycle sont responsables de l'essentiel de la compétition vis-à-vis de la culture, tandis que celles de fin de cycle influencent la qualité de la récolte et la pénibilité du travail et augmentent le stock semencier du sol. Létude du salissement doit donc prendre en compte l'ensemble du cycle.

\section{Précautions à l'installation}

Lors de la préparation du sol, un labour suffisamment profond enfouit les mauvaises herbes et leurs semences; le travail du sol à la houe ou en traction attelée ne suffit pas pour nettoyer le sol. Par ailleurs, les charrues à disques favorisent la multiplication des espèces à rhizomes ou à stolons comme Imperata cylindrica, Cyperus rotundus, Cynodon dactylon et chaque fragment donne une nouvelle plante.

Lemploi de semences propres, indemnes de graines de mauvaises herbes, limite l'introduction de plantes indésirables.

Lassociation avec une plante de couverture protège la structure du sol et réduit la prolifération des mauvaises herbes par effet d'ombrage sur les plantules et de compétition pour l'eau.

La rotation des cultures sur une parcelle permet de rompre l'infestation par des mauvaises herbes difficiles à maîtriser, en diversifiant à la fois les conditions culturales et les moyens de lutte propres à chaque culture.

\section{Le sarclage manuel}

Le sarclage manuel est la méthode de lutte la plus répandue en zone tropicale dans les petites exploitations. Bien que techniquement simple, il présente certaines contraintes :

- il doit être réalisé avant que les mauvaises herbes ne puissent concurrencer la culture. Les repousses des plantes mal enfouies par le labour, comme Digitaria horizontalis, doivent être sarclées très tôt, dès la première semaine après le semis; pour les autres espèces le délai est de trois semaines;

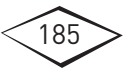


- le sarclage manuel est une activité pénible qui demande entre dix et vingt jours de travail par hectare, d'après les normes obtenues en zone de savane pour des cultures semées en ligne;

- la main-d'œuvre familiale ou salariée n'est pas toujours disponible au bon moment, en raison de la concurrence dans l'organisation du travail avec les derniers semis de plantes vivrières et les sarclages sur les premières parcelles semées;

- si le sol est humide au moment du sarclage, de nombreuses espèces, comme Commelina benghalensis, ne se dessèchent pas et parviennent à repousser.

\section{Le sarclage mécanique}

Pour les cultures nécessitant de grands écartements (maïs, sorgho, cannes fourragères), le sarclage mécanique apporte plusieurs avantages par rapport à un sarclage manuel :

- un gain de temps. Le sarclage mécanique nécessite de cinq à dix fois moins de temps que le travail manuel, même s'il faut faire un sarclage manuel sur la ligne en début de cycle;

- une réduction de la pénibilité du travail en culture attelée avec une houe tractée;

- l'enfouissement de l'engrais peut être effectué lors d'un buttage, réalisé simultanément avec un sarclage mécanique.

Toutefois, il occasionne aussi certaines contraintes :

- la disponibilité du matériel. En culture attelée la houe mécanique est souvent achetée bien après la charrue et la formation des agroéleveurs à l'emploi de ces outils est indispensable;

- la précocité des interventions. Le travail est facilité par une intervention précoce qui évite le risque de bourrage des corps sarcleurs par des plantes trop développées;

- la modification des systèmes de cultures. Le sarclage mécanique n'est pas possible si le défrichement a laissé des souches et des résidus sur la parcelle; si le semis n'est pas fait en ligne, et si l'interrang est planté de cultures associées qui empêchent le passage des outils.

\section{L'emploi d'herbicides}

Le désherbage chimique nécessite l'emploi de matériel adéquat et l'achat des désherbants. Pour être efficace, il doit être effectué à bon escient (Roberge et Toutain, 1999).

Les principales recommandations sont les suivantes (encadré 7.3) :

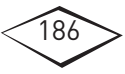


- connaître les mauvaises herbes à maîtriser pour choisir le produit et le mode d'application qui conviennent;

- utiliser des produits sélectifs;

- respecter les doses d'application et réduire les doses pour diminuer les coûts en faisant des traitements localisés quand cela est possible, mais éviter les sous-dosages ou surdosages qui sont inefficaces même avec les produits systémiques;

- intervenir au moment préconisé, ne pas traiter avec un herbicide de prélevée sur une culture déjà levée, traiter en postlevée au bon stade de développement des mauvaises herbes (rapport feuilles/tiges élevé); - utiliser des appareils adaptés aux pulvérisations d'herbicides, équipés de buses à jet plat (buses pinceau ou miroir); ne pas utiliser des appareils prévus pour les pulvérisations d'insecticides, équipés de buses à jet conique à turbulence, ou d'atomiseurs à moteur; prendre un soin particulier au réglage et à l'entretien après usage (rinçage, nettoyage);

- vérifier régulièrement l'étalonnage des appareils, afin de corriger les défauts des appareils (usure des buses) ou les défaillances des opérateurs. La quantité de bouillie épandue par hectare doit être déterminée pour faire les calculs de dilution. Il est parfois pertinent d'utiliser des buses à bas volume (20 à 30 1/ha), surtout si le traitement se fait à dos d'homme;

- préparer convenablement la bouillie. Afin d'éviter de boucher les buses, il est indispensable d'employer une eau de bonne qualité, d'utiliser un filtre et de s'assurer de l'homogénéité du mélange;

- bien maitriser la technique d'application. La répartition du produit sur la surface traitée doit être parfaitement homogène, ce qui impose un débit régulier et une vitesse d'avancement constante;

- pour préserver la santé de l'opérateur, ne pas négliger les risques de toxicité et les précautions d'emploi. Porter les vêtements et les équipements de protection nécessaires.

\section{II) Le contrôle des adventices dans les prairies permanentes}

Peu de temps après le semis ou la plantation, les espèces fourragères sont, dès le départ en végétation, en concurrence avec les plantes adventices présentes naturellement dans le sol. Laisser la nouvelle culture fourragère se faire envahir, c'est prendre le risque de la voir disparaître au profit d'une flore non désirée et de moindre qualité.

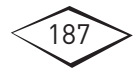




\section{Encadré 7.3. Critères de différenciation des herbicides}

\section{Spécificité}

- un herbicide sélectif respecte certaines cultures et détruit certaines mauvaises herbes de ces cultures;

- un herbicide total est susceptible de détruire ou d'empêcher le développement de toute la végétation, avec des persistances d'action variables.

\section{Mode d'action}

- un herbicide à pénétration racinaire s'applique sur le sol et pénètre par les organes souterrains des végétaux (racines, graines, plantules);

- un herbicide à pénétration foliaire s'applique sur le feuillage et pénètre par les organes aériens des végétaux (feuilles, pétioles, tiges);

- un herbicide de contact agit après pénétration plus ou moins profonde dans les tissus, sans aucune migration d'un organe à un autre de la plante traitée;

- un herbicide systémique est capable d'agir, après pénétration, par migration d'un organe à un autre de la plante traitée.

\section{Période d'application}

- en présemis après la préparation du sol et avant le semis de la culture pour permettre notamment l'incorporation des produits volatils ou photodégradables;

- en postsemis aussitôt après le semis;

- en prélevée avant la levée de la plante considérée (culture ou mauvaise herbe);

- en postlevée après la levée de la plante considérée (culture ou mauvaise herbe);

- en postlevée précoce avec un traitement qui associe un herbicide de prélevée et un herbicide de postlevée, avant la levée de la culture mais après celle des mauvaises herbes.

Ensuite, dès la première année d'exploitation, les prairies permanentes sont menacées par l'apparition de plantes non désirées, soit de peu d'intérêt ou toxiques, soit buissonnantes et parfois rapidement envahissantes.

En choisissant des espèces fourragères à croissance initiale très dynamique, semblable ou supérieure à celle des plantes envahissantes, on assure en début de végétation un certain contrôle des adventices. En revanche, les plantes à croissance initiale lente risquent, si elles sont envahies, de former par la suite un couvert fourrager peu dense et peu stable. 


\section{Précautions à l'installation}

La qualité de la préparation du sol et du semis favorise l'installation et la croissance au démarrage. Ensuite, aux premiers stades d'établissement d'une prairie, les plantes semées doivent être en mesure de se développer rapidement et de façon régulière.

Si l'on craint une forte levée de mauvaises herbes, une bonne stratégie consiste à semer un mélange d'espèces contenant :

- soit une plante à cycle court mais à levée rapide, par exemple du riz pluvial, en présence d'une graminée pérenne, le riz décline au moment où celle-ci se développe;

- soit une graminée fourragère à croissance rapide, par exemple Brachiaria ruziziensis, avec d'autres espèces à installation plus lente, par exemple Brachiaria humidicola. La première sera dominante dans un premier temps puis sera remplacée par les autres au fur et à mesure de son déclin.

\section{Désherbage à l'installation}

Si des interventions mécaniques ou chimiques sont nécessaires à l'installation, le choix des opérations à effectuer est fonction des surfaces en jeu, des adventices à détruire et des moyens techniques à disposition. Une intervention précoce peut réduire le risque d'envahissement plus tard.

Deux méthodes fréquemment employées sont présentées : l'arrachage manuel et le traitement herbicide.

L'arrachage pied par pied. Cette méthode simple est applicable à des plantes qui émettent rapidement beaucoup de semences, comme Sida spp., Mimosa pigra, Mimosa pudica, Chromolaena odorata, etc. À titre d'information, dans les campagnes françaises, les chardons (Cirsium spp.) faisaient l'objet d'arrêtés municipaux mentionnant l'obligation aux responsables des terrains de les arracher. Cette pratique s'avère lourde à mettre en œuvre si les pieds sont trop nombreux et commencent à former des taches dans le pâturage.

Le rabattage mécanisé ou motorisé (gyrobroyage, rotobroyage) apporte un certain secours à court terme, mais il est déconseillé car la plupart de ces plantes disposent d'une forte capacité de dissémination par voie sexuée et d'une reproduction végétative.

Si nécessaire, l'usage d'herbicides est conseillé. Les produits herbicides à appliquer doivent être : systémiques (produits absorbés par

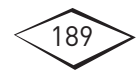


voie foliaire et véhiculés par la sève jusqu'au méristème des racines); sélectifs, cela signifie qu'ils doivent détruire les dicotylédones sans nuire aux monocotylédones, et plus particulièrement aux graminées fourragères.

Le glyphosate, très répandu en zone tropicale, est un herbicide systémique non sélectif qui détruit les dicotylédones et les monocotylédones; souvent utilisé pour nettoyer les champs après culture, il tue aussi toute couverture végétale avant la mise en place d'une prairie. Les matières actives comme l'asulame, le fluroxypyr, le piclorame, le triclopyr sont des herbicides sélectifs systémiques, sans arrière-effet marqué en région humide (précipitations $>1000 \mathrm{~mm} / \mathrm{an}$ ); toutefois ces produits sont à proscrire dans les herbages mixtes de graminées et de légumineuses, si l'on ne souhaite pas éliminer les dicotylédones fourragères en place.

À l'achat, ces produits doivent être accompagnés d'une notice mentionnant l'efficacité des molécules sur les adventices ciblées, les dosages, les dilutions, les appareils de traitement à utiliser et d'autres informations techniques. Dans ces notices, doivent être normalement signalés dans la plupart des pays la toxicité (dose létale à $50 \%$ ou DL50, sur certains animaux tels que rats, truites, abeilles, etc.), l'écotoxicité (par exemple la demi-vie de la molécule), la rémanence et les arrière-effets des produits. Suivant les législations, les produits disponibles peuvent varier d'un pays à l'autre. Le 2,4-D est par exemple proscrit en Europe, mais reste disponible dans la plupart des pays tropicaux. Hormis les exigences environnementales, différentes suivant les pays, il convient aussi d'apprécier les différences de comportement de ces produits selon les régions; par exemple la molécule piclorame a une rémanence divisée par trois en milieu tropical humide par rapport à celle observée dans les pays européens tempérés.

Les interventions chimiques doivent faire l'objet d'études préalables pour déterminer les plus faibles doses compatibles avec une efficacité optimale, notamment en se rapportant aux cycles phénologiques des plantes visées. On recommande de cibler les stades avec un rapport élevé «surface foliaire/longueur de tige». Il est parfois obtenu par un rabattage préalable de la végétation. Pour un traitement efficient, le vent doit être faible ou même absent, l'hygrométrie forte, supérieure à $70 \%$, et la pulvérisation doit produire de fines gouttelettes (recommandations sur les buses et le débit) adhérentes aux feuilles, l'adhérence peut être améliorée par des mouillants.

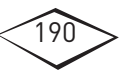


Afin d'enrayer l'apparition de nouvelles mauvaises herbes juvéniles, le couvert fourrager doit retrouver rapidement après traitement un aspect dense, épais et homogène, tout particulièrement là où des pieds, touffes et taches d'adventices ont disparu; il peut alors être intéressant de pratiquer un sursemis ou un bouturage dans ces zones. Ces combinaisons d'interventions appartiennent aux démarches de lutte intégrée.

Le recours à des herbicides connaît un fort développement, particulièrement en Amérique tropicale. Depuis la diffusion de pulvérisateurs bas volume à dos d'homme (30 1/ha de solution) et à pompe électrique, les traitements chimiques ne sont plus réservés aux prairies des exploitations motorisées. En traitement localisé, par exemple aux pieds des plantes envahissantes, l'opérateur peut intervenir rapidement; si $10 \%$ du couvert sont infestés, cela ne nécessite que 3 1/ha de bouillie. Les traitements en plein, c'est-à-dire sur toute la surface, sont recommandés pour les couverts destinés à la récolte de fourrage ou de semences. Ils peuvent aussi être conseillés pour restaurer des terrains très infestés, en réalisant un «faux semis » : après le travail de préparation du sol qui induit des levées d'adventices actives, on traite en plein ces levées sur toute la surface, avec un herbicide non sélectif et non rémanent (par exemple le glyphosate), avant de procéder au vrai semis après 20 à $30 \mathrm{~mm}$ de pluies.

\section{Recours au désherbage mécanique et chimique}

En milieu très infesté ( 25 à $50 \%$ du couvert occupé par les adventices), le gyrobroyage peut s'avérer nécessaire. Après ce travail, les graminées fourragères ne sont plus en compétition pour la lumière et bénéficient de l'azote libéré par les plantes rabattues, elles vont connaître une croissance importante pendant quelques semaines; mais par la suite, les adventices rabattues risquent de réapparaitre encore plus vigoureuses en raison de la reprise des bourgeons axillaires et du drageonnage.

C'est pourquoi l'invasion par les mauvaises herbes justifie parfois des traitements chimiques. En opération d'entretien, on se contente de pulvérisations localisées. Les traitements en plein avec des produits sélectifs préservant les graminées vont éliminer toutes les dicotylédones, y compris les légumineuses fourragères. Cette option est donc à éviter sur des couverts mixtes associant légumineuses et graminées, sauf en situations extrêmes d'infestation, et à condition d'entreprendre

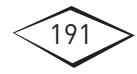


des sursemis pour rapidement couvrir les zones nues aux endroits où la végétation a été détruite.

Lusage d'herbicides sur les mauvaises herbes doit combiner plusieurs moyens de lutte successifs pour être vraiment efficace :

- une fauche basse au lieu d'un gyrobroyage, car elle dégrade moins les boutures;

- puis 3 à 4 semaines de repos pour permettre la repousse de l'herbe;

- une pâture laissant les pieds des mauvaises herbes bien dégagés;

- la pulvérisation d'un herbicide systémique sélectif sur les repousses lorsqu'elles atteignent 50 à $60 \mathrm{~cm}$ et présentent un rapport feuille/tige élevé;

- un sursemis ou un bouturage de plante fourragère deux semaines après le traitement des zones où il $\mathrm{y}$ avait une concentration de mauvaises herbes;

- un délai de six à huit semaines avant de reprendre le pâturage.

\section{ID Le désherbage des prairies de fauche}

Les parcelles destinées à la récolte de fourrage (foin, ensilage, balles enrubannées) entrent souvent dans une rotation avec d'autres parcelles. Les champs fauchés une année sont généralement pâturés l'année suivante et le soin à apporter au désherbage est tantôt celui des prairies, tantôt celui des cultures fourragères annuelles.

Pour la conservation du fourrage par voie humide (ensilage et balles enrubannées), il ne faut pas qu'il y ait d'espèces indésirables, surtout buissonnantes. Cette précaution est très importante parce que les ligneux gênent les processus de conservation, ils peuvent percer les revêtements plastiques et provoquer des entrées d'air, causes de pourrissement dans la masse de fourrage. Si une parcelle est sale, son utilisation pour produire des réserves fourragères peut être déconseillée.

Lorsque les apparitions d'espèces indésirables sont en augmentation d'une année à l'autre, l'éleveur peut choisir entre plusieurs options :

- remettre la parcelle en pâture, ce qui permet de réaliser des traitements plus poussés;

- retourner la prairie en pratiquant la technique du faux semis avec traitement herbicide (à appliquer même deux fois), puis réinstaller un couvert fourrager par bouturage mélangé avec un semis d'espèces à émergence rapide;

- installer une autre culture pendant quelques années afin d'épuiser le stock de semences de plantes indésirables dans le sol.

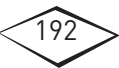




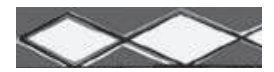

\section{La prévention et la lutte contre les maladies et parasites}

Si une maladie des plantes apparaît dans une culture fourragère, ou si l'on constate une invasion parasitaire, il est rare de réagir par une intervention chimique, non seulement en raison du coût en comparaison de la valeur du fourrage perdu, mais aussi à cause de sa toxicité potentielle pour le bétail et de sa nuisance sur l'environnement. Seules les cultures fourragères destinées à la production de semences justifient le recours aux pesticides, que ce soit contre les champignons, les bactéries et les attaques d'insectes (encadré 7.4).

Le traitement des semences avant le semis est le seul traitement chimique qui peut être recommandé pour toutes les cultures fourragères. Cette méthode est efficace et le plus souvent à la portée des paysans, en raison de son faible coût. Avant de traiter on doit s'assurer de l'innocuité des molécules actives envers les abeilles et les coprophages. La matière active, directement appliquée dans la masse des semences, crée une zone de protection tout autour de la graine. Dès leur apparition, les jeunes racines commencent à absorber la matière active, que la sève peut ensuite transporter jusqu'aux feuilles supérieures, conférant ainsi aux jeunes plants une protection contre les maladies fongiques et les insectes ravageurs.

La principale mesure pour protéger les cultures fourragères contre les attaques d'insectes et les maladies reste le choix d'espèces et de variétés résistantes. Les cultures fourragères monospécifiques s'avèrent plus vulnérables que les mélanges, surtout si elles s'étendent sur plusieurs milliers d'hectares comme en Amérique du Sud. Au Brésil, en zone amazonienne, les dégâts sur plusieurs espèces de graminées fourragères dus à un insecte piqueur appelé Deois incompleta et appartenant au groupe des Cigarrinha (cicadelles en français) justifient leur remplacement par les variétés résistantes comme Brachiaria brizantha cv. Marandu et Andropogon gayanus cv. planaltina et plaident en faveur d'une certaine diversité dans les choix.

Des travaux ont été réalisés depuis la fin $\mathrm{du} \mathrm{xx}^{\mathrm{e}}$ siècle pour trouver des alternatives avec des couverts plurispécifiques. À titre d'exemple, l'anthracnose (Colletotrichum gloeosporioides), maladie fongique, a détruit la légumineuse Stylosanthes humilis dans les années 1970 en Australie, et Stylosanthes guianensis cv. Schofield en Afrique dans les années 1980. Depuis, la recherche australienne a sélectionné des

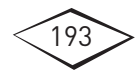




\section{Encadré 7.4. Informations sur les produits phytosanitaires}

Quand on a recours à des produits phytosanitaires, il faut être correctement informé de leur composition, de leur toxicité, de leur écotoxicité et de leur emploi; un appui technique lors des premiers traitements est recommandé. Il est également souhaitable de consulter les index phytosanitaires disponibles dans l'écorégion, comme par exemple l'index phytosanitaire de l'Acta (Association de Coordination technique agricole) actualisé tous les ans $(<$ www.acta.asso.fr $>$ ).

Des informations sur les produits phytosanitaires et leurs usages sont disponibles sur plusieurs sites Internet :

- <e-phy.agriculture.gouv.fr/> site officiel français d'homologation des produits phytosanitaires et des risques liés à leur utilisation, classement par ordre alphabétique des noms commerciaux, informations sur la réglementation applicable en matière d'application de produits;

- <www.dowagro.com/fr/agriculture/bpp/> site des bonnes pratiques phytosanitaires de Dow Agrosciences;

- <grepp.guadeloupe.ecologie.gouv.fr/doc/doc_pdf08/CORPEN_mesu.pdf> document en ligne «Mesures réglementaires concernant les produits phytosanitaires et leur incidence sur l'environnement» du Comité d'Orientation pour les pratiques agricoles respectueuses de l'environnement (Corpen) en France.

cultivars de Stylosanthes résistants à l'anthracnose, qui ont été testés en Australie, en Amérique du Sud (Brésil, Colombie), en Afrique du Sud et en Asie (Inde, Chine). Ils comprennent d'autres espèces de Stylosanthes : S. capitata, S. guianensis, S. macrocephala, S. scabra et S. seabrana.

Associer plusieurs espèces fourragères offre plusieurs avantages : un couvert dense et épais permet de contrôler les plantes adventices et de prévenir une attaque phytosanitaire généralisée. En Guyane, les attaques dans une même zone de la noctuelle défoliatrice (Spodoptera frugiperda) sont observées essentiellement sur les prairies monospécifiques, alors que les prairies plurispécifiques sont généralement très peu touchées. Lintérêt de valoriser la biodiversité du couvert herbacé pour prévenir les attaques d'insectes et les maladies est à concevoir également au niveau du territoire : on doit favoriser les paysages en mosaïques de cultures et de couverts fourragers laissant aussi la place à des arbres.

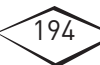


Le respect des pratiques agronomiques joue un rôle important. Ainsi, la végétation en forte croissance, pauvre en tissus de soutien, est vulnérable aux insectes ravageurs; il en est de même pour des plantes qui ont reçu une forte fertilisation azotée. Les déséquilibres du sol en certains éléments minéraux et les carences en oligo-éléments rendent les plantes vulnérables aux agressions et aux maladies. Pour sauvegarder une parcelle atteinte, une solution peut être de faucher rapidement.

\section{Régénérer, rénover et réhabiliter les pâturages}

Les altérations du pâturage traduisent des déséquilibres qui sont les conséquences, soit d'aléas climatiques (sécheresse, excès d'eau...), soit d'accidents (feux) ou d'attaques phytosanitaires, soit plus souvent d'erreurs d'exploitation. Lorsque ces processus s'échelonnent sur plusieurs années, leurs causes doivent être bien identifiées. La vigilance de l'éleveur doit porter sur les dynamiques de dégradation qui amènent la prairie à régresser peu à peu. Avec des contributions spécifiques des espèces fourragères supérieures à $30 \%$, il suffit la plupart du temps d'améliorer la gestion des pâturages, en modifiant les chargements et les rythmes de passage. Lorsque le degré de dégradation est plus élevé, des mesures plus importantes doivent être envisagées pour améliorer les pâturages.

Selon le degré de récupération à envisager, on distingue la régénération, la rénovation et la réhabilitation.

La régénération s'applique à des prairies qui présentent encore la capacité de se reconstituer par elles-mêmes moyennant quelques actions complémentaires. Le résultat n'est assuré que dans la mesure où l'éleveur parvient à connaître et à contrôler les causes de dégradation. La régénération consiste à mettre en œuvre des mesures qui stimulent la reprise de la végétation fourragère; ce sont les opérations les plus communes. Il s'agit, par exemple, de pratiquer la mise en défens de durée différente selon l'état du couvert.

La rénovation est indispensable pour des pâturages qui ne présentent plus la capacité de se régénérer spontanément. La dégradation résulte très souvent d'un envahissement par des plantes indésirables, non fourragères ou peu productives, comme dans le cas des steppes en voie de désertification. Quand la surface couverte par les plantes de bonne valeur alimentaire devient inférieure à $30 \%$, ou quand le

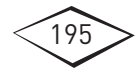




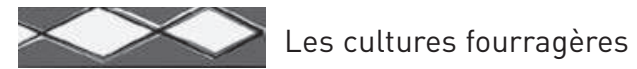

taux de dégarnissage de la surface dépasse $20 \%$, les opérations de régénération ne sont plus efficaces. Le recours à un sursemis, ou à la destruction totale de la pâture suivie d'un nouveau semis sont les seuls moyens de ramener la production fourragère à un niveau acceptable.

La réhabilitation vise une remise en état du milieu pour qu'il puisse de nouveau porter des cultures fourragères. Ce sont souvent des travaux d'aménagement très lourds et le plus souvent collectifs.

\section{IID La régénération}

La régénération commence par la mise au repos (par la mise en défens) du pâturage. Elle comprend éventuellement l'entretien physique et chimique du sol, la protection sanitaire, le maintien de la propreté de la végétation et l'enrichissement du couvert herbacé et de la flore.

\section{Actions sur le sol}

L'épandage d'amendements consiste à disperser de façon régulière en surface, soit de la matière organique, généralement sous forme de fumier bien décomposé, soit de la chaux (sous diverses formes : calcaire broyé, marne, chaux agricole). Ces amendements corrigent des déperditions lentes de matière organique ou de chaux, et ont un effet lent et durable sur la stabilité structurale du sol, le $\mathrm{pH}$ et la fertilité. Leffet sur le sol est d'autant plus rapide que la texture de la matière utilisée est fine. Pour le chaulage d'entretien, une action rapide n'est pas nécessaire, pas plus que l'incorporation rapide dans le sol; la réponse étant attendue à partir de la troisième année.

Le décompactage est une technique de travail du sol profond, sans retournement, permettant de préserver la matière organique à la surface du sol. Il se distingue du sous-solage par une profondeur de travail inférieure (30 à $35 \mathrm{~cm}$ ). On l'applique aux sols sensibles au tassement, notamment pendant les périodes très humides. Le décompactage s'effectue à l'aide d'outils non animés à dents (cultivateur lourd, chisel) ou à disques (charrue à disques) ou d'outils animés par la prise de force du tracteur (cultivateur rotatif à axe horizontal). La profondeur de travail et l'intensité de la fragmentation varient suivant l'outil utilisé.

Le sous-solage a pour but de régénérer la structure des horizons de sol localisés sous le fond de labour. Il améliore le drainage naturel et accroît la perméabilité du sol, ce qui favorise le développement

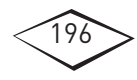




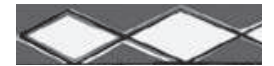

racinaire en profondeur des espèces fourragères naturelles (photo 7.1). Cette opération est réalisée avec une sous-soleuse, appareil à dents droites de 50 à $80 \mathrm{~cm}$ de long.

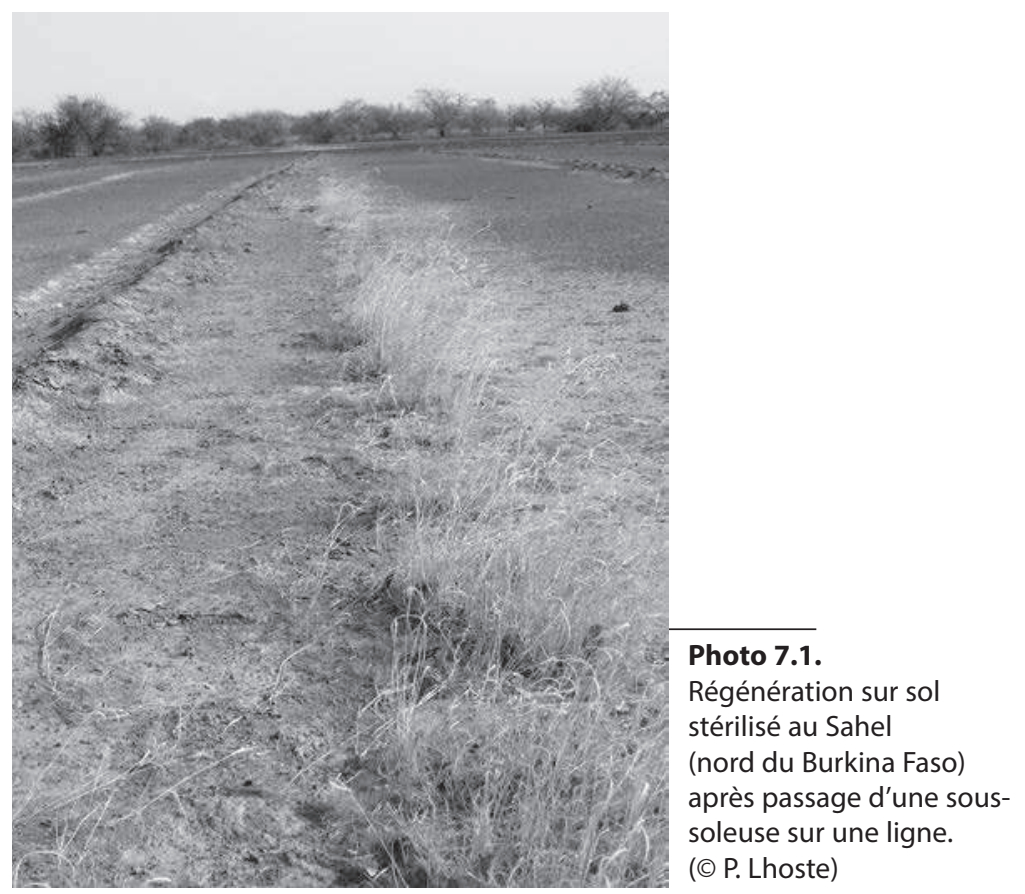

\section{Actions sur la végétation}

Le nettoyage mécanique consiste à éliminer les refus de pâture. Il favorise la reprise de la végétation herbacée et améliore la qualité de l'herbe. Une simple opération de fauche peut suffire. Si, en outre, on rencontre de la végétation adventice, notamment des rejets de plantes ligneuses, ou même de grosses touffes de graminées, on emploie des outils plus lourds (gyrobroyeur, rotobroyeur, débroussailleuse). Néanmoins, l'emploi de ces outils risque de favoriser la multiplication des mauvaises herbes.

La fertilisation pour la régénération de la prairie est une correction de fond des déficiences ou des déséquilibres chimiques du sol. Les analyses chimiques du sol ou du fourrage, l'estimation des indices de carence associés à la présence de plantes indicatrices, permettent d'orienter le choix de la fertilisation de redressement.

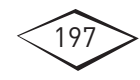




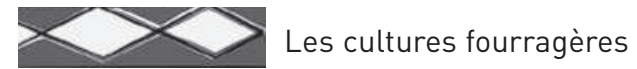

Le désherbage a aussi été développé. La prolifération d'espèces potentiellement envahissantes dans une prairie est une manifestation fréquente au cours de son vieillissement, dont les causes sont souvent multiples. L'opération de désherbage doit entrer dans une opération de lutte intégrée, associant la correction des principales causes de dégradation.

\section{ID La rénovation}

Le sursemis permet d'introduire dans une prairie en voie de dégradation du matériel végétal en préservant une grande partie des plantes en place. En choisissant un mélange d'espèces, on peut compter sur l'installation rapide de l'une d'entre elles, puis sur l'expansion progressive d'autres plantes plus durables. Au cours de cette période, l'éleveur doit orienter l'évolution de la flore vers une composition productive et durable en déterminant les rythmes et les intensités de pâture adéquats.

Le bouturage est une alternative au semis qui permet de mettre en place rapidement une végétation exploitable sur les zones les plus dégradées. Par exemple, en Guyane, des prairies vieillissantes de Digitaria swazilandensis et Brachiaria decumbens ont été régénérées en bouturant des brins de Brachiaria humidicola (densité de 0,5 x 1m). Il faut compter deux années pour que se réalise ensuite naturellement un changement de composition de la végétation fourragère.

Le retournement de prairie s'apparente à l'installation d'une nouvelle culture fourragère. Des précautions particulières peuvent être prises, notamment quand l'embroussaillement est la cause de la dégradation. Pour limiter la pression d'adventices envahissantes, il peut être nécessaire d'installer une autre culture (vivrière ou de rente) pendant un ou deux ans avant de procéder à une nouvelle installation d'espèces fourragères.

\section{|| La réhabilitation}

Les travaux de réhabilitation sont des opérations de grande envergure pour redonner au sol une fertilité compatible avec l'objectif fourrager. Très souvent, ils concernent un groupe de parcelles, voire même un bassin versant tout entier et font appel de façon non exhaustive à diverses techniques de lutte : contre l'érosion, avec par exemple

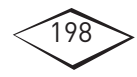




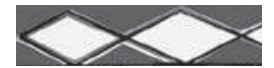

la construction de terrasses ou l'embocagement, contre la salinisation avec l'irrigation et le drainage, contre le déboisement d'espaces embroussaillés, contre les eaux stagnantes avec le drainage des zones humides par la création de réseaux de drains et/ou le profilage de sol en billons, contre le feu avec des réseaux de pare-feu, contre des vents desséchants avec la création de haies brise-vent.

Le détail sur ces travaux dépasse les objectifs d'un tel ouvrage. On se reportera à des documents spécialisés. 



\section{$\checkmark$ 8. Les particularités des fourrages ligneux \\ Les ligneux existent naturellement dans les parcours et les pâturages, ou peuvent faire l'objet de plantations tout comme les herbacées. Les techniques de culture, de mise en place, de multiplication et d'exploitation des ligneux diffèrent sensi- blement de celles des herbacées en raison de leurs durées de vie plus longues et de leurs dimensions plus importantes. Néanmoins, certains arbrisseaux peuvent être mis en place et gérés comme des plantes herbacées pérennes.}

Les schémas d'implantation et les modes de gestion des ligneux dépendent pour une grande part de l'objectif de l'éleveur, des besoins des animaux et de la biologie des plantes. Ces différents aspects sont très dépendants les uns des autres.

\section{L'installation des ligneux}

Les ligneux peuvent être groupés dans des parcelles spécifiques appelées vergers fourragers, soit en lignes en bordure des parcelles (piquets vifs et haies vives), soit au sein des parcelles et disposés en bandes boisées, bosquets et pré-bois, soit sur les courbes de niveaux antiérosives, ou selon d'autres dispositions qui associent les fonctions des parties herbacées pour le fourrage et celles des parties ligneuses pour d'autres usages (clôture, brise-vent, etc.).

\section{IID Les itinéraires techniques d'installation}

Pour associer des ligneux fourragers et des graminées dans un pâturage, on peut semer les différentes espèces en mélange. Mais comme les jeunes ligneux poussent beaucoup plus lentement que les herbes, ils peuvent être étouffés. Le désherbage autour des jeunes arbres est donc indispensable pour garantir leur survie et limiter la concurrence des herbacées, mais il est rendu difficile par la petite taille des ligneux.

Il est donc préférable pour enrichir un pâturage avec des arbres ou des arbustes fourragers, d'utiliser le semis direct ou la plantation localisée.

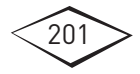




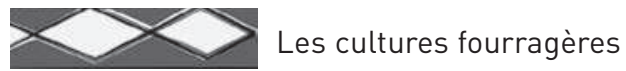

Le semis direct des ligneux est une méthode peu onéreuse, car il nécessite moins de travail que la plantation, mais il ne peut réussir dans la végétation en place que sur un sol travaillé, par exemple sur des bandes labourées. Sa réussite peut être améliorée en prévoyant de lever la dormance des graines (cas de nombreux ligneux) surtout en zones sèches et en utilisant un semoir mécanique pour assurer un bon enfouissement et des espacements réguliers. Pourtant, dans bien des cas, le semis s'avère plus aléatoire que la plantation et finalement plus coûteux à cause du prix élevé de certaines graines produites en quantité faible en raison des faibles fructifications, des attaques d'insectes, des aléas du semis (germinations irrégulières, manque d'entretien), ou à cause des destructions des jeunes plants par des herbivores et des rongeurs.

La production de plants en pépinière suivie de la plantation est une méthode plus sûre, mais la protection des jeunes arbres vis-à-vis du bétail reste nécessaire jusqu'à ce que leur taille soit suffisante. Pour cela, on utilise des protections individuelles (grillage, gaines en matériaux divers) ou on empêche les animaux d'accéder aux parcelles pendant plusieurs années par gardiennage, clôtures ou haies vives.

Le désherbage est indispensable pour une bonne croissance des plants, dans un rayon d'au moins $50 \mathrm{~cm}$ autour des jeunes pieds et pendant les deux ou trois premières années, sauf dans des systèmes intensifs, pour certaines espèces à croissance initiale très rapide implantées dans des parcelles fourragères. La plantation en lignes espacées dans le pâturage permet de simplifier le désherbage autour des jeunes arbres. Cette technique, appelée alley cropping, utilise des espèces arbustives comme Leucaena (Leucaena leucocephala) et Calliandra (Calliandra calothyrsus).

Se référer si possible à des fiches techniques ou à des manuels spécialisés.

\section{ID Les vergers fourragers}

Les vergers fourragers, parcelles dédiées à la culture de ligneux fourragers, constituent une réserve de fourrage exploitée parfois en pâture, mais plus généralement en coupe à des moments particuliers ou lors de la pénurie des autres fourrages. Les arbustes fourragers sont élevés en pépinière puis plantés en lignes. Trois espèces ont été largement vulgarisées dans les systèmes fourragers plus ou moins intensifiés des régions tropicales humides et subhumides : Leucaena leucocephala,

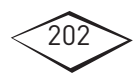




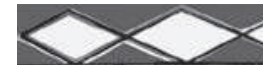

Gliricidia sepium et Calliandra calothyrsus. Elles sont connues pour leur valeur nutritive, leur multiplication aisée et leur croissance initiale rapide qui permet de réduire les désherbages après leur implantation.

Malgré les recommandations des organismes de vulgarisation, les espèces citées ci-dessus ne sont pas toujours choisies par les agroéleveurs, qui utilisent d'autres espèces indigènes utiles, dont certaines sont déjà intégrées dans leurs systèmes de production. Ces plantes locales sont d'ailleurs incluses dans certains programmes de recherche pour les améliorer et mieux les utiliser.

En Afrique subsaharienne, l'exploitation privilégiée de certaines espèces pour le fourrage a mis ces espèces en danger de disparition, comme pour Ficus sycomorus aux environs de Garoua au nord du Cameroun et pour Ficus exasperata au centre de la Côte d'Ivoire. Cela a conduit à expérimenter des vergers fourragers exploités par émondage. Ces systèmes correspondent à un début d'intensification, mais ils restent peu répandus en Afrique de l'Ouest; en revanche en Asie du Sud-Est, la pratique de l'affouragement du bétail en stabulation à partir d'arbres plantés est généralisée.

En Côte d'Ivoire (Oumé), les boutures de Ficus exasperata, qui se reproduit aisément par bouturage, sont préparées en septembreoctobre avec des branches aoûtées (coloration vert marron) prélevées sur des jeunes arbres de 2 à $3 \mathrm{~m}$ de hauteur. Les boutures mesurent $15 \mathrm{~cm}$ de longueur et $1 \mathrm{~cm}$ de diamètre au maximum, et présentent au moins deux yeux, avec ou sans feuilles. Elles sont immédiatement repiquées sous ombrières après traitement de la base de la bouture avec un fongicide; elles sont arrosées le matin et le soir jusqu'à la reprise des boutures, puis une fois par jour; les plants sont traités en cas d'attaques d'insectes et protégés des herbivores. Après six à huit mois, les boutures d'une trentaine de centimètres sont plantées au champ avec la motte de terre pendant la saison des pluies avec un écartement de $4 \mathrm{~m}$ (625 tiges/ha environ).

Ficus exasperata peut aussi être associé aux cultures pérennes (caféier et cacaoyer) et aux cultures vivrières (maïs, riz, igname) à raison de 100 à 150 arbres/ha ou planté avec de fortes densités pour créer des haies fourragères autour des parcelles.

En Asie du Sud-Est, les arbres fourragers sont plantés à des densités de 20000 à 40000 pieds/ha pour une production intensive de fourrage, mais cette densité peut être réduite à 5000 à 10000 pieds/ha si, outre le fourrage, on veut produire du bois de feu ou de service. Ces espèces,

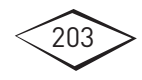




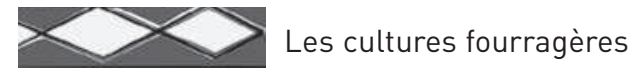

qui présentent souvent une fructification prolifique, peuvent devenir envahissantes comme Leucaena leucocephala dans la moitié sud de la Côte d'Ivoire et dans les îles du Pacifique. Des précautions s'imposent donc pour leur culture. Flemingia macrophylla et Sesbania sesban sont également diffusées dans certains pays, mais leur valeur nutritive ou leur appétibilité est moins élevée, voire plus faible que celle des herbes alentours même âgées, surtout pour Flemingia macrophylla.

Moringa oleifera est planté dans des vergers pour une production intensive de feuilles, notamment en Afrique de l'Ouest. Ce feuillage, utilisé en alimentation humaine pour réduire les carences nutritives des jeunes enfants, sert aussi à nourrir le bétail. Larbre est également planté autour des poulaillers pour l'ombrage et l'alimentation des volailles.

\section{II) Les piquets vifs et les haies vives}

Partout où la pression sur l'espace augmente avec la population et où s'étendent les cultures, l'habitat et les infrastructures, la divagation du bétail pose des problèmes et risque de mettre les éleveurs en difficulté et en conflits avec les autres usagers. Les espèces ligneuses sont très souvent utilisées pour marquer les limites des propriétés foncières, protéger les espaces vis-à-vis du bétail ou même pour enclore les troupeaux et séparer les parcelles de pâturage.

Grâce aux clôtures sur piquets vifs et aux haies vives, les deux dispositifs les plus courants, l'éleveur a la possibilité de clôturer les parcelles, de réguler la charge animale et de gérer la production fourragère; le feuillage que l'on peut récolter sur ces ligneux représente alors une réserve fourragère sur pied. Avec ce type de dispositif, l'agriculteur peut protéger ses parcelles du bétail divaguant.

\section{Les clôtures sur piquets vifs}

Les piquets vifs utilisés comme supports de clôture durables demandent peu d'entretien. Ce sont des arbres ou arbrisseaux, avec un tronc d'au moins $2 \mathrm{~m}$ de haut, plantés à un écartement de 2 à $4 \mathrm{~m}$ sur la limite de la parcelle à clôturer. La technique la plus simple et la plus rapide pour installer ces piquets vifs est la mise en place directement de grandes boutures de 2 à $2,5 \mathrm{~m}$ de long et d'un diamètre de 7 à $10 \mathrm{~cm}$, voire plus. Une fois les troncs suffisamment développés, les fils de fer barbelés sont tendus et fixés sur les troncs.

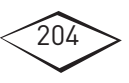




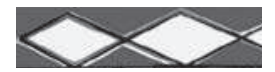

La difficulté majeure est de trouver dans le milieu naturel assez de boutures pour constituer une longue clôture; il faut donc s'organiser pour les produire. Les premiers piquets vifs sont récoltés en brousse ou fournis par des voisins. Après deux à quatre années selon les espèces, les rejets sont assez développés pour être utilisés à leur tour comme grandes boutures. Une fois ces boutures bien installées dans la clôture, les piquets vifs sont exploités en têtard, c'est-à-dire recépés à environ $2 \mathrm{~m}$ du sol pour produire des boutures, du bois et du fourrage, tandis que la base du tronc sert de piquet.

En Afrique sèche, on plante des arbres peu appétés par le bétail, à croissance rapide et d'une production aisée en pépinière, comme les eucalyptus ou les Gmelina arborea. Plus tard, ils fourniront accessoirement du bois de service et du bois d'œuvre.

En Afrique soudano-guinéenne, on utilise Erythrina senegalensis, Erythrina sigmoidea, Ficus spp., Moringa oleifera, Tectona grandis et Spondias mombin, dans les îles du Pacifique Hibiscus tiliaceus (bourao), émondé chaque année pour les bovins, ou Pterocarpus indicus (Sang dragon, photo 8.1), en Amazonie, Vouacapoua americana ou Eperua falcata (wapa en créole guyanais, wallaba en anglais).
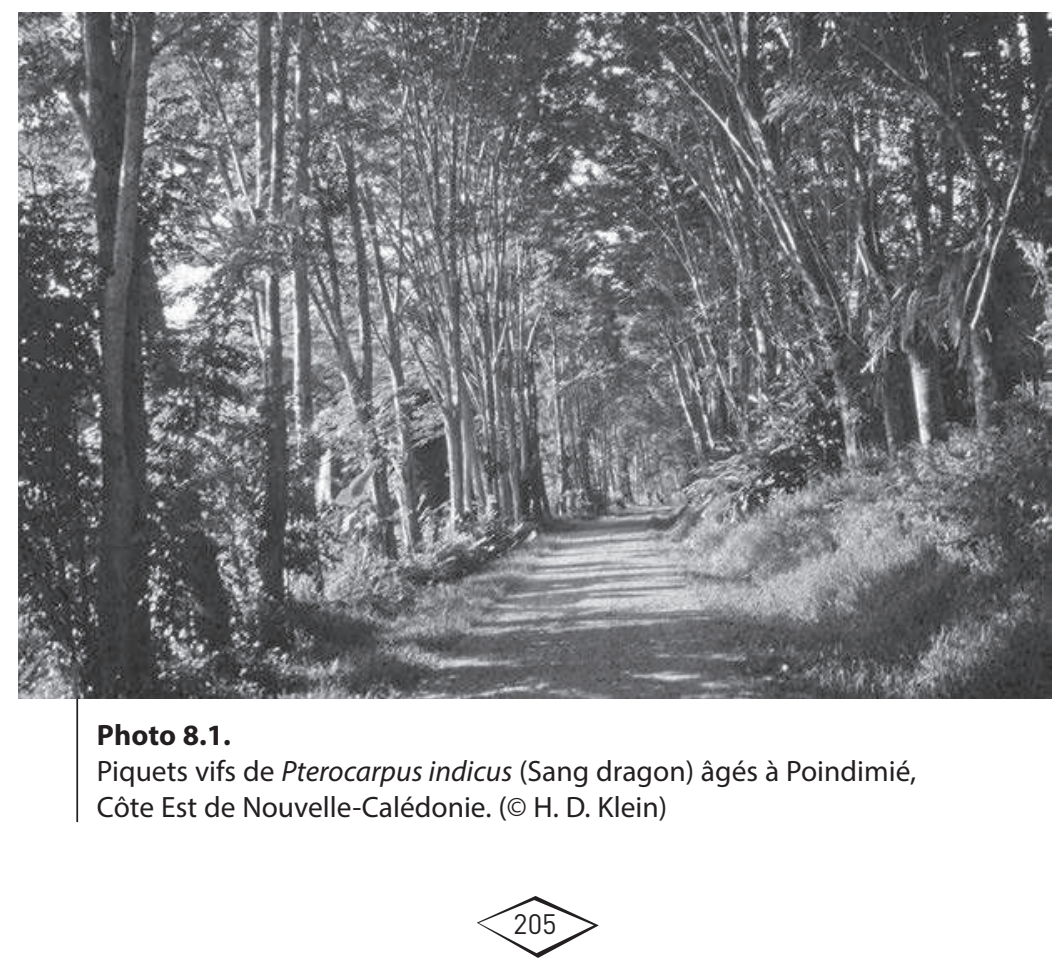


\section{Les haies vives}

On appelle haie vive une plantation linéaire d'arbres ou d'arbustes suffisamment dense pour empêcher le passage du bétail ou des personnes, et entretenue de telle sorte que l'effet de clôture dure dans le temps (photo 8.2).

Pour créer ces haies, on utilise des espèces buissonnantes fortement ramifiées dès la base, efficaces notamment contre les petits ruminants.

Les plantes épineuses sont préférées mais le caractère épineux n'est pas indispensable; certaines plantes épineuses sont également fourragères, telles Balanites aegyptiaca en Afrique soudano-sahélienne, ou le cactus armé Opuntia ficus-indica utilisé à Madagascar, et dont les raquettes, débarrassées par le feu de leurs épines, fournissent un fourrage de réserve lorsque l'herbe est devenue rare.

Gliricidia (Gliricidia sepium) planté très serré autour des parcs à bétail en Asie tropicale et en Amérique latine est remplacé en Afrique sèche par le prosopis (Prosopis juliflora). De nombreuses autres espèces autochtones commencent à être généralisées pour la constitution de haies vives mieux adaptées aux conditions locales que les espèces introduites.

Certaines espèces utilisables sont fruitières, comme le citronnier lime (Citrus aurantifolia) ou le jujubier (Ziziphus mauritiana); leurs fruits peuvent contribuer à l'alimentation humaine ou apporter quelques revenus supplémentaires. D'autres, comme Bauhinia rufescens, sont fourragères et l'abroutissement permet de limiter leur extension latérale.

Critères de sélection des espèces pour la création de haies vives

A priori les espèces de haies vives défensives doivent être épineuses (caractère défensif), buissonnantes (la ramification basse renforce l'étanchéité de la haie), sociables (pour vivre en peuplements linéaires denses), de croissance initiale rapide (pour obtenir rapidement une haie efficace), de multiplication aisée, rustiques (pour pousser sur des sols variés), peu ou pas appétibles (pour minimiser les risques liés au broutage).

Il est cependant apparu à l'usage que certains de ces critères sont secondaires, comme le caractère épineux ou arbustif qui peut être compensé par une plus forte densité de plantation sur la ligne. Une croissance initiale rapide est généralement souhaitée, néanmoins, une période d'installation longue est acceptable pour des espèces qui

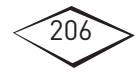



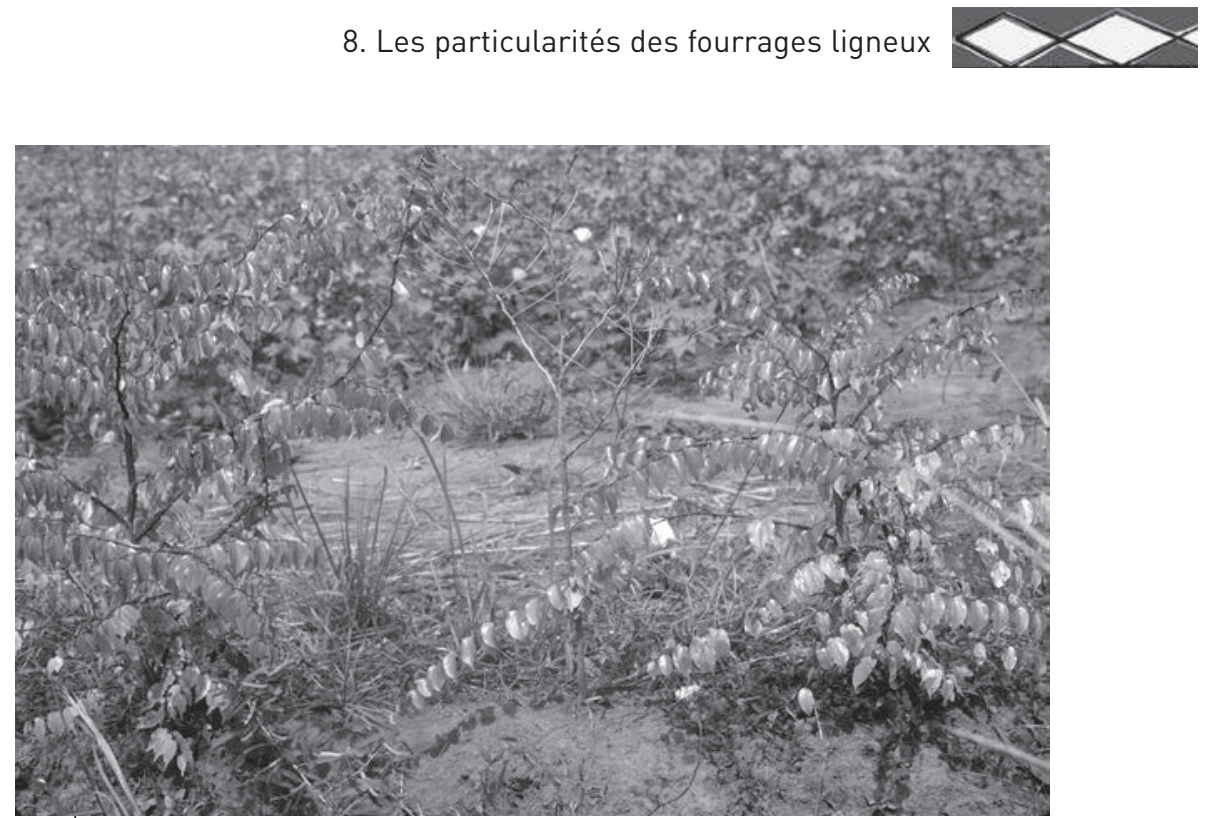

Photo 8.2.

Jeune haie vive avec Ziziphus mucronata, Korhogo, Côte d'Ivoire.

(๑ H. D. Klein)

donnent des produits recherchés comme par exemple le citronnier lime (Citrus aurantifolia) qui produit le citron vert.

D'autres critères doivent être pris en compte pour favoriser l'adoption par les agriculteurs des espèces préconisées : la multiplicité de leurs usages (bois, alimentation humaine et animale, pharmacopée), la production potentielle, fruitière ou autres, qui générera des revenus supplémentaires, la résistance aux feux accidentels et la longévité de l'espèce qui rentabilise au mieux l'investissement important que constitue la création de la haie.

Les techniques utilisables pour installer des haies vives sont la plantation, le bouturage et le semis direct.

\section{Composition d'une haie vive efficace contre le bétail}

Une telle haie sera composée dès le départ de plusieurs espèces, en mélange pied à pied, pour limiter les risques d'échec; selon les types de sol, l'une ou l'autre espèce, mieux adaptée, dominera assez rapidement. On évite ainsi l'apparition de trouées par mortalité, fréquentes dans les haies monospécifiques quand l'espèce est mal adaptée au sol ou au climat. Pour renforcer l'efficacité de la haie, il faut aussi conserver tous les ligneux qui y poussent naturellement.

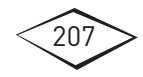


La haie doit être constituée d'une seule rangée de plants pour faciliter le désherbage. En effet, avec deux rangées de buissons, surtout s'ils sont épineux, il est très difficile de désherber entre les deux lignes où l'herbe crée un chemin privilégié de transmission des feux de brousse. Les plants de la haie doivent être rapprochés, l'optimum est de 3 plants au mètre linéaire. Ainsi, la mort d'un plant n'impose pas son remplacement pour que la haie reste efficace.

\section{Les techniques d'installation des haies vives par semis direct}

Les espèces épineuses comme Bauhinia rufescens, Dichrostachys cinerea, Haematoxylon brasiletto, Ziziphus mauritiana et Ziziphus mucronata (photo 8.2) se prêtent bien à l'installation par semis direct sous réserve de respecter un certain nombre de règles élémentaires.

On sème un mélange d'au moins deux espèces. Cette technique exige une quantité de graines plus élevée que la production de plants en pépinière mais demande moins de travail. Les graines qui le nécessitent doivent être prétraitées pour lever la dormance, puis séchées, avant d'être semées; les graines de Ziziphus doivent être extraites de leur coque.

En traction animale, on peut utiliser un semoir mécanique pour les grandes longueurs de haies. Il faut que celui-ci soit bien réglé pour éviter de gaspiller les graines. Sur des billons faits à la daba (houe manuelle) en culture traditionnelle, le semis sera manuel. Le billonnage a comme avantage de bien matérialiser la ligne de semis, ce qui facilite le repérage des semis pour les travaux d'entretien. La plus grosse difficulté dans la mise en ouvre du semis direct est en effet l'élimination des herbacées. Les jeunes semis de ligneux se développent lentement pendant les premiers mois et sont difficilement repérables dans les herbes. Souvent, des semis sont détruits lors des sarclages par manque de précaution. Les herbicides de prélevée et sélectifs peuvent être une solution pour éviter l'enherbement des plants, mais les réglementations sont de plus en plus contraignantes pour l'utilisation de tels produits qui nécessitent par ailleurs des protections adéquates.

Les espèces ligneuses communément utilisées en Afrique soudanoguinéenne pour la constitution des haies vives ont été regroupées avec des commentaires et leurs modes d'installation dans le tableau 8.1.

Une fois la haie bien installée et suffisamment haute et à condition que la charge animale soit bien maîtrisée, l'abroutissement des arbustes empêche leur développement excessif, afin de ne pas concurrencer celui du couvert herbacé.

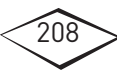


Tableau 8.1. Espèces ligneuses communément utilisées en Afrique soudano-guinéenne pour la constitution des haies vives.

\begin{tabular}{|c|c|}
\hline $\begin{array}{l}\text { Espèces utilisées } \\
\text { et utilisables }\end{array}$ & Commentaires - Mode d'installation \\
\hline $\begin{array}{l}\text { Agave sisalana, } \\
\text { Sisal }\end{array}$ & $\begin{array}{l}\text { Multiplication aisée grâce aux bulbilles qui peuvent être } \\
\text { installés sur le terrain directement ou après un temps } \\
\text { d'élevage en pépinière. Produit des fibres. }\end{array}$ \\
\hline Bauhinia rufescens & Pépinière ou semis direct. \\
\hline Citrus aurantifolia & $\begin{array}{l}\text { À produire en pépinière mais avec des difficultés pour } \\
\text { trouver des semences en quantité suffisantes car les fruits } \\
\text { sont vendus sur les marchés. La période d'installation est } \\
\text { longue : } 4 \text { à } 5 \text { ans mais la haie est très efficace et produit } \\
\text { des citrons verts en abondance garantissant un bon revenu } \\
\text { à l'agriculteur. }\end{array}$ \\
\hline $\begin{array}{l}\text { Dichrostachys } \\
\text { cinerea }\end{array}$ & Pépinière ou semis direct. \\
\hline Euphorbia tirucalli & $\begin{array}{l}\text { Multiplication aisée par boutures, petites ou moyennes. } \\
\text { Haie ornementale. }\end{array}$ \\
\hline $\begin{array}{l}\text { Erythrina } \\
\text { senegalensis }\end{array}$ & $\begin{array}{l}\text { Plantation directe au champ de grandes boutures ( }>5 \mathrm{~cm} \\
\text { de diamètre et de } 1 \mathrm{~m} \text { de haut), mais difficulté pour trouver } \\
\text { des boutures en quantités suffisantes. Nécessité de traiter } \\
\text { l'arbre en têtard pour favoriser la production de boutures. } \\
\text { Linstallation à partir de graines ou de plants éduqués en } \\
\text { pépinière est lente, d'autant que les jeunes plants sont } \\
\text { broutés. }\end{array}$ \\
\hline $\begin{array}{l}\text { Haematoxylon } \\
\text { brasiletto }\end{array}$ & Sud américain. Pépinière ou semis direct. Bois tinctorial. \\
\hline $\begin{array}{l}\text { Jatropha curcas, } \\
\text { Pourghère } \\
\text { en Afrique }\end{array}$ & $\begin{array}{l}\text { Multiplication aisée par boutures, petites ou moyennes. } \\
\text { Graines dont l'huile est utilisable directement dans les } \\
\text { moteurs diesel anciens. }\end{array}$ \\
\hline Moringa oleifera & $\begin{array}{l}\text { Les jeunes plants sont flexibles - même de plus de } 2 \mathrm{~m} \\
\text { de haut - et sont couchés par les chèvres pour brouter } \\
\text { les feuilles et rameaux. C'est la cause majeure d'échec } \\
\text { en plantation. Lutilisation de grandes boutures est } \\
\text { recommandée. L'espèce est très sensible aux termites. } \\
\text { Espèce multi-usages dont alimentation humaine. }\end{array}$ \\
\hline $\begin{array}{l}\text { Ziziphus } \\
\text { mauritiana }\end{array}$ & Pépinière ou semis direct. Fruits comestibles. \\
\hline $\begin{array}{l}\text { Ziziphus } \\
\text { mucronata }\end{array}$ & Pépinière ou semis direct. \\
\hline
\end{tabular}

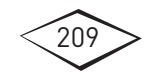




\section{II) Les bandes boisées, bosquets et pré-bois}

Les ligneux disposés en bandes boisées, en bosquets, en pré-bois, voire même isolés assurent très souvent de multiples usages : produire du bois, protéger et améliorer les sols, apporter de l'ombrage, produire du fourrage et d'autres produits alimentaires (fruits, feuilles, graines), technologiques (gommes, fibres) et médicinaux.

Les bandes boisées sont implantées ou conservées sur une largeur qui varie de quelques mètres (alignements d'arbres apparentés à des brise-vent) à une cinquantaine de mètres, voire plus. Sur les terrains en pente, elles permettent de protéger le sol contre l'érosion et favorisent l'infiltration des eaux de pluies, ce qui a un impact positif direct sur la production fourragère et sur sa pérennité.

Les bosquets et les arbres disséminés servent d'ombrage au bétail et de refuge pendant les heures chaudes de la journée. Selon les espèces présentes, ils produisent aussi un fourrage d'appoint, des fruits, du bois de feu ou du bois d'œuvre et contribuent à la fertilité à long terme des sols. Il faut veiller à ce que les arbres ne soient pas trop serrés pour que l'herbe pousse en sous-bois et apporte un fourrage encore frais en début de saison sèche, alors qu'en plein soleil, les herbes sont déjà sèches et moins nutritives.

La faible densité des arbres favorise leur vitesse de croissance et permet d'associer la production animale à la production de bois d'œuvre mais, en contrepartie, oblige à élaguer les troncs pour obtenir un bois de qualité. Le pâturage a comme avantage de limiter la biomasse combustible (herbes sèches) en saison sèche et de protéger les arbres contre les dégâts liés aux feux accidentels. En Nouvelle-Zélande, d'immenses plantations de pins ont ainsi été associées à des prairies permanentes, associant ainsi la production rapide de viande ovine et celle de bois d'œuvre à plus long terme.

Les pré-bois sont des terres de pâturage incluant des arbres disséminés et/ou en bouquets. Le pré-bois cumule des avantages écologiques et les revenus annuels de l'élevage et de la production fruitière et les revenus occasionnels de la sylviculture. Les revenus tirés du bois d'œuvre peuvent être très élevés si les arbres utilisés produisent un bois de grande qualité technologique. Dans certaines conditions, ces ligneux sont pris en compte comme puits de carbone et permettent d'obtenir un revenu au titre d'un «Paiement pour services environnementaux» (PSE), par exemple en Amérique centrale.

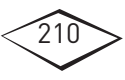




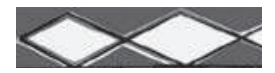

Les alley cropping sont des lignes intercalaires agroforestières implantées dans des cultures vivrières ou industrielles. Les branches sont coupées et les feuilles sont consommées par les animaux, fraîches ou sèches, après avoir été transportées et éventuellement stockées. Les surfaces occupées par les ligneux peuvent être considérées comme des surfaces fourragères.

\section{La gestion et l'utilisation des ligneux fourragers}

En raison des décalages saisonniers entre la disponibilité des fourrages herbacés et celle des ligneux, et entre leurs valeurs fourragères, plusieurs schémas d'utilisation des ligneux sont observables dans le monde tropical. Ils sont plus ou moins liés aux objectifs de l'éleveur, aux modes d'implantation, aux besoins des animaux et aux usages, dans le respect de la biologie des plantes.

Les ligneux fourragers sont principalement pâturés directement, émondés avec consommation sur place, ou exportés pour l'affouragement au piquet ou en étable ou pour la vente.

\section{En pâturage direct}

L'exploitation la plus simple et la moins onéreuse consiste à conduire le bétail dans les pâturages où se trouvent les ligneux et à laisser les animaux se servir et choisir le fourrage. Laccès aux espèces appétées par le bétail nécessite éventuellement l'intervention du berger quand les animaux sont conduits quelques heures par jour sur une banque fourragère, et requiert éventuellement un émondage pour faire consommer la totalité des feuilles.

Sans émondage (photo 8.3) les animaux ne peuvent pas brouter le feuillage des arbres au-dessus d'une certaine hauteur. Ainsi observe-ton fréquemment que la base des houppiers des arbres est horizontale, montrant la hauteur maximale à laquelle le feuillage peut être atteint par le bétail. Les bovins, qui se limitent aux feuilles et aux jeunes pousses, modifient relativement moins la forme des houppiers que les chèvres qui se dressent sur leurs pattes arrière et sont capables de prélever des quantités beaucoup plus importantes.

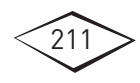



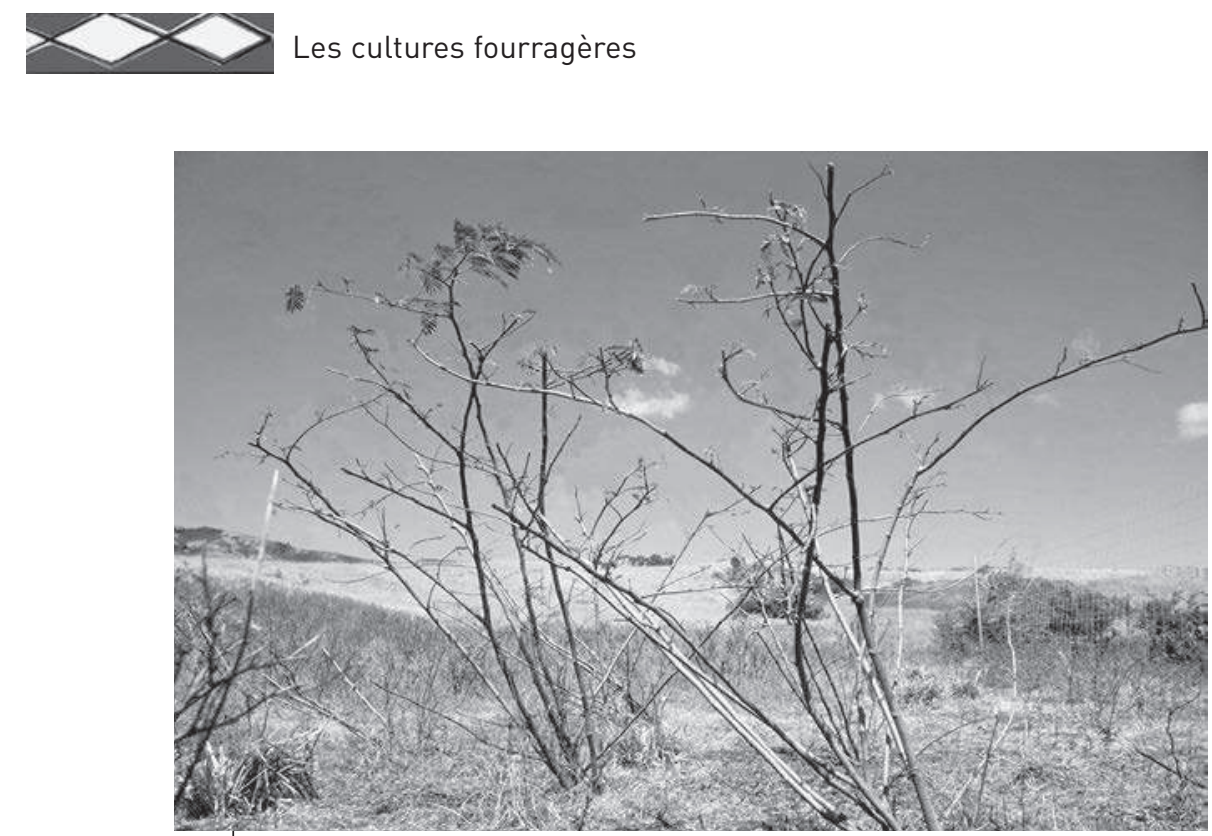

Photo 8.3.

Calliandra calothyrsus presque entièrement pâturé par les cerfs d'élevage à Port Laguerre, côte ouest de Nouvelle-Calédonie. (๑ H. D. Klein)

Si les buissons et les arbres fourragers sont suffisamment développés, le broutage des feuilles et des jeunes rameaux ne met pas en cause leur survie. Par contre, la régénération de ces espèces fourragères peut devenir difficile, voire inexistante, en cas de pâture trop importante. Le feu est un risque majeur pour la régénération des espèces ligneuses dans les régions subhumides.

Pour favoriser la régénération des ligneux fourragers, les éleveurs peuvent mettre le pâturage en défens (ou protection intégrale), incluant la protection contre les feux. Lorsque les arbres sont suffisamment développés, ils peuvent être abroutis sans risque. Ensuite, une bonne gestion du pâturage permet de réduire la biomasse combustible, particulièrement celle des herbacées et de limiter l'impact des feux accidentels.

Le rajeunissement des arbustes fourragers peut s'avérer nécessaire quand ceux-ci, en vieillissant, produisent moins. Le recépage est une technique fréquemment utilisée pour les espèces dont les souches rejettent bien : on coupe les pieds vieillis et devenus trop hauts et on protège les repousses le temps nécessaire; les bois sont utilisés comme bois de feu. Le gyrobroyage est parfois pratiqué sur certains genres comme Leucaena et certains Acacia, dont les copeaux et les brindilles protègent et enrichissent le sol.

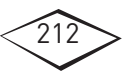




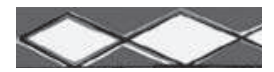

\section{Après émondage}

Pour permettre aux animaux de profiter du fourrage inaccessible, les pasteurs et les petits éleveurs villageois ou urbains pratiquent l'émondage de tout ou partie du houppier, non seulement des arbres dans les parcours, mais aussi des arbres fourragers conservés ou cultivés dans les pâtures et les champs afin de garder un troupeau près du lieu d'habitation (photo 8.4).

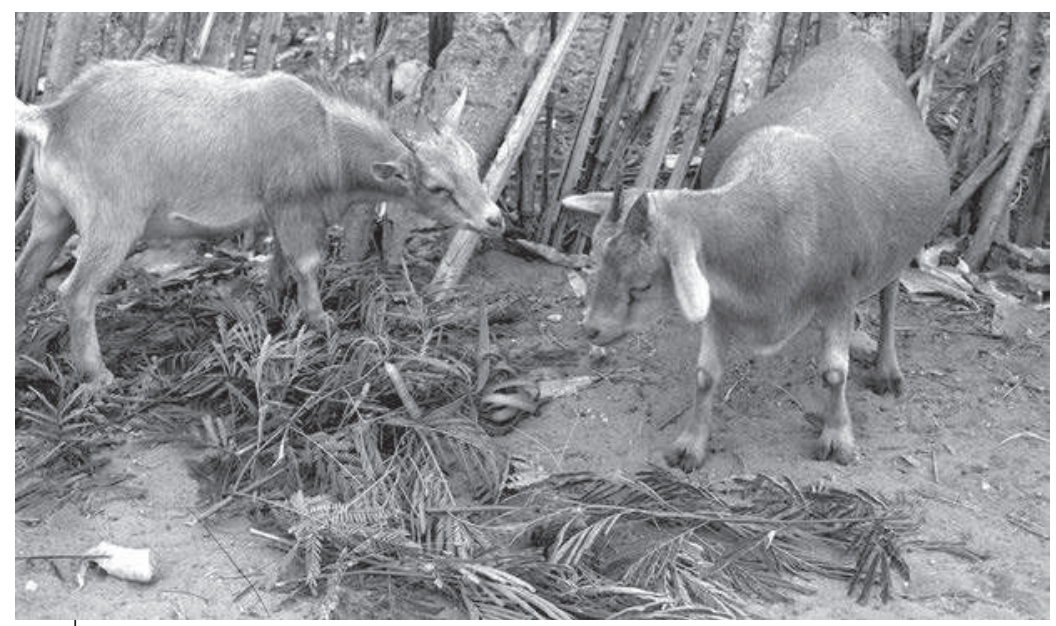

Photo 8.4.

Chèvres affouragées avec des émondes de Leucaena leucocephala,

Casamance, Sénégal. (@ D. Louppe)

L'émondage a un effet dépressif sur la production ligneuse et de mauvaises pratiques peuvent entraîner des dégâts importants dans le peuplement ligneux. Le rabattage, aussi appelé taille en parapluie, consiste en une coupe incomplète des branches pour les faire pendre afin de les rendre accessibles au bétail. Cette pratique entraîne généralement de la mortalité chez les arbres, contrairement à l'émondage avec section nette des branches.

\section{Exemple en Afrique subhumide}

En Afrique intertropicale, le fourrage ligneux récolté par émondage est à la base d'une importante filière commerciale informelle pour alimenter le bétail de case urbain, surtout pour l'engraisser avant les fêtes. Les rameaux feuillés sont amenés en ville, en vélo et charrette ou

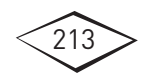


en complément du chargement de camionnette et de camion. Sur les marchés, la composition du fourrage ligneux varie selon les saisons. Ces fourrages permettent d'entretenir et d'engraisser des petits ruminants avec les mêmes performances que les sous-produits agro-industriels.

Dans le nord de la Côte d'Ivoire, les principales espèces ligneuses commercialisées sous forme d'émondes sont :

- Gmelina arborea, espèce exotique cultivée pour son bois; Mangifera indica et Blighia sapida (Aki ou Akée en Afrique), espèces fruitières plantées;

- Khaya senegalensis, Antiaris toxicaria (Upas ou Ipoh en Asie) et Afzelia africana, arbres à bois de valeur;

- Allophylus africanus, Annona senegalensis, Ficus exasperata, Guiera senegalensis, Morinda lucida et Strychnos spinosa, espèces buissonnantes et petits arbres.

Tous ces arbres fourragers sont exploités intensivement dans la brousse des environs des villes. La demande et la surexploitation des arbres, qui augmentent avec la proximité des agglomérations, conduisent à la mise en place de vergers fourragers à base de Ficus, avec Ficus sycomorus au nord Cameroun et Ficus exasperata au centre de la Côte d'Ivoire, où la culture est concentrée sur ces seules espèces qui ont tendance à disparaître.

Bien entretenu, Ficus exasperata atteint 3 à $4 \mathrm{~m}$ de hauteur en trois ans et l'exploitation en têtard du fourrage peut commencer. On le coupe à $2 \mathrm{~m}$ du sol pour garder les repousses hors de portée des herbivores. C'est aussi à cette hauteur que les coupes successives donnent le plus de fourrage : la production moyenne à cinq ans est d'une quarantaine de kilos de feuilles fraîches/arbre/an (soit 5t MS/ha/an) et d'autant de bois vert/arbre/an. Les coupes peuvent se faire toute l'année. Les périodes d'exploitation seront donc choisies en fonction de la demande en fourrage sans faire plus de deux coupes par an sur le même arbre.

Dans les vergers fourragers, la récolte du feuillage commence un à deux ans après la plantation. Les plants sont coupés à une hauteur de $50 \mathrm{~cm}$ à $1 \mathrm{~m}$ tous les trois mois environ. En conditions favorables de pluviométrie et de fertilité des sols, les productions fourragères à l'hectare espérées sont importantes :

- de 7 à $10 \mathrm{t} \mathrm{MS/ha/an} \mathrm{pour} \mathrm{Calliandra} \mathrm{calothyrsus;}$

- jusqu'à $15 \mathrm{t}$ MS/ha/an pour Gliricidia sepium et Leucaena leucocephala;

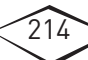




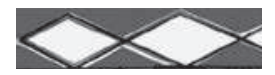

- voire $20 \mathrm{t} \mathrm{MS/ha/an} \mathrm{pour} \mathrm{Sesbania} \mathrm{sesban;}$

- environ $5 \mathrm{t}$ MS/ha/an de feuilles fraîches/arbre/an pour Ficus exasperata et autant de bois vert/arbre/an.

\section{Exemple en Inde}

Dans les régions sèches de l'Inde (Rajasthan), les émondes des arbres fourragers sont séchées et conservées en fenil jusqu'à l'utilisation en saison sèche. Ces feuillards permettent de nourrir les chèvres laitières au moment où les parcours sont très pauvres.

Le Rajasthan est l'État le plus aride de l'Inde, avec en son centre un climat sahélien ( $450 \mathrm{~mm}$ de pluies en moyenne par an sur quatre mois) et une forte variabilité interannuelle. Les forêts ne couvrent plus que $11 \%$ du territoire et sont assez dégradées. Hors des forêts, les terres sont en partie publiques (savanes), d'accès réglementé et surveillées par les agents des forêts, et en partie privées et vouées majoritairement à l'agriculture (petit mil, sorgho, maïs, moutarde, pois mungo, orge).

\section{Choix des ligneux et productions}

Plusieurs types d'arbres et arbustes sont utilisés pour le fourrage :

- Prosopis cineraria (khejri) (mesquites au Mexique). Il améliore la fertilité du sol et peut être placé dans les cultures. Le feuillage, d'appétibilité moyenne, est donné en vert aux chèvres ou séché et conservé dans un grenier;

- Acacia nilotica var. indica (babul). Il est essentiellement cultivé en bordure des champs car son enracinement superficiel gêne les labours et fait concurrence aux cultures. Ses feuilles offrent le fourrage le plus apprécié parmi les ligneux;

- Acacia leucophloea (orinja). Cette espèce est endémique de l'Inde. Au Rajasthan elle est cultivée dans les champs car elle ne gêne pas les cultures. Le feuillage est consommé seulement en vert, entre novembre et février;

- Azadirachta indica (neem). Cet arbre à feuilles persistantes est apprécié pour son ombrage, son bois dur et résistant aux parasites et l'huile de ses graines pour les lampes. Le feuillage a une valeur fourragère médiocre mais il peut être un peu consommé en saison froide par les chèvres et les moutons;

- Ziziphus nummularia (bordi) et Ziziphus mauritiana (ber). Ces petits arbres buissonnants épineux croissent rapidement. Les chèvres vont brouter leurs feuilles si elles y ont accès. Les branches sont coupées et séchées.

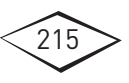




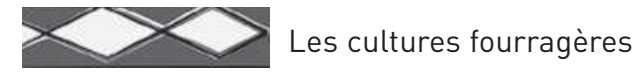

\section{Gestion des arbres fourragers}

Au Rajasthan, tout arbre fourrager localisé sur une terre privée a une valeur productive et économique; il est donc l'objet d'attention. Soit le propriétaire utilise lui-même cette production, soit il la loue à des éleveurs, avec un droit d'ébranchage organisé. Ce droit d'ébranchage est annuel et les échanges entre contractants sont redistribués chaque année. Il est fréquent que le propriétaire n'accorde le droit d'ébranchage qu'une année sur deux pour éviter d'épuiser l'arbre.

\section{ID Utilisation des fruits des ligneux}

Les fruits de certains ligneux, notamment des gousses de légumineuses, présentent l'avantage de pouvoir être consommés directement au sol, soit après leur chute une fois mûrs, soit après gaulage lorsqu'ils sont encore verts. Bien secs, ils se conservent aisément et sont commercialisés et stockés. Certaines gousses (Faidherbia albida [photo 8.5], Acacia senegal, A. nilotica, A. seyal) sont commercialisées; au Sénégal, par exemple, ces gousses alimentent en grande partie le bétail de case dakarois en saison sèche en complément de fanes d'arachide.
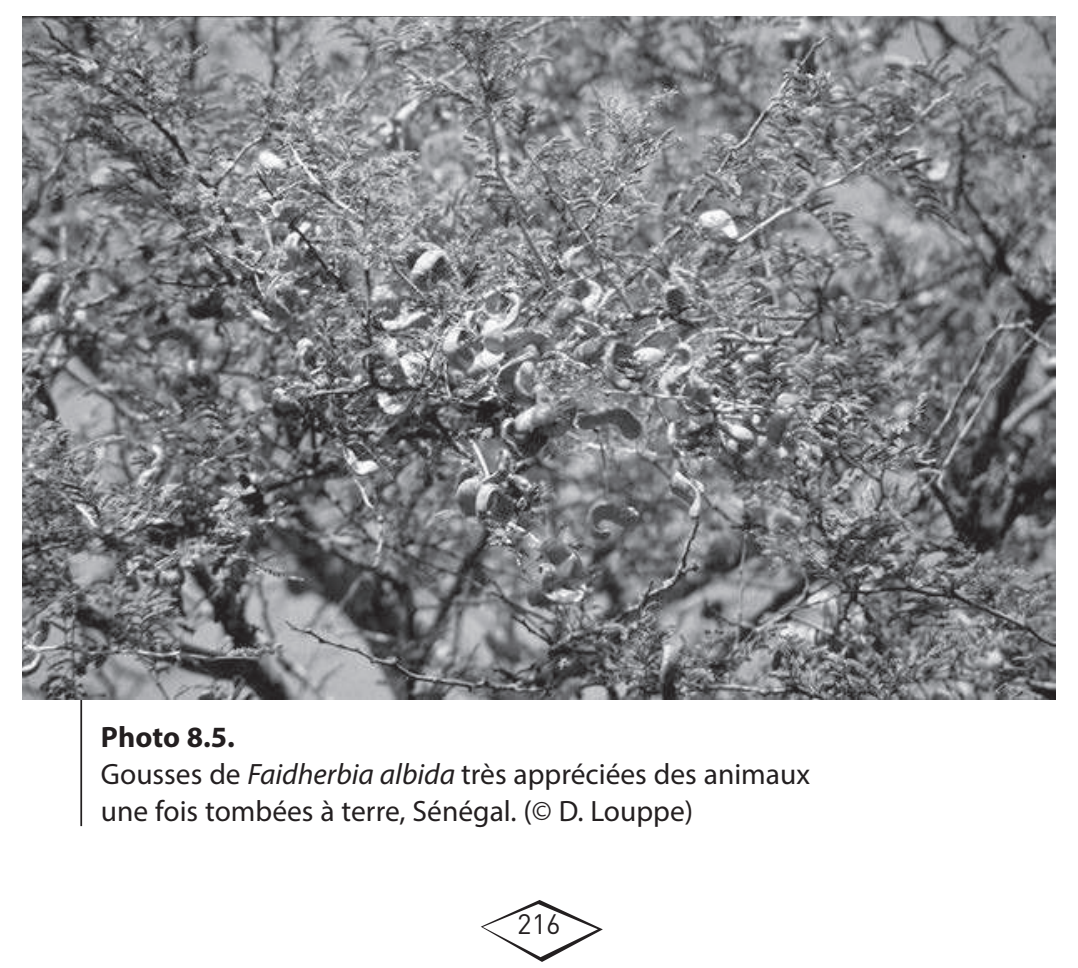
Actuellement, il semble qu'il n'y ait pas de plantation d'arbres spécifiquement destinée à la production de fruits fourragers. La récolte de fruits fourragers est encore considérée comme un avantage annexe par rapport aux objectifs principaux justifiant leur plantation, par exemple l'enrichissement des sols en azote et l'amélioration du microclimat avec Faidherbia albida.

Faidherbia albida est un arbre qui a la particularité d'être feuillé en saison sèche et défeuillé en saison des pluies. Il est traditionnellement préservé dans les terres de cultures car il améliore les productions céréalières. En Afrique subsaharienne, l'émondage total de Faidherbia albida est une pratique courante : la production feuillée, qui reste assez constante d'une saison sèche à l'autre, varie selon la dimension de l'arbre de 5 à $40 \mathrm{~kg}$ MS, à laquelle s'ajoutent 40 à $100 \mathrm{~kg}$ de bois utilisé pour la cuisson des aliments. En contrepartie, la production fruitière est réduite à quelques kilos par arbre et, même si les gousses ont une digestibilité deux à trois fois supérieure à celle des rameaux feuillés, les paysans continuent à couper les branches. Des mesures faites au Sénégal ont montré qu'avec 40 arbres/ha non émondés produisant $125 \mathrm{~kg} /$ arbre/an, la production annuelle de gousses sèches pouvait atteindre $5 \mathrm{t} \mathrm{MS} / \mathrm{ha} / \mathrm{an}$, ce qui représente environ $1900 \mathrm{UF}$, plus que toute autre production fourragère locale, tout en conservant un environnement qui améliore les productions céréalières.

\section{Conclusion}

Une grande diversité botanique d'arbres et arbustes sont fourragers. Il est important d'évaluer leur réelle productivité et leur accessibilité pour les animaux aux périodes où ils en ont le plus besoin. Pourtant cette végétation ligneuse autochtone est souvent mal valorisée. Des tentatives d'introduction d'espèces exotiques à titre expérimental, puis éventuellement par des projets, faites en zones sèches depuis plusieurs décennies, ont souvent conduit à des déboires. Ces essais ne peuvent se justifier que par des objectifs précis en complément de la diversité locale.

La végétation fourragère ligneuse autochtone est en danger du fait d'une exploitation excessive de moins en moins organisée et non contrôlée par les communautés locales, qui sont à la fois victimes et actrices de la pression sur les ressources. Cela menace la persistance de ces espèces.

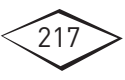




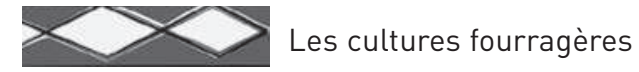

Certaines espèces ont un port prostré (Combretum aculeatum dans les régions sahélo-soudaniennes), du fait d'un abroutissement excessif. Malgré leur valeur nutritive élevée, leur contribution aux rations reste donc faible. Il faut alors s'interroger sur l'accroissement du potentiel fourrager que pourrait permettre leur domestication, leur protection et leur gestion raisonnée patrimoniale comme celle pratiquée pour d'autres espèces d'intérêt mixte agronomique (Faidherbia albida).

Des recherches sur l'appétibilité de certaines variétés d'espèces à fortes teneurs en nutriments digestibles devraient également être menées; dans un même contexte agropastoral le brout de certaines espèces peut varier selon le faciès de l'arbre, et selon les sujets. L'exploration des déterminismes de ces variations en réaction au brout (génétiques, pédologiques, biologiques) pourrait ouvrir la voie à une meilleure valorisation de ces espèces en général bien adaptées à leur milieu.

La domestication des espèces ligneuses fourragères est engagée depuis longtemps en Asie tropicale et en Australie, mais très peu en Afrique. Des recherches sur les espèces indigènes mériteraient d'y être développées car ces espèces sont adaptées aux conditions de milieu, et on éviterait ainsi les risques d'introduction de plantes potentiellement envahissantes et des maladies qui leur sont associées. Des recherches pourraient être ciblées (richesse du fourrage, modes de reproduction, de plantation, d'exploitation, croissance et productivité, etc.) afin de domestiquer ces espèces indigènes. 


\section{La production}

\section{de semences fourragères}

Le développement d'une culture fourragère doit aller de pair avec l'approvisionnement en semences de qualité quand les espèces fourragères à cultiver ne peuvent pas être implantées par bouturage. Deux grands pays du Sud produisent des semences fourragères tropicales, le Brésil et l'Australie. D'autres pays produisent des semences, notamment en Asie. Ailleurs et particulièrement dans beaucoup de pays d'Afrique de l'Ouest, l'importation de semences fourragères est difficile ou très coûteuse, voire interdite, en raison des aspects règlementaires et douaniers.

La production, la récolte et la conservation des semences de qualité pour et par des petits producteurs peut être utile, d'une part dans les pays où il est difficile d'obtenir des semences, et d'autre part pour réduire les coûts. Les aspects techniques et l'organisation de la production des semences en conditions tropicales sont présentés dans «Les semences» (Turner, 2013, coll. Agricultures tropicales en poche).

\section{Comment produire des semences fourragères}

\section{L'organisation de la production de semences}

Lagriculteur qui souhaite s'auto-approvisionner en semences doit prévoir de consacrer une partie de la surface fourragère disponible pour produire ses semences, en principe environ $10 \%$ de la surface semée. Pour mettre en place des cultures fourragères, il faut obtenir de petites quantités de semences qu'il est souvent possible d'acquérir auprès des centres d'élevage qui disposent de collections fourragères ou de jardins fourragers.

Par exemple au Sénégal et au Cameroun, en relation avec les centres de recherche, de nombreux cultivateurs, surtout des femmes, vendent avec profit des semences fourragères produites et récoltées dans leurs champs ou dans leurs jardins. Mais ces petits producteurs doivent être mieux formés et s'organiser pour fournir des semences de qualité

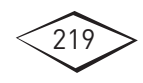


pour répondre à une demande croissante. En effet, la production de semences demande beaucoup plus d'attention et de soin que la production de fourrages, que ce soit dans le choix de la parcelle, de la préparation du sol et surtout de la fertilisation, qui doit être définie avec beaucoup plus de précision.

\section{ID Le choix du site}

Le choix du site de production doit tenir compte des conditions biophysiques déjà évoquées, de la pression pathogène (notamment des risques de charbon), mais aussi de la photopériode.

Les plantes fourragères tropicales ont été divisées en trois groupes photopériodiques : les plantes dites de «jours courts » dont la floraison est déclenchée par une diminution de la durée du jour, les plantes dites de «jours longs» qui fleurissent lorsque le jour s'accroît, et les plantes indifférentes à la photopériode. En général, plus on s'éloigne de l'équateur, plus ces plantes sont sensibles aux jours longs.

\section{Température}

La température a une grande importance et agit généralement avec le photopériodisme. Pour les latitudes proches de l'équateur, la plupart des espèces fourragères fleurissent mieux en altitude, là où la température est plus clémente. Les températures idéales se situent entre $14^{\circ} \mathrm{C}$ et $25^{\circ} \mathrm{C}$. Les pics de chaleur (plus de $35^{\circ} \mathrm{C}$ ) ou de froid (moins de $10^{\circ} \mathrm{C}$ ) ont souvent un effet critique sur la floraison.

\section{Régime des pluies}

Les pluies tombées pendant la phase végétative sont essentielles pour une bonne production semencière. De fortes pluies peuvent empêcher la pollinisation ou produire l'égrenage et/ou la verse; la sécheresse peut interrompre la végétation mais on peut y remédier par l'irrigation. Un excès de pluies et une température élevée sont à l'origine de maladies cryptogamiques des plantes. Une production de semences après la fin des pluies permet une bonne récolte et surtout un bon séchage et une bonne conservation.

\section{Des sols avec possibilité d'irrigation}

Il faut choisir de préférence des terrains fertiles, plutôt profonds, sans cailloux et irrigables en cas de sécheresse. D'un intérêt exceptionnel pour une culture fourragère, l'irrigation peut être rentable en

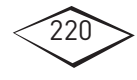




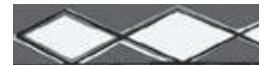

production de semences pour éviter tout déficit hydrique au moment de la mise à fleurs et pendant toute la floraison. Une asphyxie du sol par une irrigation trop importante ou un engorgement est néfaste à la floraison. Il faut donc choisir des sols bien drainants, non hydromorphes, à texture sablo-argileuse ou argilo-sableuse, pas trop lourds. Dans des sols trop argileux, la culture doit se faire sur des billons.

\section{ID La culture des plantes semencières}

\section{Nutrition minérale indispensable}

Un apport précoce d'azote sur les graminées permet d'améliorer le rendement semencier, en augmentant le nombre et la grosseur des talles et des inflorescences. Un apport tardif aura très souvent des conséquences défavorables, avec plus de fourrage et moins de semences. Lapport ne doit pas être excessif, parce qu'il réduit la durée de vie des inflorescences et le poids des semences. Le phosphore et surtout la potasse favorisent la floraison et la montée à graines.

Chez les légumineuses, une très légère fertilisation peut être favorable à une bonne implantation en début de culture. Lazote est mieux valorisé s'il est équilibré par une fumure phosphatée. Le phosphore et la potasse jouent un rôle important pour la floraison et la grenaison et le remplissage des graines en cours de végétation et en fin de cycle.

\section{Implantation du champ semencier}

La prémultiplication des variétés, c'est-à-dire l'installation des premiers champs, se fait très souvent soit à partir de semences acquises en très petites quantités (quelques centaines de grammes), soit à partir de boutures ou d'éclats de souches. Par la suite, on utilise soit les nouvelles boutures ou éclats de souche, soit les graines récoltées. Une bonne reprise ou une bonne levée dépend des conditions climatiques pendant les premières semaines après semis.

En général, les doses de semis sont plus faibles pour l'installation des porte-graines que pour celle de la production de fourrage. Pour la production de semences, il est nécessaire de diminuer la quantité de matière verte pour favoriser la montée à graines et la récolte, et assurer une meilleure pénétration de la lumière en jouant sur l'écartement des plantes sur la ligne et entre les lignes. Il faut trouver un compromis entre des doses de semences trop faibles qui entraînent l'invasion par des adventices et des doses trop élevées qui favorisent la compétition entre plantes.

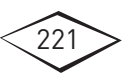




\section{Désherbage}

Il est nécessaire d'avoir des parcelles propres (sans adventices) pour favoriser la croissance de la plante fourragère cultivée et ne pas favoriser le développement de plantes adventices. Il faut également veiller à la pureté des stocks de semences, ce critère étant pris en compte pour la commercialisation des graines.

Les désherbages manuels, mécaniques ou chimiques sont donc indispensables à la production de semences. Les désherbages, conduits selon les mêmes modalités que ceux utilisés pour la production fourragère, sont beaucoup plus fréquents et très souvent chimiques, leur coût est élevé mais il est amorti par le prix de vente des semences.

\section{Production}

C'est en première ou le plus souvent en deuxième année que l'on obtient les meilleurs rendements en graines chez la majorité des plantes.

\section{Comment récolter et conditionner les semences}

La récolte peut être manuelle ou mécanisée (batteuse fixe ou moissonneuse-batteuse). Certaines plantes hétérogènes du point de vue maturité et dont les graines tombent facilement (par exemple Panicum maximum) donnent de meilleurs rendements en récolte manuelle et après ensachage des inflorescences.

\section{IID Dates de récolte}

Les dates de récolte sont le facteur principal du rendement chez les espèces à égrenage spontané et à floraison groupée comme Panicum. Lécart entre le pic de floraison et la date de récolte est de un à deux mois suivant les espèces.

\section{IID Préparation des semences}

Le séchage peut se faire à l'air libre à l'abri du soleil, ou par ventilation d'air chaud, mais la température ne doit pas dépasser $40^{\circ} \mathrm{C}$.

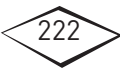


En zone tropicale humide, où la forte hygrométrie rend difficile le séchage à l'air libre, il est important de déshydrater rapidement les semences pour stopper leur métabolisme. Le séchage doit amener les semences à $8 \%$ de teneur en eau pour un stockage en sacs pour éviter les moisissures et à $4 \%$ pour une conservation de longue durée en sacs hermétiques pour éviter la condensation.

Le nettoyage des graines comprend généralement un triage par densité pour séparer les graines vides des graines pleines, un calibrage pour éliminer les graines d'autres espèces, les deux opérations étant réalisées soit à la main, soit avec un tamis ou une colonne densimétrique (type Inra), moyen simple de trier les produits en utilisant leur différence de comportement dans un même courant d'air.

\section{IID Traitement des semences}

Différents traitements peuvent s'avérer nécessaires pour lutter contre les maladies et pour protéger les graines contre les parasites naturellement présents dans le sol. Ils peuvent assurer également une protection contre des attaques précoces de maladies et de parasites au stade végétation. Le choix des substances actives (mode et spectre d'action, persistance) tient compte des analyses phytosanitaires des services agricoles locaux.

Les insecticides à base d'organophosphorés sont encore d'un emploi courant (encadré 9.1). Les plus anciens produits de la gamme comme le bromophos, le dichlorvos, le malathion sont progressivement remplacés par des insecticides plus performants, tels que le pyrimiphos-méthyl et le chlorpyriphos-méthyl. Ces derniers agissent par contact et ingestion, mais également par inhalation. Ces insecticides sont appréciés pour leur efficacité, leur persistance d'action (plusieurs mois en greniers fermés) et leur innocuité pour l'homme et les animaux domestiques. Ils seront peut-être concurrencés à l'avenir par les produits plus récents que sont l'étrimphos et le méthacrifos.

Une protection antifongique dès le semis a aussi pour but de protéger la semence, garantir la levée et même protéger ultérieurement la plante en croissance. Cette protection se pratique actuellement par enrobage de la semence. En revanche, comme les semences sont également une source de nourriture pour la faune sauvage et principalement les oiseaux granivores, elles ne doivent pas être toxiques ou à défaut elles doivent absolument présenter un effet répulsif efficace.

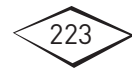


Contre les problèmes cryptogamiques il existe de nombreux produits (voir index phytosanitaire), comme ceux à base des molécules d'azoxystrobine, de captane, de fluazinam.

\section{Encadré 9.1. Informations sur les traitements des semences : sites à consulter}

Les index phytosanitaires les plus récents ou voir en ligne les spécialisés comme : Compendium of Pesticide Common Names [Alan Wood's Web site] $<$ www.alanwood.net/pesticides/index.html> ;

Glossaire des termes phytosanitaires mis en ligne par la FAO :

<www.fao.org/docrep/w3587e/w3587e00.htm\#Contents >

Catalogue des produits phytopharmaceutiques et de leurs usages des matières fertilisantes et des supports de culture homologués en France :

$<$ e-phy.agriculture.gouv.fr/>

\section{ID Ensachage et stockage des semences}

L'ensachage doit se faire dans des sacs laissant passer l'air (jute, plastique ajouré) pour une conservation de courte durée, pour une année au maximum.

Le stockage doit se faire dans des conditions de température et d'humidité relative constantes. Des variations de ces deux facteurs entraînent la perte de la faculté germinative. Leur somme ne doit pas dépasser 80 : par exemple, $80=20^{\circ} \mathrm{C}+60 \%$ d'humidité relative de l'air, pour une conservation de courte durée. Faute de mieux et pour des conservations courtes, on peut conserver en local climatisé. La conservation de longue durée doit se faire dans un local peu humide (humidité idéale inférieure à $30 \%$ et à une température idéale de $4{ }^{\circ} \mathrm{C}$ ) dans des sachets hermétiques ou dans des chambres froides. Après conservation, à l'ouverture des sachets, il faut réaliser un contrôle de la faculté de germination (voir page 128). 


\section{$\checkmark$ 10. L'économie des cultures fourragères}

Une estimation des coûts de production est nécessaire pour décider du choix et de la mise en place de cultures fourragères. Pour des cultures en cours d'exploitation, il faut pouvoir évaluer les coûts de fonctionnement afin de raisonner les choix techniques en relation avec les productions animales qui en dépendent.

Ua production fourragère s'inscrit dans un système de productions animales variées : lait, viande, énergie animale, etc. La variabilité des conditions agro-écologiques et les niveaux d'intensification visés conditionnent, entre autres, les choix d'espèces adaptées. Lanalyse économique d'un projet ou le suivi d'une production en place dépendent d'un ensemble de conditions locales, naturelles et socioéconomiques, ainsi que du projet et des choix du chef d'exploitation.

Ce chapitre vise à permettre à l'éleveur, ou à son conseiller, d'aborder l'économie des productions fourragères en tant qu'outil d'aide à la décision.

Une démarche simple est proposée pour évaluer les coûts de la production fourragère en prenant successivement en compte les différentes étapes des itinéraires techniques, depuis la préparation du terrain jusqu'à l'exploitation de la production fourragère.

\section{Les principaux éléments à prendre en compte}

Lefficacité économique des cultures fourragères dans une exploitation agricole, très souvent appréciée au niveau de l'atelier d'élevage, doit aussi être évaluée à l'échelle de l'exploitation, dans la mesure où ces cultures font partie d'un système de culture, ce qui induit de nombreuses interactions dans l'évaluation économique de l'unité de production ou de l'exploitation.

Il est donc proposé de suivre les étapes de l'itinéraire technique pour évaluer les coûts de chaque opération dans le contexte considéré. Il est aussi possible de regrouper les charges par types de dépense : maind'œuvre, fertilisation, fonctionnement... Une simulation est proposée

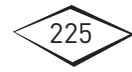


dans les tableaux suivants. Ainsi, on obtient par exemple «le coût total toutes fertilisations confondues», «le coût total de la main-d'œuvre», etc. On peut également attribuer à chaque étape de l'itinéraire technique (préparation du terrain, culture...), la part de dépense liée aux différents postes (main-d'œuvre, fertilisation, etc.), on obtient ainsi le coût de l'étape : par exemple «l'aménagement» avec ses frais de tracteur propres, ses frais de main-d'œuvre, ses frais de fertilisation de fond.

\section{L'évaluation détaillée des coûts de production}

La démarche proposée permet de prendre en compte chaque élément technico-économique nécessaire à l'établissement du coût de production estimé de la culture fourragère :

- le foncier (tableau 10.1). En propriété, en location ou en métayage, ou autre formule (échange social), chaque formule a un coût;

- les aménagements pour la mise en place de la parcelle (tableau 10.2). Depuis le défrichement jusqu'à la pose de la clôture et aux frais qui en découlent, les frais d'amortissement et les frais annuels d'entretien de ces aménagements sont évalués;

- le système d'irrigation (tableau 10.3). Collectif ou individuel, par submersion ou par aspersion, il donne lieu aux frais d'amortissement, aux frais annuels d'entretien et aux frais de consommation d'eau;

- le matériel de culture (tableau 10.4). Culture manuelle, en traction animale ou motorisée; le matériel donne lieu à trois coûts à bien identifier, le coût d'amortissement, le coût d'entretien et le coût de fonctionnement;

- les temps de travaux des différentes opérations et les frais de maind'œuvre qui en découlent (tableau 10.5);

- la fertilisation (tableau 10.6). Sont pris en compte le coût des engrais depuis les engrais de fond et les amendements à l'implantation de la parcelle jusqu'aux engrais annuels de production de la culture; - les frais de fonctionnement (tableau 10.7). Ils doivent être estimés depuis le coût des semences et des produits phytosanitaires jusqu'à celui du fonctionnement du matériel utilisé;

- les frais financiers (tableaux 10.8 et 10.9). Si un ou plusieurs emprunts ont été contractés pour mener à bien la culture fourragère, les intérêts de ces emprunts constituent une charge financière annuelle à prendre en compte.

Le récapitulatif de ces différentes charges permet, en fonction du rendement obtenu, de calculer le coût de production, par kilo par exemple, et de le comparer au prix d'achat d'un kilo du même fourrage

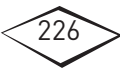


sur le marché ou de le comparer à d'autres fourrages et aliments complémentaires (paille, son, tourteau) ou de calculer d'autres indicateurs qui sont autant d'éléments d'aide à la décision pour l'exploitant.

Ce calcul se fonde sur des postes relativement classiques de l'évaluation comptable. Il peut être opportun de rajouter d'autres coûts, notamment en lien avec le contexte économique, social et institutionnel dans lequel le producteur œuvre (par exemple, le coût de transaction, le coût de l'association dans le cas d'une culture fourragère irriguée, etc.).

\section{II) Le coût du foncier}

En dehors des cas de propriété et de location, il existe d'autres formes de contrat, tel que le métayage. Certains contrats oraux ou écrits sont fondés sur des paiements en nature qui doivent être estimés.

Tableau 10.1. Charges foncières.

\begin{tabular}{|c|c|c|c|c|c|c|c|}
\hline $\begin{array}{l}\mathbf{N}^{\circ} \\
\text { Parcelle }\end{array}$ & $\begin{array}{l}\text { Superficie } \\
\text { totale } \\
\text { (ha) }\end{array}$ & $\begin{array}{l}\text { Superficie } \\
\text { culture } \\
\text { fourragère } \\
\text { (ha) }\end{array}$ & $\begin{array}{l}\text { Mode de } \\
\text { faire valoir }\end{array}$ & $\begin{array}{l}\text { Durée } \\
\text { du } \\
\text { contrat }\end{array}$ & $\begin{array}{l}\text { Coût } \\
\text { annuel } \\
\text { d'usage }^{(1)}\end{array}$ & $\begin{array}{l}\text { Droits } \\
\text { et } \\
\text { Taxes/an }\end{array}$ & $\begin{array}{l}\text { Coût } \\
\text { foncier }^{(2)} \\
\text { (ha/an) }\end{array}$ \\
\hline & \multirow[t]{3}{*}{$\mathrm{T}_{\text {total }}$} & \multirow[t]{3}{*}{$\mathrm{T}_{\text {fourrage }}$} & Propriété & \multirow[t]{3}{*}{$\mathrm{n}$} & \multirow[t]{3}{*}{$\mathrm{T} 1$} & \multirow[t]{3}{*}{$\mathrm{T} 2$} & \multirow{3}{*}{$\begin{array}{l}\mathrm{Ct}= \\
\text { (T1usage } \\
+\mathrm{T} 2 \text { droits) } \\
/ \mathrm{T}_{\text {total }}\end{array}$} \\
\hline & & & Location & & & & \\
\hline & & & Métayage & & & & \\
\hline
\end{tabular}

1. Coût annuel d'usage : il s'agit des frais de location ou du total des produits en nature échangés multiplié par leur prix d'achat sur le marché.

2. Dans le cas des charges foncières, le coût du foncier/ha/an est le même qu'il s'agisse de la culture fourragère ou de toute autre culture de l'exploitation, c'est pourquoi le coût total est obtenu en divisant $(\mathrm{T} 1+\mathrm{T} 2)$ par la superficie totale $\mathrm{T}$

Mode de faire valoir : Propriété, Location, Métayage

Coût annuel d'usage : il s'agit des frais de location ou du total des produits en nature échangés multiplié par leur prix d'achat sur le marché

Dans le cas des charges foncières, le coût du foncier/ha/an est le même qu'il s'agisse de la culture fourragère ou de toute autre culture de l'exploitation, c'est pourquoi le coût total est obtenu en divisant (T1+T2) par la superficie totale $\left(\mathrm{T}_{\text {Total }}\right)$

Dans tous les tableaux de ce chapitre, le signe «* " signifie «multiplié par» et le signe «/» signifie « divisé par»

$\mathrm{Ct}$ : charge locative de la terre

\section{ID Le coût des aménagements : amortissement et entretien}

L'aménagement foncier. Une parcelle de culture fourragère peut nécessiter de lourds travaux de déforestation, de défrichement, d'arasement, ou des travaux plus légers de simple reprise après jachère.

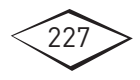


Laménagement foncier peut être partiellement ou en totalité confié à un tiers : on notera le coût de la prestation, ou le coût de la location du matériel lourd (bulldozer, engin à chenille...). Si le matériel appartient à l'exploitant, il faudra préciser la liste du matériel avec les coûts d'achat (pour le calcul de l'amortissement), d'entretien et de fonctionnement.

La mise en place d'une clôture. Dans le cas d'une clôture vive, seul le coût de plantation intervient (semis ou bouturage, coût des semences et de la main-d'œuvre).

La construction d'un abri. Il faut vérifier que l'abri ne sert qu'à la culture fourragère, sinon il y a lieu de partager les frais avec les autres cultures qui en bénéficient.

Tableau 10.2. Coûts d'amortissement et d'entretien des aménagements de la parcelle fourragère.

\begin{tabular}{|c|c|c|c|c|}
\hline & Coût total & $\begin{array}{l}\text { Durée } \\
\text { de vie }^{(1)}\end{array}$ & $\begin{array}{l}\text { Amortissement } \\
\text { (coût/an) }\end{array}$ & $\begin{array}{l}\text { Entretien }^{(2)} \\
\text { (coût/an) }\end{array}$ \\
\hline $\begin{array}{l}\text { Type d'aménagement } \\
\text { de clôture (clôture, fil } \\
\text { de fer, piquet, attache) }\end{array}$ & A1 & $\mathrm{n} 1$ & $\mathrm{~A} 1 / \mathrm{n} 1$ & $\mathrm{C} 1$ \\
\hline \multicolumn{5}{|l|}{ Main-d'œuvre ${ }^{(3)}$} \\
\hline \multicolumn{5}{|l|}{$\begin{array}{l}\text { Total : Coût par mètre } \\
\text { linéaire }\end{array}$} \\
\hline $\begin{array}{l}\text { Abri pour culture } \\
\text { récoltée }\end{array}$ & $\mathrm{A} 2$ & $\mathrm{n} 2$ & $\mathrm{~A} 2 / \mathrm{n} 2$ & $\mathrm{C} 2$ \\
\hline $\begin{array}{l}\text { Aménagement foncier } \\
\text { (Arasement des } \\
\text { butes, défrichement, } \\
\text { épierrage, etc.) }\end{array}$ & A3 & n3 & $\mathrm{A} 3 / \mathrm{n} 3$ & $\mathrm{C} 3$ \\
\hline Autres & A4 & $\mathrm{n} 4$ & $\mathrm{~A} 4 / \mathrm{n} 4$ & $\mathrm{C} 4$ \\
\hline $\begin{array}{l}\text { Coût total des } \\
\text { aménagements }\end{array}$ & $\begin{array}{l}\mathrm{Ia}=\mathrm{A} 1+\mathrm{A} 2 \\
+\mathrm{A} 3+\mathrm{A} 4\end{array}$ & & $\begin{array}{l}\mathrm{Aa}= \\
\mathrm{A} 1 / \mathrm{n} 1 \\
+\mathrm{A} 2 / \mathrm{n} 2 \\
+\mathrm{A} 3 / \mathrm{n} 3+\ldots\end{array}$ & $\begin{array}{l}\mathrm{Ca}= \\
\mathrm{C} 1+\mathrm{C} 2 \\
+\mathrm{C} 3+\mathrm{C} 4\end{array}$ \\
\hline $\begin{array}{l}\text { Coût unitaire } \\
\text { des aménagements } \\
\text { (/ha/an) }\end{array}$ & & & $\begin{array}{l}\mathrm{C}_{\mathrm{Aa}}=\mathrm{Aa} / \\
\mathrm{T}_{\text {fourrage }}\end{array}$ & $\begin{array}{l}\mathrm{C}_{\mathrm{Ca}}=\mathrm{Ca} / \\
\mathrm{T}_{\text {fourrage }}\end{array}$ \\
\hline
\end{tabular}

1. Durée théorique des clôtures : 20 ans; abri : 10 ans.

2. Coût d'entretien : on peut considérer comme coût annuel d'entretien $5 \%$ de la valeur d'implantation pour les clôtures et l'abri.

3. Les frais de main-d'œuvre peuvent figurer dans ce tableau (permettant de chiffrer la phase

d'aménagement) ou figurer dans le tableau 10.5 «Coût de la main-d'œuvre» mais en précisant qu'il s'agit de l'aménagement foncier, le risque étant d'oublier ces frais ou de les compter deux fois.

$\mathrm{Aa}$ : amortissement - $\mathrm{Ca}$ : entretien 


\section{ID Le coût de l'irrigation}

Dans le cas d'une culture fourragère irriguée, le mode d'irrigation doit être précisé, par submersion, par aspersion ou autre, en collectif ou en individuel, chaque mode entraînant des coûts différents.

Dans le tableau suivant, on considère que les aménagements d'irrigation ne concernent que les cultures fourragères. Dans le cas où d'autres parcelles de l'exploitation sont irriguées par le même système, les coûts d'amortissement et des frais d'entretien sont répartis au prorata des surfaces concernées.

Tableau 10.3. Coûts de l'irrigation suivant les modes.

\begin{tabular}{|c|c|c|c|c|c|}
\hline & $\begin{array}{l}\text { Investis- } \\
\text { sement }\end{array}$ & $\begin{array}{l}\text { Durée } \\
\text { d'amor- } \\
\text { tissement }{ }^{(1)}\end{array}$ & $\begin{array}{l}\text { Coût } \\
\text { d'amor- } \\
\text { tissement } \\
\text { (/an) }\end{array}$ & $\begin{array}{l}\text { Frais de } \\
\text { réparation } \\
\text { ou entretien } \\
(/ \text { an) }\end{array}$ & $\begin{array}{l}\text { Charges } \\
\text { d'eau } \\
\text { (/an) }^{(2)}\end{array}$ \\
\hline \multicolumn{6}{|l|}{$\begin{array}{l}\text { Irrigation par } \\
\text { submersion }\end{array}$} \\
\hline \multicolumn{6}{|l|}{$\begin{array}{l}\text { Canaux, diguettes, } \\
\text { pompes }\end{array}$} \\
\hline $\begin{array}{l}\text { a) collective } \\
\text { - aménagement }\end{array}$ & IR1 & n1 & IR1/n1 & CE1 & $\mathrm{C} 1$ \\
\hline b) en propriété & IR2 & $\mathrm{n} 2$ & IR2/n2 & CE2 & $\mathrm{C} 2$ \\
\hline \multicolumn{6}{|l|}{ Planage } \\
\hline \multicolumn{6}{|l|}{$\begin{array}{l}\text { Irrigation } \\
\text { par aspersion }\end{array}$} \\
\hline Forage sur nappe & IR3 & n3 & IR3/n3 & CE3 & $\mathrm{C} 3$ \\
\hline \multicolumn{6}{|l|}{ Pompe } \\
\hline \multicolumn{6}{|l|}{ Tuyaux } \\
\hline \multicolumn{6}{|l|}{ Asperseurs } \\
\hline $\begin{array}{l}\text { Coût total } \\
\text { d'irrigation }\end{array}$ & $\operatorname{Iir}=I R$ & & $\begin{array}{l}\text { Air }=\text { IR1/n1 } \\
+ \text { IR2/n2 } \\
+ \text { IR3/n3 }\end{array}$ & $\begin{array}{l}\mathrm{CEi}= \\
\mathrm{CE} 1+ \\
\mathrm{CE} 2+\ldots\end{array}$ & $\begin{array}{l}\text { Cir }=\mathrm{C} 1 \\
+\mathrm{C} 2 \\
+\mathrm{C} 3\end{array}$ \\
\hline $\begin{array}{l}\text { Coût unitaire } \\
\text { d'irrigation } \\
\text { (/ha/an) }\end{array}$ & & & $\begin{array}{l}\mathrm{C}_{\text {Air }}= \\
\text { Air/ } \mathrm{T}_{\text {fourrage }}\end{array}$ & $\begin{array}{l}\mathrm{C}_{\mathrm{CEi}}=\mathrm{CEi} / \\
\mathrm{T}_{\text {fourrage }}\end{array}$ & $\begin{array}{l}\mathrm{C}_{\text {Cir }}=\mathrm{Cir} / \\
\mathrm{T}_{\text {fourrage }}\end{array}$ \\
\hline $\begin{array}{l}\text { 1. Durée théorique et } \\
\text { durées localement adm } \\
\text { sont ferrugineuses, alor } \\
\text { difficiles. } \\
\text { 2. Charges eau : elles so } \\
\text { exemple : Prix du tour } \\
\text { d'heures d'utilisation p } \\
\text { Air : amortissement - }\end{array}$ & $\begin{array}{l}\text { ée réelle : } \\
\text { s. Par exen } \\
\text { u'elle s'am }\end{array}$ & $\begin{array}{l}\text { orage, pompes, } \\
\text { hple une pompe } \\
\text { ortira sur une p } \\
\\
\text { soit par ha, soit } \\
\text { tours d'eau pou } \\
\text { rivé). } \\
\text { éparation et d'e }\end{array}$ & $\begin{array}{l}\text { tuyaux, asperseur. } \\
\text { de forage ne dure } \\
\text { ériode plus longue } \\
\text { par ha et par cultu } \\
\text { r un système collec } \\
\text { ntretien - } \mathrm{Ci} \text { : char }\end{array}$ & $\begin{array}{l}\text { est préférable de } \\
\text { que } 5 \text { ans au Séné } \\
\text { ns un pays aux co } \\
\text { oit par le volume } \\
\text {; Puissance de la } \\
\text { en eau }\end{array}$ & $\begin{array}{l}\text { rrendre les } \\
\text { gal, où les eau } \\
\text { nditions moins } \\
\text { utilisé (Par } \\
\text { ompe x nb }\end{array}$ \\
\hline
\end{tabular}

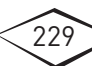




\section{IID Le coût des matériels : amortissement et entretien}

Suivant le mode de culture pratiqué (manuel, en traction animale, en culture motorisée), un certain type de matériel sera utilisé. Il s'agit de renseigner le prix d'achat de chaque matériel utilisé, sa durée de vie moyenne localement et le temps d'utilisation de ce matériel uniquement consacré à la culture fourragère par rapport au temps total annuel d'utilisation de ce même matériel. Ce matériel devra faire l'objet, dans tous les cas, d'un calcul de coût d'amortissement et d'un coût d'entretien, et tenir compte de l'insertion de l'exploitant dans une coopération d'utilisation de matériel agricole (Cuma, par exemple).

\section{Remarques sur le prix de revient horaire d'un tracteur}

Canevas du calcul du prix de revient horaire d'un tracteur

- Frais fixes annuels

- Intérêts du capital (si achat du tracteur à crédit)

- Prime d'assurance

- Charges d'abri

- Taxes (carte grise...)

- Frais variables sous certaines conditions, annuels

- Amortissement du tracteur (et éventuellement du stock de pièces de rechange)

- Entretien et réparations (pièces et main-d'œuvre)

- Frais essentiellement variables, annuels

- Carburant

- Lubrifiant

- Conduite et entretien (salaire et charges)

La somme de ces trois types de charges, divisée par le nombre d'heures d'utilisation annuelle du tracteur, donne le prix de revient horaire :

Total des charges annuelles $(1+2+3) /$ Nombre d'heures d'utilisation annuelle $=$ prix de revient horaire du tracteur

Si le tracteur est intégré à une exploitation importante, il peut être nécessaire d'ajouter un quatrième type de charges annuelles, les «Frais généraux annuels (personnel, investissements, fonctionnement, divers...) » au prorata de la valeur d'achat du tracteur par rapport à la valeur de tout le parc de matériels de l'exploitation. 
Tableau 10.4. Coûts d'amortissement et d'entretien du matériel.

\begin{tabular}{|c|c|c|c|c|c|c|c|}
\hline Matériels & $\begin{array}{l}\text { Durée de vie } \\
\text { théorique }^{(1)}\end{array}$ & $\begin{array}{l}\text { Durée de } \\
\text { vie locale }\end{array}$ & $\begin{array}{l}\text { Investis- } \\
\text { sement }\end{array}$ & $\begin{array}{l}\text { Estimation annuelle } \\
\text { temps consacré aux } \\
\text { cultures fourragères }\end{array}$ & $\begin{array}{l}\text { Toutes } \\
\text { cultures }\end{array}$ & $\begin{array}{l}\text { Amortissements } \\
\text { (/an) (calcul) }\end{array}$ & $\begin{array}{l}\text { Entretien }{ }^{(2)} / \text { Réparation } \\
\text { (/an) (calcul) }\end{array}$ \\
\hline $\begin{array}{l}\text { Culture manuelle : semoir, } \\
\text { épandeur d'engrais, } \\
\text { machette, houe, etc. }\end{array}$ & de 3 à 7 ans & $\mathrm{n} 1$ & $\mathrm{O} 1$ & H1 & HT1 & $(\mathrm{O} 1 / \mathrm{n} 1)^{*} \mathrm{H} 1 / \mathrm{HT} 1$ & $\mathrm{C} 1 * \mathrm{H} 1 / \mathrm{HT} 1$ \\
\hline \multicolumn{8}{|l|}{$\begin{array}{l}\text { Culture attelée : âne, bouf, } \\
\text { cheval, petit matériel, } \\
\text { charrue, disque, herse, } \\
\text { bineuse, semoir, épandeur } \\
\text { d'engrais, etc. }\end{array}$} \\
\hline \multicolumn{8}{|l|}{$\begin{array}{l}\text { Culture motorisée : tracteur, } \\
\text { charrue, disque, herse, } \\
\text { bineuse, semoir, épandeur } \\
\text { d'engrais, cultipacker, } \\
\text { faucheuse, andaineuse, } \\
\text { botteleuse, ensileuse. }\end{array}$} \\
\hline Coût total du matériel (/an) & & & Io & & & $\begin{array}{l}\mathrm{Ao}=(\mathrm{O} 1 / \mathrm{n} 1)^{*} \\
\mathrm{H} 1 / \mathrm{HT} 1+\ldots\end{array}$ & $\mathrm{CEO}=\mathrm{C} 1 * \mathrm{H} 1 / \mathrm{HT} 1+\ldots$ \\
\hline Coût du matériel (/ha/an) & & & & & & $\mathrm{C}_{\mathrm{Ao}}=\mathrm{Ao} / \mathrm{T}_{\text {fourrage }}$ & $\mathrm{C}_{\mathrm{CEo}}=\mathrm{CEO} / \mathrm{T}_{\text {fourrage }}$ \\
\hline \multicolumn{8}{|c|}{$\begin{array}{l}\text { 1. Durées de vie théoriques sont données à titre indicatif, suivant le type de matériel, il y a lieu de prendre la durée généralement admise dans le pays ou localement : } \\
\text { Culture manuelle e semoir, } 5 \text { ans ; épandeur d'engrais, } 7 \text { ans; machette, houe, } 5 \text { ou } 3 \text { ans; âne, bouff, cheval, } 5 \text { ans; petit matériel, } 2 \text { ans. } \\
\text { Culture attelée et culture motorisée : tracteur, } 10 \text { ans; charrue, } 10 \text { ans; disque, } 15 \text { ans; herse, } 10 \text { ans; bineuse, } 5 \text { ans; semoir, } 5 \text { ans; épandeur d'engrais, } 7 \text { ans; cultipacker, } 8 \text { ans; } \\
\text { faucheuse, } 8 \text { ans; andaineuse, } 10 \text { ans; botteleuse, } 8 \text { ans; ensileuse, } 8 \text { ans. } \\
\text { 2. Les frais d'entretien du matériel peuvent être évalués à } 7 \text { à } 10 \% \text { de la valeur d'achat par an. } \\
\text { Ao : frais d'amortissement - CEo : frais d'entretien }\end{array}$} \\
\hline
\end{tabular}




\section{Encadré 10.1. Remarque sur l'amortissement}

Il faut aussi tenir compte du temps pendant lequel le matériel est consacré à la culture.

Exemple de l'amortissement d'un tracteur

- Coût total : 4000000 FCFA

- Durée d'amortissement de 10 ans soit : 400000 FCFA / an

- Utilisation annuelle : $800 \mathrm{~h}$

- Coût d'amortissement horaire : 400000 FCFA/800 = 500 FCFA / h

- Nombre d'heures consacrées aux cultures fourragères : $15 \mathrm{~h} / \mathrm{an}$

- Amortissement sur cultures fourragères : 500 FCFA x 15 h = 7500 FCFA

\section{II) Les coûts de main-d'œuvre : en fonction des temps de travaux}

Chaque culture fourragère exige des travaux spécifiques avec des durées spécifiques. Pour l'homme et la femme de l'exploitation on pourra prendre le coût d'opportunité de la main-d'œuvre localement, et pour les salariés, le coût réel (tableau 10.5).

Tableau 10.5. Coûts de main-d'œuvre sur culture fourragère.

\begin{tabular}{|c|c|c|c|c|c|}
\hline & $\begin{array}{l}\text { Exemple } \\
\text { culture } \\
\text { Niébé(1) }^{(1)}\end{array}$ & $\begin{array}{l}\text { Homme } \\
\text { (jour/an) }\end{array}$ & $\begin{array}{l}\text { Femme } \\
\text { (jour/an) }\end{array}$ & $\begin{array}{l}\text { Salarié } \\
\text { (jour/an) }\end{array}$ & Coût/an ${ }^{(2)}$ \\
\hline $\begin{array}{l}\text { Opérations Préparation } \\
\text { sol, labour, hersage, } \\
\text { semis, fertilisation, binage } \\
\text { ( } 2 \text { fois), coupe, fanage } \\
\text { (retournement), collecte, } \\
\text { ramassage, bottelage }\end{array}$ & & $\mathrm{H} 1$ & $\mathrm{~F} 1$ & $\mathrm{~S} 1$ & $\begin{array}{l}\mathrm{MO} 1= \\
\mathrm{H} 1 * \mathrm{CO}_{\mathrm{H}} \\
+\mathrm{F} 1 * \mathrm{CO}_{\mathrm{F}} \\
+\mathrm{S} 1 * \text { Salaire } \\
\text { journalier }\end{array}$ \\
\hline $\begin{array}{l}\text { Coût total } \\
\text { main-d'œuvre (/an) }\end{array}$ & & & & & $\begin{array}{l}\mathrm{Cm}= \\
\mathrm{MO} 1+\ldots\end{array}$ \\
\hline $\begin{array}{l}\text { Coût total } \\
\text { main-d'œuvre (/ha/an) }\end{array}$ & & & & & $\begin{array}{l}\mathrm{C}_{\mathrm{Cm}}= \\
\mathrm{Cm} / \mathrm{T}_{\text {fourrage }}\end{array}$ \\
\hline
\end{tabular}

1. Temps de travail par opération : préparation sol, labour, hersage, $1 \mathrm{j} / \mathrm{ha} ;$ semis, fertilisation, binage ( 2 fois), coupe, $0,5 \mathrm{j} / \mathrm{ha}$; fanage (retournement $3 \mathrm{x} 0.5 \mathrm{j} / \mathrm{ha}$ ), $1 \mathrm{j} / \mathrm{ha}$; collecte, ramassage, bottelage.

2. $\mathrm{CO}_{\mathrm{H}}$, coût d'opportunité de la main-d'œuvre pour les hommes; $\mathrm{CO}_{\mathrm{F}}$ coût d'opportunité de la maind'œuvre pour les femmes. 


\section{Le coût de la fertilisation}

Dans le coût de la fertilisation sont prises en compte la fertilisation de fond ou fumure de redressement (amendements calciques, phosphore, fumure organique...) réalisée lors des aménagements pour la mise en place de la parcelle est prise en compte, ainsi que la fumure de production et d'entretien ( $\mathrm{N}, \mathrm{P}, \mathrm{K}$, matière organique, etc.) (tableau 10.6).

Tableau 10.6. Coût de la fertilisation sur culture fourragère.

\begin{tabular}{|c|c|c|c|c|}
\hline Type de fertilisants & $\begin{array}{l}\text { Quantité } \\
\text { par passage }\end{array}$ & $\begin{array}{l}\text { Nombre de } \\
\text { passages }^{(1)}\end{array}$ & Prix achat & Coût/an \\
\hline $\begin{array}{l}\text { Fertilisation de fond ou } \\
\text { de redressement }(\mathrm{Fa})^{(2)} \text { : } \\
\text { fertilisant 1a, 2a, 3a }\end{array}$ & q1 & 1 & P1 & $\begin{array}{l}\mathrm{Fa}= \\
1 * \mathrm{P} 1+ \\
\mathrm{q} 2 * \mathrm{P} 2+\ldots\end{array}$ \\
\hline $\begin{array}{l}\text { Fertilisation de production } \\
(\mathrm{Fb}) \text { : fertilisant } 1 \mathrm{~b}, 2 \mathrm{~b}, 3 \mathrm{~b}\end{array}$ & q1 & 1 & P1 & $\begin{array}{l}\mathrm{Fb}= \\
\mathrm{q} 1 * \mathrm{P} 1+ \\
\mathrm{q} 2 * \mathrm{P} 2 \ldots\end{array}$ \\
\hline $\begin{array}{l}\text { Fertilisation d'entretien } \\
(\mathrm{Fc}) \text { : fertilisant } 1 \mathrm{c}, 2 \mathrm{c}, 3 \mathrm{c}\end{array}$ & q1 & $\mathrm{p} 1$ & P1 & $\begin{array}{l}\mathrm{Fc}= \\
\mathrm{q} 1 * \mathrm{p} 1 * \mathrm{P} 1+ \\
\mathrm{q} 2 * \mathrm{p} 2 * \mathrm{P} 2 \ldots\end{array}$ \\
\hline Coût fertilisation (/an) & & & & $\mathrm{Cf}=\mathrm{Fa}+\mathrm{Fb}+\mathrm{Fc}$ \\
\hline $\begin{array}{l}\text { Coût fertilisation } \\
\text { (/ha/an) }\end{array}$ & & & & $\mathrm{C}_{\mathrm{Cf}}=\mathrm{Cf} / \mathrm{T}_{\text {fourrage }}$ \\
\hline
\end{tabular}

1. Pour une culture pérenne (par exemple, Panicum), il faut généralement fertiliser après chaque coupe; on le notera dans «Fertilisation d'entretien» $(\mathrm{Fc})$

2. Dans le cas d'une fertilisation de fond à l'installation ou d'un apport périodique (tous les 3 ans, tous les 5 ans) il faut tenir compte de cette périodicité pour répartir le coût sur une année. Par exemple, dans le cas d'un apport de fumure organique comme du fumier, à la dose de $6 \mathrm{t} / \mathrm{ha}$ tous les 3 ans, le coût à imputer à une année correspond à $6 \mathrm{t} / 3$, soit $2 \mathrm{t} / \mathrm{ha} / \mathrm{an}$.

\section{Les frais de fonctionnement: les charges variables liées à la culture}

En dehors des coûts d'amortissement et des coûts d'entretien du matériel utilisé, la culture nécessite des frais de fonctionnement et l'achat d'intrants (semences, engrais, produits de traitement, carburant du tracteur, etc.) qui constituent des charges variables, proportionnelles aux surfaces ou au temps consacré à la culture fourragère (tableau 10.7).

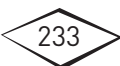


Tableau 10.7. Frais de fonctionnement des cultures fourragères $(\mathrm{Cv})$.

\begin{tabular}{|c|c|c|c|}
\hline & $\begin{array}{l}\text { Coût } \\
\text { annuel }\end{array}$ & $\begin{array}{l}\text { Répartition }^{(1)} \text { : } \\
\text { Cultures fourragères/ } \\
\text { Toutes cultures }\end{array}$ & $\begin{array}{l}\text { Coût total annuel } \\
\text { sur culture fourragère }\end{array}$ \\
\hline Semences fourragères & a1 & $\begin{array}{l}\text { ra } 1=100 \% \text { dans } \\
\text { le cas des semences } \\
\text { fourragères }(=1)\end{array}$ & $\mathrm{Cva} 1=\mathrm{a} 1 * \mathrm{ra} 1$ \\
\hline $\begin{array}{l}\text { Produits } \\
\text { phytosanitaires }\end{array}$ & a2 & ra2 & $\mathrm{Cva} 2=\mathrm{a} 2 * \mathrm{ra} 2$ \\
\hline $\begin{array}{l}\text { Culture attelée : } \\
\text { animaux, main- } \\
\text { d'oeuvre, location, } \\
\text { vaccination, soins } \\
\text { vétérinaires, } \\
\text { concentrés, vitamines, } \\
\text { taxes sur animaux }\end{array}$ & b1, b2, bn & $\begin{array}{l}\text { rb1, rb2 (exemple } \\
30 \%), \ldots, \text { rbn }\end{array}$ & $\begin{array}{l}\text { Cvb1 = b1*rb1, } \\
\text { Cvb2 = b2*0,30 } \\
\text { (exemple), Cvbn }\end{array}$ \\
\hline $\begin{array}{l}\text { Culture motorisée }{ }^{(2)} \text { : } \\
\text { location de matériel, } \\
\text { carburants, lubrifiants, } \\
\text { prestation, assurance }\end{array}$ & $\mathrm{c} 1$ à cn & $\begin{array}{l}\operatorname{rc} 1(\text { exemple } 20 \%), \ldots \\
\text { rcn }\end{array}$ & $\mathrm{Cvc} 1=\mathrm{c} 1 * 0,20$ \\
\hline \multicolumn{4}{|l|}{ (exemple) } \\
\hline $\begin{array}{l}\text { Charge variable } \\
\text { (/an) }\end{array}$ & & & $\begin{array}{l}\mathrm{Cv}=\mathrm{Cva} 1+\mathrm{Cva} 2+ \\
\mathrm{Cvb} 1+\mathrm{Cvb} 2+\mathrm{Cvc} 1+.\end{array}$ \\
\hline $\begin{array}{l}\text { Charge variable } \\
\text { (/ha/an) }\end{array}$ & & & $\mathrm{C}_{\mathrm{CV}}=\mathrm{Cv} / \mathrm{T}_{\text {fourrage }}$ \\
\hline \multicolumn{4}{|c|}{$\begin{array}{l}\text { 1. Les produits ou le matériel utilisé doivent être imputés à la culture fourragère en fonction d'une clé } \\
\text { de répartition entre la culture fourragère et les autres cultures, proportionnelle au temps ou aux hectares } \\
\text { consacrés à cette culture. } \\
\text { 2. Dans le cas d'un tracteur appartenant à l'exploitant, le calcul du prix de revient horaire d'un tracteur doit } \\
\text { être effectué. Dans le cas d'une location du tracteur, noter le coût de location dans cette rubrique puis les } \\
\text { frais de fonctionnement occasionnés (carburant...) en tenant compte de la clé de répartition entre la culture } \\
\text { fourragère et les autres cultures. Dans le cas d'un travail sur les cultures fourragères réalisé par un tiers, } \\
\text { remplacer ces rubriques par le coût total de la prestation. }\end{array}$} \\
\hline
\end{tabular}

\section{II) Les charges financières}

Les intérêts des emprunts contractés constituent des charges financières à prendre en compte, au prorata du volume du capital consacré à la culture fourragère (tableau 10.8).

Si l'annuité est constante (capital remboursé + intérêt remboursé), chaque année le capital remboursé augmente et l'intérêt remboursé diminue. Pour établir les frais financiers annuels (dernière colonne du tableau 10.8), il faut donc calculer l'intérêt annuel I de chacun des emprunts $(1,2,3)$. Chaque emprunt donne lieu à l'établissement d'un

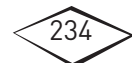


tableau de remboursement, dont on peut extraire l'intérêt dû pour une année donnée ou faire la moyenne des intérêts sur les $\mathrm{n}$ années de l'emprunt.

Exemple : emprunt d'un capital $\mathrm{C}=10000$ euros, sur une durée n de 5 ans, avec un intérêt i de $10 \%$ par an.

$\mathrm{FRC}=0,10(1+0,10)^{5} /(1+0,10)^{5}-1=0,2637975$.

Lannuité est donc égale à : capital emprunté * FRC $=10000 * 0,263$ $7975=2637,97$ euros

Tableau 10.8. Les charges financières (CI).

\begin{tabular}{lllllll}
\hline $\begin{array}{l}\mathbf{N}^{\circ} \\
\text { Emprunt }\end{array}$ & $\begin{array}{l}\text { Capital } \\
\text { total } \\
\text { emprunté }\end{array}$ & $\begin{array}{l}\text { \% Capital } \\
\text { total pour } \\
\text { cultures } \\
\text { fourragères }\end{array}$ & $\begin{array}{l}\text { Capital } \\
\text { destiné aux } \\
\text { cultures } \\
\text { fourragères }\end{array}$ & $\begin{array}{l}\text { Durée de } \\
\text { l'emprunt } \\
\text { (en } \\
\text { années) }\end{array}$ & $\begin{array}{l}\text { Taux } \\
\text { d'Intérêt } \\
\text { annuel }{ }^{(1)}\end{array}$ & $\begin{array}{l}\text { Frais } \\
\text { financiers/ } \\
\text { an (Intérêts } \\
\text { emprunts) }\end{array}$ \\
\hline $1,2,3, \ldots$ & $\mathrm{C} 1, \ldots$ & $\mathrm{p} 1$ & $\mathrm{C}^{\prime} 1=\mathrm{C} 1{ }^{*} \mathrm{p} 1$ & $\mathrm{n} 1$ & $\mathrm{i} 1$ & $\mathrm{I} 1{ }^{(2)}$ \\
\hline $\begin{array}{l}\text { Charge } \\
\text { financière } \\
\text { annuelle }\end{array}$ & & & & & $\mathrm{CI}=\mathrm{I} 1+\ldots$ \\
\hline $\begin{array}{l}\text { Charge } \\
\text { financière } \\
\text { (/ha/an) }\end{array}$ & & & & & & \\
\hline
\end{tabular}

1. On suppose un emprunt simple avec remboursement du capital plus intérêt à taux fixe chaque année (système de remboursement à annuités constantes).

2. Les intérêts des emprunts découlent du calcul de l'annuité constante. Pour un capital emprunté C, une durée $\mathrm{n}$ en années et un taux d'intérêt annuel i, il faut calculer au préalable le facteur de recouvrement du capital $(F R C): F R C=i(1+i){ }^{n} /(1+i)^{n}-1$ pour obtenir le montant de l'annuité

Un taux d'intérêt «i» de $10 \%$ est noté dans la formule sous la forme 0,10

Le montant du remboursement annuel (annuité constante) est égal à : Capital emprunté * FRC

Ainsi, pour un capital emprunté de 10000 euros, on remboursera en 5 ans 13189 euros, par annuités constantes de 2637,97euros (capital + intérêt). C'est l'intérêt inclus dans cette annuité qui constitue les «frais financiers» de l'année.

Les frais financiers du tableau 10.8 découlent directement de ce tableau de remboursement et sont indiqués dans la colonne «intérêt remboursé». Soit on affecte à la colonne «Frais financiers / an» le montant de l'intérêt remboursé une année donnée, soit on affecte à cette colonne la valeur moyenne de l'intérêt remboursé, c'est-à-dire $\mathrm{I}=3189,87 / 5=638$ euros.

On procède de la même manière pour chaque emprunt réalisé $(1,2$, 3 , etc.). L'ensemble de ces «intérêts remboursés» constitue les charges financières $\mathrm{CI}$.

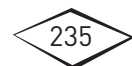


Tableau 10.9. Tableau de remboursement d'un emprunt en euros (système à annuités constantes).

\begin{tabular}{llllll}
\hline Année & $\begin{array}{l}\text { Capital } \\
\text { dû début }\end{array}$ & $\begin{array}{l}\text { Intérêt remboursé } \\
(\mathbf{C} \text { dû } * \mathbf{i})\end{array}$ & $\begin{array}{l}\text { Capital } \\
\text { remboursé }\end{array}$ & $\begin{array}{l}\text { Annuité } \\
(\mathbf{F R C} * \mathbf{C})\end{array}$ & $\begin{array}{l}\text { Capital } \\
\text { dû fin }\end{array}$ \\
\hline 1 & 10000 & 1000 & 1637,97 & 2637,97 & 8362,03 \\
\hline 2 & 8362,03 & 836,20 & 1801,77 & 2637,97 & 6560,26 \\
\hline 3 & 6560,26 & 656,03 & 1981,94 & 2637,97 & 4578,32 \\
\hline 4 & 4578,32 & 457,83 & 2180,14 & 2637,97 & 2398,18 \\
\hline 5 & 2398,18 & 239,81 & 2398,16 & 2637,97 & 0 \\
\hline & 3189,87 & 10000 & 13189,85 & \\
\hline
\end{tabular}

\section{ID Synthèse des coûts de production de la culture fourragère}

Pour les cultures fourragères pérennes, il faut cumuler les productions des différentes coupes de l'année.

\section{Récapitulatif des données à collecter :}

Rendement Brut de la culture en matière verte (MV)/ha : A (tonne $\mathrm{MV} / \mathrm{ha}$ )

Rendement en tonnes de matière sèche (MS) /ha : B (tonne MS/ha) Valeur fourragère (UF, MAD ou PDI) : $\mathrm{C}(\mathrm{UF} / \mathrm{kg}$ de MS) et $\mathrm{D}(\mathrm{g}$ $\mathrm{MAD} / \mathrm{kg}$ de MS)

Production animale sur la période : E (litres lait ou kg PV [poids vif]) Prix des produits animaux sur le marché : F (Unité monétaire / litre lait ou / kg PV)

Coût Complémentation (sans culture fourragère) sur la période : $G$ (Unité monétaire)

Coût Complémentation (avec culture fourragère) sur la période : $\mathrm{H}$ (Unité monétaire)

Coût Ration de culture fourragère sur la période : I (Unité monétaire)

\section{Récapitulatif des éléments du coût de production (/ha /an) :}

Charges foncières (ou locatives) de la terre : $\mathrm{C}_{\mathrm{Ct}}$

Charges d'entretien des aménagements : $\mathrm{C}_{\mathrm{Ca}}$

Charges d'entretien des moyens d'irrigation : $\mathrm{C}_{\mathrm{CEi}}$

Charges eau : $\mathrm{C}_{\mathrm{Cir}}$

Charges d'entretien du matériel : $\mathrm{C}_{\mathrm{CEo}}$

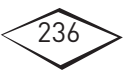




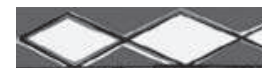

Charges de main-d'ouvre : $\mathrm{C}_{\mathrm{Cm}}$

Charges de fertilisation : $\mathrm{C}_{\mathrm{Cf}}$

Charges variables de fonctionnement (semences, produits...) : $\mathrm{C}_{\mathrm{Cv}}$

Charges financières : $\mathrm{C}_{\mathrm{CI}}$

Coût de production total sans amortissement (/ha /an) :

$\mathrm{CO}=\mathrm{C}_{\mathrm{Ct}}+\mathrm{C}_{\mathrm{Ca}}+\mathrm{C}_{\mathrm{CEi}}+\mathrm{C}_{\mathrm{Cir}}+\mathrm{C}_{\mathrm{CEo}}+\mathrm{C}_{\mathrm{Cm}}+\mathrm{C}_{\mathrm{Cr}}+\mathrm{C}_{\mathrm{Cv}}+\mathrm{C}_{\mathrm{CI}}$ Amortissement des aménagements : $\mathrm{C}_{\mathrm{Aa}}$

Amortissement moyens d'irrigation : $\mathrm{C}_{\text {Air }}$

Amortissement matériel : $\mathrm{C}_{\mathrm{Ao}}$

Coût de production total avec amortissement (/ha /an) :

$\mathrm{CT}=\mathrm{CO}+\mathrm{C}_{\mathrm{Aa}}+\mathrm{C}_{\mathrm{Air}}+\mathrm{C}_{\mathrm{Ao}}$

\section{Critères économiques d'aide à la décision pour l'implantation d'une culture fourragère}

Connaissant le coût de production total d'un hectare de culture fourragère, on peut en déduire le coût de production par unité de production (par exemple la tonne de la culture fourragère considérée) :

- CT/A dans le cas d'un affouragement en vert;

- CT/B dans le cas de la matière sèche.

Par exemple pour une culture de niébé fourrager non irrigué au Mali dans les années 1990, d'un coût de production total de CT = 120000 FCFA/ ha et d'un rendement $\mathrm{B}$ de $3,3 \mathrm{t} \mathrm{MS} / \mathrm{ha}$, le coût de production par tonne est de 36364 FCFA, soit 36 FCFA/kg MS. Ce prix est comparé au prix du niébé vendu sur le marché local, ou au prix d'un autre aliment de complément, artisanal ou industriel, local ou importé.

Au même moment sur le marché local, le foin de niébé peut valoir $50 \mathrm{FCFA} / \mathrm{kg}$ MS et le complément industriel disponible, l'ABH, au minimum $37 \mathrm{FCFA} / \mathrm{kg}$ MS dans les villes de l'intérieur, mais beaucoup plus à d'autres périodes. La comparaison par les prix est le premier élément qui permet de décider s'il est intéressant ou non de se lancer dans la mise en place d'une culture fourragère.

Mais la quantité de fourrage produite n'est pas le seul critère à prendre en compte. Deux autres critères sont tout aussi importants et concernent la valeur fourragère de la culture fourragère :

- la valeur en énergie (Unités Fourragères : UF/kg MS);

- la valeur en protéines (grammes de matières azotées digestibles : g de MAD/kg MS).

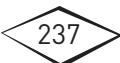


Ainsi pour le niébé fourrager récolté au stade début floraison, la valeur du foin de niébé est de 0,74 UFL et de $105 \mathrm{~g}$ de MAD $/ \mathrm{kg}$ MS, soit 49 FCFA l'UF et 34 FCFA/100 g de MAD. Comparativement, sur le marché local, l'aliment du bétail disponible est l'ABH (0,67 UF et $200 \mathrm{~g}$ de MAD/kg MS) et vaut au minimum 55 FCFA/UF et seulement 18 FCFA/100g de MAD. Suivant le déficit à combler des rations alimentaires, en quantité, en énergie ou en protéines, le recours à un aliment est nécessaire et justifie la mise en place d'une culture fourragère dont il faut évaluer la rentabilité potentielle.

Toutefois, le prix de la culture fourragère n'est pas le seul critère, pour tous les autres aliments qui pourraient être achetés localement, il faut avoir une connaissance du marché des aliments du bétail : disponibilités et aléas sur les quantités, prix et périodes.

Une seconde manière d'apprécier l'opportunité de mettre en place une culture fourragère est de calculer le coût par unité de produit animal (lait ou viande), avec une ration habituelle sans culture fourragère, à base uniquement de complémentation (tourteau, son, $\mathrm{ABH}$ ) (voir les variables p. 236) : soit (G / E) sur une période donnée (par exemple sur une période de 100 jours d'embouche ou sur une période de lactation) et de le comparer au coût avec la ration d'un niveau de complémentation différent $(\mathrm{H})$ mais comportant la culture fourragère (I) soit $(\mathrm{H}+\mathrm{I}) / \mathrm{E}$. Pour ce calcul, si l'exploitant a mis en place plusieurs cultures fourragères, I est la somme des coûts de toutes les cultures fourragères qui ont été distribuées dans la ration pendant la période donnée.

En rapportant le coût de la ration sur la période ( $\mathrm{G}$ d'une part et $\mathrm{H}+\mathrm{I}$ d'autre part) à la production (E) de lait ou de gain de poids vif de la même période, on obtient le coût de production du litre de lait ou du kilo de poids vif. Ce sont ces deux chiffres qu'il faut comparer au prix du litre de lait ou au prix du kilo de poids vif sur le marché local, pour se rendre compte du gain éventuel procuré par la culture fourragère.

\section{Conclusion}

La culture fourragère s'inscrivant dans un projet de production animale, c'est-à-dire dans un système d'élevage, voire dans un système mixte de production (intégrant l'agriculture et l'élevage), il est important de pouvoir en évaluer les coûts de production pour les mettre

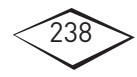


en rapport avec les revenus obtenus par les productions animales produites. Ces productions (lait, viande, travail animal) peuvent être vendues ou autoconsommées et il faut les prendre en compte dans les deux cas : par exemple, la valorisation du travail des animaux de trait dans les parcelles de l'exploitation pour laquelle il n'y a pas de recette monétaire mais bien un transfert d'énergie dans le système de culture qui peut être évalué.

La démarche proposée permet d'évaluer les coûts de la production fourragère, pour les principaux postes de dépenses de l'itinéraire technique. Lestimation de ces coûts demande d'adapter les calculs à la situation réelle considérée : avec défriche ou sans défriche, en traction animale ou en motorisation, avec ou sans irrigation, avec affouragement en vert ou après conservation et stockage.

Cette analyse des coûts de la production fourragère a évidemment plus de sens dans une situation où les produits de l'élevage sont monétarisés (vente de lait ou d'animaux embouchés) que dans des situations ou la vente des produits de l'élevage est secondaire par rapport à d'autres fonctions (travail animal sur l'exploitation par exemple).

Il s'agit donc souvent de situations complexes dans lesquelles l'approche économique des coûts de la production fourragère constitue une aide à la décision, mais doit être bien replacée et discutée dans le contexte du système de production concerné. Dans l'exemple déjà évoqué d'un attelage (une paire de bœufs, par exemple) utilisé pour les transports et la culture attelée sur l'exploitation elle-même, comment prendre en compte la réduction de la pénibilité du travail humain et les gains de temps réalisés par les membres de la famille? 



\section{Conclusion générale}

Le thème des cultures fourragères tropicales n'est qu'une partie du vaste sujet des ressources fourragères : il comprend les fourrages cultivés mais ne prend pas en considération la végétation des espaces naturels (parcours et prairies naturelles), les produits et les sous-produits de l'agriculture (céréales, racines et tubercules, pailles, fanes et enveloppes des graines), ainsi que les sous-produits agro-industriels. Or, malgré la restriction de cet ouvrage aux cultures fourragères tropicales, le sujet est encore vaste en raison de la grande diversité à la fois des milieux concernés, des plantes potentiellement utilisables et des modes de production et d'utilisation des fourrages.

\section{Valorisation de la grande diversité des cultures fourragères}

\section{IID Diversité de plantes}

Les espèces cultivées ont été initialement choisies dans les flores spontanées parmi les plantes prisées par les animaux, puis sélectionnées et parfois génétiquement améliorées et surtout largement diffusées dans toutes les zones tropicales. Elles ont des formes et des qualités très diverses, allant des petites herbes couvrant bien le sol aux arbustes fourragers, bien représentés en régions tropicales.

\section{Diversité des milieux}

La production de fourrage, moins exigeante que beaucoup d'autres cultures, peut être pratiquée dans de nombreuses situations. Depuis des terres fortement sableuses jusqu'aux plus argileuses, des sols acides désaturés aux terrains calcaires, des terrains bien drainés aux espaces temporairement gorgés d'eau, la gamme des conditions édaphiques acceptables pour des cultures fourragères est considérable.

\section{ID Diversité des modes de culture}

Mettre en place puis entretenir et récolter des cultures fourragères sont des opérations qui relèvent de l'agriculture, selon les mêmes principes

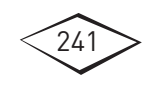


que pour d'autres productions végétales : disposer de terrain, préparer le sol, disposer de semences ou de plants, employer des moyens d'entretien, de récolte et de conservation... Mais ces cultures ont leurs spécificités et montrent une très grande variété de modes d'installation, d'exploitation, d'entretien et de durée d'occupation du sol.

\section{ID Diversité des modes d'utilisation}

Les fourrages produits peuvent être directement pâturés par le bétail, ou coupés, distribués verts ou subir des transformations comme le hachage et le séchage. La conservation des fourrages sous forme de foin ou d'ensilage permet de compenser les inégalités de production au cours de l'année, voire de transporter et de vendre des produits fourragers. Les technologies de conservation offrent des solutions, onéreuses certes, mais précieuses pour réguler l'offre fourragère, concentrée dans le temps et dispersée dans l'espace, face à une demande alimentaire relativement régulière toute l'année et parfois localisée.

\section{ID Diversité des productions}

Le producteur de fourrage attend de ses cultures une certaine quantité, mais aussi une qualité et, plus encore, des disponibilités fourragères au moment où il en a besoin. Pour ce faire, il peut jouer sur l'amélioration du sol, les fertilisations, le choix des plantes, les modes d'installation, d'entretien et d'exploitation, qui, comme nous l'avons vu, sont extrêmement divers.

\section{ID Diversité des usages et fonctions}

Léleveur peut tirer parti des effets indirects des cultures fourragères sur l'environnement : entretien de la fertilité des sols, protection des sols contre l'érosion, entretien de la biodiversité, construction de paysages et stockage du carbone à partir du gaz carbonique de l'air.

\section{Bien concevoir des systèmes de production cohérents, intégrés et rentables}

Il faut organiser les filières animales, depuis la production des ressources alimentaires à la production animale, en conciliant plantes disponibles, milieux et systèmes de production. Les opportunités et

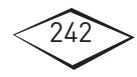




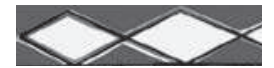

les limites des productions fourragères jouent en partie sur la forme d'élevage qui pourra être engagée : les décisions sur le végétal et sur l'animal sont liées.

Les productions fourragères doivent être intégrées aux différents systèmes de production de l'exploitation : autres cultures, bétail auquel elles sont destinées, autres objectifs (commerciaux, environnementaux, etc.). Elles complètent le plus souvent les autres ressources fourragères disponibles, telles que les parcours et les sous-produits agricoles.

Lobjectif fourrager doit être fixé en tenant compte non seulement des opportunités de l'exploitation mais aussi de ses limites techniques et économiques. Léleveur programme ses activités quand il fait le choix d'introduire des cultures fourragères. Face aux besoins alimentaires des animaux pour chaque jour de l'année, il construit son système fourrager et prépare le calendrier de ses ressources et des utilisations fourragères correspondantes.

Pour mettre au point ou faire évoluer son système de production, l'exploitant prend en compte plusieurs contraintes.

Les règles foncières, attachées à la disponibilité des terres. Dans certaines régions tropicales où les ressources fourragères sont communautaires, les droits d'usage sont peu favorables à la forme d'intensification que représente la culture de fourrage pour un seul éleveur et des formules acceptables par tous doivent être trouvées. Dans d'autres régions, au contraire, une culture fourragère est un moyen commode pour sécuriser l'appropriation d'une terre.

La bonne intégration avec les autres systèmes de production végétale. Le jeu des rotations et des assolements, les avantages et les inconvénients comme précédents culturaux, les cultures en association sont à prendre en compte.

Des référentiels techniques pour prévoir les résultats des travaux engagés. Les informations fournies par les stations expérimentales ne sont pas toujours facilement applicables par les producteurs. Les systèmes de vulgarisation et la diffusion d'un éleveur à l'autre sont souvent les moteurs de la diffusion de nouvelles pratiques.

Les risques liés à la production de fourrage. Selon les régions, des incertitudes de production existent en raison de la variabilité des précipitations ou d'autres caractères climatiques (par exemple l'occurrence de gelées), ou en raison de menaces d'épisodes de maladies

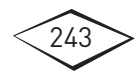


ou de parasites affectant les plantes choisies ou les stocks constitués. Il est essentiel dans ces conditions de bien choisir les espèces et les variétés résistantes ou tolérantes à ces risques.

La disponibilité en matériel végétal pour établir les cultures fourragères (semences, plants, boutures). Laccessibilité, souvent faible, aux semences commerciales ainsi que leur prix sont des freins énormes, dans certaines régions ou pour certaines catégories d'exploitants, à la diffusion des espèces fourragères cultivées.

Les disponibilités et les contraintes en matériel de culture, de récolte et de stockage, en force de travail aux moments opportuns. Avant de parvenir à la perfection technique, on recherche les solutions facilement applicables et économes.

Les avantages économiques des cultures de fourrage. Linvestissement que représentent les cultures fourragères doit pouvoir être compensé par l'amélioration des profits que l'on retire ensuite de leur valorisation par l'animal et même dégager des bénéfices. C'est pourquoi certaines productions animales relativement intensives comme le lait ou l'embouche vont apparaître comme les moteurs de l'expansion des cultures fourragères.

Les besoins des animaux (apports saisonniers en énergie, en azote et en minéraux) et les forces de travail disponibles. Les cultures fourragères entrent dans les flux des matières organique et minérale de l'exploitation et s'inscrivent dans un système de production qui permet de les rentabiliser.

En somme, connaissant ces éléments variables attachés aux fourrages et face aux besoins alimentaires de ses animaux, c'est toute sa stratégie de production fourragère que l'éleveur est amené à mettre au point. Celle-ci sert à établir le système fourrager, c'est-à-dire le programme prévisionnel de culture et d'utilisation des divers fourrages et aliments dans le temps pour répondre à ses objectifs de production animale.

\section{Les perspectives}

Même si le développement des cultures fourragères est très variable d'un continent à l'autre, d'une région tropicale à l'autre, des tendances se dessinent; notamment l'accroissement important de la demande en lait, en viande et en autres produits animaux dans les pays tropicaux.

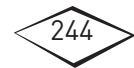


Une grande partie de l'augmentation future des productions carnées portera surtout sur la production des viandes blanches (volailles et porc principalement), qui s'appuie sur la production de céréales et de protéagineux, et beaucoup moins sur la production de viande rouge et de lait (ruminants) qui s'appuient en grande partie sur les fourrages pour des raisons techniques et de coûts de production. Les raisons de cet accroissement prévisible de demande sont l'augmentation du nombre de consommateurs, l'amélioration progressive de leurs revenus et l'urbanisation rapide qui modifie les habitudes alimentaires.

Laccroissement de la production animale contribuera à augmenter le besoin en terres arables dans les régions chaudes pour produire des fourrages afin de compenser en partie la perte des pâturages naturels mis en culture pour produire des cultures vivrières, industrielles et énergétiques. Il y a donc un risque d'une sévère compétition économique, la culture fourragère n'étant pas forcément la plus avantageuse ; produire des céréales ou des cultures industrielles est très souvent plus rentable que conduire un élevage et vendre les produits animaux. À l'inverse, l'élevage permet sous certaines conditions de revaloriser certains sols (podzols en Amazonie) en installant des cultures fourragères très productives. Le foncier et les compétitions agronomique et économique entre les différentes productions agricoles sont bien sûr aussi un enjeu.

Cela suppose aussi une amélioration notable des techniques de production dans le sens d'une intensification. Cette tendance est déjà observable dans les ceintures périurbaines où des productions laitières et des ateliers d'embouche se développent à proximité des centres de consommation. Lintensification des productions aura pour conséquence d'accroître les coûts de production. Produire à des coûts raisonnables sera un enjeu majeur des cultures fourragères tropicales.

Parallèlement à cette extension de l'agriculture, se développe un besoin de compenser les pratiques agricoles intensives par des pratiques agricoles durables et écologiques. Lavenir des productions agricoles doit passer par des systèmes de culture très diversifiés, très productifs, tout en étant économes en ressources rares, et sans effet dégradant sur l'environnement. Or les cultures fourragères s'accordent parfaitement avec ces objectifs.

Actuellement, $50 \%$ des terres arables dans le monde sont utilisées pour produire des aliments pour les animaux souvent installés dans

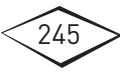


des zones très éloignées des zones de production fourragère. Il est temps de repenser l'espace «saltus» par le biais de l'intensification écologique.

Dans cette perspective, il est très probable que les cultures fourragères prendront une place croissante dans les activités agricoles des pays tropicaux et l'on peut s'attendre à ce que les recherches et les expérimentations se poursuivent pour mieux répondre aux différents systèmes de production et aux contextes environnementaux dans lesquels se développeront les élevages. 


\section{Glossaire}

Acid Detergent Fiber : en analyse chimique des fourrages, l'ADF est une estimation des lignocelluloses obtenue par un traitement acide.

Adventice (weed): en agronomie, plante herbacée ou ligneuse indésirable, mauvaise herbe.

Allélopathie (allelopathy): ensemble des interactions biochimiques directes ou indirectes, positives ou négatives, d'une plante sur une autre (micro-organismes inclus).

Amendement (amendment) : en agriculture, ce mot désigne toute opération visant à améliorer un sol, mais aussi les produits apportés au sol, généralement en grandes quantités, pour améliorer les qualités physiques (structure et texture) et chimiques (minérales ou organiques).

Anaérobie (anaerobic) : désigne des micro-organismes se développant dans des milieux dépourvus d'air ou d'oxygène.

Annuel (annual) : «qui revient chaque année », une plante annuelle effectue son cycle complet en moins d'un an, et passe donc la saison difficile sous forme de semences. Elle diffère en cela d'une plante pérenne.

Apomixie (apomixis) : forme de reproduction asexuée sans fécondation observée chez certaines plantes. Les descendants issus de graines ont les seuls caractères génétiques de la mère.

Assimilat : substance synthétisée grâce à la photosynthèse dans le tissu chlorophyllien d'une plante.

Bande boisée : plantation d'arbres ou d'arbustes, allongée et étroite de quelques mètres, voire de 10 à 20 mètres. Les brise-vents de deux rangées d'arbres ou plus sont un exemple de bande boisée étroite.

Bocage (bocage) : type de paysage composé de parcelles (champs et prairies) de formes irrégulières et de dimensions inégales, limitées et closes par des haies vives.

Bourgeonnement (budding) : sortie des bourgeons des arbres au moment de la reprise de végétation.

Branchaison : architecture de la distribution des branches dans un arbre ou un arbuste; manière dont une branche ou un rameau s'insère sur le tronc ou une autre branche (ramification).

Brout, Broutage (browsing) : action de brouter, de manger en arrachant des feuilles sur les plantes. En parallèle au paissage (lorsque l'animal mange de l'herbe), il désigne alors spécifiquement l'alimentation de gros herbivores sur des arbres et arbustes.

Charge animale/ chargement (stocking rate): nombre d'unités animales (espèces, poids vif standard) sur un pâturage par unité de surface, pour une durée déterminée (charge instantanée, par cycle de végétation, saisonnière, annuelle). Il est important de distinguer ces pas de temps pour la gestion des cultures fourragères.

Compétition (competition) : interaction qui s'établit entre des organismes, des populations ou des espèces pour l'utilisation d'une même ressource (lumière, eau, éléments nutritifs), lorsque la demande dépasse les disponibilités. 
Concurrence (competition) : interaction qui s'établit entre deux ou plusieurs organismes et dont l'origine peut être chimique (allélopathie entre deux plantes) ou énergétique (compétition entre deux espèces graminée et légumineuse).

Continentalité : ensemble des caractères climatiques déterminés par l'affaiblissement des influences maritimes vers l'intérieur d'un continent.

Cultivar (cultivar) : désigne une variété commerciale de plante obtenue par sélection et déposée.

Culture en allées (alley croping) : culture en couloirs ou en bandes alternées, intercalant des bandes boisées de faible largeur plantées avec des espèces agroforestières et des bandes de cultures, plantes annuelles ou pâturage.

Cycle de végétation (vegetation cycle) : ensemble des étapes du développement d'une plante, du repos hivernal à la chute des feuilles.

Dégradation d'un pâturage (pasture deterioration, pasture degradation) : évolution ou modification de la végétation qui en réduit la production ou la qualité fourragère de façon plus ou moins permanente.

Déprimage (topping) : technique de gestion d'une prairie consistant à faire pâturer les graminées avant qu'elles ne parviennent au stade montaison, pour favoriser le tallage et retarder l'épiaison.

Digestibilité (digestibility) : critère qui définit le degré de digestion de la matière organique (ou de la matière azotée) par un animal (différence entre les produits ingérés et excrétés).
Dose létale (DL) (letal dose) : quantité de substance qui, administrée à des animaux de laboratoire, entraîne la mort. Elle est généralement exprimée en $\mathrm{mm} / \mathrm{kg}$ de poids corporel. DL 50 est la dose entraînant $50 \%$ de mortalité dans un groupe d'animaux.

Dormance des graines : état d'inactivité biologique se traduisant par l'arrêt momentané du développement; la fin de cette situation est la levée de dormance, qui, pour les graines, est souvent l'effet du froid, d'un traitement mécanique ou du passage par le tube digestif d'un animal.

Efficacité d'un herbicide (herbicide efficiency) : dépend de la dose épandue. On définit une dose limite d'efficacité qui peut varier en fonction de la plante et de la période d'application. Le spectre d'efficacité correspond à l'ensemble des espèces maîtrisées par un produit à une dose donnée.

Élagage (prunning): coupe de certaines branches d'un arbre.

Émondage (pollarding) : taille modérée des arbres qui supprime les branches latérales, l'extrémité des branches ou, parfois, la cime d'un arbre et favorise généralement la repousse du feuillage. Le bétail peut être alimenté en feuilles fraîches avec les émondes.

Énergie (energy) : grandeur physique possédée par un système capable de produire un travail ou de la chaleur. Elle garde la même valeur au cours de toutes les transformations internes du système (loi de conservation) et a la capacité de modifier l'état d'autres systèmes avec lesquels 
il entre en interaction. L'unité est le joule ou la calorie.

Énergie brute : concentration en énergie d'un fourrage ou des produits de sa digestion. Elle est déterminée par combustion d'une bombe calorimétrique ou estimée à partir de sa composition chimique.

Énergie digestible d'un aliment (digestible energy) : est calculée à partir d'essais de digestibilité. C'est l'énergie brute moins l'énergie des fèces (soit 50 à $85 \%$ de l'énergie brute).

Énergie métabolisable (metabolisable energy) : énergie digestible diminuée de l'énergie des gaz éructés et de celle des urines. Elle représente 40 à $70 \%$ de l'énergie brute.

Énergie nette (net energy) : part de l'énergie métabolisable diminuée de l'extra-chaleur d'utilisation des aliments. Elle est utilisée pour calculer le métabolisme d'entretien et de production (développement, croît, lait, travail) et partiellement fixée dans les produits animaux.

Ensilage (silage) : mode de conservation humide des fourrages obtenu par fermentation maîtrisée en condition anaérobie (mise en silo fermé).

Épiaison (ear emergence) : stade où l'inflorescence (épi ou panicule) d'une graminée se dégage de la gaine des dernières feuilles.

ETP (potential evapotranspiration) : évapotranspiration potentielle, qui caractérise la demande d'eau d'une culture provenant du climat.

Exotique (exotic) : appliqué à une espèce végétale, désigne une plante n'appartenant pas à la flore locale, introduite volontairement ou accidentellement.
Fane (haulms) : tiges et feuilles non consommées par les humains de certaines plantes herbacées cultivées (pomme de terre, légumineuses) que l'on laisse flétrir ou sécher. Ces fanes peuvent être utilisées comme fourrage ou comme litière pour du bétail.

Fermentation lactique anaérobie (lactic starter) : en technologie alimentaire et fourragère, cette technique biologique transforme des sucres constitutifs des tissus végétaux en acide lactique en l'absence d'air et d'oxygène. Cette fermentation se produit notamment lors de la fabrication de l'ensilage.

Fibres (fibers) : tissus de soutien des végétaux composés principalement d'hémicellulose, de celluloses et de lignines. Les teneurs de ces constituants sont les principaux facteurs de variation de la digestibilité, donc de la valeur énergétique, et de l'ingestibilité des fourrages. Les fibres sont caractérisées par la méthode de fractionnement acide Van Soest, en particulier pour déterminer les teneurs en Acid Detergent Fiber et en lignine.

Foin (hay) : herbe séchée au-delà d'une teneur en matière sèche de $75 \%$ pour en assurer une bonne conservation.

Haylage (haylage) : mode de conservation de fourrage par préfanage poussé pour obtenir un taux de 35 à $40 \%$ de matière sèche, puis stockage en silo hermétique pour parvenir à une fermentation lactique. Le produit est intermédiaire entre le foin et l'ensilage. Le mot désigne également le fourrage obtenu par ce procédé.

Houppier (crown) : en sylviculture, synonyme de cimier, cime, partie supérieure d'un arbre. 
Hybride (hybrid) : se dit d'une plante issue du croisement entre des parents nettement différents, appartenant à la même espèce (croisement entre lignées) ou à des espèces voisines (hybrides interspécifiques).

Ingestibilité d'un fourrage (ingestibility of a forage) : caractère d'un aliment à pouvoir être consommé par un animal. Le niveau d'ingestibilité d'un fourrage dépend de l'encombrement de cet aliment et de la capacité d'ingestion de l'animal.

Lignine (lignin) : biopolymère présent dans les végétaux vasculaires, l'un des principaux constituants du bois, présent aussi dans les tissus de soutien des fourrages. Ses principales fonctions sont d'apporter de la rigidité, une imperméabilité à l'eau et une grande résistance à la décomposition, lors de la digestion. Les lignines sont considérées comme non digestibles, le teneur en lignine (3 à $5 \%$ dans les feuilles, 5 à $20 \%$ dans les tiges herbacées, 15 à $35 \%$ dans les tiges ligneuses) est donc un indicateur de la digestibilité d'un fourrage.

Lutte intégrée (integrated pest management IPM) : combinaison de mesures biologiques, chimiques, physiques et culturales, mises en œuvre sur les cultures. L'emploi de préparations phytopharmaceutiques y est limité au strict nécessaire pour maintenir les populations d'organismes nuisibles au-dessous du seuil à partir duquel apparaît une perte ou des dommages économiquement inacceptables. Synonyme de "protection intégrée».

Métayage (share-farming) : contrat d'exploitation agricole où le propriétaire loue à une personne en échange d'une partie des récoltes.
Mimosine (mimosin) : alcaloïde toxique existant dans des espèces de la famille des mimosaceae (par exemple Leucaena leucocephala). Des bactéries du rumen sont capables de détoxifier le fourrage en dégradant cette molécule.

Mise en défens (exclosure) : protection intégrale de la végétation ou interdiction d'un parcours au bétail pour favoriser la régénération naturelle des ligneux et/ou la repousse de la végétation herbacée.

Mycorhize (mycorrhiza) : résultat de l'association symbiotique du mycélium d'un champignon et d'un arbre ou d'une plante à fleurs au niveau des racines.

Montaison (boot stage) : phase du cycle de végétation des graminées correspondant à l'allongement de la tige, avant que l'inflorescence ne sorte de la dernière gaine foliaire.

Nutriment (nutrient) : ensemble des composés organiques et inorganiques nécessaires à la croissance et au développement d'un organisme vivant.

Parcours (rangelands) : en élevage, ce mot désigne les espaces de vaine pâture. Ce sont souvent des terres non cultivées et non forestières fournissant une faible production végétale.

Pérenne (perennial) : se dit d'une plante survivant plusieurs années à la saison sèche, grâce à ses structures souterraines (racines, bulbes et tubercules)

Période de soudure : dans les régions tropicales à longue saison sèche, période plus ou moins longue selon les années, située entre l'épuisement des stocks de la récolte précédente 
et les premières récoltes à venir. Elle précède la saison des pluies.

pH : en chimie, le pH mesure l'acidité (l'alcalinité) d'une substance. C'est le logarithme décimal de l'inverse de la concentration en ions $\mathrm{H}+$ d'une solution. Le $\mathrm{pH}$ varie de 0 (le plus acide) à 14 (le plus alcalin), le pH 7 est neutre. Dans le sol, le $\mathrm{pH}$ varie habituellement de 4,5 à 9,5.

Pluvial (rainfed) : qui relève de la pluie. En agriculture, cet adjectif est appliqué aux cultures alimentées en eau par la pluie, par opposition aux cultures irriguées.

Prairie (grassland) : formation végétale herbacée, naturelle ou artificielle, fermée et dense où dominent les graminées.

Pré-bois (wood pasture) : appellation française qui désigne une unité d'exploitation sylvopastorale constituée d'une mosaïque de bois et d'herbages. La production y est mixte et, suivant le milieu naturel et les pratiques, la répartition et la dynamique de la végétation arborescente et herbacée peuvent fortement varier.

Ranching : système d'élevage extensif sur des parcelles privées de grandes dimensions, avec des limites et souvent des clôtures.

Refus (refused herbage, refusal) : en agriculture, désigne les plantes ou parties de plantes qui sont délaissées par le bétail lors du pâturage ou la consommation à l'auge. Les causes de ce phénomène sont diverses : toxicité, manque d'appétence, mauvaise gestion (sous-pâturage), salissement.

Rémanence, persistance d'action (remanence) : durée pendant laquelle un produit phytopharmaceutique manifeste une activité biologique. Cette persistance peut être le fait de la substance active, de ses produits de dégradation ou de sa formulation. Il est toujours nécessaire de s'assurer de l'absence d'arrière-effet d'un produit sur la culture suivante.

Reproduction végétative (vegetative propagation) : mode de multiplication de plantes par des voies asexuées, notamment greffage, bouturage et marcottage.

Résilience (resilience) : capacité de récupération ou de régénération d'un organisme ou d'une population.

Rhizobium (Rhizobium) : bactérie aérobie du sol capable de former une symbiose avec des plantes supérieures (généralement des légumineuses) au niveau des racines. C'est aussi le produit du commerce contenant des bactéries vivantes sur un support neutre pour ensemencer un sol.

Scarification : abrasion mécanique ou rayure du tégument des graines dures pour permettre à l'eau d'atteindre l'intérieur de la semence et faciliter ainsi la germination.

Sélectivité des pesticides (selectivity) : propriété d'une préparation, qui, utilisée dans des conditions d'emploi définies, permet de lutter contre des organismes nuisibles aux plantes cultivées en épargnant les organismes utiles (pour un herbicide, respect de la plante cultivée ; pour un insecticide, respect des auxiliaires utiles).

Sevrage (weaning) : en élevage, arrêt de l'alimentation lactée du jeune à la mamelle pour passer progressivement au régime des adultes.

Stabulation : séjour du bétail dans un bâtiment ou un parc. 
Stolon (stolon) : tige poussant au niveau du sol ou dans le sol, sans feuilles (ou réduites à des écailles), s'enracinant aux nœuds au contact du sol et donnant alors naissance à une nouvelle plante.

Sursemis (oversowing, overseeding) : consiste à semer une ou plusieurs plantes sans labour préalable, sur un pâturage préalablement affaibli pour réduire la concurrence entre les plantes, ou dans les soles de culture, sur un sol nu ou couvert d'une plante de couverture, détruite ou affaiblie le plus souvent avec des herbicides.

Systémique (systemic) : qualifie une substance capable, après pénétration dans la plante, de migrer à l'intérieur de celle-ci. On parle de systémie ascendante lorsque la substance migre dans la sève brute et de systémie descendante lorsque la substance migre dans la sève élaborée.

Talle (tiller) : désigne pour une graminée, soit l'ensemble des tiges d'une graminée, y compris les feuilles (talle principale ou primaire), soit les rejets à la base de la tige primaire (talle secondaire).

Tanins (ou tannins) (tannins) : substances d'origine végétale, composés phénoliques classés en hydrolysables et condensés. Présents dans presque tous les végétaux, et dans toutes les parties, surtout très abondants chez les ligneux. Ils sont indigestibles et diminuent la digestibilité des autres composants des fourrages, notamment leurs fibres et matières azotées.

Tégument (tegument) : tissu formant l'enveloppe de la graine.

Unités animales standards : en référence aux besoins énergétiques d'un animal à un stade physiologique donné. En zones tropicales francophones, deux unités sont couramment utilisées UGB et UBT.

Unité Gros Bétail (UGB) (Livestock Unit $L U)$ : définie par une vache laitière de $600 \mathrm{~kg} \mathrm{PV}$ produisant annuellement 30001 de lait, consommant $19 \mathrm{~kg}$ de MS/jour et ayant des besoins énergétiques annuels de 3000 unités fourragères.

Unité Bétail Tropical (UBT) (Tropical Livestock unit) : correspond à une vache allaitante de $250 \mathrm{~kg}$ PV à l'entretien et consommant $6,25 \mathrm{~kg}$ de MS/jour.

Unité d'encombrement (Fill unit) : exprime l'ingestibilité d'un fourrage et la capacité d'ingestion d'un ruminant. Laliment de référence est une bonne herbe de pâturage $(15 \%$ MAT et $20 \%$ de cellulose brute par rapport à la MS et une digestibilité in vivo de la MO de $77 \%$ ).

Voie végétative (Vegetative propagation) : multiplication des plants par voie asexuée (greffage, bouturage, marcottage). 


\section{Bibliographie}

Sur le cédérom, des textes de référence numérisés sont mis en lien par chapitre et une bibliographie très complète est présentée.

Audru J., Boudet G., César J., Dulieu D., Gaston A., Mandret G., Merlin P., Rippstein G., Roberge G., Toutain B., 1987. Terroirs pastoraux et agropastoraux en zone tropicale : gestion aménagement et intensification fourragère. Maisons-Alfort, IEMVT, Études et Synthèses 24, 418 p.

Bayer W., Waters-Bayer A., 1999. La gestion des fourrages. Wageningen, Pays-Bas, CTA, Eschborn, Allemagne, GTZ, 246 p.

Botton H., 1958, Les plantes de couverture de Côte d'Ivoire. Guide pratique de reconnaissance et d'utilisation des Légumineuses en Côte d'Ivoire. Muséum national d'histoire naturelle. Journal d'agriculture tropicale et de botanique appliquée, vol. 4 et 5, $194 \mathrm{p}$.

Boudet G., 1984. Manuel sur les pâturages tropicaux et les cultures fourragères. $4^{\mathrm{e}}$ éd. Paris, Ministère de la Coopération, IEMVT, $266 \mathrm{p}$.

Brégeat, 1978. Valeur alimentaire de plusieurs fourrages, mesures de consommation en fonction des niveaux de complémentation. N'Gaoundéré, Cameroun. Rapport annuel 19761977, 30-33

Breman H., Kessler J. J., 1995. Le rôle des ligneux dans les agro-écosystèmes des régions semi-arides. Wageningen, Pays-Bas, CABO, 288 p.

Breman H., Sissoko K. (dir.), 1998. L'intensification agricole au Sahel. Paris, Karthala, 996 p.
Buckles D., Eteka O., Osiname O., Galiba M., Galiano G. (eds), 2000. Plantes de couverture en Afrique de l'Ouest. Une contribution à l'agriculture durable. Ottawa, Canada, CRDI, Sasakawa Global, bilingue, 292 p.

Buldgen A., Dieng, Abdoulaye, 1997. Andropogon gayanus var. bisquamulatus. Une culture fourragère pour les régions tropicales. Gembloux, Belgique, Presses agronomiques de Gembloux, 171 p.

Chenost M., Kayouli C., 1997. Utilisation des fourrages grossiers en régions chaudes. Étude FAO Production et santé animales $\mathrm{n}^{\circ} 135$. Rome, FAO, 172 p. < www.fao.org/ docrep/W4988F/W4988F00.htm >

Cirad, Gret, MAE, 2002. Mémento de l'agronome. Versailles, Quæ, 1692 p. +2 cédéroms.

Corniaux C., Le Bel S., Sarrailh J.M., 1998. Productivité et utilisation de Calliandra calothyrsus pâturé par le cerf en fonction de sa densité de plantation et de sa hauteur de recépage. Revue d'élevage et de médecine vétérinaire des pays tropicaux, 51 (3), 231-238.

Daget P., Godron M., 1995. Pastoralisme : Troupeaux, espaces et sociétés. Paris, Hatier, 510 p.

FAO / AGP, 2009. Grassland Species Profies. < www.fao.org/ag/AGP/ AGPC/doc/GBASE/Default.htm >.

Floret C., Pontanier R., 2001. La jachère en Afrique tropicale. Rôles, Aménagement, Alternatives. Actes du Séminaire international, Dakar, 13-16 avril 1999. Paris, John Libbey Eurotext, 777 p. 
Floret C., Pontanier R., 2001. La jachère en Afrique tropicale. De la jachère naturelle à la jachère améliorée. Le point des connaissances. Actes du Séminaire international, Dakar, 13-16 avril 1999. Paris, John Libbey Eurotext, 356 p.

Giffard P.L., 1974. L'arbre dans le paysage sénégalais. Sylviculture en zone tropicale sèche. Dakar, Sénégal. Centre technique forestier tropical, $431 \mathrm{p}$.

Granier P., Razafindratsita R., 1970. Contribution à l'étude de la culture dérobée de fourrages en rizière dans la région de Tananarive. Revue d'élevage et de médecine vétérinaire des pays tropicaux, 23 (1), 101-108.

Granier P., Bigot A., 1971. La culture des sorghos fourragers à Madagascar. Utilisation à contre-saison. Revue d'élevage et de médecine vétérinaire des pays tropicaux, 24 (1), 125-136.

Grimaud P, Thomas P., 2002. Les systèmes d'alimentation à base de graminées dans les élevages bovins de l'île de la Réunion. Fourrages, 44, 202-223.

Havard-Duclos B., 1967. Les plantes fourragères tropicales. Paris, Maisonneuve et Larose, Techniques agricoles et productions tropicales vol. $10,397 \mathrm{p}$.

Hnatyszyn M., Guais A., 1988. Les fourrages et l'éleveur. Paris, Lavoisier, Tec\&Doc, 440 p.

Hubert B., Girault N. (eds), 1988. De la touffe d'herbe au paysage. Troupeaux et territoires, échelles et organisations. Paris, Inra, 336 p.

Hubert B., 2004. Pour une écologie de l'action : savoir agir, apprendre, connaittre. Paris, Arguments, Coll. Parcours et Paroles, $430 \mathrm{p}$.
Huguenin J., Le Masson A., Lecomte Ph., 2001. Travail de la Recherche impliquée dans des actions de développement sur la gestion des prairies tropicales humides. L'implantation et la gestion durable des prairies en Guyane. Fiches techniques d'élevage, Cahier de l'éleveur et du technicien. Kourou, SCEBOG, Cirad, UE, 31 p.

Huguenin J., Laurent C., Marion S., 2008. Aptitudes du couvert herbacé à y contrôler des plantes adventices envahissantes dans les prairies amazoniennes de Guyane française. In : Cruz P., Jouany C., Theau J.-P. (eds.). Outils pour la gestion des prairies permanentes. Toulouse, UMR AGIR, p. 193-212. Les Cahiers d'Orphée, 1.

Humphreys L.R., 1991. Tropical Pasture Utilisation. Cambridge University Press, $218 \mathrm{p}$.

Jaffré T., Rigault F., Sarrailh J.M., 1994. La végétalisation des anciens sites miniers. Bois et Forêts des Tropiques, 242, p 45-57.

Klein H.D., 1999. Critères de choix et classements des légumineuses introduites dans les systèmes agropastoraux intertropicaux pour le développement d'une agriculture durable. In : Rasolo F. et Raunet M. (eds). Gestion agrobiologique des sols et des systèmes de culture. Actes de l'atelier international sur la gestion agrobiologique des sols et des systèmes de culture, 199803-23-28, Antsirabe, Madagascar. Montpellier, Cirad, Coll. Colloques, p. 195-212.

Koechlin J., 1981. Écosystèmes pâturés tropicaux. Recherches sur les ressources naturelles, XVI Unesco / Pnud / Fao

Landais E., Lhoste P., 1990. L'association agriculture-élevage en 
Afrique intertropicale : un mythe techniciste confronté aux réalités de terrain, Cahiers des Sciences Humaines, 26 (1-2) : 217-235.

Landais E., Lhoste P., Guerin H., 1991. Systèmes d'élevage et transferts de fertilité. In: C. Piéri (ed.), Savanes d'Afrique, terres fertiles? comment produire plus de façon durable en zone de savanes au sud de Sahara. Actes des rencontres internationales, Montpellier, France, 10-14 décembre 1990, Montpellier, France, Cirad, p. 219-270.

Lhoste Ph., Dollé V., Rousseau J., Soltner D., 1993. Zootechnie des régions chaudes : les systèmes d'élevage. Paris, Ministère de la Coopération, Manuels et précis d'élevage, $288 \mathrm{p}$.

Louppe D., Ouattara N, Zoumana C., César J., 2000. Influence de trois ruminants domestiques sur la dynamique de la végétation des jachères (Nord de la Côte d'Ivoire). In : Floret C. et Pontanier R. (eds), La jachère en Afrique Tropicale. Vol. 1 Rôles, aménagement, alternatives. Actes du séminaire international, Dakar, 13-16 avril 1999. Paris, John Libbey Eurotext, 515-533.

Louppe D., Yossi H., 2001. Les haies vives défensives en zones sèche et subhumide d'Afrique de l'Ouest. In : Floret C. et Pontanier R. (eds), $L a$ jachère en Afrique tropicale. Vol. 2 De la jachère naturelle à la jachère améliorée. Le point des connaissances. Actes du séminaire international, Dakar, 13-16 avril 1999. Paris, John Libbey Eurotext, p. 293-309.

Mandret G., Ourry A., Roberge G., 1990. Effet des facteurs température et nutrition azotée sur la croissance de plantes fourragères tropicales. Revue d'élevage et de médecine vétérinaire des pays tropicaux, 43 (1), 119-124.

Mandret G., Hassoun P., Paillat J.M., Tillard E., Blanfort V., 2000. L'élevage bovin à la Réunion - Synthèse de quinze ans de recherche. Montpellier, Cirad, Coll. Repères, 391 p.

Milleville P., 2007. Une agronomie à l'cuvre: Pratiques paysannes dans les campagnes du Sud. Versailles, Quæ; Paris, Arguments, Coll. Parcours et paroles, $252 \mathrm{p}$.

Ministère de la Coopération et du Développement, Cirad-IEMVT. Fiches techniques d'élevage tropical (Ressources alimentaires), 1989 à 1991. Les feux de brousse. I - Généralités. Les feux dans la zone humide, $\mathrm{n}^{\circ} 3,12 \mathrm{p}$.; II - Les feux au Sahel et les méthodes de lutte et le contrôle selon les zones éco-climatiques? $\mathrm{n}^{\circ} 6,8 \mathrm{p}$.

Ministère de la Coopération et du Développement, Cirad-IEMVT Fiches techniques d'élevage tropical (Ressources alimentaires), 1989 à 1991. Les ligneux fourragers et fruitiers en zones tropicales et subtropicales. I - Les types de plantations possibles dans les systèmes d'exploitation traditionnels, $\mathrm{n}^{\circ} 3,8 \mathrm{p}$.; $\mathrm{n}^{\circ} 6$, 8 p.; $\mathrm{n}^{\circ} 10,8$ p.

Ministère de la Coopération et du Développement, Cirad-IEMVT. Fiches techniques d'élevage tropical (Ressources alimentaires), 1989 à 1991. Amélioration du disponible fourrager en Afrique tropicale humide. I - Le choix des cultures et la protection des plantes, $\mathrm{n}^{\circ} 2,6$ p.; II - La prairie permanente, $\mathrm{n}^{\circ} 6,10 \mathrm{p}$.

Ministère de la Coopération et du développement, Cirad-IEMVT. Fiches techniques d'élevage tropical (Ressources alimentaires), 1989 à 1991. Les réserves fourragères. I - Le foin, 
1992, no 3, 12 p.; II - Les pailles et leur valorisation, 1994, $\mathrm{n}^{\circ} 2,8 \mathrm{p}$.; III - Lensilage, 1994, n 3, 8 p.

Mott G. O., 1960. Grazing pressure and the measurement of pasture production. In : Proceedings 8th International Grassland Congress 1960, p. 606-611.

Onana, J., 1992. Étude monographique d'un fourrage ligneux du Nord Cameroun Ficus sycomorus subsp gnaphalocarpa (Miq.) C.C. Berg. I. Multiplication et croissance. Revue d'élevage et de médecine vétérinaire des pays tropicaux, 45 (2), 191-196.

Ouattara N., Louppe D., 2000. Aménagement des terroirs ruraux et sécurisation des exploitations agricoles et pastorales au nord de la Côte d'Ivoire. In : Floret C., Pontanier R. (eds), La jachère en Afrique tropicale - rôles, aménagement, alternatives. Actes du séminaire international, Dakar, 13-16 avril 1999. Paris, John Libbey Eurotext, 721-732.

Richard D., Guérin H., Fall T.S., 1989. Fedds of the dry Tropics (Senegal). In: Jarrige R., Ruminant nutrition : recommanded allowances and feed tables. Paris, Inra / John Libbey Eurotext, p. 325-346.

Rippstein G., Escober G., Motta F., 2001. Agroecologia y biodiversidad de las Sabanas en los Llanos Orientales de Colombia. Montpellier, Cirad, Ciat. 302 p. < http://clayuca.org/ es/descargar/pdf/Agroecologia_y_ biodiversidad.pdf >

Roberge G., 1988. Lintensification fourragère et l'irrigation en milieu tropical sec. Revue Sénégalaise des Recherches Agriçoles et Halieutiques, 1(1), 18-28.
Roberge G., Toutain B. (eds), 1999. Cultures fourragères tropicales. Montpellier, Cirad, Coll. Repères, $370 \mathrm{p}$.

Steinfield H., Gerber P., Wassenaar T., Castel V., Rosales M., de Haan C., 2009. L'ombre portée de l'élevage. Impacts environnementaux et options pour leur atténuation. Rome, LEAD-FAO, 464 p., < ftp.fao.org/ docrep/fao/012/a0701f/a0701f.pdf >

Suttie J.M., 2004. Conservation du foin et de la paille, pour les petits paysans et les pasteurs. Rome, FAO, Coll. Production végétale et production des plantes, $\mathrm{n}^{\circ} 29,303$ p. < ftp:// ftp.fao.org/docrep/fao/008/x7660f/ x7660f00.pdf >

T'Mannetje L., R.M. Jones (Ed.), 1992. Plant Resources of South-east Asia. $n^{\circ} 4$ Forages, Wageningen, Pudoc Scientific Publishers, 300 p.

Toutain B., Klein H.D., Lhoste P., Duteurtre G., 2009. Histoire et avenir des cultures fourragères en Afrique tropicale. Fourrages, 200, 511-523.

Turner M.,2013.Lessemences.Éditions Quæ, CTA, Presses agronomiques de Gembloux, Coll. Agricultures tropicales en poche, $224 \mathrm{p}$.

Vivier M., Vissac B., Matheron G. (eds), 1995. L'élevage bovin en Guyane - Une innovation majeure dans un milieu équatorial de plaine, 1975-1990. Cirad-Emvt, Inra, Repères, 302 p.

Xandé A., Garcia-Trujillo R., Caceres O., 1989. Fedds of the humid tropics (West Indies). In Jarrige R., Ruminant nutrition : recommanded allowances and feed tables. Paris, Inra / John Libbey Eurotext, p. 347-362. 


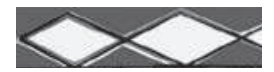

\section{Index}

abreuvement 58, 149, 150

adventice (plante mauvaise herbe) 4, 21, 85, 88, 89, 101, 110, 115, $117,123,139,142,148,153,176-$ 178, 184, 184, 187-192, 194, 197, $198,221,222$

affouragement 13, 14, 112, 124, 143, $147,161,162,165,182,183,203$, $211,237,239$

Afrique centrale 14, 109, 161

Afrique de l'Est 14, 48, 57, 98, 112

Afrique de l'Ouest 7, 14, 45, 48, 56, 81, 103, 110, 112, 203, 204, 219

Afrique du Nord 6, 90

agrocarburant (biocarburant) 5, 32, $33,95,96$

agropastoral (parcours, ressource, système) 11, 66, 74, 98, 99, 104, 106, 108, 170, 218

alley cropping 202, 211

aménagement hydraulique 117, 121

Amérique centrale 14, 73, 88, 129, 210

Amérique du Sud 14, 30, 54, 56, 83, 88, 111, 136, 193, 194

antiérosif 5, 117, 119-121, 201

Asie 7, 14, 51, 54-56, 89-91, 118, 169, 194, 203, 206, 214, 218, 219

association voir cultures associées Australie 14, 31, 32, 33, 37, 39, 44, 51, $54,56,62,88,90,109,126,127,136$, 158, 193, 194, 218, 219 azote

fertilisation $26,44,50,61,66,81$, $86,87,89,107,125,133,142,154$, 178-183, 191, 195, 217, 221

fixation de l'azote 9, 10, 28, 34, 38, 134, 146 matière azotée (valeur nutritive, ration animale) $21,24,34,40,43$, 64, 66-68, 70, 71, 75, 78-80, 82, 97, 101, 111, 133, 163, 164, 173, 244

bande boisée (bosquet) 201, 210 banque fourragère 44, 111, 113, 157 besoins alimentaires (des animaux) 101, 243, 244

biomasse 14, 19, 26, 86, 87, 94-96, 144-146, 153, 154, 159, 160, 163, 210, 212

bocage (embocagement) 91, 199

bouturage (plantation de boutures) $21,32,105,114,117,130-132,152$, 158, 176, 187, 191, 192, 198, 203, 207, 219, 228

bouture 15, 21, 41, 114, 117, 125, 130132, 153, 192, 203-205, 209, 221, 244

bovin $74,75,162$

Brésil 6, 39, 52, 56, 111, 112, 119, 124, 126, 127, 134, 136, 139-141, 152, 193, 194, 219

Burkina Faso 6, 22, 23, 84, 92, 103, 197 calcium 61, 71, 86, 125, 179, 182 calendrier fourrager 97,102

Cameroun 54, 57, 84, 134, 139-141, 165, 167-171, 203, 214, 219

caprin (chèvre) 33, 40, 45, 79, 178, 209, 211, 215

Caraïbes 14

carbone 5, 10, 26, 63, 92-95, 113, 118, 210, 242

charge animale (chargement par unité de surface) $69,93,101,105-107$, $109,110,114,150-152,156,158-$ 161, 165, 167, 169, 175-177, 195, 204, 208 
climat 10, 17, 26, 42, 47-54, 56-58, 60, $72,73,92,107,120,122,124,133$, 143, 144, 152, 169, 207, 215

aride 122

équatorial 51

humide 122

sahélien 106, 215

soudanien 53

tropical 26, 47, 48, 51, 53, 73

clôture $45,92,149,150,152,153,157$, $158,201,202,204,205,206,226$, 228

Colombie 11, 35, 61, 170, 194

complément (aliment, fourrage, complémentation) $13,14,40,78,79,82$, 97, 99, 100, 110-113, 119, 156-158, 162, 169, 170, 173, 174, 216, 217, 227, 236-238

conduite des animaux 64, 90, 93, 148, 177

conduite des cultures 86, 102, 176, 177 conservation (des fourrages) 13, 99, $102,114,144,147,161,163,166$, $168,181,192,219,220,223,224$, 239,242

Côte d'Ivoire 40, 41, 89, 123, 134, 170, 183, 203, 204, 207, 214

coût de production 225, 226, 236-238, 245

culture

annuelle 94, 104, 113, 117, 180

dérobée 38, 132, 134, 135

intercalaire 84, 88, 135, 211

pluviale $56,73,76$

pure $39,113,132$

vivrière $17,56,88,100,111,186$, 198, 203, 211, 245

cultures associées 21, 23, 28, 34, 38-40, $54,56,58,88,106,111,113,130$, 132-134, 140, 141, 151, 171, 179, $183,185,186,203,210,243$ cut and carry 41, 112

défrichement 9, 88, 117-119, 186, 226228

dégradation (du pâturage, pâturage dégradé) 10, 55, 90, 109, 136, 137, $141,143,148,151,154,159,161$, 164, 175, 178, 192, 195, 198, 215, 245

déprimage 99, 102, 152, 176

désherbage 184-186, 191, 192, 198, 201-203, 208, 222

digestibilité 43, 66, 67, 69, 71, 78-80, 134, 154, 217

digestion 40, 64, 78

dissémination 27, 89, 96, 189

dormance 49, 128, 129, 202, 208

émondage (émonde) 41, 42, 78, 203, 211, 213-215, 217

engrais (des cultures) 19, 36-38, 44, $60,63,86,87,107,114,125,131$, 136, 139, 142, 152, 154, 156, 175, 180-184, 186, 226, 231, 233

engraissement (des animaux) 34, 70, 75, 78, 79, 97, 108, 111, 152, 157, $162,169,214$

ensilage $13,86,99,100,109,112,143$, $147,161,163,165,166,168,169$, $171,172,175,180,192,242$

entretien des animaux (régime d'entretien) $13,64,67,70,72,75,152$, 159 ,

entretien des cultures 13, 20, 21, 90, 105-107, 114, 115, 117, 122, 123, $133,151,160,175,182,184,187$, 191, 196, 202, 208, 226-231, 233, 236

envahissante (plante) 38, 41, 89, 90, 148, 151, 184, 188, 191, 198, 204, 218

érosion 10, 15, 85, 88, 91, 93, 107, 118, 119, 121, 179, 198, 210, 242 


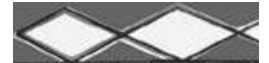

extensif (extensification, système de production, système d'élevage, conduite) 13, 106, 108, 113, 150, 161

fertilisation

des plantes, du sol 21, 30, 31, 61, $69,71,86,93,99,102,105,106,110$, $114,115,117,125,133,134,142$, 160, 171, 178-184, 195, 197, 220, 221, 225, 226, 232, 233, 237, 242

azotée 61, 133, 178-180

minérale 86,178

organique 110, 178, 179, 184

fertilité (du sol, amélioration de la fertilité du sol) 10, 15, 17, 21, 37, $42,47,61,63,64,69,85,86,88$, $95,96,98,100,107,111,123-125$, 166, 179, 182, 196, 198, 210, 214, 215,242

feuillard 215

foin $30-34,37,55,73,86,99,100,109$, $112,143,147,161,163-166,169-$ $173,175,192,237,238,242$

foncier 5, 58, 63, 92, 103, 104, 123, 226-228, 245

forêt 51, 52, 91, 94, 118

fruit 6,35

fumier $60,86,110,124,125,161,183$, 184, 196, 233

gardiennage 149, 202

Guyane 23, 90, 94, 113, 119, 134, 152, 169, 171, 180, 184, 194, 198

haie vive $73,92,110,111,121,201$, 202, 204, 206-209

haylage 112, 168, 169

herbicide 96, 136, 139, 140, 186-192, 208

implantation 5, 93, 104, 117, 119, 126, 131-133, 179, 183, 201, 203, 211, 221, 226, 228, 237

Inde 41, 43, 54, 56, 83, 92, 194, 215 inoculation (des semences) 129

insecticide 127, 132, 187, 223

intensif (intensification, système de production, système d'élevage, conduite) $13,14,17,20,32,36$, $66,67,73,75,97,100-103,105-107$, 109-113, 147, 149, 152, 154-157, 161, 173, 182, 183, 202-204, 225, 243-246

intercalaire 84, 88, 135

irrigué (système irrigué, irrigation) 21, $32,33,38,56,57,59,62,69,73,76$, 78, 90, 91, 99, 100, 102, 104-107, $112,114,117,121-124,141,147$, $148,155,166,170,220,221,226$, 229, 236, 237

itinéraire technique 93, 113-115, 117 , 201, 225, 226, 239

jachère $30,39,76,84,86,88,101,108$, 111, 135, 185, 227 ,

jardin fourrager 110, 112, 219

lait (production laitière, élevage/ animal laitier) $13,14,17,24,34$, 54, 56, 64, 70, 78, 97, 98, 101, 103, 106-108, 111, 112, 124, 152, 156, 157, 159, 162, 166, 169, 170, 172, $173,182,215,225,236,238,239$, 244, 245

la Réunion 6, 57, 58, 90, 113, 169, $171,172,180$

ligneux 5, 6, 37, 40, 41, 43, 50, 71, 73, 78-81, 87, 91, 96, 100, 106, 113, 119, 126, 151, 157, 178, 192, 201, 202, 204, 207, 208, 210-216

Madagascar 51, 111, 112, 141, 206

maladie (des plantes) 19, 21, 38, 127, 175, 193-195, 218, 220, 223, 243

matière organique $10,59,60,66,69$, 79, 80, 85-89, 93-95, 114, 120, 123, $125,133,143,148,160,179,181$, 196, 233, 244 


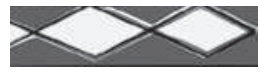

Les cultures fourragères

mise en défens 99, 100, 104, 136, 195 , 196

Nigeria 14

Nouvelle-Calédonie 54, 55, 109, 136, 137, 138, 158, 205, 212

Océanie 89

ovin (mouton) 40, 75, 78, 79, 112, 173, 158,215

paille $14,40,69,73,76,83,96,101$, $110,173,227,241$

parcours 13, 14, 40, 63, 73, 76-79, 100, 101, 104, 106, 110, 113, 117, 157, $163,170,178,201,213,215,241$, 243

pâturage (prairie) 10, 11, 13, 14, 20, 22, 36-40, 45, 52, 53, 59, 63, 90, 92-95, 99, 102, 105, 107, 109, 119, 136, 137, 149, 152, 155, 157-161, 169, 170, 177, 183, 184, 189, 195, 196, 198, 201, 202, 211, 213, 245

pâturer (pâture, tenue au pâturage, pâturage intensif, direct, libre, continu, en rotation, etc.) 21,24 , $26,27,32,33,34,36-39,55,56,58$, $63,69,71-78,85,89,93,100,102$, $106,108-111,114,139,143,146-$ $161,163,175-179,181,183,184$, $192,195,198,210-212,242$

phosphore $34,40,60,61,68,71,86$, 87, 107, 125, 134, 142, 177, 179, 181-184, 221, 233

plantation (plante pérenne, arbre) 41, $52,53,56,89-92,121,139,201,202$, 206, 207, 210, 214, 217, 218, 228

plante

annuelle 13, 139

de couverture 136-141

à deux fins 83, 85, 111

semencière 221

vivace $20,43,44,104,139$ à usages multiples (ou arbres) 17 , $37,83,88,91,210$

potasse 107, 142, 179, 181-183, 221

prairie (pâturage)

entretien 19, 87, 90, 93-95, 118, 124, 178-183, 187, 190-192, 194-198

exploitation 13, 97, 108, 133, 147, 151-154, 159, 170, 176, 177

implantation 52, 87, 77, 93, 184, 189,210

type de végétation 19, 30-33, 37-39, 52-58, 63, 73, 80, 109, 111, 113, 127, $183,187,188$

production 110, 169, 176

pré-bois 210

préparation du sol 117, 125, 185, 188, 189, 191, 220

production animale $9,11,14,17,63$, $66,93,100,107,108,122,143,149$, 154, 169, 175, 210, 225, 238, 239, 243-245

production de viande (embouche) 13, 17, 64, 70, 75, 97, 107, 111, 156, 172, $173,210,225,238,239,244,245$

production végétale $48,100,102,106$, $149,169,242,243$

projet fourrager 17, 97, 100, 101

protection du sol 5, 63, 242

ranching 40, 52, 73, 98, 149

récolte en sec 13, 183

récolte en vert $13,26,30,32,33,39$, $52,106,110,112,135,143,147,161$, $162,165,182,215,237,239$

refus $21,26,69,72,88,100,106,148$, 151, 153, 154, 157, 160, 161, 175, 176, 197

régénération 24, 78, 195-197, 212

réhabilitation 119, 195, 196, 198

rénovation 90, 181, 195, 198 


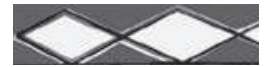

resemis $21,141,158$

résidus $14,17,56,73,78,82,83,87$, 96, 108, 110, 173, 186

revégétalisation 37

Rhizobium 21, 37, 38, 129, 130

rotation $11,30-33,38,39,54,93,97$, $99,110,140,149,151-153,156,175$, 176, 185, 192, 243

salinité (salinisation) 31, 32, 45, 62, 122-124, 199

sarclage 131, 135, 185, 186, 208

savane $6,40,44,53,54,103,109,120$, $141,160,170,182,186,215$

sécheresse 9, 19, 21, 22, 30-33, 36-39, $43-45,115,195,220$

semence $5,15,17,19,22,24,27,36$, $37,41,49,90,107,115,117,120$, $126-132,136,147,185,189,191-$ 193, 209, 219-224, 226, 228, 233, 234, 237, 242, 244

achat, disponibilité (semences de plantes fourragères) $17,127,209$, 219, 226, 228, 233, 242, 244

conservation, préparation des semences, traitement 90, 120, 126, 128-133, 193, 219, 220, 223, 224

production $15,19,22,24,36,37,41$, $132,147,193,219-224$

semis

installation, préparation du lit de semence $21,22,50,89,105,114$, $117,120,126,128-132,136,139$, $140,141,142,152,153,176,182$, 185-189, 191-193, 196, 198, 201, 202, 207-209, 221, 223, 228, 232

à la volée 131

direct 114, 132, 136, 139-141, 201, 202, 207-209

en ligne 131

en poquet 131
Sénégal 7, 56, 72, 147, 148, 170, 174, 213, 216, 217, 219, 229

séquestration (du carbone) 5, 10, 63, 93

soudure (période de) 81, 82, 110, 250

sous-produit $60,78,83,101,110,111$, $214,241,243$

steppe $54,62,90$

stockage 13, 87, 93, 94, 95, 102, 127, $164,179,223,224,239,242,244$

surpâturage 21, 31, 90, 150, 151, 154, 161

sursemis 105, 131, 191, 192, 196, 198

symbiose (Rhizobium) 28, 34

système

de culture 74, 225, 239, 245

d'élevage 5, 6, 13, 15, 71, 73, 97, 108, 111, 113, 117, 169, 238, 241

de production $5,9,14,17,66,82$, $93,98,102,108,113,123,143,203$, 239, 242-244, 246

mixte (agriculture-élevage) 5, 6, 106, 108, 110, 170, 239

pastoral 108

prairial 58, 108

talle $22,27,132,221$

travail du sol 13, 60, 105, 110, 139, 185, 196

UBT (unité bovin tropical) 106, 159, 160,162

UGB (unité gros bovin) 159

Usage, utilisation ou fonction (des fourrages, des plantes fourragères, multiple, fourrager) $14,15,17,21$, $28,30,31,33,34,36-39,42,43,45$, 63-95, 102, 108, 112, 133, 134, 136, 141, 143, 147, 152, 154, 155, 161, 168-170, 176, 177, 183, 201, 207, 209-211, 215, 216, 229, 241-244 
valeur alimentaire $6,13,19,20,26$, $63,64,66-69,71,72,74,75,81,83$, 133, 154, 163, 164, 196

valeur azotée $68,70,71,75,78-80$

valeur énergétique $68,69,75,78-80$ valeur fourragère $38,81-83,98,101$, 133, 144, 163, 211, 215, 237

valeur nutritive $21,34,39,40,43-45$, $66,71,72,78-82,159,203,204,218$

verger fourrager 106, 201-203, 214

Vietnam 57, 162, 169 

Photo de couverture :

Affouragement à l'auge (Pennisetum purpureum) des bovins de la race jaune

(C) Cirad - Paulo Salgado

Édition : Claire Parmentier (PAG), Claire Jourdan-Ruf (Éditions Quæ)

Infographie : Éditions Quæ

Mise en pages : Hélène Bonnet

Impression : Jouve

Dépôt légal : octobre 2014 